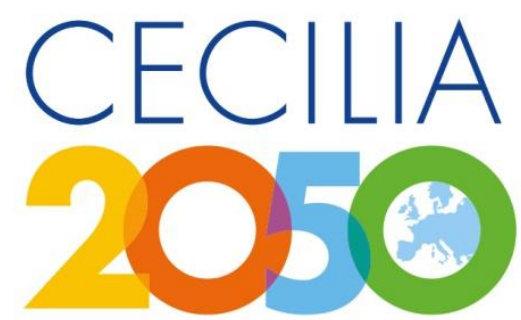

OPTIMAL EU CLIMATE POLICY

Choosing Efficient Combinations of Policy Instruments for Low-carbon Development and Innovation to Achieve Europe's 2050 climate targets

\title{
INSTRUMENTATION STRATEGIES AND INSTRUMENT MIXES FOR LONG TERM CLIMATE POLICY
}

\author{
Gjalt Huppes, SebastiaAn Deetman, \\ RUBEN HUELE, ReNÉ KLEIJN, \\ ARJAN de Koning, ESTER VAN DER Voet
}




\section{AUTHORS}

Gjalt Huppes*, CML

Sebastiaan Deetman, CML

Ruben Huele, CML

René Kleijn, CML

Arjan de Koning, CML

Ester van der Voet, $\mathrm{CML}$

*Corresponding author huppes.cml@gmail.com

With substantial comments by:

Benjamin Görlach, Ecologic

Project coordination and editing format provided by Ecologic Institute.

Final Manuscript, 28 October 2015

Document reference Huppes, Gjalt; Deetman, Sebastiaan; Huele, Ruben; Kleijn, René; Koning, Arjan de; Voet, Ester van der (2015) Instrumentation Strategies and Instrument Mixes for Long Term Climate Policy. CML, Leiden University, Leiden, DOI 10.13140/RG.2.1.1061.6409

Work Package
Document Type
Date
Document Status WP6, Deliverable D6.1 Report

28 October 2015

Final version

\section{ACKNOWLEDGEMENT \& DISCLAIMER}

The research leading to these results has received funding from the European Union FP7 ENV.2012.6.1-4: Exploiting the full potential of economic instruments to achieve the EU's key greenhouse gas emissions reductions targets for 2030 and 2050 under grant agreement $n^{\circ} 308680$.

Neither the European Commission nor any person acting on behalf of the Commission is responsible for the use which might be made of the following information. The views expressed in this publication are the sole responsibility of the author and do not necessarily reflect the views of the European Commission.

Reproduction and translation for non-commercial purposes are authorized, provided the source is acknowledged and the publisher is given prior notice and sent a copy. 


\title{
INSTRUMENTATION STRATEGIES AND INSTRUMENT MIXES for Long Term Climate Policy
}

Gjalt Huppes, Sebastiaan Deetman, René Kleijn, Arjan de Koning,

Ester van der Voet

\author{
CML, Leiden University \\ Leiden, 2015
}




\section{Contents Summary}

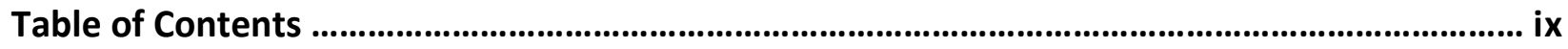

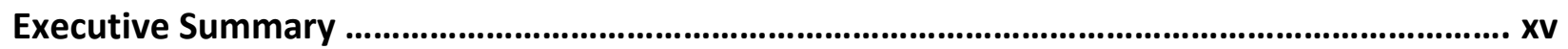

Ch 1 Towards instrumentation for long term climate policy .................................................... 1

Ch 2 Imagining 2-degrees futures domains ..................................................................... 8

Ch 3 Bottom up development and top down design of instrumentation .............................. 21

Ch 4 Main types of instrument building blocks ....................................................................... 29

Ch 5 Instrument mixes for four emission pricing options and four main sectors ................. 72

Ch 6 Towards full sets of instruments for long term climate policy ..................................... 98

Ch 7 Pathways towards Planning \& Control and Institutionalist Instrumentation ............. 104

Ch 8 Comparing strategic Instrument mixes ................................................................ 128

Ch 9 Key outcomes and general recommendations .............................................................. 135 


\section{Preface}

This report is part of the CECILIA2050 project funded in the EU FP7 program in call ENV.2012.6.14 Exploiting the full potential of economic instruments to contribute to achieving the EU's greenhouse gas emissions reduction objectives for 2050.

The project has been set up in six workpackages in content.

- WP1 Taking stock of the current instrument mix

- WP2 Understanding the impacts and limitations of the current instrument mix in detail

- WP3 Development of scenarios to 2030 and 2050, also covering instrument building blocks

- WP4 Development and assessment of an optimal instrument mix for 2030 and 2050

- WP5 International context: competitiveness implications; global climate policy and global markets

- WP6 Integration and synthesis of results: Towards an 'optimal' instrument mix for climate policy.

The final workpackage concerns Workpackage 6. It has three deliverables in content, ultimately joined in a final fourth deliverable where the full analysis is stated in a single document. Short term and long term climate policy instrumentation is analyzed in a strategic context, D6.1 and D6.2, next also reckoning with options for EU centralization and decentralization and with different development options for global climate policy, in D6.3. The reporting first is in three separate reports, one for each of the three deliverables. One is on short term instrumentation, 'Short-term Development Options for the EU Climate Policy Mix' (Deliverable 6.2). The second deliverable, this volume, has the long term view, 'Instrumentation strategies and instrument mixes for long term climate policy' (Deliverable 6.1). A third volume is on supranationality and international developments 'Assessment of EU Instrument Options under Different Supranational Governance Scenarios' (Deliverable 6.3). It varies assumptions on long term development of the EU in terms of centralization and decentralization and on the global developments of climate policy, more aligned and binding or more fragmented and voluntary. The consequences for short term and long term EU climate policy instrumentation are investigated under these deviating assumptions. The last deliverable of the Workpackage is the single document bringing the three deliverables in content together (Deliverable D6.4). Major parts of results are also brought together in a special issue for the Journal Climate Policy, covering major subjects in ten scientific papers.

The work in Deliverable 6.1 on strategic long term instrumentation design here builds on preceding work in the project, in the Workpackages 1 to 5 , with the deliverable reports on the project website, and on additional work by partners in the project, in the so called Challenges. These challenges first cover five main sectors in society, energy; industry; buildings and households; transport; and agriculture. Agriculture and non- $\mathrm{CO}_{2}$ emissions have only been touched upon, requiring instruments mostly of a different nature than those for $\mathrm{CO}_{2}$. Next there are Challenges having a more systemic nature, on carbon pricing; public infrastructure; electricity markets; financing \& investment; innovation; and life styles. A list of these challenges with their authors is in the annex to this volume. The work here on instrumentation strategy and design draws on all these contributions; on broader discussions in the project at workshops and conferences; and of course also on literature and public discussions.

Leiden, 28 October 2015

Gjalt Huppes 


\section{Abstract}

The 2-degrees climate goal, with around $90 \% \mathrm{CO}_{2}$ emission reduction for the $\mathrm{EU}$ by 2050 , can be achieved with different sets of instruments. The two sets developed here are internally consistent and they are mostly mutually exclusive. They link to specific views on governance. Current instrumentation is partial and is internally inconsistent, with mutually conflicting instruments. Most basically, current instrumentation lacks a clear long term strategy based on design thinking. It seems improbable that the current piecemeal approach will be able to reach the deep reduction target: it is not single instruments but the full mix which is to be considered.

Strategy development for instrumentation starts at a governance level: how will the deep transformation required be set up, fitting into broader governance approaches and into broader socio-economic and cultural developments? There is no single answer, as strategies require choices. Two main strategies can be discerned in industrialized democracies, and for the EU: a planning \& control strategy with a project and targets orientation and an institutionalist strategy with an incentive and enabling orientation. Their long term instrumentation, starting from now, is the main subject of this study. The planning \& control school links to welfare theory and optimization, with broad integration of several policy goals in instrumentation. The institutionalist school links to institutionalism in history, economics, sociology and political science, developing institutions for incentives and opportunity creation.

Design of long term climate policy instrumentation has a starting point in the deep transformation required for the 2-degrees goal, as opposed to short term satisficing and medium term optimizing approaches. All activities in society will have to adapt to that goal, both in production and consumption, requiring deep innovation. For any instrumentation strategy, sparseness and encompassingness are starting points for design, while avoiding overlap of instruments as much as possible. More generic instruments are preferred, following a seven-type instrument typology with increasing specificness and bindingness. Taken together these abstract lines of reasoning constitute the design thinking for strategy development.

Currently, the core instrument of carbon pricing, the ETS cap-and-trade system, covers less than half of all $\mathrm{CO}_{2}$ emissions and does not apply systematically to all sources, not even covering all electricity production and only part of industrial emissions. In transport, fleet standards cover light transport in different ways, leaving out most heavy transport, while aviation is part of ETS pricing. The most successful instruments, feed-in tariffs and other renewables subsidies, have been implemented at the national level. They undermine the ETS, and are at variance with an open EU electricity market. The ETS itself is a mixture of concepts now, without a clear strategy orientation. It is intended to be a pure cap-and-trade system but is now reducing volumes of emission permits to create a higher more relevant price. The pure cap-and-trade system, when functioning at relevant prices as intended, makes decentral initiatives senseless as these only make emissions for others cheaper. 
The planning \& control strategy builds substantially on current instrumentation, improving it. It focuses on technology specific measures, using subsidies and standards as prime instruments. Core are feed-in tariffs, with proven success, and other subsidies for renewables; subsidies for battery development and employment; emission standards for fossil combustion and incineration; insulation and heating standards in buildings; reduction of energy use, as by refurbishing building insulation and product standards; subsidies and standards for heat and electricity storage systems; dynamic standards in industry, etc. Electricity markets remain national markets internationally linked, with national transmission grid operators, partly private, owning the international linkages. In this planning \& control strategy the ETS is undermined and fades. There is a tendency towards centralization, as when member states don't act according to the stated yearly emission reduction targets. The international agreement aspired is stated emission reduction targets for as many countries as possible, in the Kyoto-Copenhagen-Paris line of negotiations.

The institutionalist strategy takes the ETS as a starting point, mends its current deficiencies and strengthens it. Firstly, the domain of application is expanded so as to cover all fossil carbon. For all smaller emitters without adequate administration this is possible only through upstream carbon measurement, at least at gas, coal and fuel providers who have adequate administrations, then also covering all transport, building emissions and industrial emissions. The simplest and most systematic level of administration is at primary production of all fossil fuels, their imports and the imports of energy products, mirrored by a refund upon export and CCS. Secondly, the opposition between ETS and national and local initiatives is resolved by adapting volumes to price development, reducing cap volumes when local actions are successful. This may first be done through rising price floors and ceilings. As a bandwidth has no function with price related variable volumes, a fully stabilized predictably rising price path is established, without the complexity of trading. The administration can further be simplified by shifting from a permit system to an excise system, as a tax.

With an emission tax in place, the second main instrument task is to make the price signal work effectively, requiring an open and equal for all, real time electricity market. In EU electricity transmission, pricing is congestion pricing, not for covering costs let alone proceeds maximation. This market design goes one step beyond the Single European Electricity Market and Supergrid ideas. These two EU instruments together create the long term incentives for the institutionalist strategy. Public funding of research is for basic funding, with exceptionally important and large projects implemented directly like, in a different domain, the set-up of the internet once was. Technology specific instruments are hardly used and then temporarily only, mainly at member state level. EU level instruments are restricted to incentive and opportunity creation, leaving all other instrumentation to member state level and below and to firms and civil society; instruments like fleet standards and renewables standards are abolished. The international agreement aspired specifies equal emission taxes for a core group starting, open to joining by all countries on equal footing, with all proceeds national. 
Both instrumentation strategies require further instruments as for spatial planning and infrastructure and for research and development, but filled in differently. For planning \& control, joint public-private infrastructure development is key as is active engagement in RD\&D, to create and know what can and should be forced into the market, 'picking winners' by necessity. There are further similar elements in both strategies, like spatial planning allowing for slower types of transport, including a reduction in air transport, and temporary subsidies to create learning curves for novel technologies.

Comparing long term instrumentation strategies on effectiveness, efficiency and feasibility is a non-quantified endeavor, as the long term future is substantially unknown. Comparison of instrument mixes shows soft, only qualitative differences, with maybe slight advantages for medium term emission reduction in the planning \& control strategy and longer term effectiveness and efficiency in the institutionalist strategy. Strategy choices are ultimately based however on generic governance considerations, also relevant broader in society. An explicit strategy choice is required for setting out consistent instrumentation in main lines, thus preparing for wellreasoned and well-informed choices, and contributing to legitimacy, the ultimate basis for the feasibility of effective climate policy. 


\section{Contents}

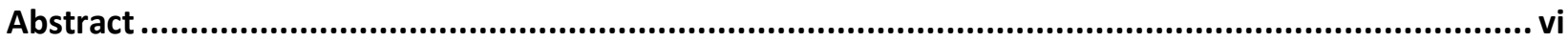

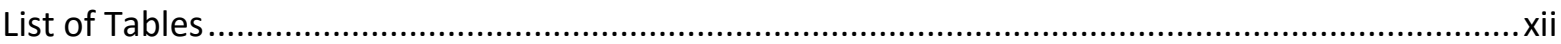

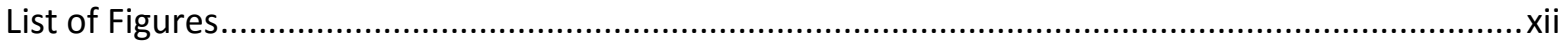

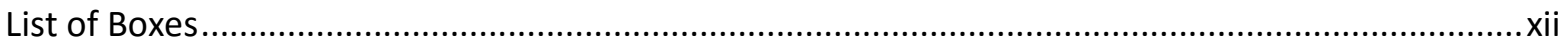

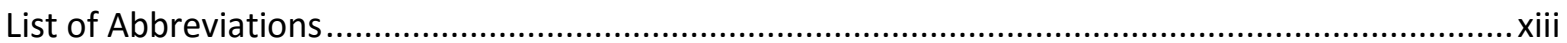

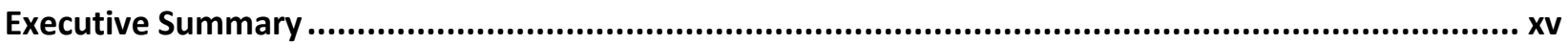

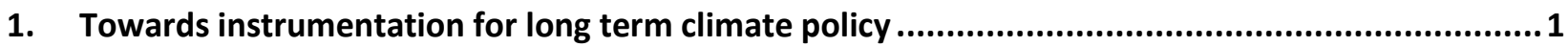

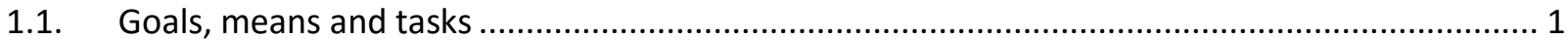

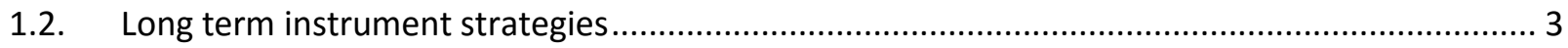

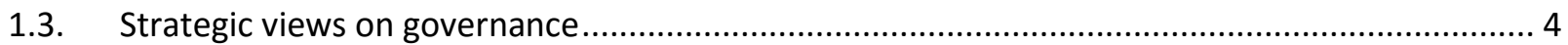

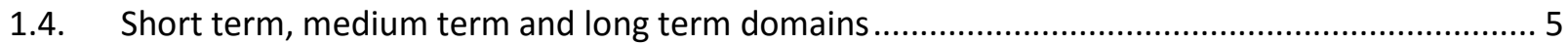

1.5. EU constitutional constraints and international developments .............................................. 7

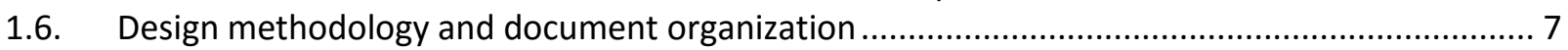

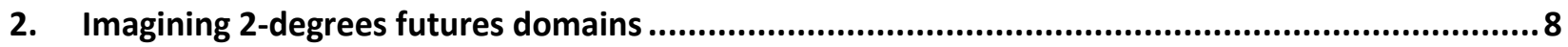

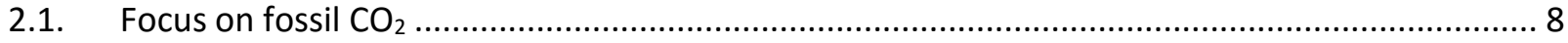

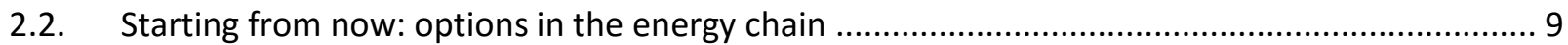

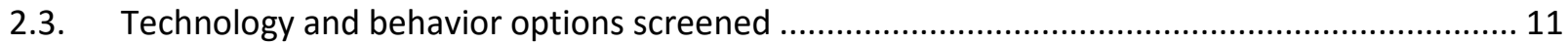

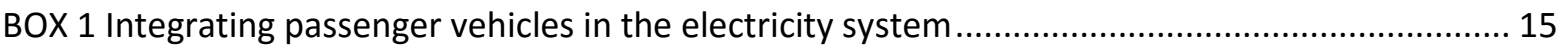

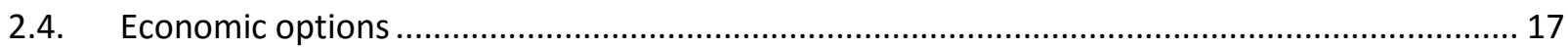

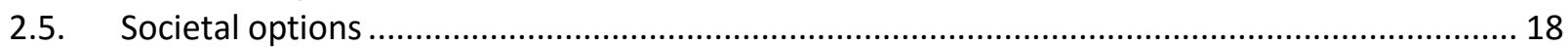

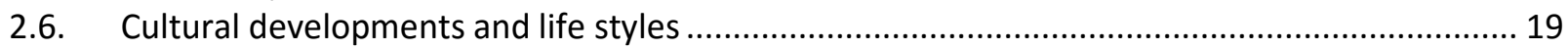

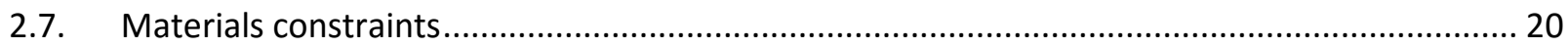

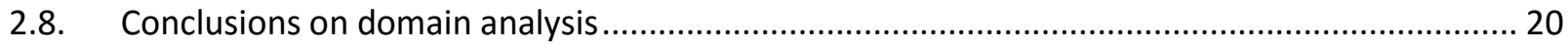

3. Bottom up development and top down design of instrumentation.........................................21

3.1. From incremental improvement to strategic design ............................................................. 21

3.2. From practical instrument development to strategic design ............................................... 23

3.3. Planning \& Control and Institutionalist Strategies for long term instrumentation..................... 26

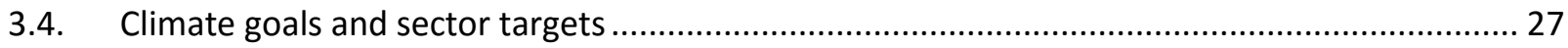

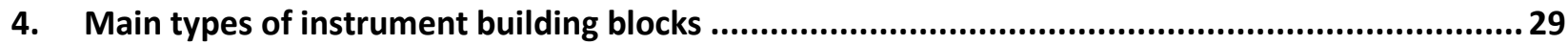

4.1. A brief history of environmental policy instruments: what we have and need....................... 29

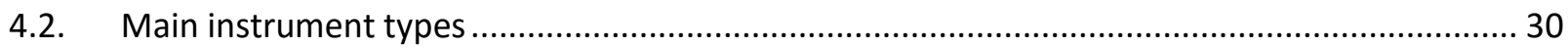

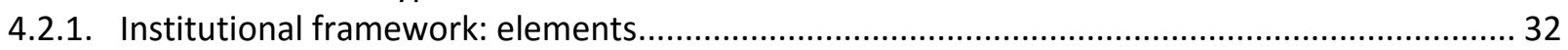

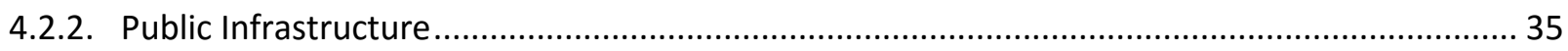

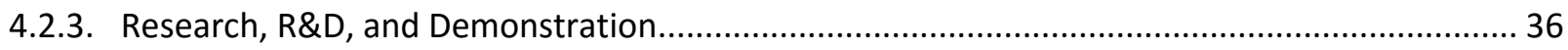

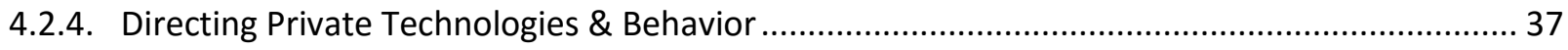

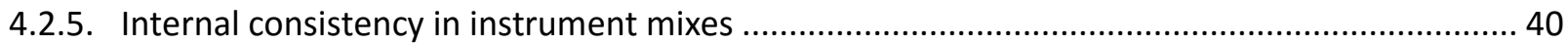

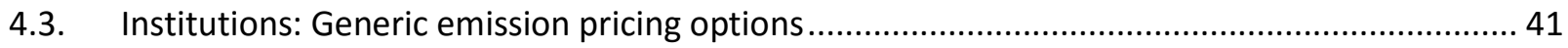

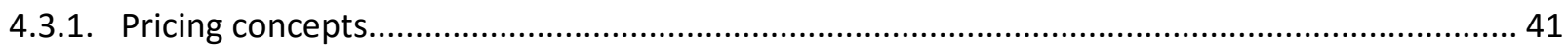

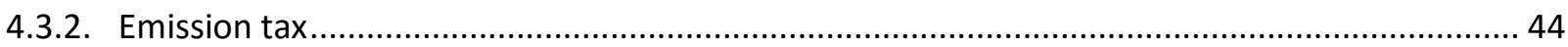

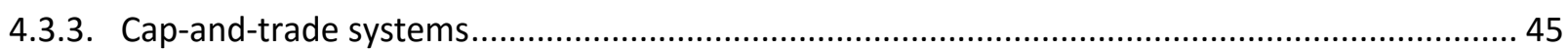

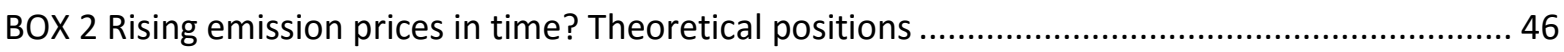

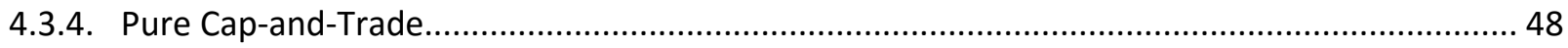

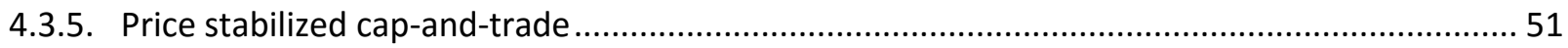

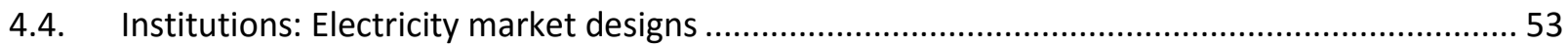

4.4.1. Extreme numbers coming up in production and consumption markets ................................. 53

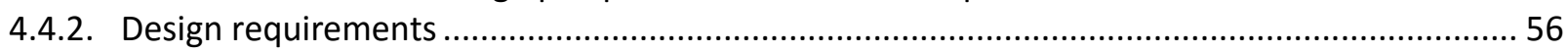




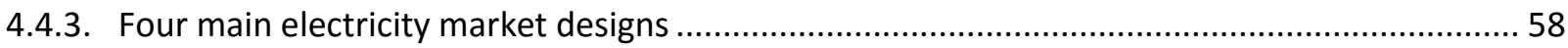

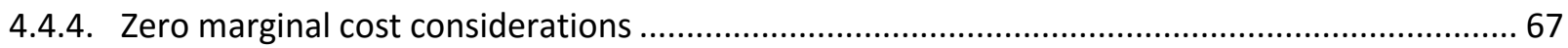

4.4.5. Energy storage and market stabilization: the heat pump example ....................................... 68

BOX 3 Heat pump investment under different electricity market regimes and $\mathrm{CO}_{2}$ emission prices 69

4.5. EU instruments, EU induced instruments and Member State instruments............................ 70

5. Instrument mixes for four emission pricing options and four main sectors...............................72

5.1. Climate Policy Instruments in the Electricity Production Sector........................................... 74

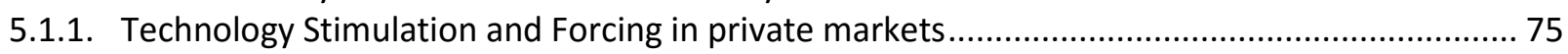

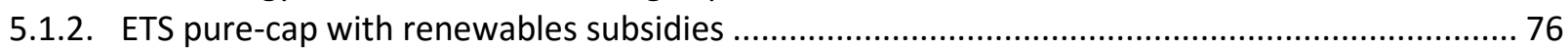

5.1.3. Price Stabilized Cap-and-Trade with national technology support........................................ 78

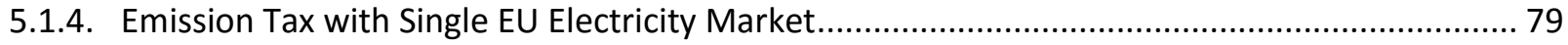

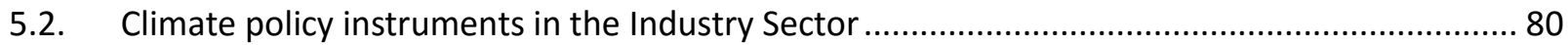

5.2.1. Technology Stimulation and Forcing in the Industry Sector ................................................. 81

5.2.2. Pure cap-and-trade with BATs implemented in permits and with subsidies/taxes.................. 83

5.2.3. Price stabilized cap-and-trade, with specific industrial policy ................................................ 84

5.2.4. Emission Tax with Single EU Electricity Market: Industry ................................................... 85

5.3. Climate policy instruments in the Building \& Consumption Sector ....................................... 86

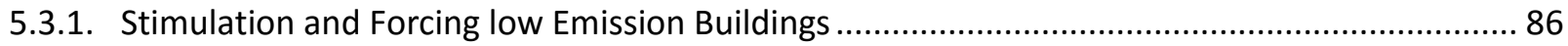

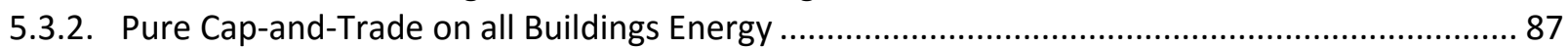

5.3.3. Hybrid Cap-and-Trade (price stabilized) on all Building Energy ............................................. 88

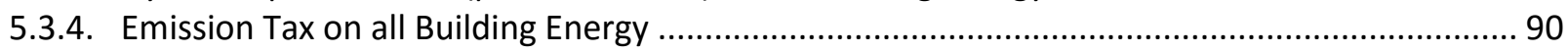

5.4. Climate policy instruments in the Transport Sector........................................................... 90

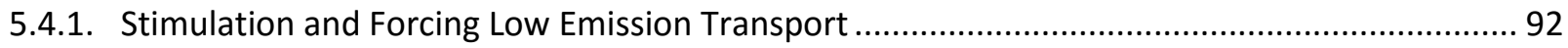

5.4.2. ETS pure-cap on Transport Fuels + National Subsidies ........................................................ 94

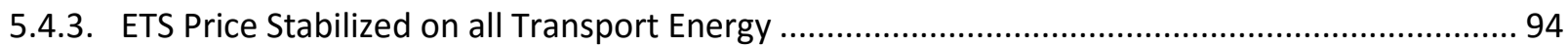

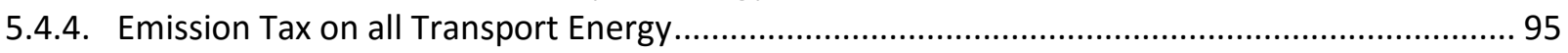

BOX 4 Emission pricing and real time electricity markets for electric drives with grid stabilization .. 96

6. Towards full sets of instruments for long term climate policy .................................................98

6.1. From satisficing and optimizing to deep transitions and transformations: timing ................... 98

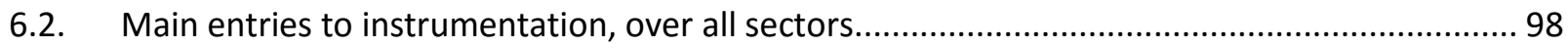

6.3. Reduced emission pricing options in long term strategies ................................................ 101

6.4. Developing Planning \& Control and Institutionalist Instrument Mixes ................................. 102

6.4.1. Strategic choices on emission pricing: not pure cap-and-trade.......................................... 102

6.4.2. Strategic choices on emission pricing: two pathways and directions .................................... 103

7. Pathways towards Planning \& Control and Institutionalist Instrumentation ............................ 104

7.1. Long term Instrumentation in the Planning \& Control Strategy ........................................... 104

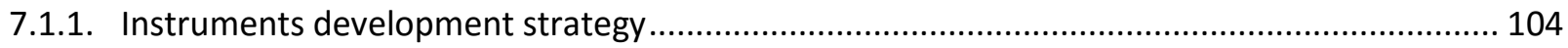

7.1.2. Instrumentation in the electricity sector and large industries........................................... 105

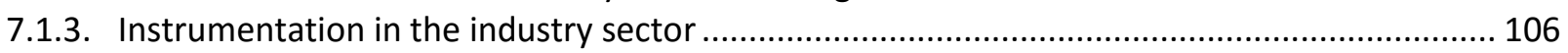

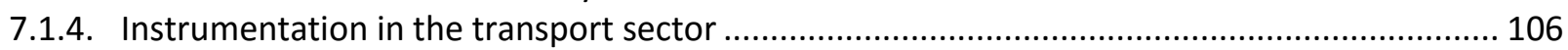

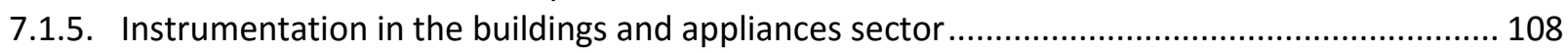

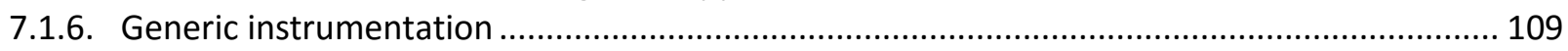

7.1.7. International aspects under Planning \& Control Instrumentation ....................................... 110

7.2. Long term Instrumentation in the Institutionalist Strategy ............................................... 111

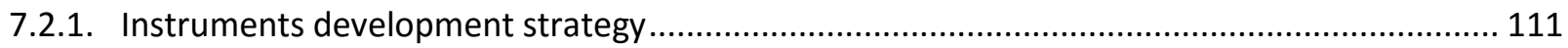

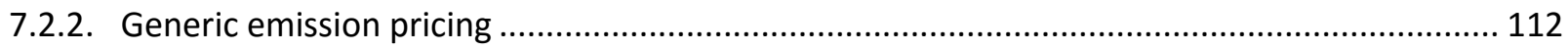

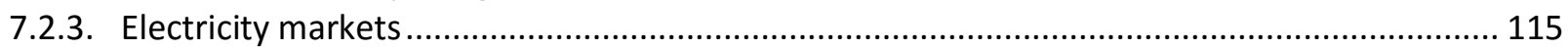

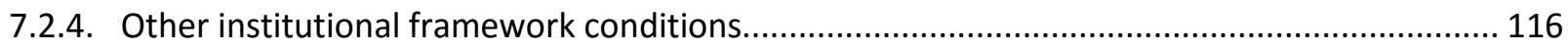




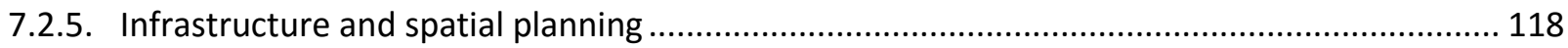

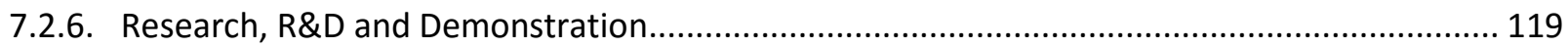

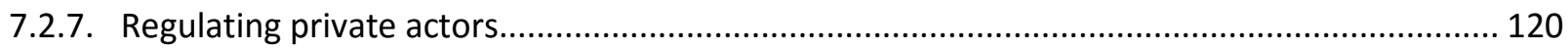

7.2.8. International aspects under Institutionalist Instrumentation............................................ 122

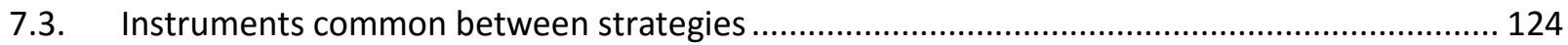

7.4. Divergent pathways managed in the short, medium and long term ................................... 125

8. Comparing strategic Instrument mixes..................................................................... 128

8.1. Effectiveness, Cost-effectiveness, Feasibility and Optimality …........................................ 128

8.2. Long term effectiveness and cost effectiveness ......................................................... 128

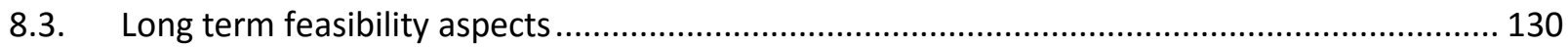

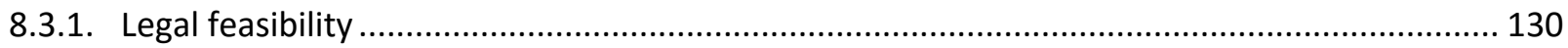

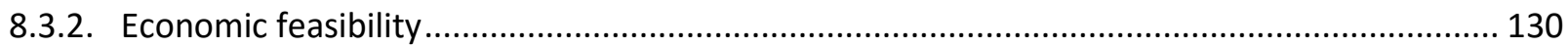

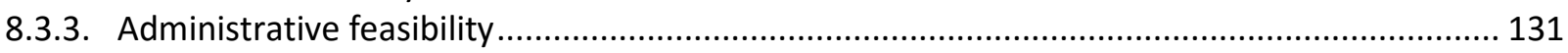

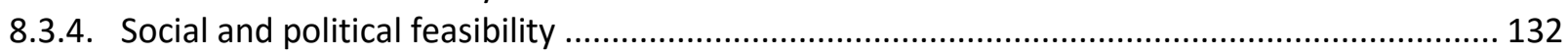

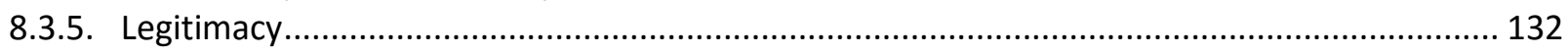

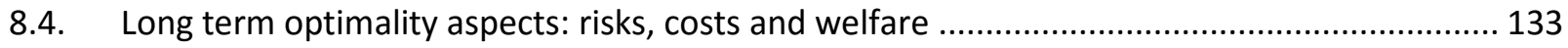

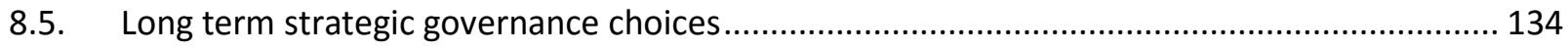

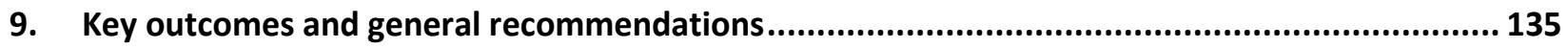

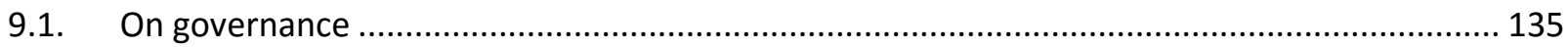

9.2. On combined energy and climate policy instrumentation................................................ 135

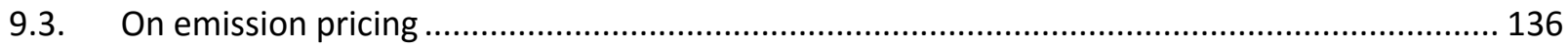

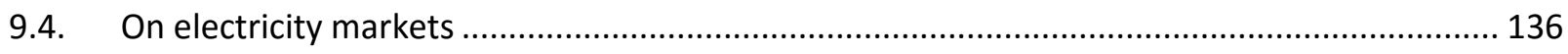

9.5. On research, research and development, and demonstration ........................................... 137

9.6. On instruments regarding specific technologies, markets and behaviors ............................ 137

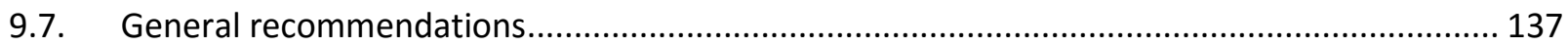

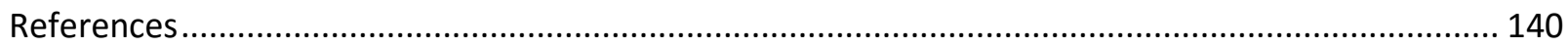

Annex 1 List of Challenge Papers used as input in D6.1, D6.2 and D6.3 ....................................... 153 


\section{List of Tables}

Table 1 Global warming potential (GWP) per MWh of primary electricity sources 12

Table 2 Dimensions and layers in governance, after (Voss and Bornemann 2011)

Table 3 Typology of instruments for climate policy.

Table 4 Sectoral domain, administrative level and price stability of emission pricing instruments.....

Table 5 Proceeds of emission pricing: emission price starting at $100 € /$ ton in 2020 rising by $10 €$ per year48

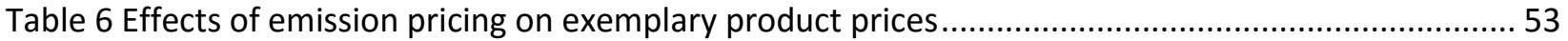

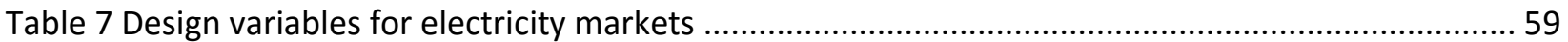

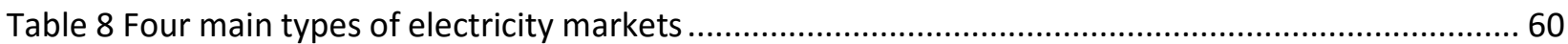

Table 9 Heat pump with heat storage under different electricity market designs and emission prices .... 70

Table 10 Electricity market operations with car battery ( 1 car, 10 years) ............................................ 97

Table 11 Instrument Mixes in Planning \& Control and Institutionalist Governance................................. 126

\section{List of Figures}

Figure 1 Energy input, transformation and final use EU-28 in 2012, in Mtoe ........................................ 9

Figure 2. Demand and supply for emission permits under pure cap-and-trade: graphical analysis. ......... 50

Figure 3. Actors potentially involved in market clearing in the long term electricity market .................... 55

\section{List of Boxes}

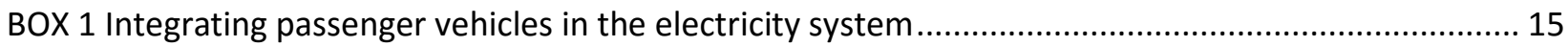

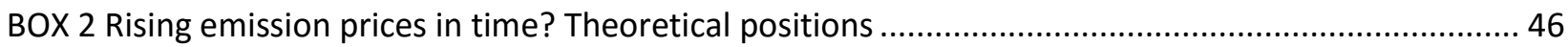

BOX 3 Heat pump investment under different electricity market regimes and $\mathrm{CO}_{2}$ emission prices ........ 69

BOX 4 Emission pricing and real time electricity markets for electric drives with grid stabilization .......... 96 


\section{List of Abbreviations}

\begin{tabular}{|c|c|}
\hline 2DS & $2^{\circ} \mathrm{C}$ Scenario \\
\hline AR5 & $5^{\text {th }}$ Assessment Report, IPCC \\
\hline ARPA-E & Energy Advanced Research Project Agency, USA \\
\hline BAT & Best Available Technology \\
\hline BCA & Border Carbon Adjustment (equal to BTA) \\
\hline BTA & Border Tax Adjustment \\
\hline CAP & Common Agricultural Policy \\
\hline CaT & Cap-and-Trade \\
\hline CARP & Climate Advanced Research Project \\
\hline CCS & Carbon Capture and Storage (also: Sequestration) \\
\hline CENELEC & European Committee for Electrotechnical Standardization \\
\hline CFD & Contract for Difference (related to FiT) \\
\hline CEM & Continuous Emission Measurement \\
\hline $\mathrm{CO}_{2}$ & Carbon Dioxide \\
\hline CoM & Covenant of Mayors \\
\hline DARPA & Defence Advanced Research Projects Agency, USA \\
\hline DC-HVTG & Direct Current High Voltage Transmission Grid \\
\hline DCHV & Direct Current High Voltage \\
\hline EEA & European Environment Agency \\
\hline EED & Energy Efficiency Directive \\
\hline EPA & Environmental Protection Agency \\
\hline EPBD & Energy Performance of Buildings Directive \\
\hline ENTSO-E & European Network of Transmission System Operators-Electricity \\
\hline ER2050 & Energy Roadmap 2050 \\
\hline ETD & Energy Taxation Directive \\
\hline ETS & (European) Emissions Trading System (of emission permits under a cap) \\
\hline ETSI & European Telecommunications Standards Institute \\
\hline FCV & Fuel Cell Vehicle \\
\hline FiT & Feed-in-Tariffs \\
\hline FiP & Feed-in-Premium \\
\hline GATT & General Agreement on Tariffs and Trade \\
\hline GDP & Gross Domestic Product \\
\hline GHG & Green House Gas \\
\hline GW(h) & gigawatt(-hour) \\
\hline HVDC & High-Voltage Direct Current \\
\hline IEA & International Energy Agency \\
\hline IMF & International Monetary Fund \\
\hline IPCC & Intergovernmental Panel on Climate Change \\
\hline KET & Key Enabling Technologies (EU term) \\
\hline KICs & Knowledge and Innovation Communicities \\
\hline kWh & kiloWatt hour \\
\hline LCOE & Levelized Cost Of Electricity \\
\hline
\end{tabular}


$\begin{array}{ll}\text { LULUCF } & \text { Land Use, Land Use Change and Forestry } \\ \text { MSR } & \text { Market Stability Reserve } \\ \text { MWh } & \text { Mega Watt hour } \\ \text { N2O } & \text { Nitrous Oxide } \\ \text { NEDC } & \text { New European Driving Cycle } \\ \text { NOGEPA } & \text { Netherland Oil and Gas Exploration and Production Association } \\ \text { NGO } & \text { Non-Governmental Organization } \\ \text { OECD } & \text { Organisation for Economic Cooperation and Development } \\ \text { OMC } & \text { Open Method of Coordination } \\ \text { OSGP } & \text { Open Smart Grid Protocol } \\ \text { PFCS } & \text { Perfluorocarbons } \\ \text { PPP } & \text { Polluter Pays Principle } \\ \text { PV } & \text { Photo Voltaic } \\ \text { R\&D } & \text { Research \& Development } \\ \text { RED } & \text { Renewable Energy Directive } \\ \text { RD\&D } & \text { Research, Development \& Demonstration } \\ \text { RCP2.6 } & \text { Relevant Concentration Pathway: radiative forcing }<2.6 W / \mathrm{m}^{2} \text { in } 2100, \text { linked to }<2^{\circ} \mathrm{C} \text { rise } \\ \text { SRES } & \text { Special Report on Emissions Scenarios (by IPCC) } \\ \text { SSP } & \text { Shared Socio-economic Pathway } \\ \text { TSO } & \text { Transmission System Operator } \\ \text { TWh } & \text { Tera Watt hour } \\ \text { UNCTAD } & \text { United Nations Conference on Trade And Development } \\ \text { UNFCCC } & \text { United Nations Framework Convention on Climate Change } \\ \text { vkm } & \text { vehicle kilometer } \\ \text { WLTP } & \text { Worldwide harmonized Light vehicles Test Procedures (to replace NEDC) } \\ \text { WP } & \text { Work Package } \\ \text { WTO } & \text { World Trade Organization }\end{array}$ 


\section{Executive Summary}

\section{Ch1 Towards instrumentation for long term climate policy}

How may effective long term climate policy instrumentation evolve? Basic options for instrumentation have been developed and analyzed for well-founded decisions on EU climate policy. The long term instrumentation is to realize a $90 \% \mathrm{CO}_{2}$ emission reduction by 2050 , in line with the global 2-degrees climate stabilization goal. Effectiveness is assumed here. How to fit successful policy into the broader fabric of society is the more detailed question. The instrumentation is to realize emission reductions cost-effectively, at low administrative effort and low regulatory costs in society, and in a manner acceptable to society at large. Also, the steps towards the instrument mixes are to be feasible, avoiding jumps of a too difficult political nature. Assumed is further that the EU constitutional constraints as specified in the Lisbon Treaty will remain operant mainly. Also, other countries, at least major trade partners are assumed to reduce emissions similarly, making the EU effort worthwhile from a global perspective. The time frame for analysis plays a key role in instrumentation design. The long term is open in many respects technical-economic, political and administrative - as opposed to short term satisficing within current constraints and medium term optimization within known options space. There are many options for long term instrumentation, ultimately to be fitted into a few clear strategies, linked to major governance views in society. The design methodology first builds on a basic instrument typology; secondly has a bottom up starting point, indicating directions for the instrument evolution in four main sectors; and thirdly, top down, uses strategic views on governance, one more in a planning direction and one more in an incentivizing direction.

\section{Ch2 Imagining 2-degrees futures domains}

How can we imagine the long term domain of a low carbon society? It has technical aspects, like the use of solar and wind power in electricity production and the increased use of electricity and possibly hydrogen in intermediate and final energy use. Long term technology development is partly determined already as fundamentally new technologies cannot have a dominant position by 2050 due to stickiness in their large scale introduction. However, current and new technologies certainly will evolve. Which role specific technologies will play is hard to predict however, unless by planned implementation. How a low carbon society may look like in a broader sense is very open as well. There is deep uncertainty on economic development, as in the speed of productivity growth and how low marginal cost technologies may lead to changes in the coordination mechanisms in the economy. However, the globalized market economy will continue in some form, so is the assumption, with monopolistic tendencies somehow checked. In a broader social and political sense, a substantial civil society will remain a core European asset, with a multilayered political system leaving room for decentralized initiatives, also in the climate domain. Cultural development, only very indirectly influenced by central governments, may move away somewhat from consumerism, with however earning income and spending income remaining core activities. 


\section{Ch3 Bottom-up development and top down design of instrument mixes}

Development of climate policy instrumentation by necessity has current instrumentation as its starting point. What is there already, like ETS and Fleet Standards, may be transformed but cannot be exchanged for totally different instrumentation on short notice: there is path dependency also regarding policy instruments. With a longer time horizon however, development may move from slight short term improvements, to medium term major additions and optimizations, to stepwise and ultimately deep transformations in the long term. Deep transformations will not come about bottom-up however. The strategic choice to develop into a certain direction gives guidance to short/medium term smaller steps in development. The current ETS may wither, with other instruments being more attractive; it may be expanded; it may be transformed into a price stabilized instrument; and then next may develop stepwise into an emission tax, see Section 4.3 for details. Top down strategic views determine long term development of emission pricing. Similarly, the currently fragmented electricity markets in Europe may develop in different directions, all with increased international trade. The set-up of carbon pricing and electricity market design constitute two core framework conditions at an institutional level. They are however part of a broader set of adjoining climate policy instruments.

Such broader sets may first relate to four main sectors: Electricity, Industry, Buildings \& Appliances, and Transport. These constitute four instrument challenges: how to decarbonize each substantially so as to reach the overall emission reduction target for 2050, see Chapter 5, substantially different between strategies.

\section{Ch4 Main types of instrument building blocks}

Instruments may be specified in many different ways. The classification used here first splits them in two groups, one regarding public actions and one regarding private actors and actions. Public actions create the background for private behavior. The first level refers to institutional framework conditions, with as main examples emission pricing and the set-up of electricity markets. The second level is Public Infrastructure, also for private use, like EU high tension grids and public hydrogen storage, and spatial plans as for low emission transport. The third level is public funding of Research, R\&D and Demonstration. The order of public instruments is towards greater specificity regarding technologies and behavior. Most generic instruments at the institutions level, like emission pricing, exert broadest influence, on private parties but also on decisions regarding infrastructure and research and R\&D. These three levels of public actions incentivize and enable by creating options.

The fourth type of public action regards private actors, by stimulating and forcing technologies and behavior. The least binding is information, allowing better informed choices on production technologies and products, here including information on climate effects. Stronger guidance is given with financial incentives, like taxes on coal fired power stations and subsidies on solar panels. Strongest influence is by standards and regulations, relatively open to technologies with performance standards, like EU Fleet Standards, and most technology binding by prescriptions and prohibitions, like in BAT specifications. The order of instruments directing private actors is towards increasing bindingness.

Four main emission pricing options are distinguished: pure cap-and-trade, vulnerable due to more specific instruments reducing its price to irrelevant levels; price stabilized cap-and-trade, with a price floor and ceiling collar, where price variation has lost its function mainly; fully price stabilized 
permits; and emission taxes as administratively simplified fully price stabilized permit system, administered upstream at fossils primary production and import, mirrored with refund upon CCS and export. The encompassing upstream emission tax is administratively simplest and gives clearest guidance on long term decisions like on infrastructure, research, R\&D and investments. Electricity markets, increasingly important, will have to deal with large numbers of primary and secondary producers and with internet of things. They may be designed to increase the share of renewables, as with feed-in tariffs and adjoining capacity payments to cover peak demand. Or they may be designed as a single priced EU wide market, with real time equal prices for all and with market based grid stabilization. Smart grids will strongly depend on market design.

Instruments may be opposed or may fit together. Feed-in tariffs don't reduce emissions under an effective pure cap-and-trade system, but align with an emission tax. Fragmented mainly national oligopolistic electricity markets hardly translate emission pricing to users.

\section{Ch5 Instrument mixes for four emission pricing options and four main sectors}

Four options for emission pricing are starting points for bottom up creation of instrument mixes, these options relate softly to strategy choices as yet; strategy based instrumentation design is in chapters 6 and 7. The four pricing options are: no generic emission pricing but Technology Stimulation and Forcing; Pure cap-and-trade; Price Stabilized Cap-and-Trade; and Emission tax. The second element in the mix is the corresponding set-up of the electricity market, with also four types. They range from primarily national markets fragmented as by renewables support, capacity payment, to an EU-wide single price real time electricity market. Detailing covers four sectors: Electricity; Industry; Buildings \& Appliances; and Transport. Instrument sets for sixteen combinations are sketched.

The Technology Stimulation and Forcing Instrument Mix has no generic emission pricing. It has substantial planning in the electricity sector using renewables subsidies, emission standards and capacity payments, mostly at a national level. In Industry it uses dynamically developed and implemented BAT standards. In Housing \& Appliances there is a mix of subsidies as for insulation and renewables application and a shift to electricity, backed up by increasingly stringent standards. In Transport, Fleet Standards are simplified to emissions only, with a sales volume element added, and covering all road transport.

The Pure Cap-and-Trade Mix covers all sectors with upstream administrative implementation, as do the other emission pricing instruments. This mix sets the ETS reduction rate in the electricity sector high enough to become the dominant instrument, and avoids renewables subsidies. The electricity market is open or fully open. The Price Stabilized Cap-and-Trade Mix sets a rising price floor and ceiling, with the cap volume adjusted to remain between these values. All the encompassing emission pricing systems have fewer technology specific instruments, leaving actions to lower administrative levels and more spontaneous bottom-up actions, most so with the pure cap-and-trade system.

On average the emission price will be highest in the pure cap system. This is due to the uncertain level of the long term price of emission permits; limited use of adjoining instruments; and due to disincentivizing bottom up initiatives, also in civil society. The price difference will be most substantial during high growth periods, when the permit price rises due to the inelasticity of supply and demand. The price level set in the other two options will be quite similar. The more extensive use of adjoining instruments in the price stabilized cap-and-trade mix will allow for 
setting the price level lower than for the emission tax. The more clear market development in the pure emission tax mix may deliver the same results more smoothly, allowing for a somewhat lower overall costs of emission reduction. Of course the price comparison cannot be made empirically.

\section{Chapter 6 Towards full sets of instruments for long term climate policy}

Combining sector options is not by permutation and then choice. It is not possible to have different emission pricing systems in different sectors. It may technically be possible to some extent to differentiate the domain of application of cap-and-trade systems between sectors, as now is the case for aviation. In general this is not part of strategic design as it creates difficult to resolve boundary issues. An example is natural gas, paid for in electricity production and hence indirectly when used in buildings. If it not paid for when delivered to buildings as natural gas, there is a climate policy induced inefficiency. And worse, there then is an incentive to replace emissions-paid-for clean electricity by decentral gas based power generation with emissions, as in using the - now often subsidized - Sterling engine. Also the option of leaving the transport sector out of carbon pricing will encounter difficulties as when transport, especially heavy transport, starts using natural gas large scale. This is the intention currently of large LNG producers and traders. Similar market distortions may be created by such partial climate policies when leaving hydrogen out of the system.

In strategic design the number of pricing options is reduced to two: Not pricing or not pricing relevantly by using other instruments effectively, as currently is the case, or pricing most clearly, using the encompassing upstream emission tax. This tax can evolve by stepwise repairing the deficiencies of the current near pure cap-and-trade system: move administration upstream; make it encompassing, stabilize prices ultimately to zero variation; simplify the administrative set-up from paid for emission permit to emission tax set up as an excise.

These two remaining options link directly to the Planning \& Control Strategy, with ETS fading to insignificance; and the Institutionalist Strategy, with ETS transformed to full-fledged emission tax. The electricity market design remains mainly national in Planning \& Control with mainly bilateral trade between member states and is a fully European real time single priced market in the Institutionalist mode. Infrastructure and Research have overlap but different emphasis, as is the case with creating learning curves. Planning \& Control has substantial technology specific regulation of private parties (Level 4), directly at EU instruments or controlled by the EU ultimately by member state caps to be realized. The Institutionalist approach has no EU policy instruments at all at level 4, but has a more purely public role in infrastructure and large scale high risk projects.

\section{Ch7 Pathways towards Planning \& Control and Institutionalist Instrumentation}

Reasoning in climate policy instrumentation may go two directions, in all stages of development: the detailed design of instruments, the selection of instruments for the mix, and the pathways of introduction of specific instrument mixes.

In the Planning \& Control Strategy the practical starting point is: How can we improve performance? If coal emits high amounts of $\mathrm{CO}_{2}$, how can we resolve that? Quite directly the answer here is to reduce coal use and shift to other energy sources, or apply CCS. Focusing on major emission sources, one answer is to stimulate alternatives and the other to press the high emission sources out of the market, by special taxes and standards. The strategic choice for 
planning \& control implies a choice for Technology Stimulation and Forcing. Core instruments are first standards for the forcing part of instrumentation, in many instances equivalent to high taxes on these activities. They are: Emission standards in electricity production; expanded Fleet Standards in all road transport; Energy \& Emission standards in buildings heating and cooling, with forced refurbishing of existing stock; Energy standards in apparatus; and minimum standards for emissions in industry linked to BATs. Improving industrial dynamics (BATs refer to existing technologies) is through public funding of technology development and public-private partnerships in market introduction. The other core instruments refer to Stimulation of technologies replacing fossil based energy cycles, mainly by subsidies and information. As subsidies cannot cover all energy related activities long term, most subsidies are restricted in time, like with investment subsidies and production premiums.

In the electricity domain, all renewable technologies have a start-up feed-in-premium (or the similar UK Contracts for Difference) plus investment subsidy till they can survive in the market. Intermittency is resolved by subsidized storage, at micro and sector level, again till the technologies can survive in the market or are replaced by other technologies.

In the Institutionalist Strategy, the ETS domain is expanded, first to all gas and coal and next to all oil, and price stabilized, with zero bandwidth. It ultimately evolves into an emission tax, administered as an excise on carbon in primary fossils production and imports of fossil energy products, with a refund upon export and authorized CCS. It functions as a carbon deposit: not returned, no money back. The second main element is the development of an adequate panEuropean electricity market. This market development is essential for low emission development as electricity will become more central in primary energy production and throughout the use chain. As the number of producers for the electric grid, both primary and secondary, will rise from a few hundred a decade ago to a few hundred million by 2050, a fully new market design is required, also reckoning with the near zero short term marginal cost of most renewables. The solution is a real time variable price market structure, open to all primary and secondary producers at equal prices and to all users at equal prices, for them including payment for transmission and distribution based on congestion prices. As electricity grids are monopolistic, they are publicly owned and managed, at the EU international level the DC-HVTG (Direct Current High Voltage Transmission Grid). Development of this pan-European electricity market has a high priority, including the building of the required grid infrastructure. National grids, also publicly owned, are left to the discretion of member states. There is substantial research and R\&D, limited demonstration projects, and limited use of technology specific instruments, with Fleet Standards phased out. There is temporary financial support for creating learning curves for few high potential technologies coming on the market.

\section{Ch8 Evaluating strategic instrument mixes}

Customary evaluation concepts for policies are effectiveness and efficiency, as cost-effectiveness. Such concepts may be applied quantitatively on the short and medium term optimization but not long term when transformative change is to be induced with as yet uncertain technologies. In the CECILIA2050 project the concept of feasibility has been introduced as part of the mainly qualitative 'optimality' analysis.

Comparing the strategies on effectiveness does not differentiate: they both are capable of reaching the reduction target for 2 -degrees stabilization. However, planning \& control will start 
faster and will have more difficulty in sticking to the targets, while the institutionalist mode will start slower but may reach deeper transformations.

Feasibility may refer to different aspects: legal, economic, administrative, and social and political feasibility of instrumentation. An encompassing feasibility aspect is the overall legitimacy of climate policy, as part of total policy. These aspects function in the realm of successful climate policy in a comparative way, stating relative feasibility of overall instrument mixes.

Legal feasibility does not pose a problem in either strategy, remaining within the confines of the Lisbon treaty and not requiring substantial centralization. The required administrative capacity, and concomitant private administrative burdens, will be higher in the planning \& control strategy. Also economic feasibility, with as a core issue the required speed of transformation, seems resolvable in both strategies, slightly differently. Administrative feasibility seems simple, as all instruments are part of well-developed experience, and major problems can be resolved in advance by design, like shifting lab tests in fleet standards to representative real life measurement. Social and political feasibility are assesses under the assumption of effectiveness. Expected slightly lower costs of the institutionalist strategy might constitute a long term advantage. Overall the feasibility analysis may show a slight advantage for the institutionalist mode, but not decisive in any way.

A more fundamental difference may be in terms of long term legitimacy. The detailed regulatory activities in the planning \& control mode are annoying and open to continuous complaints by those specifically targeted. Also, when member states are not active enough in emission reduction, a centralization with more stringent EU actions may have to follow. The institutionalist mode does not have specific regulatees targeted and functions through more abstract market mechanisms. This leaves the political system available for other subjects, and other subjects, like economic growth (and now refugees and violence) don't press out the climate subject; decentral and private climate action remains within domain of adapted functioning of markets, and activities by civil society.

\section{Ch9 Key outcomes and general recommendations}

The two governance directions developed can be recognized in many strategy documents of the EU, being part of core discussions in the liberal market economy we are in. When developed strategically and systematically they lead to very different instrumentation for climate policy.

Climate policy instrumentation is part of broader governance with overlap on other policy domains like energy policy, transport policy, air quality policy, and income distribution policy. However, before integrating, it is better to develop climate policy first independently.

The current near pure cap ETS system is instable. Emission pricing may develop towards no emission pricing, being taken over by technology specific instrumentation, or towards a price specified system, ultimately as an emission tax covering all fossil emissions on a predictably rising price path in an administratively most simple way.

Electricity markets play an increasingly important role as the number of primary and secondary producers explodes towards 2050 and demand shaving by all users becomes a core issue due to intermittency of most renewables. Technology specific instrumentation in a planning mode leads to a somewhat restricted market development, barely in line with the Energy Union strategy. The institutionalist incentive mode leads to a market stabilized single open electricity market with 
equal prices for all producers and all consumers, with public transmission and distribution, with congestion pricing.

The Institutionalist mode focuses on Research with some R\&D and few high risk Demonstration projects, while the Planning \& Control mode of governance has its focus on R\&D and linked Demonstration projects, also to create dynamics in BATs to be implemented in standards. Stimulation and forcing of specific technologies and behaviors is limited in the Institutionalist mode and constitutes the core in the Planning \& Control mode.

One most practical recommendation is to specify reduction targets not in percent points relative to 1990 or other base year but in the more usual compound interest rates per year, then comparable to economic growth, population growth and efficiency improvements. For example: climate efficiency improvement minus GDP growth equals emission reduction rate.

The core recommendation for the EU is to actively develop explicit governance strategies for climate policy instrumentation, not one but several to allow for better public discussion and more long term views on policy development and its instrumentation. The strategic directions as developed here can form a starting point. 


\section{INSTRUMENTATION STRATEGIES AND INSTRUMENT MIXES for Long Term Climate Policy}

"A different voice may be particularly effective in disturbing the existing participants into re-examining matters they had come to take for granted."

$\underline{\text { Stefan Collini }}^{1}$

\section{Towards instrumentation for long term climate policy}

\subsection{Goals, means and tasks}

How may effective long term climate policy instrumentation evolve? Basic options for instrumentation can be developed and analyzed for well-founded decisions on EU climate policy. This analysis is to open up discussion on strategic choices in climate policy instrumentation, the ultimate goal of this study. The more focused goal of this analysis is to investigate how effective climate policy instrumentations may be developed for the long term. In the long term what now may seem fixed becomes malleable, with different options and directions coming up, several being substantially incompatible. One cannot have a pure cap-and-trade system reducing emissions the coming decades predictably, as the EU-ETS intends to do, and simultaneously have a clear long term price signal. The cap price is difficult to predict not just for technical and economic reasons but also depending on other climate policy instruments, like feed-in tariffs and the forced closing of coal fired power stations. It is unpredictable long term, probably being volatile over years and decades. Similarly, extensive feed-in tariffs on renewables, the workhorse in climate policy till now, and maybe coming for nuclear energy, are incompatible with an open real time electricity market. The essence of feed-in tariffs is price differentiation between producers, using fixed prices. And one cannot have EU inter-member state cap-and-trade and also clear national emission responsibility fixed in national targets. Reducing coal fired power stations in one country frees emission permits, allowing others to expand in other countries; that is the essence of tradable permits. Such contradictions might be resolved somewhat in a practical short term way, based on satisficing reasoning (Grubb, Hourcade et al. 2014) following (Simon 1956) and in economics (Cyert and March 1963), like national governments then buying up the permits coming on the market due to their national policies. Grubb's medium term optimizing may improve on satisficing in terms of long term effectiveness and efficiency, like somehow trading national targets between countries. Also broader optimization will however remain within known constraints and options, giving limited guidance for basic choices in policy and economy. Long term transformations for the 2-degrees climate goal require long term strategic choices on instrumentation. There is no single road: different strategy options lead to different designs, requiring basic choices. Short term remedies and medium optimization will return, then as tactical parts of an explicit strategy being implemented.

\footnotetext{
${ }^{1}$ Collini, S. (2012). What are universities for?, Penguin UK. Ch. III
} 
Room for maneuvering in instrumentation requires design strategies for the reasoned development of the climate policy instrumentation. It is not a permutation of instrument variants and for each one choosing the best, and then adding the best to the best. It is a reasoned design process towards overall instrumentation, with specific instruments having a well-defined place in each instrument mix, adapted to the functioning of the mix, and fitting in the broader governance of EU and member states. The reasoning is a general one, based on coverage of relevant instruments, consistency in design; and intricately linked to strategic approaches to governance, of which climate policy instrumentation is an increasingly important part. It has its starting point in the here-and-now however.

The goal translates to tasks at a more concrete level, to design instrument mixes capable for an emission reduction with over $80 \%$ by 2050 . Where emissions are very difficult to reduce, as from agriculture, some basic industries and probably aviation, other activities will have to reduce their emissions with substantially more than $80 \%$ relative to 1990 , in the order of $90 \%$. How this reduction may be distributed over sectors is open yet, depending on instrumentation and technology development. For the hard kernel of energy supply however, the electricity sector becoming so, an emission reduction by around $95 \%$ seems required.

Whatever the precise direction of instrumentation development may be, there are general considerations of optimality which apply to any mix. These relate to effectiveness and costs, combined into cost-effectiveness, and to the feasibility of the instruments, of single instruments and ultimately of the full set of instruments to be effectively developed and implemented, see in this CECILIA2050 project (Görlach 2013). For long term instrumentation development here, the base requirement is that each mix should be capable of reaching the 2-degrees goal, as the EU part in that global endeavor. Cost-effectiveness of the mix, or equivalent: its efficiency, then is determined by the expected costs. In the long term, costs of technologies and also their relative costs are substantially unknown. Emission standards for power stations function differently under cap-and-trade, emission taxes, or with no emission pricing system. Their functioning also depends on the broader domain they are functioning in. Subsidies on insulation to owners, even if high and costly, are hardly effective in older houses if tenants may have to move out temporary at substantial costs and will next have to pay a higher rent for the improvements to their dwelling. In assessing expected future costs, reasoning on how a mix may induce innovation plays a core role. Long term expected cost assessments of single instruments and full instrument mixes can hardly be quantified, making this cost and efficiency criterion a mainly qualitative one, based on more general knowledge and assumptions. Next to the long term cost assessment there are feasibility issues, including political feasibility as acceptability and administrative feasibility as volume and complexity of the implementation task. The political feasibility must be considered under the general requirement of effectiveness of climate policy. The burdens of climate policy then are unavoidable, of course different for different instrumentation options. Explicit statements on individual instruments may be possible: people prefer subsidies over taxes. But subsidies are to be paid for and hence then taxes are part of the broader instrument mix. The political feasibility of a full and effective instrument mix therefor can be established only in terms of general considerations, including political vulnerability, see the survey by (Rey, Markandya et al. 2013), Chapter 6. Administrative feasibility may be the most operational criterion. Fleet standards, adapted ones, and emission taxes can be implemented quite simply. Emission permits per emitter require a very substantial and capable administrative staff and adjoining capabilities 
in the firms involved. The transformation to a low emission society will be conditional on the broader functioning of society, and will have impacts on society, positive and negative. So flanking policies may be required, see (Görlach 2013). Examples are better functioning markets for funding and implementation of energy efficiency improvements in housing and measures to reduce income inequality effects.

Climate policies are intricately related to other policy domains and goals, ranging from energy security and income distribution; to air quality \& health and fiscal policies; and to economic growth and innovation, general innovation. Co-benefits and co-costs may play an important political role. How to integrate policies is a subject of clear governance importance. But before entering the discussion on relations with goals and means in other domains, first climate policy instrumentation is to be developed, avoiding the most adverse effects if easily possible but neglecting them if non-climate policies may more easily deal with them. If such domains of policy have been developed independently already, these subjects need not be part of climate policy. So the core question on the table is which strategies to follow in the development of long term effective climate policy instrumentation, softly reckoning with expected costs; with political and administrative feasibility; and with relations to broader goals and functioning of society.

\subsection{Long term instrument strategies}

The reasoning for long term instrumentation is substantially different from short and medium term development of instrumentation, where empirical predictions may play a substantial role still. There, more direct goals and targets may be involved, in principle leading to expanding the set of instruments, to cover what was not covered yet, fine-tuning on what was too coarse, and more generally to improve on the instruments that were there already. This medium term is governed by optimality considerations, making policy, here climate policy, more effective and efficient, and maybe also more just. Such short to medium term tactical development will then lead to a rising number of instruments, with increasing complexity and overlap, also in the relations between the administrative levels of the EU and its Member States.

Ultimately, long term considerations on instrumentation are to guide short and medium term development, pruning and focusing, based on more general governance views, and reasoned from the deep transitions required for the long term climate goal. The current discussions on reducing EU regulations, though not having an explicit governance view yet, can be placed in this longer term perspective. For the climate aspect this discussion is not yet linked to the dramatically increased effectiveness which is required. To reach an $80 \%$ reduction goal only, a shift is required from emission reductions of less than $1 \%$ per year ${ }^{2}$ in the last thirty years to over $5 \%$ per year in the next three decades toward 2050. The yearly reduction rate is to be substantially higher for reaching the $90 \%$ and $95 \%$ reduction targets, and starting later increases the required reduction rate further. The deep emission reduction goal requires also deep transitions in governance, going beyond pruning and efficiency and optimizing. Efficiency of course remains important in the long term as well but cannot be established in a concrete sense now as future technologies are too unspecified to allow for such an analysis. Some conditions conducive to efficiency can be built into instrumentation, different per strategy.

\footnotetext{
${ }^{2}$ Here yearly compound reduction rates are used; not percent points relative to a base year like 1990.
} 


\subsection{Strategic views on governance}

There are divergent views and options for societal coordination, not only in different cultures like the European, the Chinese and the Indian, but also within the EU and individual countries, and spread over the political specter.

More vertical - more horizontal; more planning - more incentivizing; more goal oriented - more value oriented; more top down instrumental - more bottom up consensual; more contractual more market based; more blueprint - more reflexive \& evolutionary; etc. These dichotomies may seem highly abstract but translate quite directly in different policy approaches and different policy instrumentations. A central characteristic is that they indicate mutually exclusive directions. One cannot go for two directions at the same time. These dichotomies can be generalized in terms of mutually exclusive governance directions, linked to strategic views on policy and instrumentation. Though seemingly far away from climate policy instrumentation, deep transformations for 2-degrees link to basic discussions in Western society on how power relations are organized, balancing control and centralized power and more diffuse and decentralized power. Athenian and Greek constitutional developments were analyzed along such lines by Aristotle in Politics, $4^{\text {th }}$ Century BC, with modern development starting with Magna Carta (1215); Bill of Rights (England 1689; USA 1789) and the constitutions following the French Revolution, all with substantive procedures to reduce direct hierarchical power. The Treaty of Lisbon (2007) forms one current background condition for developing climate policy instrumentation.

The options are not just technical-neutral. Industrialized market based society has not come about spontaneously; it has involved political clashes, ranging from the Corn Laws in the UK to the liberal, socialist and communist versions for industrial society in the $20^{\text {th }}$ Century. In the current political domain they are represented in and between all shades of liberal, Christiandemocratic and socio-democratic ideologies. In the pluralist market based democratic society we are in, these distinctions may be summarized as Autonomy versus Control, see (Dahl 1982). The strategic views on governance distinguished in this study relate to these basic dichotomies on how society can be governed, with a deep transformation for climate reasons in mind. Broader views, as on leaving capitalism, may be investigated. Climate change is too urgent however to bet on fundamental change within decades.

A first governance strategy links to control. It is the usual mode of reasoning for short term improvements and medium term optimization in policies, in indicating specific targets in specific domains to be reached with specific instruments, see the nice summary on these time frames in the next section building on (Grubb, Hourcade et al. 2014). But that practical approach may be applied long term as well, with instrument development on the go, always having short to medium term targets. Of course there then is the task to envisage how the long term future may be actively created. Some abstraction from specific future instruments and technologies and behavior is required however; there also must be substantial new regulation on the go, with future technologies and markets as may come up. Main target groups are in electricity production; heavy industry; buildings and related consumption and expenditures in households and offices; and all modes of transport. Getting to effective results includes controlling the dynamics required to some extent, with time paths specified as concrete as possible as with emission caps and emission standards. This is a Planning \& Control Strategy, tending to a vertical; planning; goal oriented; top down instrumental; contractual; blueprint mode of governance. The 
more integrated concrete views link to broader principles like justice and equity, not just climate issues. There is substantial literature representing this mode of governance, see Chapter 3.

The second mode of governance puts most emphasis on long term incentives for emission reduction, basically linked to changes in the institutional framework of society. It does not matter where emissions are reduced and which technologies are used, as long as they are reduced. Civil society plays an autonomous reflexive role, generating ideas and options bottom up. Generic instrumentation is key, with additional more specific instrumentation only where generic incentives cannot function or cannot function well enough. In our globalized market economy this includes: where markets are lacking and where they cannot function adequately enough, as with some small lenders markets and markets tending to oligopoly and monopoly. But also in other domains it is not markets determining what is set in motion as clearly is the case with infrastructure and research. Also long term technology system development is substantially public government based, exemplified by the development of nuclear power, most IT, internet, and GPS. See on this public role (Mazzucato 2011). Central EU level control on technologies is very limited here, but a substantial amount of basic research, as opposed to development and demonstration, is part of this strategy. At EU level, there are a few core uniform institutions: internalization of climate effects through carbon pricing and an open real time electricity market. This is the Institutionalist Strategy, tending to a more horizontal; incentivizing; bottom up consensual; market based; and reflexive-evolutionary mode of governance. There is also substantial literature representing this mode of governance, see Chapter 3.

This strategy choice on climate policy instrumentation might be reasoned from customary aspects like effectiveness, efficiency and feasibility. Though there are differences along these lines, the ultimate choice on strategies derives from broader views on how society is to be governed. Only for given strategy choices tactics become guided.

\subsection{Short term, medium term and long term domains}

Following (Grubb, Hourcade et al. 2014) the reasoning for climate policy on the short, medium and long term domain is substantially different. In the short term, most options are given, with incidental improvement options to be introduced on a case by case level, as in improving test procedures for fleet standards in automotive regulations. Satisficing, a term coined by Herbert Simon (Simon 1956) and used broadly in micro-economics (Cyert and March 1963), indicates what one can practically achieve now, accepting all other as given. The improvement realized is 'good enough' in the given context, not considering a range of options for broader optimization. In the medium term more options are designed and considered, allowing for a more systematic approach to improvements. System aspects come to the foreground, requiring coordination towards optimization, with a focus on effective least cost options for emission reduction, reckoning also with other value domains. This is a mode of reasoning linked to welfare economics as the dominant discipline, starting early in the Enlightenment with 'the greatest happiness for the greatest numbers' with (Bentham 1776). Such optimization will now also include broader welfare relevant aspects like distributional and justice issues. This broadened welfare theoretical approach has developed after 1970, with Sen as a major author, building on the more economist welfare theory of (Samuelson 1977). This approach has recently most eloquently been described in (Stiglitz, Sen et al. 2009), with policy instrumentation based on 'doing what is necessary, in the most efficient way'. The intention is to make the welfare function as operational as possible and 
then do the best to improve society. More detail in specification gives a better basis for optimization. More specifics in all variables covered may well lead to a short to medium term focus in Grubb terms. However, with some generalization this approach may also be applied for the long term. The welfare theoretical framework covers aspects beyond only climate policy, indicating for example that increased energy prices due to climate policy may also have energy policy effects and distributional effects to reckon with. Redressing such non-climate issues then may be part of climate policy instrumentation but may also part of other policy domains and then part of broader overall instrumentation. The relation to energy policy is physically quite direct, as the current fossils based system will have to be substantially replaced by non-fossil sources. In the original proposal by the Commission in 1991 (COM 1991), the carbon tax was half carbon half energy, see the assessment by (Pearson and Smith 1991). In ETS and Fleet Standards, the focus has been reduced to greenhouse gas emissions. Distributional effects of climate policy will be limited as compared to the role of other policies and instruments. The distributional effects of tax systems and public spending may be quantitatively of a very different order than what climate policy might induce, but climate policy is part of the distributional policy domain. Long term climate policy then links to income distribution mechanisms as due to globalization and other mechanisms see (Piketty 2014). However, the tendency to the concrete will tend to link issues at the action level in the climate policy domain, then combining with energy policy, clean air policy, development policy and distributional policies, as is well visible now in the global climate discussions.

For the long term, reasoning may start at this more practical and operational level, looking for transitions and transformations in the climate domain first, for long term climate policy, but may be differently for the medium term, see (Bausch, Roberts et al. 2014). Looking at the energy system in Figure 1, the climate transitions can be indicated as a full transition of the electricity system, a full transition of the heavy industry system, a full transition of the building energy system and a full transition of the transport systems, together implying a substantial transformation of economy and society, see the diverging outcomes of modelling exercises in the CECILIA2050 project as by (Meyer, Meyer et al. 2014, Solano and Drummond 2014, De Koning, Huppes et al. 2015). It is however not possible to say in advance what will be the new system in any technology detail, let alone if it may the most efficient and broader optimal system, by then. Of course, by then, the more short-to-medium term efficiency considerations will play a role, as they do now for current and nearby policies and technologies. But efficiency considerations should not hamper transformations; society should not get stuck at an efficiently reached and efficiently functioning still too high emission level. On the other hand, getting from now to the low emission future also requires the continuous functioning of economy and society, not just a climate transformation. So the long term deep emission reduction with deep societal transformations is the goal. But on the way towards it society is to remain functioning, open to transitions and transformations required, and geared to them somehow. Closing down all fossil power stations in the next decade is a highly effective policy measure. But it is not a feasible measure as the economic and social costs would be enormous. The path is to be acceptable with required emission reductions possible only in the longer term. Scenarios for a 2-degrees future, $R C P 2.6$ scenarios in the IPCC jargon, therefor tend to allow emissions to be reduced gradually, several with negative emissions in the second half of the century, see (IPCC-AR5-WGIII 2014), Figure 6.7. 


\subsection{EU constitutional constraints and international developments}

The future is open in many respects, also regarding supranational government structures evolving. However some developments are more probable than others. It seems not so probable that the EU will move much towards supranationality beyond what the Lisbon Treaty provides, but it is not impossible. From a climate policy point of view such a move would facilitate easier decision making, a majority vote in EU parliament and Council to support what the Commission proposes, and a more direct say in what now is Member States' domain in climate policy. The current tendency towards decentralization in climate policy, as in using different national subsidies for renewable energy systems in the ETS domain, similarly may not hold long term. Such a decentralization may be seen as temporary, as deep transformations ultimately cannot be subsidy based, and certainly not at a level of individual member states. Some supranational EU level coordination of subsidies would be required at least, as feasible in the Lisbon Treaty level of supranationality. Though other options exist, see on options and their evaluation (Bausch, Roberts et al. 2014) and (Markandya, Rey et al. 2015), the base assumption here is the roughly current level of centralization.

Similarly, a binding UN climate agreement would make EU policy easier as adverse competition effects would be reduced. Such a 'universal, legally binding agreement', as is the aim of COP21, is not probable however. This is due to several factors combined, like the lack of central authority in enforcement; the large number of countries involved; the high uncertainty on outcomes; the unequal distribution of cost and benefits; and the complexity of climate technical and broader ethical issues as are involved in establishing emission shares for countries for the coming decades. On the other hand however, it is difficult to imagine that major players will not come to some form of emission reduction agreement, in the medium and long term. The full or no agreement and the middle of the road with some agreement correspond to the three levels distinguished in (Zelljadt 2014), but with options for instrumentation filled in slightly different under the governance strategies considered here.

So for both issues we assume modest development. The EU will mainly remain within the Lisbon Treaty realm but will be as capable in policy development as it used to be in other domains. This does not mean fast decision making but means that effective political processes are ongoing and that countries cooperate in the end, in a process of give and take. Similarly, though a binding climate agreement may not evolve, several countries - the EU taken as one here - will advance their climate policies and reduce their emissions, under some form of agreement. So our background assumptions here are middle of the road: no disasters and no political revolutions towards internationalization in the EU and globally. In a parallel CECILIA2050 report D6.3 (Markandya, Rey et al. 2015) deviating assumptions on these international developments are investigated, with their possible consequences for EU climate policy instrumentation.

\subsection{Design methodology and document organization}

There are different entries to the design process for climate policy instrumentation. One, the bottom up approach, is to start with what is there, and see how this instrument mix may evolve, improving effectiveness and efficiency, and broader optimality, in the process, see (Görlach 2013). In terms of (Grubb, Hourcade et al. 2014) this approach is most fit for the medium term however, easily overlooking the requirements and options for deep long term transformations as 
are required for deep emission reductions with effective climate policy. Applied to long term climate policy, the concreteness of actions as required will fade. Optimality relates to effectiveness and costs, to feasibility and to broader functioning of society, but in a soft more strategic way of reasoning. The second approach is analytic. What instruments are there, how can they be set up individually and how may they consistently be combined? As there are many instrument types with ever more sub-variants, the guidance on selecting relevant options is to come from additional criteria, first like effectiveness and optimality.

The third approach, top down and strategic, states general principles for governance, here applied in the climate policy domain for development of long term instrumentation. All designs here require a view on the future domain in which each climate instrument mix is to function. This domain analysis, see (Grubb, Hourcade et al. 2014), is in Chapter 2, giving the context in which the instruments are to function. As the future is substantially open, the domain analysis is about possible futures in which the low carbon society is to come about and function.

Next, in Chapter 3, is the more detailed analysis of how bottom up development and top down design may be filled in. The bottom up development has main current EU instruments as a starting point: ETS and Fleet standards, and looks to how to adapt and expand instrumentation so as to effectively cover and reduce emissions in all sectors. The top down design has governance strategies as a starting point, either in a more technology specific Planning \& Control direction, or in a more generic incentivizing Institutionalist direction. These governance oriented strategies require explanation here, as ultimately, in Chapter 6 and 7, they determine how instrument mixes may be developed, and how their possible numbers may strategically be reduced. The analytic approach to instruments is prepared in Chapter 4, covering main types, in a typology and filling these in with substantial detail for main instruments: emission pricing, electricity markets, and fleet standards. Next, the triple design methodology is applied at sector level for four main sectors, in a primarily bottom up vein. Together they cover the full chains of energy use and emissions in the EU, see Chapter 5 . These sectoral instrument designs may be combined into four full sets of instruments, taking together what fits. What fits is analyzed from a strategic perspective, see Chapters 6 and 7, reducing to what is fit in either of the two long term strategies distinguished. Chapter 7 adds detail while also indicating pathways for instrument development, linking to medium term instrument development options as specified in a parallel study (D6.2). The two instrument mixes are analyzed in Chapter 8 as to potential effectiveness, political and administrative feasibility and vulnerability, and as to some further feasibility aspects of optimality, with legitimacy as one overarching result. This volume ends in Chapter 9 with a number of concluding outcomes and recommendations.

\section{Imagining 2-degrees futures domains \\ 2.1.Focus on fossil $\mathrm{CO}_{2}$}

The instrumentation developed here concerns only fossil $\mathrm{CO}_{2}$, for a number of reasons, the first being that it is the major source of greenhouse gas emissions. Other major greenhouse gases are methane, nitrous oxide $\left(\mathrm{N}_{2} \mathrm{O}\right)$ and perfluorocarbons (PFCs), and non-fossil $\mathrm{CO}_{2}$ from calcium carbonate processing as in cement production, and from land use change. From an instrumentation point of view these non-fossil GHGs differ in that emission measurement mostly 
is not possible, also not indirectly, as is well possible with fossil carbon. The instrumentation for methane and nitrous oxide emissions from agriculture can only be quite indirect through technology and behavior regulation, including demand shifts (Kuik and Kalfagianni 2013). Land use change emissions can hardly be linked to specific actions on specific locations. Where emission measurement is possible, as with nitrous oxide $\left(\mathrm{N}_{2} \mathrm{O}\right)$ from industrial chemicals production and perfluorocarbons (PFCs) from aluminium production, these emissions may be included similar to the instrumentation options for $\mathrm{CO}_{2}$. They are included in the current ETS already. However, they can only be administered at the firm level, not upstream as is possible with fossil $\mathrm{CO}_{2}$ emissions based on their carbon content. Options for instrumentation for non- $\mathrm{CO}_{2}$ emissions will not be investigated systematically. Starting point now is the fossils dominated energy system, see Figure 1.

Figure 1 Energy input, transformation and final use EU-28 in 2012, in Mtoe

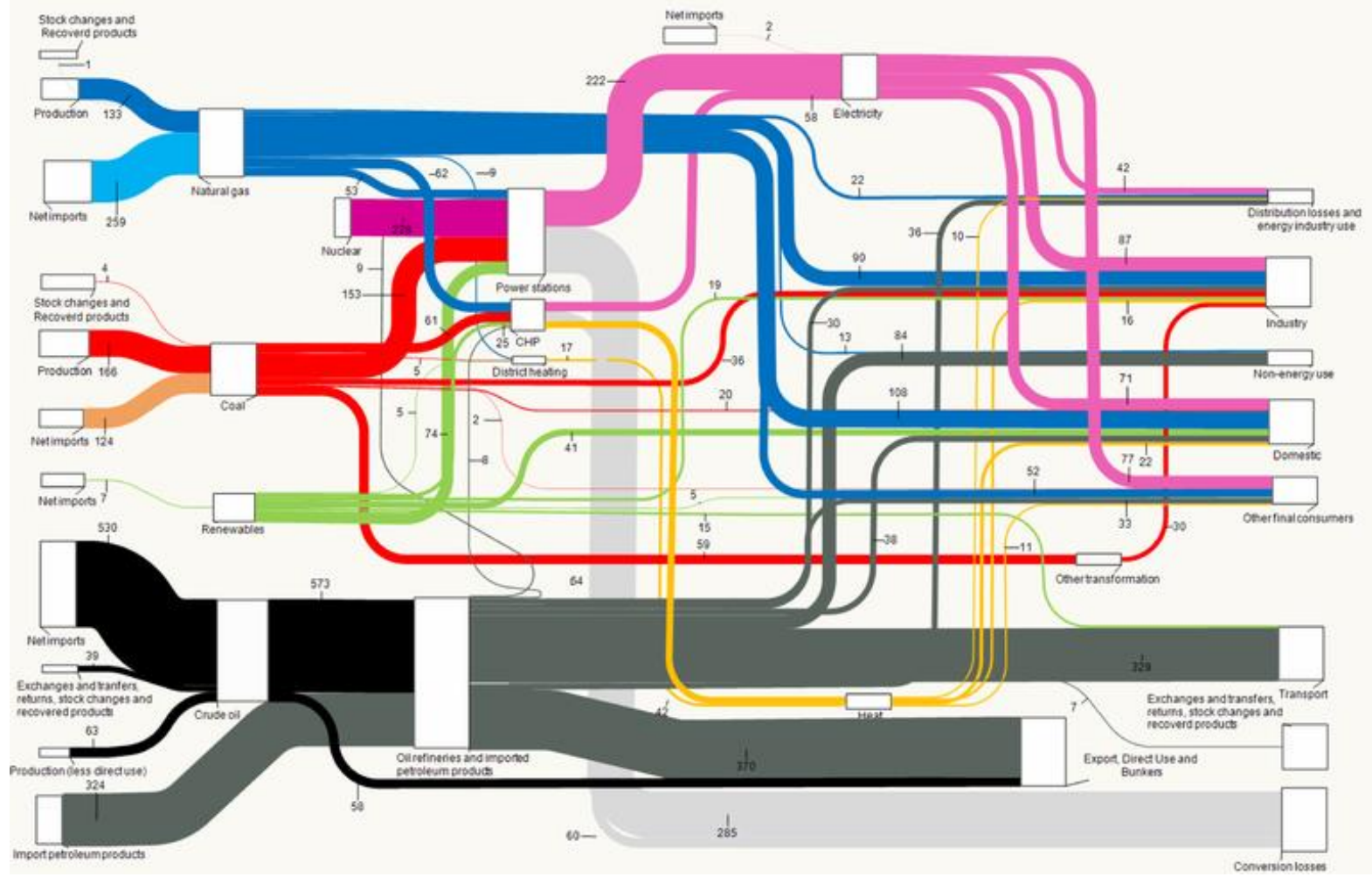

Source (EEA 2015) version September, downloaded 07Sep15

\subsection{Starting from now: options in the energy chain}

The current energy system is dominated by oil, gas and coal, with nuclear and the old renewables following, especially hydro power, with new renewables coming in in small amounts as yet. Apart from the Carbon Capture and Storage (CCS, also as 'Sequestration') route, deep emission reductions can only be based on weaning from fossil energy, shifting to a new energy supply and use system. Non-fossil primary energy may be from a large variety of sources, all with constraints. Modeling in CECILIA2050 in WP3 (Meyer, Meyer et al. 2014, Solano and Drummond 2014) has 
shown the strong dependence of expected costs of technologies on the shares that may evolve, while social constraints, like on nuclear, on land wind power and CCS are not amenable to empirical modelling and are mostly assumption based.

Least constrained in a technical sense is solar, with wind following, both highly intermittent however, with intermittency also being variable, and being fully non-dispatchable as yet. IEA estimates/predictions on the global share of solar PV in 2050 have proven unstable, as rising from $11 \%$ in 2010 publications to 16\% in 2014 (IEA 2014). Nuclear is fully non-intermittent but has limited production flexibility (but see (IEA 2014). It has risks and it has as yet unresolved waste disposal problems, creating economic and societal unknowns on its potential. Geothermal has high capacity at limited locations and with unknown costs. Biofuels compete with other land use, for food and materials, and for nature, while intensifying agriculture may well lead to rising nitrous oxide $\left(\mathrm{N}_{2} \mathrm{O}\right)$ emissions. Some further technologies have more limited capacity for development. Hydro has severe limitations for expansion in the EU; wave energy has limited total capacity and is probably inherently expensive, and is also intermittent, with a moon rhythm. Extreme options, like beaming in solar energy from space or the moon (Valinia, Moe et al. 2013) may be interesting but can hardly play a role next half century. The main sources of primary energy with capacity to produce a main share of total societal energy requirement at no too extreme costs are solar and wind. A wide variety of technologies for them exists already and will develop further. Especially solar energy is in rapid development, in many directions. See (IEA 2015) for a survey of technologies and their potential. Conclusion on this short survey is that most probable sources for rapid expansion of non-fossil primary energy are either highly intermittent (solar PV, wind, wave, tidal) or can be adapted to demand variation to a limited extent only (nuclear with some delay, solar heat-to-electricity only for daily variations).

The next domains of technology, energy transformation, energy storage, and energy use systems again have a number of relative certainties and at a more detailed level ever more uncertainty on which technologies can be available. The near certainty is that the technology system to evolve is to be resilient to the sum of intermittent and constant base load supply and substantial demand variations partly regular over days, weeks and seasons, and partly incidental, as with heat waves. Options to create such resilience exist already technically and are extremely diverse, ranging from micro heat storage using peak electricity with heat pumps; to chemical storage in oxidizedreduced metal systems; to pumped hydro; to electric battery systems; and to storable chemical energy like hydrogen and aluminium; and to physical storage like compressed nitrogen or $\mathrm{CO}_{2}$ and flywheels, and ultimately also to final demand variation, with smart grids and internet-ofthings. On each of these, and more, substantial literature exist and all of them can be developed further; and all have their uncertainties and capacity constraints.

The diverse final use systems are to align with the diverse intermediate energy transformations, and both are to be aligned to diverse options for primary energy production. But certainly there are no certainties at a more detailed level. One may expect electricity to take over in near final and final use systems, including for heat and transportation. But other options may prove more viable at least partly, like the hydrogen route with easy decentralized distribution and storage feeding into ever more efficient fuel cells.

There is substantial uncertainty on the role of energy efficiency. The industrial revolution was based on extreme increases in energy efficiency, leading however to extreme increases in energy use, the Jevons Paradox, in the energy and environment domain now covered under the term 
'rebound'. The long term volume of final energy use may be linked to specific technologies like insulation, efficiency increases on propulsion systems, etcetera. However, several rebound mechanisms may decrease the net effect of technical improvements, a major one being the income effect of efficiency increases. See (Font Vivanco and van der Voet 2014a, Font Vivanco, Freire-González et al. 2014b) on mechanisms involved and main empirical examples. Also the often encountered assumption that added renewables replace fossils to the same amount does not generally hold: they add to the total supply of energy and through market mechanisms press out only a part of fossil supply. 'Energy conservation' and 'energy savings' may therefore be misleading terms. For an assessment of medium term options and their net effectiveness the energy efficiency discussion is however highly relevant, see (Meyer, Meyer et al. 2014, Solano and Drummond 2014). In the long term a mainly emission free energy system is to evolve however. Then the volume aspect becomes less important, see the discussion below, after Table 1.

The combination of technology uncertainty in primary production; in transformation and storage systems; and in (near) final use systems leads to extreme uncertainty on the precise nature of the low emission energy system which may develop. This holds even more for the specific technologyvolume combinations and total volumes which may be involved in all energy flows concerned. This extreme technologies and volumes uncertainty is to be matched to the full certainty of a low carbon energy system to exist by 2050 , under the novel design of an effective climate policy instrumentation. For a potentially successful innovator, exceptions are the goal, setting you apart from the pack. This is to be kept in mind: the unusual and unexpected may be the most beautiful and effective.

\subsection{Technology and behavior options screened}

There is substantial modelling available on how a low emission future might be accomplished. In the IPCC scenario systematics these are the Relevant Concentration Pathways for a 2-degrees world: the RCP2.6 scenarios, see the extensive analysis and survey of scenario studies by (van Vuuren, Stehfest et al. 2011). These scenarios are peak-and-decline scenarios, first over-emitting relative to the 2-degrees climate goal till around 2050, requiring negative emissions thereafter. The models used are global integrated assessment models with feedback between economy and environment and with regional disaggregation, and they include non- $\mathrm{CO}_{2}$ emissions and effects of land use change (LULUCF: Land Use, Land Use Change and Forestry). For the instrument discussion on Europe with focus on non-LULUCF $\mathrm{CO}_{2}$ emissions, three types of simpler models have been developed in CECILIA2050, giving more insight in mechanisms involved. They are an energy optimization model (Solano and Drummond 2014), the ETM-UCL Model; an instrument rich macro-economic model (Meyer, Meyer et al. 2014) the GINFORS Model; and a technology specific input-output scenario for 2050 (Koning, Huppes et al. 2014, De Koning, Huppes et al. 2015), the EXIOBASE Input-Output Model. The two economic modelling approches have a predictive element, assuming (abstract) technologies with certain characteristics and costs. With adequate input assumptionis the ETM-UCL can produce the desired emission reductions by 2050, with the Ginfors model coming only close, and the EXIOBASE Input-Output model not even coming close. The input-output scenario is free of dynamic mechanisms but looks at consistent future in the year 2050. The latter assumes high increases in efficiency and adds substantial 
emission reducing technologies. But deeper changes are required. The outcomes of these three complementary approaches are analyzed in (Drummond 2014).

Emission reductions will have to come mainly from weaning off of fossil fuels. The other option is CCS, which is difficult to apply in mobile and small scale sources but may be applied to larger scale fixed installations. There it may play a role but seems not capable even at the micro level to reach the $95 \%$ emission reduction in electricity production as investigated here, see Table 1 , indicating reduction options there in the order of $65 \%$ (in terms of greenhouse gases but referring mainly to $\mathrm{CO}_{2}$ ). The IPCC numbers in that table include upstream emissions.

Table 1 Global warming potential (GWP) per MWh of primary electricity sources

\begin{tabular}{|c|c|c|c|}
\hline Technology & Min & Median & Max \\
\hline \multicolumn{4}{|c|}{ Currently commercially available technologies } \\
\hline Coal - PC & 740 & 820 & 910 \\
\hline Gas - combined cycle & 410 & 490 & 650 \\
\hline Solar PV - utility scale & 18 & 48 & 180 \\
\hline Solar PV - rooftop & 26 & 41 & 60 \\
\hline Concentrated solar power & 8.8 & 27 & 63 \\
\hline Geothermal & 6.0 & 38 & 79 \\
\hline Hydropower & 1.0 & 24 & 2200 \\
\hline Wind offshore & 8.0 & 12 & 35 \\
\hline Wind onshore & 7.0 & 11 & 56 \\
\hline \multirow[t]{2}{*}{ Nuclear } & 3.7 & 12 & 110 \\
\hline & \multicolumn{3}{|c|}{ Pre-commercial technologies } \\
\hline CCS - Coal - PC & 190 & 220 & 250 \\
\hline CCS - Coal - IGCC & 170 & 200 & 230 \\
\hline CCS - Gas- combined cycle & 94 & 170 & 340 \\
\hline CCS - Coal-oxyfuel & 100 & 160 & 200 \\
\hline Ocean (tidal and wave)) & 5.6 & 17 & 28 \\
\hline
\end{tabular}

Source (IPCC-WG3 (2014) Annex 3, p10)

These upstream emissions will become lower by 2050 as then also many of these emissions will have been reduced, see on this point the conceptually innovative paper by (Hertwich, Gibon et al. 2015). However, upstream infrastructure involves steel and cement, where emission reductions will be limited. So the role of CCS may be supplementary, for difficult cases where weaning off is not an acceptable option, like with steel. Also, the public perception of CCS is mixed, see the survey of the extensive literature by (L'Orange Seigo, Dohle et al. 2014) and the underlying problem of where long term storage may be proven safe.

So, apart from the quite uncertain nuclear expansion, see the balanced view by (Lévêque 2014)it is only the renewables that can transform the energy domain towards deep emission reductions: solar, wind, tidal, geothermal and hydro, and maybe a few more. Hydro-energy can be expanded 
only to a limited extent in Europe, tidal has limited and unproven capacity, and geothermal may be restricted to hot beds close to the surface, so the resilience bet is on wind and solar, which have proven to be expandable at industrial scale. Rolling them out with adequate speed is one of the great challenges. Quantifications based on optimization models, see for a detailed example (Solano and Drummond 2014), tend to be bounded, with all technologies each playing a moderate role. Such outcomes are roughly indicative of options, as they assume cost prices which long term are not well known and market mechanisms which are highly conditional on policy instrumentation.

The IEA gives prospective costs of electricity supply in terms of levelized cost of electricity (LCOE), for 2020. The levelized cost concept has been developed for (US-type) highly regulated fossils based monopolistic electricity sector and has limited meaning in an open market situation with low short term variable costs of most renewables. In that old situation electricity prices are an input rather than an output of investors' profitability calculations. To assess whether the cash flow of a new project is sufficient to reimburse the investment and capital costs the net present value (NPV) or internal rate of return is used, based on expected exogenous electricity prices, see (IEA 2015) Chapter 11 for a discussion. More relevant measures include system costs, always to be borne somehow, and take into account expected price developments, their variability, and their uncertainty over time, including policy induced effects though all sorts of market mechanisms. Predicting technologies long term therefore seems not well feasible, unless induced by assumed effective technology specific policies.

Reduction of energy use through energy efficiency increases plays a limited role in deep emission reduction in the long term, as opposed to the short and medium term, for structural reasons and due to policy limitations. By then all energy flows will mainly be emission free. Then using $40 \%$ less solar PV hardly reduces emissions. With $5 \%$ of emissions left in the electricity system by 2050 , an extreme energy reduction of $40 \%$ will help reduce emissions from $5 \%$ to $3 \%$. That is a hardly relevant reduction but with a severe burden on society: energy is an essential ingredient in virtually all economic processes. There is a Herculean task ahead in climate policy. Confounding this task with an as yet not well-defined task in energy policy seems overcharging the political and economic system. Some have argued that energy efficiency improvement is a main technology entry for emission reduction. There is the 'huge potential for improving energy efficiency' (Grubb, Hourcade et al. 2014) p160 and similar (Hood 2011) Ch2 on 'unused energy efficiency'. However, there is also is a huge potential to increase the energy intensity of production and consumption, partly fed by the rebound mechanisms of lowered costs of final energy use due efficiency increases. Faster transport alone can accommodate near endless increases in energy consumption, from fast trains and long haul normal aviation to supersonic flight and space tourism. That is a matter of energy prices and energy policy guiding technology, while the focus here is on having an economy with substantially reduced $\mathrm{CO}_{2}$ emissions. If supersonic flight is possible with near zero emissions, that reduction then is enough for climate policy. If climate policy kills off that option, tant pis for supersonic flight. But from a climate point of view there is nothing against supersonic flight as such.

Of course in the short and medium term, the overlap between energy and climate policy is environmentally and politically highly relevant, see (Hood 2011, Bausch, Roberts et al. 2014). There are conflicting elements however. For supply security reasons diversification of fossils supply may create a barrier for effective climate policy. Also, adding energy efficiency 
requirements as through standards may substantially increase the cost of emission reduction as compared to generic emission reduction policy, see the survey paper by (Parry, Evans et al. 2014) on the transport domain, and may help create lock-ins on long term detrimental technologies, like efficient combustion cars. If rising energy prices due to climate policy lead to a reduction of energy use, inducing somewhat lower emissions due to the volume effect, such an effect is of course fine from a climate policy point of view. But reducing specific fossil energy technologies will also lead to lower fossils prices, see (Meyer, Meyer et al. 2014), stimulating fossil energy use diffusely in all applications. Energy efficiency increases are always part of technology development but tend to be slow. They have proven to be difficult to speed up with policy measures, see (Tietenberg 2009), with emission pricing emerging as a major policy instrument. Whatever the precise role of energy efficiency may be, also in a medium term instrument mix for climate policy, it is not part of the long term strategy delivering $90 \%$ emission reduction.

So for climate reasons, some mix of renewables, unknown as yet as to composition and volume, will have to take over, together with an also unknown volume of nuclear energy (with limited dispatchability) and some biobased energy as from agriculture. Biofuels are widely disputed as to their net effects on climate emissions, a discussion we will not go into, also related to land-use change. Their overall role will be limited, due to competition with food and materials for an increasingly wealthy global population. Solar and wind seem to have the option for the extreme capacity increase required, solar especially if printable-like mass production becomes available, integrated in infrastructure as in wall cladding and roof constructions and other surfaces that are to be built and cladded anyway. Somehow their intermittency is to be resolved, not only per day and week but also over the seasons, if heating and cooling would be substantially electricity based. Another option might be solar hydrogen or other solar fuel. We cannot know that in advance but policy instrumentation is to reckon with such options: by actively creating one option, or several, or by incentivizing any of them, including the provision of the required infrastructure.

The bottleneck for increasing renewables production hardly seems technical. A back-of-theenvelope quantification may indicate the size of the task. EU final energy use currently is around 8 petawatt-hour, of which now 3PWh is electric. Efficiency of electricity use as for heating can be a factor 3 higher than for natural gas, and similar efficiency gains are possible in person transport when shifting from fossil to electric drives. Primary electricity production in 2050 may be estimated at around $3 T W h$. At $300 \mathrm{kWh}$ per $\mathrm{m}^{2}$ per year an area of solar cells then is required of $10000 \mathrm{~km}^{2}$, with required land a factor of two higher at $20000 \mathrm{~km} 2$, around $0.5 \%$ of the EU28 land surface, with North Africa waiting. So the land requirement for shifting even to full only-PV production hardly seems a problem. The area of solar cells to be produced per year, assuming $5 \%$ of the installed capacity in 2050 , is $500 \mathrm{~km}^{2}$ per year ${ }^{3}$. Assuming some sort of printable or coating process to emerge, that surface can be compared to car coating. This PV surface is less than the surface for car coating. At 12.5 million cars per year with a multi-layered coated surface of on average $80 \mathrm{~m} 2$ each (EGTEI 2005), the total coating surface is around $1000 \mathrm{~km}^{2}$ per year ${ }^{4}$. Again, the amount of solar cells to be produced would hardly pose a problem, certainly not if also

\footnotetext{
${ }^{3}$ At $300 \mathrm{kWh} / \mathrm{m}^{2} /$ year a PV surface of $10000 \mathrm{~km}^{2}$ delivers $3 \mathrm{PWh} /$ year. This requires a solar cell production rising to $500 \mathrm{~km}^{2} /$ year, assuming a life time of 20 years.

${ }^{4}$ Current sales of 12.5 million cars at $80 \mathrm{~m}^{2}$ per car is 1000 million square meters, which is $1000 \mathrm{~km}^{2}$.
} 
reckoning with wind, hydro, nuclear power, etc. Even this extreme PV-only option seems feasible. Also the intermittency problem does not seem basic, as it might be solved using the capacity of the transport fleet alone, see BOX 1.

Whatever the exact role of PV and other sources may be, a major part of long term new electricity production will be highly intermittent, not linked to intermittency of demand. There are many ways in which supply and demand can be matched, real time clearance being a strict requirement in the electricity market. Shifting demand, storage and secondary production are the solutions, with many options available. Current swing producers, who now match supply to varying demand, will have left the market well before 2050, so the full problem is at the table. Again, however, even current technologies can already take care of market clearance over days at least: battery storage, hydro storage, secondary production as with fuel cells together can do so, and certainly in combination with smart grid developments to shave demand peaks, including with heat pumps with heat storage creating substantial flexibility over days, weeks and seasons. The IEA assumes in a highly assumption based study that a number of such technologies together may reduce peak demand by in the order of $30 \%$, see (Heinen, Elzinga et al. 2011). At the peak supply side, just the electric drive passenger car park of 2050, with battery storage or with hydrogen storage with fuel cells, is more than enough to produce for any total daily peak demand, see BOX 1 . This of course is not a prediction but goes to show that several technical solutions for load balancing are available in required quantities in principle. Climate policy instrumentation will determine which ones may come up, with innovation playing a key role, intermingled.

BOX 1 Integrating passenger vehicles in the electricity system

Beware: This is not a prediction but an investigation of one corner of feasible technology options relevant for climate policy instrumentation.

\section{Peak load supply by passenger car fuel cells or car batteries}

With primary electricity coming substantially from wind, solar PV and other intermittent sources there will be a regular non-match with peak demand for electricity, and a severe one at exceptional times, as when the sun does not shine (at night), solar PV is covered with snow, and when wind power is at a fraction of its installed capacity (stable high pressure over Europe) while electricity use is high due to extreme cold or extreme heat with high air conditioner use. Meeting peak demand is a key issue, to be always resolved. There are several ways to resolve this problem as by centralized peak shaving, also as by using stronger East-West connections, and by decentralized peak shaving using the options of the internet of things as one line in smart grid development. The highly decentralized electricity system which may develop under the umbrella of an open real time electricity market can go many directions, not yet to be predicted. So there are solutions possible in many directions. But can they be sufficient? A simple technology scenario can help grasp the magnitude of feasible change, by picking out just one arbitrary but feasible option: hydrogen fuel cells of cars connected to the grid when standing idle. Transport vehicles tend to be used more hours per day, but may have a similar role when idle.

Current peak demand in the EU is in the order of 800GW (Brauner, D'Haeseleer et al. 2013). With shifts towards electricity use in heating and transport this may rise to in the order of $3000 \mathrm{GW}$, a very high estimate according to (Brauner, D'Haeseleer et al. 2013). Now imagine, exemplary, that all person cars and similar will be hydrogen fuel cell driven ${ }^{5}$. This is hardly probable but some form of non-fossil onboard

\footnotetext{
${ }^{5}$ Hydrogen refilling stations are being rolled out by Shell in Germany now, 400 planned, with other countries following, see http://www.ft.com/intl/fastft/406871/shell-aims-boost-hydrogen-vehicles-germany. Toyota is
} 
stored energy will be present in transport to drive the electromotors for the wheels. An average car will have a fuel cell power of at least $50 \mathrm{~kW}$, with some additional battery power for peak acceleration. (Tesla Model S has $310 \mathrm{~kW}$ peak power now.) Assume there is an incentive to connect the fuel cell car to the grid, when the price is high enough to make this attractive for the individual car owner, or for the private fleet owner. This price must cover the cost of the hydrogen to be acquired, the additional cost of running the fuel cell, the cost of connecting to the grid, and the cost of the nuisance to go to this effort. Assume that half of all cars are connected at peak times. And assume there are only 100 million fuel cell vehicles, a very low estimate for the total number of passenger cars in the EU. Their combined power then is: $0.5 \times 100.10^{6}$ $x 50 \mathrm{~kW}=2500 \mathrm{GW}$, roughly the total peak power demand for 2050, the high estimate. Overall, the efficiency of this hydrogen route would be relatively low, assuming the hydrogen is produced from renewable electricity. With a to-and-fro efficiency rising to $80 \%$ by then this would lead to an overall efficiency of $60 \%$, to be paid for by the temporary high electricity price. However, there may be more attractive options for hydrogen production by then, like directly from solar (research for different technologies ongoing). Full electric cars would have a higher overall efficiency in delivering to the grid. But they can deliver a smaller amount if the gap between primary production and demand lasts. Many more options for secondary peak delivery exist, like pumped hydro, diverse static battery systems, and more esoteric systems like fly wheels, chemical storage, pressurized gases, etc. And of course there will not just be primary production with non-dispatchable renewables.

With relevant markets installed, covering the daily peak power problem of intermittent sources might be resolved with the car hydrogen fuel cell technology route alone, or by the battery car alone. Of course the future will be different, including as yet unknown options. The longer term mismatch between supply and demand - over weeks and seasons and in exceptional circumstances - may also be covered by the fuel cell car with hydrogen storage; not by the battery electric vehicle.

With the energy supply system mainly electrified, the next technical problem is how the electrification of the energy system is to work downstream, in applications formerly served by fossil electricity or fossil heat as with district heat from fossil fired power stations or dedicates fossil heating systems. For heating purposes, including hot water use, electricity based heat pumps with heat storage seem a most relevant option now available already. There is substantial experience with such systems. However, especially the seasonal energy storage may not have the right total capacity yet. Underground heat and cold storage in aquifers, for example, uses a larger underground area than the building area served above ground. Also ownership of the underground capacity is not well established yet, with first come first get a permit currently being the situation in the Netherlands. If such systems don't develop, heat pumps may lack seasonal storage capacity and then may revert to air based heat pumps, as is the most used heating system now in Japan already. Substantial R\&D and Demonstration seems due.

In industry, there is much diversity in energy use. With low temperature heat use the solutions are similar or even the same as for space heating and hot tap water. For higher temperature furnaces deeper adaptations may be required, requiring redesign and new investment in capital goods. The instrument mix will have to give the right impulses for such changes.

currently marketing its Mirai fuel cell car. How this will work out long term is unknown but learning curves will certainly be created. 


\subsection{Economic options}

The speed of economic development may be modelled by international bodies but remains substantially uncertain, and will certainly vary in time as well. The current downward trend in productivity growth in developed countries is not well explained, but ways to increase economic growth are very actively searched for. Climate policy does not have a strong relation with economic growth probably, see (Meyer and Meyer 2013), as other factors dominate. It will reduce growth somewhat due to somewhat higher energy costs. Conversely, the investment induced by climate policy as by renewables subsidies may have a macro-economic impact. This impact will be limited however as generic macro-economic policies will reckon with these impacts as part of broader macro-economic policy. The net effect therefore may well be close to zero.

The trend towards reduced income differences between countries may well continue due to industrialization of nearly all now poor countries in the globalizing world. Globalization again means that fundamental national differences will be reduced, as based on available national resources, minerals and soils/climate combinations. Overall these sectors have a limited share in total production however. So the general development will be determined more by the capacities of the labor force and the institutions regulating the dynamics in society. International specialization may well change towards 'the first one with economies of scale', a variant of the prime mover motive, not based on any basic national relative production advantage. Cultural developments in the economic domain are also governed by global issues; the globalization of consumption patterns continues given the increasing role of global scale production and advertising, and internet based marketing.

More specific developments relate to shifts in economic structure and economic mechanisms. Economic structure in Europe may revert back to more material production, as in the aspired renaissance of manufacturing. This reindustrialization would lead to higher European emissions, reversing the deindustrialization of the last decades which helped reduce EU emissions, see for empirical analysis (Wiebe, Bruckner et al. 2012)see for the method of analysis involved (Kokoni and Skea 2014). It seems difficult to predict such structural developments, apart from what is needed for the renewable energy supply and the electrification of energy use.

There is one substantial macro-economic mechanism involved in effective climate policy. The rent incomes earned by coal, oil and gas producing companies and countries will be replaced by more competitive lower rent production domains, as for wind and solar installations. From a global point of view this may be a substantial effect, especially in oil producing regions. But as primary fossils production in the EU is limited, this mechanism will play a limited role in Europe.

Also the share of the working age population in the total population is going down. The working age population in Europe will diminish substantially by 2050 , especially if immigration is halted. This is not just a European issue. Japanese labor force is diminishing even faster, with China following closely after. Economic growth as production per head, is on a downward trend as well, without clear causes as yet. Overall EU emissions therefore are on a downward trend, but by far not fast enough for the extreme reductions required. This will have consequences for saving and investments and for the economic organization dealing with such developments. The share of savings will have to rise for capital fund based pensions, or taxes will have to rise to fund publicly paid pensions. There is a weak link to climate policy. Savings and investments will rise, creating room for investment also in climate technologies. 
One element to be analyzed is the combination of intermittent production of renewables, a market-technical issue, and their mostly very low level of short term marginal costs, possibly leading to different types of societal organization, see next section and especially section 4.4.4. Summarizing, the main outcomes of this long term domain analysis are the following. There is no hard predictions possible on general economic development; low growth may contribute to emission reduction but is not a development to bet on. Climate policy will have limited effects on general economic development, partly dependent on the instrumentation chosen. Globalization will reduce differences between countries, with prime mover advantages probably becoming more important in international specialization. Loss of rent income from fossils production will play a relatively limited role in Europe. The main economic factor to reckon with is the emergence of low marginal cost production systems in the energy domain, and beyond.

\subsection{Societal options}

The global move to market economies may lose momentum but can hardly be reversed. Globalization is ongoing still. The WTO is one of the strong international institutions, with the US and China accepting court rules on conflicts, as with the export restrictions on neodymium by China. There are some long term views on a move away from globalized market economies. One is ideological, relate to local development ideologies as in the DeGrowth movement (see www.degrowth.org), linked to anarchist and communist ideals. It seems not probable that such movements towards a different society will become a dominant factor in the next half century. Another more system analytic approach is by (Rifkin 2014), based on structural change in production technologies, especially their low marginal cost at relevant production volumes. He sees low marginal cost society as heralding the end of capitalism. This certainly has a link to climate policy as many renewable technologies have near zero marginal costs. Before being taken over by his stream of ideas converging to the collapse of capitalism some basics first on what exactly constitutes zero marginal costs. The reasoning of Rifkin is that the old mechanism of firms expanding their volumes of production till marginal cost equal average cost at its lowest point no longer applies: there are economies of scale, with marginal cost remaining very much below average cost in the feasible domain of production. If markets are priced at marginal costs prices will tend to near zero. However, it then is essential to be clear on the meaning of marginal cost, differentiating between short term and long term marginal cost.

Long term, not short term, marginal costs are relevant when considering investment decisions. There are many industries where short term marginal costs are low. Hotels and air lines are old examples, and in the energy domain oil and gas production, nuclear electricity and solar PV, hydro, and wind power have very low marginal cost. Short term decisions are based on short term marginal costs. But long term decisions like investments are based on long term marginal costs, including the cost of capital, to be more than balanced by expected long term proceeds. The industry as a whole will not overinvest, in that way keeping prices high enough for covering long term marginal cost. Of course overinvestment is possible, depressing prices substantially. Airline companies are a main historical example: they have had long term losses due to overinvestment in national flagships, funded by taxpayers. This reasoning reduces the strength of Rifkin's arguments. Very low short term marginal costs are not dominant in the economy as a whole, and where they exist they mostly do not lead to very low prices long term, as investments are based on long term marginal costs, not their short term cousin. 
However, though not heralding the end of capitalism, Rifkin's reasoning might be important for other reasons. Operations with decreasing costs due to low marginal costs can be expanded so at to reach near monopolist positions, as is a trend in many IT based firms with global coverage. The solutions to be investigated there, like detailed pricing rules; reduced domain of intellectual property rights to increase competition; open access on data carrying infrastructure, managed as public utilities and maybe publicly owned; and breaking up firms linking related domains of activities. It must be remembered however that main sectors of the economy do not exhibit low short term marginal costs, from heavy industry and mining, to the building industry; and to car manufacturing. The issue of private monopoly prevention is important, also in the energy domain, but seems to have no special bearing on climate policy; monopolistic tendencies as in fossil electricity production will be reversed with the reduced role of fossils. There is another reason why the tendency towards monopoly does not seem to be linked specifically to low emission energy. Most renewables based electricity production like solar and wind is decentralized and therefor hardly amenable to monopolistic development. Their emergence will even be counter to the old oligopolistic structure in the fossil energy sector.

The conclusion on long term societal development is again middle of the road. There are many potential developments, most of them remaining within the mainly capitalist social order, with market based globalized economies remaining dominant, barring disasters. Deviations from that pattern, as in Rifkin and cultural developments like the DeGrowth movement, don't yet sketch a feasible future with enough detail to link to European Union climate policy instrumentation. Monopolistic tendencies will come up and must be countered and low short term marginal cost production systems require attention in terms of their integration in electricity markets.

\subsection{Cultural developments and life styles}

Life styles are a basic cultural phenomenon, where direct public intervention is problematic. Governments can be paternalistic to a limited degree only, and being effective in that seems not easy. Examples where life style changes have resulted with a clear role of governments tend to specific domains, as opposes to the all permeating climate issue. Examples are seat belts, smoking in public, gender equality and gay marriage. Ultimately public policy has made seat belts and nonsmoking areas compulsory, and has created the administrative option for gay marriage. What governments can do regarding more generic life style issues is to facilitate developments, including by changing incentives. One general cultural direction for instrumentation might be to confer climate responsibility to private parties. This relates to climate governance strategies directly and from there to climate policy instrumentation. Responsibility and legal liability are close cousins, with liability rules adapted to such cultural developments. Facilitating and stimulating low carbon life styles may connect to other climate policy instruments quite directly, like emission pricing, spatial planning and infrastructure, and enabling part time work and making lower life time working times more attractive. This last option links to a most basic cultural development: produce and consume less, as advocated by the DeGrowth movement (see: http://www.degrowth.org/) and analyzed more reflectively by (Jackson 2011) and discussed more critically by (van den Bergh 2011). Reduced growth may have a substantial long term effect: reducing growth by $1 \%$ halves national income over 70 years. Most institutions are geared to growth however, with few openings for reduction. 
The provisional conclusion here is that broad cultural development is important but difficult to steer other than by enabling and soft incentivizing.

\subsection{Materials constraints}

The Club of Rome published Limits to Growth (Meadows, Meadows et al. 1972) indicating that economic growth would be halted by input constraints in terms of resources and by the consequences of waste and emissions, like climate changing emissions. Climate policy deals with emissions but might be constrained, or be superfluous by a lack of resources. Certainly there is not a shortage of fossils as was expected till recently; proven reserves will have to remain underground even with more modest climate policy than implied in the 2-degrees goal. However, the transformation to a low carbon society implies a new energy infrastructure, new production processes and new products. Such low carbon technologies mostly are more materials intensive than their current fossil equivalents, of course only if leaving the fossils themselves out of account. Several constraints may come up, as has been the case with rare metals before, as when platinum catalysts were required in the catalytic converters in cars. Prices exploded but since then have stabilized mainly. The neodymium experience has shown the risk of monopolistic supply, as when China effectively halted exports, hurting Toyota's hybrid electric car, using neodymium permanent magnets and hurting wind turbine builders all over the world, while favoring those in China. However, Tesla's full electric car and the turbines of some producers don't use neodymium but copper variable strength magnets. When such substitutes don't exist one should be careful to rely on such supply, and avoid relying on its use. In general the limits to increased production, increasing with higher prices, can roughly be known, including estimates for recycling when stocks have been built up. Lithium is in near endless supply and has a relatively short time horizon for expanding production See: (Riley and Tongudai 1964, Yaksic and Tilton 2009). Copper is not in short supply, but expanding production with new mines requires a time horizon of well over 20 years, expecting markets to be there by then. Gold is in short supply and also requires substantial time for opening up new mines. Golden houses will never be built for the masses, though golden rings are perfectly possible. Research into supply options and more certainty on the climate policy to come can guide developments, avoiding the price peaks as occurred with platinum and neodymium. See for an extensive prospective analysis Kleijn et al. (2014).

The conclusion here is that with experience and knowledge built up in the resource domain materials shortages in terms of extreme price variations can be avoided, not specifically for climate reasons. Constraints in materials supply are there but not different from those in other domains.

\subsection{Conclusions on domain analysis}

The overall picture that emerges from this domain analysis is that reducing $\mathrm{CO}_{2}$ emissions as the core of climate policy can be managed starting from now and does not have basic limitations in terms of the technologies required. Most are there already and can be improved further, though predicting specific technologies towards 2050 remains impossible. The economic and social conditions in which the deep transformation towards near zero emission society are to take place will remain roughly as they are, while also cultural developments will not have an autonomous 
deep development on emission reducing behavior. Also from a materials supply point of view, climate policy has no special constraints above what society can manage normally in principle.

Coherent story lines on futures are to integrate the long term domain analysis, covering feasible options, relevant for climate policy and its instrumentation. There are many potential developments, most of them remaining within the mainly capitalist social order, in a globalized market economy. Deviations from that pattern, as in Rifkin and cultural developments like the DeGrowth movement, don't yet sketch a feasible future with enough detail to link to European Union climate policy instrumentation. Story lines in climate scenarios don't start with a domain analysis. They all tend to a market economy, with more or less regionalization and more or less emphasis on sustainability, see the surveys in (Nakicenovic and Swart 2000, van Vuuren, Riahi et al. 2012, Nakicenovic, Lempert et al. 2014). Also economic models covering climate policy rely heavily on market mechanisms and optimization tendencies, also in the CECILIA2050 project. The two instrument strategies developed here both align with these broad story lines, but differ quite substantially.

Taken together the picture emerges that the deep transformations required require substantial effort, but along lines as are usual in our Western societal development. The overall integration of the different entries to long term climate policy would require coherent story lines. This is required both for developing consistent instrumentation and for discussing climate policy and its instrumentational broader in society. Strategic governance choices then precede more specific instrumentation choices.

\section{Bottom up development and top down design of instrumentation}

\subsection{From incremental improvement to strategic design}

The Grubb distinction between short term satisficing, medium term optimization and long term transformation can be placed in a general governance framework as has been developed after WWII in political and administrative sciences for pluralist liberal democracies, as opposed to autocratic fascist and communist regimes. Policy develops in an interactive process between several actors involved in negotiation processes. Big changes are the exception: small steps as incremental improvements are the norm. This view on the political process has been developed by Lindblom and Dahl, see their influential (Dahl and Lindblom 1953). A main question arising directly then is how more aligned policies can come about from negotiations, reckoning with the complex interrelations in modern societies. The political process itself has obvious limitations in this respect. Coordination and alignment between specific policies becomes a role for policy specialist and especially for public administrations, in the preparatory phase of the policy development process. The first step is to coordinate policies and instruments and manage their overlap. More general principles then start to play a role, like efficiency and optimization, helping create a better society for all. Such broadly accepted principles then permeate the somewhat longer term view on development of policies and their instrumentation. Striving for tactical alignment in instrumentation is already stronger based on such broadly accepted more general principles and views. Welfare theory gives the underpinning of what is better integration and alignment, based on linking what is important to all in society. Basically this is the Bentham 
principle of the greatest happiness for the greatest numbers, but then in a more operational version, as for example involving cost-benefit analysis as developed in that period. The theoretical level is that of the Bergson-Samuelson welfare function, see (Samuelson 1977), with distributional issues resolved by the hypothetical Pareto improvement. In the following decades this coordinating governance view broadened from the initially somewhat narrow economic domain to broader welfare issues, with Sen and later Stiglitz as core contributors, see (Sen 1970). A snapshot on the broadened discussion is by (Nussbaum and Sen 1993), and recently (Stiglitz, Sen et al. 2009) with emphasis on the climate problem. In the political domain the issue of simplification through better coordination and alignment is recurrent due to increasing rule density and complexity (see (Simões, Huppes et al. 2015) for a detailed case analysis), and the resulting lack of legitimacy. In the US Sunstein had that explicit role of simplification in the Obama administration, see (Sunstein 2014) and in the EU Commission there now is a Vice-President on Better Regulation and Inter-Institutional Relations (currently Timmermans), followed by initiatives like the setting up of High Level Group on Simplification by domain commissioners. That line of coordination and alignment still lacks direction, as strategic design. Such explicit direction by necessity moves away from reasonable agreement, to some extent at least. What might be reasonable directions to investigate, reasonable meaning substantially accepted in principle, and what might be more daring directions, investigated and supported by smaller groups in society? The reasonable approach was surveyed by (Dahl 1982), indicating two basic directions for policy development, autonomy versus control, roughly linked to the two strategic directions for climate policy distinguished here, a Planning \& Control mode and an Institutionalist mode of governance incentivizing autonomous parts of society. What is added here to the Dahl distinction is a clear climate policy goal: arriving at the 2-degrees Celsius stabilization target. Autonomy then means establishing generic incentives for emission reduction, including the deblocking of obstacles for this bottom-up process like lacking electricity markets. The planning and control mode is linked to more specific targets setting and specifying the means of implementation, ultimately in terms of specification of technologies and linked behavior.

Summarizing, there are four different ways how the mix of EU climate policy instruments could evolve.

- Incremental improvements to individual instruments, for instance moving from feed-in tariffs to feed-in premiums or improving vehicle performance measurements for $\mathrm{CO}_{2}$ standards. This development links to Grubb's short term Satisficing.

- Better coordination of instruments and management of overlaps as in eliminating gaps and imbalances in the coverage of instruments that lead to market distortions, for example emission pricing as applied differently now to different modes of transport. This development links to a first part of Grubb's medium term Optimizing.

- Tactical alignment as in removing tensions between instruments, as in better aligning country-level and EU level instruments; top-down and bottom up initiatives; phasing out of overlapping instruments without convincing justification. This constitutes a second part of Grubb's medium term Optimization.

- Strategic design of instrument mixes, based on different regulatory philosophies, like technology-specific measures and top-down planning versus more incentive based instruments changing framework conditions and allowing for bottom-up developments rather 
than pursuing specific particular (technological) solutions. This links to Grubb's long term Transformation.

These steps from incremental improvement to strategic design are not mutually exclusive. The types of reasoning can all four be seen as steps towards long term development of the instrument mix for EU climate policy. If a grand idea is to develop effectively, it is to start now, giving direction to incremental improvement, better coordination, and tactical alignment, as steps aligned to long term strategic design. Some improvements on specific instruments may fit into any strategy, like better measurement of climate performance of vehicles, be they used for fleet standards or consumer information. And some improvements may be temporary important, till other instruments take over, like the weeding out of multiple purpose elements out of Fleet Standards, till emission pricing is strong enough to take over, if that emission pricing line is followed. But overall the ultimate strategy will determine or at least color the other three steps. In a technologically specific planning mode it does not make sense now to repair the ETS and establish a trading authority as currently proposed (Kettner, Köppl et al. 2012, Edenhofer 2014).

The descriptive and normative improvement paths may be used for empirical analysis as well. In one strategic direction, it is highly improbable that certain developments will take place, like detailed fleet standards for all road transport vehicles in an institutionalist mode, or sticking to a pure cap-and-trade system in a planning \& control mode. Also in the institutionalist mode, there is no logic to link to a pure cap-and-trade instrument for carbon pricing. Decentral initiatives by cities and countries and private parties would become less relevant.

\subsection{From practical instrument development to strategic design}

Developing instrumentation by necessity starts at current instrumentation, with the short term, medium term and long term domains leading to different approaches for development, with satisficing, optimizing and transformation as main lines of change. Satisficing and optimizing take the current situation as a prime basis. However, also long term transformations, though possibly guided by overarching and new considerations, cannot avoid the constraints of current instrumentation. It is not possible to have a tabula rasa in instrumentation design, starting from scratch. This is the case for several reasons. Instruments as have been implemented give rights to those regulated, though usually limited in time. Feed-in tariffs have a time to expiration. ETS and Fleet Standards have a fixed period towards revision. Revising instruments takes time both for procedural and political reasons. Different instrumentation may require different organizations and rules for their implementation. However, such constraints are never fully rigid and are softer in the long term. An analogy with innovation is the Schumpeterian creative destruction (Schumpeter 1947 (1942)): overruling existing instrumentation by novel instruments. In the electricity sector renewables are destroying the existing market structure creating losses for fossil producers, based on novel instruments like feed-in tariffs and fossil electricity emission standards, these overruling the pure cap-and-trade system of the ETS. Destruction will not always be required if the old instrument can remain in a niche application, as with $19^{\text {th }}$ century regulations still apply to steam engines in many countries.

By adapting, replacing or destructing the old instrumentation, fundamental changes are well possible in the long term. Such changes will however not come about by incrementalist piecemeal decision making alone as seen and advocated by (Dahl and Lindblom 1953, Lindblom 1959) as the 
main mode of policy development. A strategic guiding element then has to be added here, as strategic governance views for climate policy. These in turn will be based on the broader views on societal governance of which they are part. The bottom up strategy starting from now will therefore be matched somehow with long term strategies, top down. The bottom up strategy also has an element of specificity as to domains of application: fleet standards apply to the road transport sector and feed-in tariffs to electricity production. In the longer term transformative development such sectoral domains may be a starting point. However, it is overall effectiveness of climate policy determining choices substantially, not necessarily linked to any sectoral delineation.

The instrument development process starting from now and passing by short term satisficing and medium term optimizing is basically different from the strategic approach to long term instrument development starting from general views and principles, condensed in strategies. In a most general way the long term analysis has a focus on coherency and simplicity. Why have two instruments if one can cover the actions involved adequately already? Certainly multiplicity is to be avoided if instruments are not mutually supportive, as with long term feed-in tariffs functioning in a pure cap-an-trade domain. That means distributing subsidies without climate effect, which may at best be useful for non-climate reasons. The discussion on improving the ETS functioning by temporary reducing the amount of permits brought in the market as by the Strategic Market Reserve typically is satisficing, not strategic, focused at one instrument only. The pure cap-and-trade system then is abandoned a bit, in order to create a higher, more relevant emission price. In a strategic approach the reasoning is reversed. How can a relevant emission price be brought about, to guide long term decision making? How can emissions be reduced predictably? What is the role of emission permit trading? What is the role of price fluctuations in a trading system? What is the role of a mixed quantity-and-price based system, relative to their pure extremes, the pure cap-and-trade and the pure emission tax? Might it that the mix has disadvantages only, with the volume of emissions not specified anymore and the price not predictable yet? Can the variants of emission pricing be implemented effectively? Already at this level answers cannot be given in proven way: they depend on strategic views and priorities. With emphasis on predictable results, the answer goes towards the pure cap-and-trade system, with permits to control total volume of emissions and permit trade to help reduce cost of the specified emission reduction, accepting the reduced long predictability of the emission price and hence reduced dynamic efficiency. Adjoining instruments then should also focus at creating dynamic incentives. With emphasis on also long term incentivizing, the fixed price system comes up as a predictably rising emission tax, accepting uncertainty in emission reductions but focusing on dynamics, with maybe some price adaptation long term. Adjoining instruments would be directed mainly at domains not guided by markets or where markets are limited and deficient, first improving them where possible. The in-between options seem not to be part of a strategic design. Why have trade if price stabilization is the goal and why have price variability? They don't have a function themselves but were functional in the pure cap-and-trade system. Strategically therefore only two types of emission pricing remain, linked to two more general strategic choices. Also in expanding emission pricing with other instruments towards a full set of instruments, the more general strategic choice is guiding. With a cap system domain expanded, it does not seem logical in a strategy sense to add economic instruments in the same domain, like carbon taxes on fuels. Again, there may be non-climate reasons for such taxes. With an emission tax in place, it does not 
seem logical in a strategy sense to reduce emission of fossil power stations by $\mathrm{CO}_{2}$ emission standards for climate reasons. There might be non-climate reasons again like air quality issues, though these might be better served with more focused instruments. The central methodology issue to keep in mind in developing long term climate instrumentation is that is strategy driven, top down, and only then linked to the practical question on what to do now.

Table 2 Dimensions and layers in governance, after (Voss and Bornemann 2011)

\begin{tabular}{|c|c|c|c|}
\hline $\begin{array}{l}\text { Dimensions: } \\
\text { Levels: }\end{array}$ & $\begin{array}{l}\text { Policy } \\
\text { problems and solutions }\end{array}$ & $\begin{array}{l}\text { Polity } \\
\text { rules and structure }\end{array}$ & $\begin{array}{l}\text { Politics } \\
\text { interaction and process }\end{array}$ \\
\hline $\begin{array}{l}\text { Micro } \\
\text { focal } \\
\text { interaction }\end{array}$ & $\begin{array}{l}\text { Problems and goals of a } \\
\text { specific governance } \\
\text { process }\end{array}$ & $\begin{array}{l}\text { Rules of procedure for a } \\
\text { specific governance process }\end{array}$ & $\begin{array}{l}\text { Struggle for dominance among } \\
\text { participants of a governance } \\
\text { process }\end{array}$ \\
\hline $\begin{array}{l}\text { Meso } \\
\text { policy } \\
\text { domain }\end{array}$ & $\begin{array}{l}\text { Problem definitions and } \\
\text { policy approaches } \\
\text { dominant within a policy } \\
\text { domain }\end{array}$ & $\begin{array}{l}\text { Institutional arrangements } \\
\text { within a policy domain }\end{array}$ & $\begin{array}{l}\text { Struggle of organized political } \\
\text { actors for dominant positions } \\
\text { within a policy domain }\end{array}$ \\
\hline $\begin{array}{l}\text { Macro } \\
\text { political } \\
\text { system }\end{array}$ & $\begin{array}{l}\text { Discourse on fundamental } \\
\text { political values and beliefs }\end{array}$ & $\begin{array}{l}\text { Constitutional rules and } \\
\text { political culture }\end{array}$ & $\begin{array}{l}\text { Struggle for dominance among } \\
\text { broad social groups, sectors, } \\
\text { classes, or regions }\end{array}$ \\
\hline
\end{tabular}

The strategy domain can be viewed specifically for climate policy instrumentation but is unavoidably part of broader views on governance. A recent analytic approach to governance directions is in (Voss and Bornemann 2011). The political policy domain is analyzed by distinguishing between levels of generality in the discourse, ranging from micro, to meso and macro, and the subject of discourse related to: policy domains; the polity with its procedures; and politics with power elements, all three connected to the three levels of domains. The climate governance discussion does not touch the Politics domain directly (but decisions are based on power) and it is connected to the meso and macro level only, not the micro level of governance, see the four emphasized cells in the table. Of course the micro level plays a role in filling in daily operations of public policy. However, a long term strategy development reckoning with all possible details will falter in complexity. This is contrary to the view that all options have to be taken into account in detail; that focus on one level without consideration of the others leads to inconsistency, friction, inefficiency and / or deadlock. This links to the optimization ideal of the medium term. In the economics domain this passion for control has been linked to reality by (Cyert and March 1963) long time ago. Even the best efforts to optimization fall short of the information required for doing so. Of course the development of generic approaches has to deal with micro options in a general sense, building on administrative experience. So strategic development of long term policy instrumentation deals with governance at the meso and macro level, filled in at the micro level in due time. The strategies chosen depend on inclusion of political values and beliefs here implies that the strategy development is a legitimate subject of public discourse, a major starting point. For which class of vehicles which test norms will be applied and when is a matter of micro level politics, not for strategic policy development. However, reckoning with administrative problems of test procedures is part of generic considerations. 


\subsection{Planning \& Control and Institutionalist Strategies for long term instrumentation}

The Planning \& Control Strategy may first be linked to broad optimization approaches, looking for welfare improvements wherever possible, with improved climate performance as the entry variable, but linked to all other relevant dimensions. Any option increasing overall welfare in society is useful, with priority on the most useful ones, while taking a long term perspective in the analysis. Quantification of climate damage per unit of emission is required for placing climate policy in the overall welfare perspective. Though historically linked to somewhat restricted economic reasoning, the definitions on collective welfare have broadened since the Seventies and now include fully distributional and justice issues and environmental issues, including global public goods like climate stability. See for an eloquent presentation (Stiglitz, Sen et al. 2009). The medium term domain has to deal with institutional issues as well, but in a slightly more practical manner. The issue of emission pricing is also highly relevant for medium term instrumentation, like expanding the ETS. Still, the Planning \& Control Strategy links easiest to the concrete, improving on what is there already, in a quantified way. In a governance sense it links to a stepwise incrementalist approach, focusing on political and administrative feasibility, and avoiding big mistakes. This governance tradition first was described by (Dahl and Lindblom 1953, Lindblom 1959), with more strategic aspects added later. The European Commission has its Strategic Planning and Programming Cycle (akin to the US PPBS system starting in the Sixties), with yearly checks on achieving objectives. Also longer term issues tend to be stated in terms of targets, with instruments adapted on the go; not explicitly as strategic planning of long term instrumentation development. The focus on optimization leads to placing climate policy in a broader context, linked to broader policy domains like economic growth, energy supply, housing and income distribution. Optimization cannot just be a climate affair. Applied welfare functions have been at the start of this approach, developing theoretically and empirically after WWII. A few big names are Bergson, Samuelson, Arrow, Sen and Stiglitz, mostly Nobel Prize winners, and Arrow, Sen and Stiglitz active in climate policy. The core reasoning, generalizing Bentham, is: What is best collectively is to be realized. For easy familiarization the Planning \& Control governance strategy may be thought of as the Stiglitz strategy. In the climate policy domain this governance approach is dominant now. (Wiseman, Edwards et al. 2013) survey eighteen post-carbon strategies. Most have an incremental approach, all in a planning \& control mode of governance, also when indicating transformational change.

The other approach is from the more empirical oriented institutionalist school studying long term societal development, with (Acemoglu, Johnson et al. 2005), (Mokyr 2004) and (North 1990) as main history oriented representatives; see (Coase 1999) for a survey on institutional economics; see (Immergut and Anderson 2008, Munck af Rosenschöld, Rozema et al. 2014) for a social science entry; and (Chang 2002) for political science oriented views on institutionalism, and (Carrigan and Coglianese 2011), linking to soft instrument options Ha-Joon Chang argued against the simplistic non-institutional neo-liberal view of "the" market, which erroneously abstracts from the institutions which can create and regulate markets in very different ways (Chang 2002). Institutions constitute the basic relatively stable fabric of society, including constitutional arrangements, the legal system, the judicial system, the educational set-up, public-private delineations, and more or less fixed normative and ethical principles. Many of these are vested in specific organizations like ministries and universities. Here institutions are taken as the more 
abstract rules. The patent system is an example of a more specific legal rule system, with fast domain expansion in recent decades. Thinking about the role of the patent system belongs to governance, with developments part of strategic governance development, by necessity open to discussion and hence contested. See (Boldrin and Levine 2008) for a dissenting discussion on the patent issue, not a subject directly of climate policy but directly related to long term innovative developments relevant for climate policy. In the institutionalist school, stable long term change comes from creating the right institutions, of course in their stream also using shorter term instruments additionally, but modestly, and not counteracting main incentives. The generic nonplanning structure allows for bottom up developments both in the private and the public domain, the power of which has been shown by (Ostrom 2010). This is the Institutionalist Governance Strategy, as second governance approach used in this study. For easy familiarization this institutionalist strategy may be thought of as the Ostrom strategy. Here their names are the Planning \& Control Strategy and the Institutionalist Strategy.

In both strategies there is planning involved, but at different levels. In the words of Dwight D. Eisenhower: Plans are nothing. Planning is everything, referring to higher levels of still concrete planning. Similarly Mintzberg advocates a more abstract and creative approach to strategic planning, somewhat disconnected from the single concrete plan, see (Mintzberg 1994, Mintzberg 1994b). The concept of design thinking may go fully beyond the specific plan, see (Buchanan 1992), who cites Dewey (1929) on open design as '...not fixed and complete, but which is capable of direction to new and different results through the mediation of intentional operations.' (p6). There is a direct link to bottom up processes in (Ostrom 2010), guided by institutions, but not determined.

Institutions will play a role in any strategy; the choice is on specific in institutions. Planning and control creates fragmented electricity markets at the EU institutional level, but not as a climate policy instrument. Conversely, in the institutionalist strategy an open real time electricity market is a key climate policy instrument. Similarly, institutions for emission pricing can be set up very different, as pure cap-and-trade; price-stabilized hybrid cap-and-trade; or emission tax, mutually exclusive, see (Goulder and Schein 2013). Choice is based on their expected general functioning, also reckoning with broader environmental policy instrumentation. Pure cap-and-trade is fully competing with technology specific regulation; closing a coal fired power station reduces cap prices so others can emit cheaper. Hybrid cap-and-trade and emission tax don't have this incompatibility. They also give more guidance on long term emission price levels, these guiding long term investment decisions, including in research and R\&D. The hybrid cap has price variability without function; that function exists in the pure cap system only. Long term strategic considerations then lead to full price stabilization, without trade and banking. With simplified administrative implementation the emission tax results. Reasoned strategic choice is reduced to the pure-cap or the emission tax.

\subsection{Climate goals and sector targets}

The EU climate target to be achieved is an over $80 \%$ reduction by 2050 . For $\mathrm{CO}_{2}$ emissions from fossils use and cement production this would involve a $\mathrm{CO}_{2}$ emission reduction by close to $90 \%$, as most non- $\mathrm{CO}_{2}$ emissions are more difficult to reduce. The $\mathrm{CO}_{2}$ emission reduction rate then would have to rise from minus $0.65 \%$ per year from 1990 to 2012, see (Olivier, JanssensMaenhout et al. 2014) based on the EDGAR database, to minus 5.5\% per year from 2012 to 2050 
in order to reach EU 2-degrees target of over $80 \%$ reduction relative to 1990 . Of course the jump to such high reduction rates is not possible on short notice, implying still higher reduction rates later. Also, if economic growth picks up to maybe years of $4 \%$, the decrease in $\mathrm{CO}_{2}$ emission intensity would have to rise to nearly $10 \%$, a virtual impossibility. As indicated previously for specific domains, the overall reduction can be translated into minimum $\mathrm{CO}_{2}$ targets for the four main sector domains distinguished here, roughly.

- Electricity production $\quad-95 \%$

- Industry $-80 \%$

- Buildings \& Consumption $\quad-90 \%$

- Transport $-80 \%$

But of course if solar fuel develops for aviation and heating of buildings these indicative targets would change; only the overall target of around $90 \%$ reduction relative to 1990 is assumed given here.

Electricity production can be nearly fully decarbonized, with current technologies already, and is indicatively set at minus $95 \%$. Industrial emissions are difficult to reduce by $90 \%$ for some industries, like iron and steel and cement production, and in the chemicals industry. In the iron \& steel and cement production hardly any emission reduction could be seen due to the ETS in which they are covered, see (Branger and Quirion 2013). The sector target is set indicatively at $80 \%$ reduction, but must be substantially higher for the non-steel \& cement industries. In transport, aviation emissions may be difficult to reduce, also as flight volumes are rising substantially still, setting reduction for transport overall at $80 \%$ and for non-aviation transport at $95 \%$ as well. So electricity production and fossil use in buildings have a relatively high reduction task, at $95 \%$ and $90 \%$ respectively, with the non-steel \& cement industries and surface transport having similarly high reductions to achieve.

The remaining fossils based $\mathrm{CO}_{2}$ emissions should be well below the $80 \%$ reduction target set as a minimum overall climate target, as non- $\mathrm{CO}_{2}$ emissions mostly are difficult to reduce, especially from agriculture. Current non- $\mathrm{CO}_{2}$ emissions from agriculture have a share of around $10 \%$ in total EU emissions (Kuik and Kalfagianni 2013). The reductions in the last decade seem not related to climate policy but to the reduction of production, especially meat production. Some emissions can be reduced by technology changes, like methane from agriculture and PFCs in industry. However, diffuse $\mathrm{N}_{2} \mathrm{O}$ emissions from agriculture may well increase due to increases in the intensity of agriculture as for long term rising food production and aggravated by bioenergy production. If non- $\mathrm{CO}_{2}$ emissions from agriculture would remain at current levels, an $80 \%$ overall reduction would imply a reduction of all other emissions by aro0und $90 \%$.

In terms of technologies to be used by then, the options basically are there, but may be overtaken by other more attractive options not yet available now. There is some certainty but also deep uncertainty. The certainties are few. Electricity will play a major role, in primary production, transformations and storage, and in final use. In primary production, wind and solar will have a major share, with their intermittency to be resolved. Only hydro and geothermal energy are flexible, over days and seasons, while solar heat can be flexible diurnally. Hydro is however not stable over years, implying years with limited availability. Especially solar tends towards decentralized production. For energy storage and demand variation many options exist, ranging from large scale hydro and battery systems and chemical storage as in hydrogen, to highly decentralized storage as in batteries, and decentralized secondary production is with hydrogen 
based fuel cells. Heat pumps with heat and cold storage may well take a main role in space heating and air conditioning, as low carbon alternatives are not yet available. All these technologies are available in some form already, but with uncertain capacity and uncertain long term cost profiles. Other technologies may come up, like ocean farming, artificial algae and space solar, with as yet even more uncertain capacities and cost profiles. Innovation remains basically uncertain.

Whatever will come will depend substantially on the regulatory framework as may be developed for climate policy, the core task in this study, with a key connecting role for electricity markets, and other energy markets, as are to be developed not only for reasons of climate policy.

\section{Main types of instrument building blocks \\ 4.1.A brief history of environmental policy instruments: what we have and need}

Environmental policy has extensively used the operating permit since the start of the industrial Revolution in the $17^{\text {th }}$ Century, with broad discretion of authorities on what was allowed and what not. At the start of the post-War growth spurt in the 1960s, new instruments came up. Liability rules were used in Japan, starting with the mercury tragedy and then expanded to SOx emissions and collectivized through government emission taxes from which health damages were paid. They induced deep emission reductions there. In the Netherlands a water pollution tax led to extreme reductions in emissions to water (Huppes and Kagan 1989). These financial instruments were exceptions however, with the operating permit remaining the core environmental policy instrument. The static nature of such permits led to new developments in the Seventies, shifting from technology specification to performance specification, requiring improved and novel emission measurement. The emission permit was born. To reduce acidification, toxicity and water pollution, emissions were regulated per installation. The allowable emission level was not linked to specific production volumes or production values but to local and regional environmental quality standards. With quality below standards newcomers were blocked, reducing economic growth. Somehow dynamics had to be built into regulation to accommodate economic growth. With larger numbers of polluters the problem of equal treatment came up: how to justify the distribution of allowable emission levels over specific economic activities? One solution was to cover several polluters with an overall emission cap, not yet formally traded, but internally looking for lowest cost solutions between the regulated companies involved, in that sense looking for equal marginal reduction costs. This flexible form of agreement was used in the Netherlands, as in the NOGEPA covenant (Huppes, Davidson et al. 2007). The first broad cap-and-trade system was introduced for SOx emissions from power stations in the US, covering a limited number of publicly regulated facilities, see (Schmalensee and Stavins 2013). This was the muster for the EU ETS cap-and-trade system 15 years later. The other solution to the lack of dynamics had been ready conceptually since the 1920s: internalizing damage costs, as through Pigovian emission taxes (Pigou 1932 (1920)), again also in a sense solving the equality problem, as an equal emission price for all in the case of climate emissions. Every polluter pays for the damages he causes. Two issues made broad application of this internalizing tax cumbersome: precise emission measurement and the exact value of damages caused by these emissions. In the climate domain, 
emission measurement has been resolved administratively: carbon inputs can be measured relatively well and leave as $\mathrm{CO}_{2}$ output at incineration or combustion. The uncertainty in establishing damage value has not been resolved (against some outliers like (Tol 2008)) but has practically been resolved as by (Baumol and Oates 1971, Baumol 1972). Following their argument, the total amount of emissions is specified politically, based on some rough idea on the level of damages to be realized or reduced, reckoning with estimated emission reduction cost. The emission price required to get to the corresponding emission reduction then is set, politically, with the volume following. That same amount can also be used to politically set a cap, with a market price following. These two options for more pricing of emissions, any, are now at the heart of climate policy instrumentation. Being fully technology independent in principle, they belong to the institutional framework of society.

However, the deep entrenchment of climate emissions in society, and the need for fast emission reduction may well keep the older policy instruments at the table, standards and technology specific taxes and subsidies, and bring in new instruments, focusing on the broader role of government in the economic functioning of society: broader institutional instruments, especially market reforms; infrastructure; public research; research \& development and demonstration, R, $R \& D$ and RD\&D; and emission price independent market dynamics as by creating learning curves and overcoming lock-ins for promising technologies.

\subsection{Main instrument types}

There are many ways to typify instruments for climate policy and broader environmental policy: legal status (law, permit), result specification (emission standard), primary working mechanism (emission pricing), main working mechanism (internalization of external effects), sanction mechanism (fine, liability, jail), and more, all with their relevance. Here the prime characteristic of instruments is their instrumentality: what they set in motion is what they do, regardless of intentions, targets or goals, and legal status. Emission pricing, from taxes to fines, incentivizes emission reduction; an emission standard allows actions not exceeding the standard; a public road opens the option to drive on it; and product information allows for better informed choices. The bewildering amount of instrument options can be reduced to seven main types, see Table 3. They are in two groups: operations of government, nr. 1-4, and number 4 further subdivided as to how regulatees are influenced, by the prime working mechanism of the instrument, see Table 3. The operations of government go from generic to more technology specific. Institutions in principle are generic, as generic as possible, but also involving spatial planning and development of more specific markets, like for electricity. Infrastructure is by necessity specific, but in many ways it is more option creating for others in society, allowing for different technologies in their use, than binding them. You may use the road, or the railway, or neither of them as a behavioral choice, and you may drive a Diesel or an electric car on that road. Next, research, R\&D and demonstration projects are one step more concrete, but again in principle open to all others if they want to use the specific results coming out of projects. When influencing the behavior of private actors, type nr. 4, there is an increasing level of bindingness from 4.1 to 4.3 , related to the prime working mechanism involved. Generic taxes belong to the institutional domain as in internalizing external effects according to the polluter pays principle, type 1, while specific taxes, like a prohibitive tax on high emitting coal fired power stations, is technology specific and belongs 
to type 4.2. The ETS extension to aviation is partly separate from the broader application in industry and electricity production, them moving in the direction of type 4.2.

Institutions, public infrastructure and public RD\&D have long term effects on society beyond specific costs and benefits, though of course their effects will also be specific and then different for different groups in society. Regulating private actors has a closer connection to inducing costs and benefits, with distributional consequences. Effective climate policies shift prices and volumes in markets in our mixed market economy, unavoidably and intentionally. This is visible most directly where instruments apply, but also indirectly, and regardless mainly of their prime inducing mechanisms. The Japanese Top Runner Program, an informational instrument, has induced new technologies and has next driven laggards out of the market. Emission standards as in electricity production and for cars create markets directly and have a deep influence on prices in their upstream and downstream economic connections, and for substitutes. Public procurement has a subsidy element in paying more than otherwise would be the case, but may also have a specified quantity aspect, and of course the subsidy is to be paid for somehow, by others, and then some others don't sell their product.

Table 3 Typology of instruments for climate policy

\begin{tabular}{|l|l|l|}
\hline Types/Levels & Examples & Current applications \\
\hline $\begin{array}{c}\text { 1. Public Institutional } \\
\text { Framework }\end{array}$ & $\begin{array}{l}\text { Generic emission pricing; } \\
\text { electricity markets; climate liability; etc. }\end{array}$ & EU ETS; Unbundling Directive; ... \\
\hline $\begin{array}{c}\text { 2. Public Infrastructure } \\
\text { Hydrogen storage and transmission; EU- } \\
\text { wide electricity transmission grid; etc. }\end{array}$ & Electricity grids; roads; harbors; ... [as exists] \\
\hline $\begin{array}{c}\text { 3. Publicly funded } \\
\text { Research and RD\&D }\end{array}$ & $\begin{array}{l}\text { Research programs; R\&D subsidy } \\
\text { schemes; etc. }\end{array}$ & $\begin{array}{l}\text { NER300: Basic PV research; planned exemplary CCS; } \\
\text { climate relevant parts of H2020; etc. }\end{array}$ \\
\hline $\begin{array}{c}\text { 4. Public Regulation of } \\
\text { Private Actors: }\end{array}$ & $\begin{array}{c}\text { Labelling schemes; BAT information; etc. } \\
\text { Instruments }\end{array}$ & $\begin{array}{l}\text { Energy labelling schemes electric appliances; NEDC } \\
\text { based standards car performance; etc. }\end{array}$ \\
\hline $\begin{array}{c}\text { 4.2 Financial } \\
\text { Instruments }\end{array}$ & $\begin{array}{l}\text { Subsidies \& Taxes (including tax } \\
\text { deductions; price guarantees; etc) }\end{array}$ & $\begin{array}{l}\text { Feed-in-Tariffs non-fossils; investment subsidies heat } \\
\text { pumps, solar, wind parks; etc. }\end{array}$ \\
\hline $\begin{array}{c}\text { 4.3 Standards \& } \\
\text { Regulations }\end{array}$ & Prescriptions; prohibitions & $\begin{array}{l}\text { EU Fleet Standards; standards utilities on CO }{ }_{2} \text { per } \\
\text { kWh; maximum speed; operating permit; etc. }\end{array}$ \\
\hline
\end{tabular}

The core issue of instruments is their instrumentality: what they set in motion is what they do, regardless of intentions, targets or goals. At the level of Institutional Framework, for example, an extension of class action options in liability rules is just that. They may be introduced and used to tackle large climate emitters. But they may also be used to effectively oppose wind turbines, or they may make NGOs liable for their actions, reducing long term policy dynamics. Fleet standards set standards for car producing firms determining the composition of the fleet. How that is done is up to them. Decreasing prices of low emitting smaller cars is a most direct option, then also leading to a larger number of cars sold. Increasing fuel efficiency of larger cars, or all cars, also are options to comply, in line with normal longer term technology development, but speeding up. Getting sales out of the domain of the fleet standards also is an option as was the case with SUVs quite successfully. What will happen? That will differ between producers and countries. With cheap gasoline it is an interesting option to get out of the fleet standards domain with heavy cars, as is happening now in the US, and maybe also in the EU with longer term low oil prices. Such developments may have global cultural effects as was the case with the wave of SUVs styled cars 
conquering the world. Pick-up trucks are the main profit maker in the US market currently, with all global firms joining in, including the biggest: Volkswagen and Toyota. Did the EU Fleet Standards work? That is not an easy to answer question. The fact that the 2015 compliance was realized ahead of time suggests they did not: other instruments, including national subsidy programs may have been instrumental, and more generally other factors, including virtual ones like special lab tests on performance. See on the causality issue regarding current instrumentation the survey by (Drummond 2014) and the analysis by (Meyer and Meyer 2013), focused at three (groups of) instruments: EU-ETS, renewables subsidies and environmental tax reforms, with a prime role for renewables subsidies. How markets will function dynamically and long term is difficult to predict, as culture, technology and overall economic development interact. This makes it quite impossible to specify the long term impact of individual instruments in advance. It also points to the problem of what exactly constitutes climate policy instruments.

The options for Regulating Private Actors mostly lead to mixed systems, also directly. Feed-in tariffs are a specific form of subsidy for producing electricity with a specific technology. They may be linked to a second instrument, like a tax to fund the subsidy, for example as a surcharge on the electricity price for some users. But funding may also be from general taxes, as with electric car subsidies in many countries. Fleet Standards have a fine system for non-compliance which may perfectly function as a quite indirect emission tax. Publicly funded RD\&D may also function as a subsidy to specific technologies and market parties, detrimental to other market parties. Emission permits may be exchanged between emitters if emission location is not relevant, with the trade next regulated, as in the EU-ETS. The emphasis of the combined instrument then may shift from a permit system to a pricing system.

The emission reducing effects of an instrument cannot be seen directly, nor can costs effects be specified so easily, making cost-effectiveness (here taken to be equal to efficiency) a somewhat hypothetical issue. There is an element involved of counterfactual analysis: what would have been the case with some alternative situation, with other instruments or none, see (Meyer and Meyer 2013) on this counterfactual issue and on this relative nature of cost-effectiveness (Mehling, Bausch et al. 2013), Table 2, based on (Görlach 2013).

\subsubsection{Institutional framework: elements}

Institutions, as the general principles and rules adhered to in society, are fixed but malleable. Ownership rules are most basic and well developed in a market based society, ultimately depending also on court rules and their implementation. Liability rules are a core part of them and have been developed to also cover environmental liability, with efforts to also apply them for climate liability, see the survey of options and constraints analyzed by (Faure and Peeters 2011). Though applicable in principle, the practice is difficult as yet: there are billions of emitters, at a global level, with effects at a global level, with a substantial delay in time of effects coming up, and with many options for adaptation to avoid damages. Strict and several liability has widened the legal options, making major actors in the chain responsible, but have effectively been applied only in clean-up of toxic waste sites, especially in the US (Superfund) and the Netherlands, and play an important supporting role in toxic emissions. Though already relevant in the insurance domain these options will not be analyzed further here.

Ownership and liability rules create markets, with additional rules on specific markets. Also these are mainly fixed but malleable in time. They are of central importance for markets where new 
low emission technologies are to function. Electricity markets belong to the most strictly regulated markets, also after privatization in most OECD countries, due to the monopolistic nature of transmission and distribution. The EU Unbundling Directive sets a more or less binding principle for national regulations in the electricity market domain, reducing the monopolistic and oligopolistic power of large fossil electricity producers. The specifics of renewables in terms of intermittency and dischargeability may lead to market adaptations as being detailed below, see Section 4.4. Markets may be designed in different ways and their domains may be restricted. Slaves cannot be traded anymore, and international trade in toxic waste is prohibited mostly. Most economic activities in the market domain have a direct bearing on climate emissions. Restricting the market domain seems hardly possible; ordering the market domain through climate relevant markets design seems a core of long term climate policy, involving both opening up of markets, like for electricity in the EU, and restricting markets, as in allowing only air conditioners on the market with a certain minimum energy efficiency, depending on strategies followed.

The principles-based detailing of institutional rules is the normal way of adapting the institutional framework of society, reckoning with economic and social developments and re-interpreting principles and stating new ones. When environmental policy came up in the Seventies of last century, some order as to instrumentation was created internationally by establishing the Polluter Pays Principle, supported by all OECD countries (OECD 1972). That principle has two elements: the polluter should pay for emission reduction and he should pay for the damages remaining, according to Pigovian or Baumol-type reasoning. Emission standards make the polluter pay for emission reduction but not for the damages remaining, as do freely allocated emission permits. Auctioned permits and emission taxes cover the Polluter Pays Principle fully. Internalization of External Cost is another way of stating the Polluter Pays Principle, with a slightly broader domain, as it may cover other effects than emissions. For principles to be valid operationally, they need to be filled in with more detailed rules, as on what the costs are the polluter should pay and what the external costs are, and how they should be internalized.

One option for partial internalization, not reckoning with damages remaining, is to reckon with an assumed environmental damage price, equal in all environmental policy, in public investment in infrastructure and regulations regarding private actors. This implicit emission price may be attributed to specific policies or private actions. Some estimates of implicit emission prices reflected in the Great Britain feed-in tariffs for some solar PV technologies were in the range of 800 Euro per tonne of $\mathrm{CO}_{2}$, with German feed-in tariffs slightly lower (OECD 2013). These subsidies might be seen as subsidies not-to-pollute, hardly in line with the Polluter Pays Principle. However, the reasoning behind these subsidies was of a different nature, making the implicit price not so relevant. These subsidies were temporary to create learning curves, allowing for future lower cost prices of these technologies. This dynamic aspect makes this implicit emission price mostly irrelevant for long term considerations. Such instruments may be relevant for short term considerations, reducing emission levels next years. Feed-in tariffs of several decades of duration, as considered for the new nuclear installations in the UK, of course are not learning curve payments but part of long term climate (and energy) policy. Furthermore, an implicit price might be established for technology-specific regulations intended to reduce climate emissions, then amongst other emissions however, as with coal fired power stations. This is mostly difficult as other emissions and other external effects will then have to be valuated as well, which mostly is 
not well possible, and certainly not in a dynamic way. For long term transitions such implicit emissions prices give limited guidance to policy makers and to society. The principles are to be more firmly embedded in general rules to effectively hold. So more generic pricing rules are to come to the aid in redirecting market activities dynamically.

Innovation is a key long term issue for climate policy. However, the innovative capacity of society is not specific for climate policy and its instrumentation. Innovative capacity substantially depends on culture, including local culture and broader institutions, not related to climate policy. See (Mazzanti and Antonioli 2013), also on the issue of broader embedding of climate policy, as in using techno-organizational training efforts, and (Mazzanti, Antonioli et al. 2014) on the financing of innovation, with generic financing institutions the main route, while bottlenecks to be resolved maybe, like related to the exceptionally long term nature of some climate investments. What climate policy can do is to shift the direction of innovation, with generic incentives dominant in the long run and technology-specific incentives in the short and medium term, the latter to avoid crowding out of other innovative actions and developments.

Pricing instruments in the form of taxes and subsidies tend to be technology-specific, from a long term perspective mostly relevant for temporary inducing innovation but not for normal functioning from then on, then preferably being subject of long term dynamic incentives. Main examples of such temporary support are publicly funded demonstration projects and feed-in tariffs and premiums and investment subsidies to create learning curves. Subsidies require some sort of funding which then cannot be spent otherwise. There are many taxes with climate relevance, more distant like differentiated value added taxes and more direct like fuel excises for transport fuels. Fuel excises have a serious volume effect, as shown in the extreme differences in gasoline and Diesel use between roughly twice as high excises in countries like Europe and Japan as compared to low excise countries like the USA (with China following suit), leading to roughly half the fuel use per person. These excises had been set up however for reasons of funding and traffic reduction and hence are difficult to interpret in terms of transport based emission tax. They might be set up that way, as a complement to a cap or carbon tax in non-transport domain. In terms of strategic design the logic would then be to apply the generic pricing principle to transport fossils as well and leave the fuel excises to the national domain with country specific reasoning for their functioning and with substantial differences in what they are intended to finance.

Subsidies tend to be technology specific, also the relatively open tax reduction mechanisms. Also taxes can be technology-specific, as in taxing specific types of coal fired power stations, for example only the least efficient ones. Such instruments belong to the domain of directing private actions, instrument type 4.2. There are gradations towards more generic mechanisms. The tax on coal fired power stations may be based on actual $\mathrm{CO}_{2}$ emissions. It may cover all coal fired power stations, and also all gas fired power stations, and all oil fired power generation. A next step may be to also cover non-electricity related emissions from fossil combustion processes, also for heating. At a certain level of uniform encompassingness, the $\mathrm{CO}_{2}$ emission pricing rules become so general that they become part of the institutional framework. Then the general rule is emission pricing, with maybe some exceptions, like combustion of fossils in heavy non-road going transport, for practical reasons. This then would be a temporary exception with also covering such heavy transport emissions under emission pricing rules when circumstances allow. There then is no technology-specific relation with emission pricing any more. This would be a major step in practically implementing the polluter pays principle, and in a way internalizing external climate 
effects. The current ETS is in the middle domain, applied nearly fully on electricity production and energy intensive industry, but not on smaller industrial emissions and not on heating of buildings, and not on transport, with the exception of inland aviation. Its overall GHG emission coverage is now around $45 \%$ and will decline if $\mathrm{CO}_{2}$ emissions in its domain are reduced and other emissions not.

One further institutional domain concerns the financing of the very substantial investments in low emission energy production and energy use systems. The institutional framework for financing is there, evolving dynamically for its own reasons. Lifting out the domain of low carbon energy by creating a generic energy related institutional structure for funding would require specific reasons: issues not solved by the general financial institutions regarding investments. There are specific domains where financing does not work properly, as in household investments in low emission systems. When financial markets fail on such issues, specific measures, like combined subsidies and financing for insulation programs would be appropriate, not changing general framework conditions in the financial system. Changing these general framework conditions of course may be urgent for non-climate reasons, like improved transparency and stability, and better serving small borrowers.

The two major institutional framework conditions, emission pricing and electricity markets will be detailed, surveying a number of variants, in Sections 4.3 and 4.4.

\subsubsection{Public Infrastructure}

Public built infrastructure may have a direct climate relevance as when supplying primary energy (like tidal energy systems and wind parks); transporting energy (like electricity, heat and hydrogen); and transporting $\mathrm{CO}_{2}$ for CCS. Infrastructure construction itself relates to energy consumption directly. The built infrastructure as is already near saturation in the EU and other developed countries. There is no strict delineation between public and private infrastructure in terms of their nature. Nuclear power installations and transmission grids may be purely public or purely private or have mixed ownership, and various forms of markets and management. Wind and solar may be community owned in the $\mathrm{EU}^{6}$ and state owned in other countries. Focus here is on public infrastructure development as a policy instrument, while influencing private infrastructure development with other instruments. Views on ownership and public supply rules differ substantially in a political sense, with conservative type neoliberal policies privatizing formerly public infrastructure, even if monopolistic in nature.

Infrastructure requires activities with emissions in construction and maintenance but the main contribution is that it generates use, with direct emissions, and more complex effects indirectly. Expanding roads, railway lines and airports allows for more traffic. Modal shifts from aviation to rail transport may reduce emissions overall. Infrastructure requirements depend substantially on other policies and developments. Improving the transport infrastructure to reduce congestion is one option. Capacity pricing of road infrastructure is another option however, now used in several countries. It reduces congestion and reduces the need for additional infrastructure. Reducing subsidies, these including tax exemptions (see (IEA-OECD 2015) for the strong adverse role of

\footnotetext{
${ }^{6}$ The largest community owned solar facility now is in the UK: http://www.wired.co.uk/news/archive/2012$11 / 06 /$ community-solar-park .
} 
such subsidies), as with air transport, and increasing taxes, as possible with all transport, reduces the need for infrastructure as well.

Built infrastructure has a long life time, often extending to a century, so a long term view is due. Does the system fit into a low carbon society? Can it function with (near) zero emission energy input? Does it fit with other developments in society? Improving transport infrastructure for efficiency reasons will nearly always backfire through rebound mechanism. Total transport volumes tend to be restricted by maximum travelling times per day, with higher speeds then leading to higher travel volumes (Hupkes 1982 (1977), Metz 2010). There is one domain where design of infrastructure can more directly contribute to a low emission society; the urban infrastructure. Cities with pleasant low speed zero emission transport, like walking and biking, are there already and may become more attractive, as with options for driverless cars, integrated (clean) workplaces and improved leisure facilities.

With electricity dominant in the energy domain, a substantial EU transmission grid would have to evolve for effectively making electricity a European product. A central role for hydrogen would require a hydrogen distribution system. A central role for heat (solar, nuclear, geo) would require a substantial heat transport and distribution system. The volumes of final energy use in general would not need to be subject of specific limitations through energy curbing instruments, other than through general market mechanisms. Reasons for reducing or increasing volumes of specific transport infrastructure are beyond climate policy if transport is near zero emission. Aviation then might be an exception, avoiding investment in airports. The current investment in warm water transport for district heating may lose importance without fossil electricity but might then be used in combination with solar heat, geothermal heat, and stored heat and cold systems. A more detailed analysis is per sector in Chapter 5, reckoning with climate strategies which will lead to different developments of public infrastructure.

\subsubsection{Research, R\&D, and Demonstration}

The option creating research and demonstration instruments are mostly well developed, in research programs for research institutes and subsidy schemes for private partners, with EU Horizon2020 as a major program now. What then is to be specified is the programming of specific subjects. The place of public funded research can be more fundamental or more applied. In basic research the high potential is often not clear until research success comes, not proving commercial success but proving potential, as with graphene and high temperature near zero electrical resistance materials. Such research has long term relevance mainly, and will hardly overlap with privately funded research. Also the social science domain is relevant, as for better insight in behavioral mechanisms, options for market designs and strategic issues related to long term policy development.

Research and Development (R\&D) is closer to the market and may already involve private parties. The focus may already be on market -technology combinations with high long term potential, avoiding lock-ins on short term attractive developments as might be the case with high efficiency Sterling external combustion engines. One issue with this type of research is how to avoid crowding out of similar research in the private domain. If competitors are substantially funded publicly it is wise not to invest in R\&D in that domain. Waiting for public money options may be a most relevant tactical approach. Public research funding may then have clear project results but limited overall results. Avoiding this trap is difficult as the crowded out research is not visible. One 
route might be to focus on projects where there are no competitors in the field, or where all competitors are funded more or less equally. Advanced research projects (ARPA_E in the US, following DARPA) might be set up with a focus on single originators, hardly with competitors. Avoiding crowding out in the R\&D domain has always been a challenge, more difficult for long term projects as insight in competitive issues there is even more limited. Generic research support, also for other policy goals including economic growth, might be a solution, albeit maybe an expensive one.

Demonstration, the second ' $D$ ' in RD\&D, is bringing developed products and technologies in the operational domain. The role of demonstration is to show their practical feasibility, ranging from CCS to the production of graphene. That function is to convince others of the usefulness of such products and technologies, implying that results should be open to scrutiny by other interested parties. Both examples may show shortcomings in reasoning. CCS is fully operational in several places in the world already, for decades already close-by in the Sleipner field in Norway. Funding projects then might be more an act of climate policy implementation than RD\&D. As to graphene, there are several research groups competing in the development of potential technologies, with outsiders coming in. Again, choosing winners now may well cut off the ingenuity and creativity still possible in this domain, including private developments. Again, that crowding out cannot be made visible as unknown developments just will not happen. Dealing with crowding out is a not well resolved issue here, a subject of research itself.

There is one subject at the boundary of demonstration and full implementation: public development, as advocated eloquently by (Mazzucato 2011). A major example, development of the Internet, combines two characteristics: the technology development itself as a science and technology public research issue and the key role of public infrastructure in its implementation. That role is not a research role but a public role infrastructure development, similar to heat transport, underground low resistance train systems and underground hydrogen storage. If such potentially monopolistic infrastructure starts and remains public or can privately be developed depends on broader institutional arrangements, beyond climate policy. Public research funding for climate reasons is to reckon with such refinements, related to strategic governance choices in climate policy.

For long term development it would be wise to keep the research instrument clean, not linking inherently with other instruments, as now is the case for example in NER300/400, where ETS permits are used as a subsidy ingredient.

\subsubsection{Directing Private Technologies \& Behavior}

The main types of instrument regarding private actors are based on the prime working mechanisms set in motion, thus defining the instrument. In order of bindingness, they are Information; Financial Incentives; and Standards \& Regulations, including prescriptions and prohibitions. The legal status may vary, from a contractual relation with one party; covenants with several parties, rules binding all concerned and operating permits with conditions specified. For the long term, the goal of also these instruments directing private actors is to help induce the deep innovations and transformations required for 2-degrees. The instruments at Level 4 roughly coincide with (Grubb, Hourcade et al. 2014) Pillar I, p79ff, including the specific pricing instruments from Pillar II. 
Informational instruments, to stimulate and clarify markets, leave all decisions to the then better informed private parties. Labels on energy use of electric appliances and Best Available Technology (BAT) specifications are examples for consumers and producers, information, with standards setting possibly following. The information instrument is difficult to fill in for long term development, but may be relevant only for creating shorter term dynamics. The Japanese Top Runner program might be an example where such dynamics are created. The Top Runner in the market receives broad public attention and an exclusive label for a limited period. This leads to a price premium (Nishitani and Itoh 2014), creating an effective incentive for R\&D for the firms in the market for electric appliances, see (Hamamoto 2011). The regulatory follow up is to set standards following the top runner, pressing laggards out of the market. The very differentiated top runner structure for cars, in many weight classes showed an adverse effect in statistical analysis according to (Hamamoto 2011). It is not sure for cultural reasons if such programs can effectively be introduced in the EU.

The issue of educating the public towards environmental and climate values is politically laden. With values belonging to the private domain and from there feeding also public policy, they should be left to the private domain. Public education will however have a value element included next to informational aspects and may be directed at value creation conducive to climate friendly behavior. This active cultural development does not find a right place yet in the instrument typology developed and applied here.

Financial instruments, of any legal status, influence actors in markets, changing trade-offs. Taxes, duties, excises, charges and product surcharges, and even fines, all mean: payment. To view an extreme: the EU Fleet Standards fines on non-compliance are set up as a regulatory instrument, related to the volume of emissions above a standard. They start at around $20 € /$ tonne $\mathrm{CO}_{2}$ and rise to around $380 €$ per tonne 7 . They might be used as an emission tax, setting the fines at levels corresponding to carbon pricing in other domains. Whether they are a fine, tax, duty or excise does not make a difference in their functioning. Subsidies are there in many forms as well, all meaning: receiving. Subsidies may be direct, or they may be as tax deduction or exception, or as a product price guarantee, and more. Their effectiveness depends on their specific nature, their level and on the nature of the markets involved. Both taxes and subsidies need to be linked to some object or behavior as a condition for their payment, either some physical or technical aspect indirectly relevant, like home insulation and road payment, or directly relevant, like a carbon based fuel tax. Then an upstream administered emission tax would however be simpler. Indirect effects of financial instruments relate to broader market effects than their specific domain of application. Subsidies on non-fossils increase total energy supply, pressing out some fossil use only, while taxes on fossils use, including reduced subsidies, reduce total supply, see (Hood 2011). Standards \& Regulations, including prescriptions and prohibitions, remain as a main instrument also in climate policy. The may refer to a specific climate performance, as in $\mathrm{CO}_{2}$ emission standards for cars per km or for electricity per kWh; to a variable related to emissions, like energy standards in electric appliances; or to specific technologies prescriptions like minimum insulation standards in building, only indirectly related to emissions, in a binary way: yes/no.

\footnotetext{
${ }^{7}$ The fine is expressed per gram $\mathrm{CO}_{2}$ over the fleet standard, in the average car in the fleet per $\mathrm{km}$. The figure per tonne emitted is based on life time driving distance of a car set at $250.000 \mathrm{~km}$. A fine of $95 € / \mathrm{g}$ then corresponds to a tax of $380 € /$ tonne $\mathrm{CO}_{2}$.
} 
They may act directly, as in limiting $\mathrm{CO}_{2}$ emissions per kWh electricity produced or per km driven in a car, or indirectly, like in prohibiting new coal fired power stations to be built. A fine may be used for non-adherence to a standard, as now considered by the EPA for Volkswagen. This is different from the emission volume related fine as currently in the EU Fleet Standards and the ETS.

For all instruments the legal status may vary from international agreement or legally specified rules to contractual relations between groups as in covenants, or with single parties, or as permit or license granted to a single firm. National agreements may be used to engage parties more voluntarily, important for dynamics and functioning most effective 'in the shadow of the law': regulators then must have broad discretion to enforce stringent compliance, as by building in financial instruments or strict standards to fall back on, see (Vogel 1986, Meidinger 1987) on such regulatory culture based differences between countries.

In principle the choice of technology specific measures may be based on their implicit costs of emission reduction, which may be linked to static efficiency. The costs and amount of emission reduction are based on modelling mechanisms and assumptions. Current instruments may lead to large differences in implicit costs, between countries and technologies, ranging from near zero to above 1000 Euro per tonne of $\mathrm{CO}_{2}$ reduced, see (Rey, Markandya et al. 2013), Chapter 5. Though static efficiency is important for overall costs of climate policy it is not decisive in specific cases. The high costs of photovoltaics have been justified by the substantial price decreases induced by learning curves as created by their subsidized introduction. It is the expected long term cost of emission reduction which may guide the choice of technologies to be brought into the market. Dynamic efficiency cannot easily be linked to technology and behavior specific instrumentation however, depending more on direct innovation and incentives created. In a most extreme way of reasoning, subsidies filling the gap between current costs and current market prices for renewables may reduce incentives for innovation. Actual developments in fast decreasing costs of photovoltaics and wind power have shown the opposite however. Technology choices now cannot be based on substantiated predictions however. In some instances the potential may be established. The Sterling engine has the highest efficiency of all combustion motors in principle. In spite of substantial investments that potential has not been realized in the last two centuries. Still, if such an option would come up in the low emission domain, it may well be worth the try. A choice may be due between further public RD\&D for possible later introduction, and forced or induced market introduction now. In the consideration the avoidance of lock-ins possibly created relative to long term more interesting options play a role. Current forced improvements in fuel efficiency of combustion engines through Fleet Standards certainly are useful in the short to medium term but may be judged also involving this long term perspective. The inherent uncertainty of longer term technology development shifts instrumentation to generic dynamic incentives, as intended with the ETS. A link between ETS and development of emission reducing technologies has not been established however, see (Rey, Markandya et al. 2013) Section 5.2, also due to low and varying price of its emission permit price and the still short period of its functioning. They indicate the positive role of more technologyspecific instruments, slightly different for different technologies, see their survey of literature there.

A special challenge is in the instrumentation for CCS technologies, not for enhanced fossil recovery but for pure final storage. CCS requires capital outlays and substantial amounts of 
energy. With generic emission taxes, a refund upon is due CCS, wherever it takes place in the tax jurisdiction. With tradable emission permits, there is a direct emission reduction with lower permit requirements if the $\mathrm{CO}_{2}$ producing firm takes care of CCS itself. With independent CCS operators they would receive tradable emission permits for what they store. Price stabilized permit prices would easier induce the long term investments required for CCS. The permits granted are to be subtracted from the cap volume brought on the permit market. Without emission pricing, technology specific instruments are due quite unavoidably.

Standards and regulations are most technology binding, like emission standards for power stations and maximum speed for person cars. They have been, and still are, the workhorse of environmental policy, and climate policy. They are mostly seen as stifling technological progress, and hence not fit for long term climate policy. They also require a substantial and reliable public and private administrative system not always present, as for fleet standards. Performance specification allows for more technology dynamics than technology specification. However, even the most restrictive regulations might induce innovation, see the Porter Hypothesis (Porter and Van der Linde 1995). This can result from a prime-mover mechanism or by forcing change in firms, just any to get them moving, see the literature review by (Ambec, Cohen et al. 2013). The speed of emission reduction through these mechanisms may be limited however. Setting dynamic standards has been the main thrust towards technology specific dynamic emission reduction, which however requires a strong political and administrative involvement, continuously.

\subsubsection{Internal consistency in instrument mixes}

In designing instrument mixes, some instruments go well together while others don't. Examples abound.

Feed-in tariffs for renewables and nuclear violate open market principles essential for inducing decentral energy storage systems. Subsidies on low emission cars are not sensible under effective fleet standards; they waste public money without climate effect. Under a strict and pure cap-andtrade system, measures to reduce emissions, like closing old coal fire power stations, don't reduce emissions, also not by creating learning curves and inducing innovation. They only make emissions cheaper for others by reducing the emission permit price.

In general when several instruments are in place in the same production-consumption chain, they will overlap, being either mutually supportive, with possible overacting, they may be unconnected, they may be neutral, or they may be counteracting. With more instruments in place it becomes increasingly difficult to disentangle these relations, see (Simões, Huppes et al. 2015). Avoiding both over-instrumentation and counteracting mechanisms seems most directly approached by having the lowest possible number of instruments covering $\mathrm{CO}_{2}$ emission sources fully and enough. This relates to the discussion started by Tinbergen in 1952, indicating that in a policy domain the number of instruments should equal the number of policy targets (Tinbergen 1970). A larger number of instruments will usually lead to inconsistency. However, adding more instruments may be desirable implying a broader point of view, when there "are other targets, implicitly assumed" ((Tinbergen 1970), p137. More targets require more instruments. This analysis holds for quantitative targets in a given structure and foundations of society. Moving to changing structure and changing foundations will lead to a new situation where this consistency restriction holds. Also, by detailing targets and government organizations, one may then increase the number of allowable instruments, related to targets at different levels, see (Rio and Howlett 
2013). The consistency analysis then is more complex but would basically remain the same. The most basic point however is that in the instrumentation analysis here the structure and even foundations of society are somewhat malleable; there is a substantial divide between the Planning and Control and the Institutionalist governance strategies. Concluding, for both strategies, it seems wise to keep the number of instruments as low as possible, while covering all sources and avoiding overlap as much as possible. The qualitative guidance then is to go for Sparseness, Completeness and Non-Overlap.

\subsection{Institutions: Generic emission pricing options}

\subsubsection{Pricing concepts}

The long term quantitative climate policy target, above $80 \%$ emission reduction ${ }^{8}$, allows for different approaches to pricing, from emission tax and different versions of cap and trade, to using in reference price in using other instruments. Emission pricing by whatever means may relate to very different pricing concepts, though there is some correspondence with specific instruments. Behind all is a relation between emissions and some damage concept, fully quantified or not.

Putting a price on emissions may be done in different ways. One is to specify the social cost of carbon, indicating the value of damages a unit of emissions induces. There is a rich literature on this subject. In the domain of economics, see (Tol 2008) for a somewhat limited view, and (Stern 2008) taking a broader view, also on discounting options. There is not a clear outcome, for quite basic reasons: the damages are uncertain (Heal and Millner 2014) and spread out in time; the methods of discounting are varied and disputed and will remain so, see the survey by (Portney and Weyant 1999); and catastrophic effects are not amenable to the usual economic valuation methods (Weitzman 2009). Solutions are sought for but don't give single outcomes, see for example (Dasgupta and Maskin 2005, Tol 2008, Hof, van Vuuren et al. 2010, van den Bergh and Botzen 2014). This pricing approach links to (Pigou 1932 (1920)), who advocated taxes as a policy instrument to internalize external costs into market considerations. The lack of consensus on the social cost of carbon is one reason why this version of emission tax has not clearly emerged. Quantification is arbitrary, given the very substantial spread in outcomes. A second price concept involves a practical solution to the quantification problem, by setting a price required to arrive at an intended emission level, first proposed by (Baumol and Oates 1971, Baumol 1972). This takes the social cost issue to the political domain, when emission (reduction) targets are set. This approach is behind the caps set for tradable emission permits and also for setting emission tax levels, as discussed below. Both the Pigovian and the Baumol approach are in line with the OECD Polluter Pays Principle (OECD 1972), repeated in the Rio Declaration 1992. The Baumol line links with the major options, cap-and-trade and emission tax.

The analytics for different options for emission pricing are surveyed in Table 4. Pricing systems may be set up in covering fossil $\mathrm{CO}_{2}$ emissions only partly, in the sense of not covering all fossils, and for the fossils covered not covering all sectors and all firms, as now is the case with the EU ETS. Both cap-and-trade and tax can be expended to cover all fossils in all sector domains, including consumption and other final demand. In a long term strategy there are no good reasons for partial application of emission pricing so the full coverage is applied in both pricing systems.

\footnotetext{
${ }^{8}$ The 2020 and 2030 targets of the EU are here for the short and medium term.
} 
This position is reinforced by the administrative characteristic of $\mathrm{CO}_{2}$ emissions: They can hardly be measured at actual source and can be most easily measured fully at source, then covering all fossil carbon. The administrative level may vary. An early survey of options is in (OECD 1992) by (Victor 1992), p.244. Victor distinguishes four possible loci of administrative application, with points of carbon taxation at primary production; at key transport locations; at processing (refineries, power plants); at final sale to end-users (fuel sales and electricity delivery). The direct option, of pricing at source of emission, has been left out, as direct emission measurement was deemed too complex. Though lacking a full system perspective, main corresponding elements as specified here are visible, see Table 4. The option of taxing at end-use has been extensively discussed but falters at the lack of an accepted method of allocation of upstream emissions. Allocating refinery emissions over all its products; power station emissions over heat and power; and dairy emissions over meat, milk, butter and cheese is done in very different ways in different studies, with ISO 14040ff retreating from a choice. See (Guinée 2002) for a deep treatment of this allocation issue and (Guinee, Heijungs et al. 2004) for details and examples on the most generally applicable method, economic allocation. Lack of agreement on methods makes emission pricing at the final product level not feasible. Tools for carbon footprint specification as have been developed give a rough indication, not accepted facts to base pricing on.

Current ETS applies at the level of installations, based on the administration of the firm owning or operating them. It is the firm administration of inputs of fossil carbon, excluding biogenic carbon, not actual emissions. There is a double relation with sectoral domain. Smaller firms and households lack an administration of the fossil inputs into their actually emitting installations and it would require a disproportionate private and public administrative effort to cover them. Going up at least one level, to their suppliers, shifts the administrative application to different firms and sectors. At that level at least that of the suppliers, all downstream installations are covered implicitly. But why should it stay there, if a move higher up the supply chain would resolve the intricacies of overlapping flows, like coal used for electricity administered at a different place than coal used in industry and households? The move to upstream application has its logical end at primary production in the EU and imports of fossil energy products, reducing the number of regulatees very substantially, even as compared to the currently limited application of the ETS, covering only $45 \%$ of emissions by larger firms only, already in the tens of thousands. The move upwards in administrative level is applicable to both cap-and-trade and emission tax. The third dimension is how prices are set. The situation for $\mathrm{CO}_{2}$ is very different from that of $\mathrm{SOx}$ and later NOx, where the US EPA set up a price direct emission measurement system ${ }^{9}$ for larger emitters, who then had to purchase the corresponding emission allowances. The current ETS is a near pure cap-and-trade system, with the cap volume of emission allowances (see on the term (Schmalensee and Stavins 2013) ${ }^{10}$ ) adjusted only incidentally to keep the price up to more relevant levels. The Market Stability Reserve does not refer to price levels but only to oversupply. However in the discussions in the EU Parliament the motive for accepting the MSR was "in order to support the price" (EP-PressOffice 2015). From a long term perspective it seems a curious position to not explicitly state the price goal when adjusting the system to that effect. A clear

\footnotetext{
${ }^{9} \mathrm{CEM}$ : Continuous Emission Measurement system.

${ }^{10}$ The term allowance was introduced in the US $\mathrm{SO}_{2}$ trading system because in US administrative-legal text the more common term permit had a different meaning already. The term permit is used here, as is common in economic and regulatory literature.
} 
choice is due: stabilize the price, or not. If not, there is the pure cap-and-trade system, with advantages and disadvantages as discussed below. If the price is stabilized, with a floor and a ceiling, there is a clear cap-and-trade system as well, a hybrid one, also with its advantages and disadvantages. For the emission tax system the price is fully fixed, determined exogenously.

Table 4 Sectoral domain, administrative level and price stability of emission pricing instruments

Sectoral Domain

1. ETS now: electricity
production, larger industries
(+ some non- $\mathrm{CO}_{2}$ )
2. Also natural gas in small
firms and households
heating

3. Also all other natural gas

4. Also all other coal

5. All coal, oil products and natural gas

$\rightarrow$ All fossils
Administrative Level

1. ETS now: level of emitting firms and installations

2. With electricity producers and energy distributors (for gas, possibly also some coal)

3. With primary producers and wholesale traders, firm level

4. With primary producers coal and gas and importers, firm level

5. With primary producers and importers, product flow basis
Price Stability/Predictability

1. ETS now: price dependent on volume, MSR to increase price coming 2019

2. Price floor indicated (rising) floor, by reducing permit volumes in the market

3. Bandwidth specified, indicative midlevel, permit volume following

4. Bandwidth zero, long term specified permit price level, volume following

5. Bandwidth not an item, fully specified rising excise/tax level

The three dimensions distinguished in Table 4 are not fully independent. As indicated, moving upstream in the administrative level will by near necessity correspond to an upward shift the sectoral domains covered. The step to include all coal seems trivial, as most coal is covered under the ETS already. However, with a rising price of alternatives coal becomes attractive, with multifuel stoves also for coal coming in the woodstove market now already, next to wood pallets, etc. The third dimension is more independent. One might try to implement a fixed price system at an intermediate administrative level to some but not all firms. There certainly is no good strategic reason for that, creating partial implementation, creating unnecessary cumbersome administrative implementation, and requiring other instruments to fill the gaps left. The pure cap at level 1 and the pure encompassing emission tax at level 5 are clear options. Price floors and bandwidth by adding ceilings may keep the price at deemed relevant levels. But if relevant price levels are the aim, not the emission level, then a move to a fixed (rising) price level, bandwidth zero, is the logical next step.

The current near pure cap-and-trade ETS system - fully applied to all fossil emissions on the road to 2050 - could first be transformed into a price stabilized system, then narrowing the collar between floor and ceiling in next steps. When floor and ceiling touch, the cap system comes close to an emission tax in pricing but not yet in administrative set up. In a last step the permit system can be replaced with an excise/tax system, functionally the same but with a much simplified administration. For all systems the administrative implementation can be by member states and the revenues of emission pricing may go to the member states. This is not fully the case now with the ETS, where auctioning is centralized, controls are decentral, and revenues remain partly at the EU level.

In a long term design of instrumentation a mechanism is preferably built in administratively, where the controlling body has the clear interest to get in what is due, and the paying bodies have 
an interest in not paying more than is due. If an administrator has no disadvantage in overlooking emissions, and the firm involved deserves support, not seeing is a reasonable mode of operation, to be kept in check with forceful internal administrative procedures, backed up politically as they are unpleasant and costly. With opposed interests between regulatee and the tax-type receiving administrator they can come to terms on the best established carbon flow specification. Such a mechanism is not present in the current EU ETS, making that pricing system vulnerable in its administrative controls. See for such administrative issues for example (Künze 2012). The US experience in the cap-and-trade for SOx indicated that trust in others' emission reporting was an important factor for success, see (Stone and Zaelke 2005) and (Kruger and Egenhofer 2005) on the essential role of reliable compliance in the SOx case. The development by the EPA of the CEM (Continuous Emission Measurement) system played an important role there, showing to all parties involved, a few hundred only, what the others emitted. In the US that cap system was halted due to political-administrative problems, see (Schmalensee and Stavins 2013).

Administrative implementation remains always open to limitations, fraud and misuse, requiring permanent controls and adaptations. Moving the administration upstream eases implementation. The ETS also has shown options for fraudulent tax evasion, for the years 20092010 estimated by Interpol to be in the order of five billion $\left(5^{*} 10^{9}\right)$ Euro see (Interpol 2013). Those options have been reduced, and perpetrators punished, also the banks that allowed the fraud to come up. However, with a non-mass product with different legal surroundings in different countries fraud remains possible see (Interpol 2013) for some insights, and will become more attractive with rising emission permit prices. Non-fraudulent tax evasion (like tax routing) will always remain an option. This is inherent in the trading system, including derivatives trading. Zero bandwidth cap and emission tax don't share this characteristic.

\subsubsection{Emission tax}

The emission tax resulting can be quite straightforward in the case of $\mathrm{CO}_{2}$ emissions. Direct emission measurement is mostly not possible of feasible but indirect measurement is possible with reasonable precision based on input measurement of carbon. The further upstream administrative measurement is placed, the more reliable the measurement becomes, avoiding transformations and losses as in refineries. The ultimate measurement level is at primary production and imports, with exemption or refund upon export, very similar to alcohol excises. Also at CCS the refund then is due, the carbon not being emitted as $\mathrm{CO}_{2}$. All emissions are covered this way, the $\mathrm{CO}_{2}$ emission tax being set up as a carbon deposit. Such deposit system to burden emissions with a 'tax' was earlier proposed for climate emissions by (Huppes 1993), Chapters 4 and 5, and for hazardous substances, especially toxic metals by (Huppes 1993, van der Voet, van Egmond et al. 1994) and more recently specifically for carbon by (Huppes 2011) and similar by (Mignone 2010). The level of the tax is to be set 'to reach the target'. There is substantial discussion on the reasons for having a rising, decreasing or rising and then decreasing structure of the tax in time, see BOX 2. Assumed here is a starting point with a linearly rising level, for example starting at $25 €$ per tonne in 2020 and then rising with $5 €$ per tonne each year, see Table 5, similar to the mechanisms in the UK Price Floor tax and the British Columbia (Canada BC) emission tax (BC 2014).

Setting the price level towards 2050 is not a straightforward issue. Econometric and economic modelling (see for example (Solano and Drummond 2014); (Meyer, Meyer et al. 2014); (Vuuren, 
Stehfest et al. 2011); and (Deetman, Hof et al. 2014) come to prices per ton rising from $\$ 300$; to up to $\$ 500 ; \$ 600$; and up to $\$ 1000$ respectively ${ }^{11}$. Volume effects, based on elasticities of supply and demand, can be analyzed from the past, and based on investment rules for given technologies, prices and markets. But the past certainly is not a guarantee for the future during transformative change. It is also extremely difficult to estimate substitution mechanisms when relative prices will certainly be changing, and now products and technologies will be coming up. At which emission price level electric drives may take over is not so easily established, being fundamentally dependent on innovations to come, not just for electric cars but in the full electricity system, including demand stabilization and storage innovations, and substantially depending on developments in the electricity market structure. Such important elements are difficult to include in modelling and are lacking in the models indicated. See for an example on the potential of current technologies for combustion drives and battery-electric drives BOX 4 . There may be some back-of-the-envelope anchor points, related to price levels as are considered. From a certain level of emission price, coal fired power stations certainly will lose out against natural gas. And under reasonable assumptions regarding cost price of batteries, and with functioning of open markets, electric cars will outcompete gasoline cars. Similarly, installing natural gas based installations for the heating of buildings will be a loss making investment. This gives an indication of the level of the emission tax required, not a prediction of the technologies coming up. These may well be fully different, and then more attractive.

The administrative set-up is according to the constraints of the Lisbon treaty. The EU sets the framework while administrative implementation are at the national level and proceeds are at the national level according to the share of each member state in total EU emissions. This is similar to current ETS procedures, where however a share of total proceeds is now falling, tax-like, to the central EU budget. An international agreement on the level of emission pricing would strengthen the price signal by making the price level less prone to political pressures, see in this sense (Mackay, Cramton et al. 2015) and (Nordhaus 2015).

\subsubsection{Cap-and-trade systems}

For cap-and-trade systems, there are more options, starting from current ETS. The domain is expanded long term so as to cover all fossil $\mathrm{CO}_{2}$ emissions as there are no strategic reasons to get stuck halfway, and the IPCC stresses "that that a consistent carbon pricing, covering all sectors of the economy, is a defining feature of the $2{ }^{\circ} \mathrm{C}$ scenarios" ((IPCC-AR5-WGIII 2014), Annex III, paragraphs 183, 184 and 187), quoted approvingly by the expert group preparing for COP21 (UNFCCC-Experts 2015). All emission permits are auctioned. The pure volume based cap system sets emission levels and leaves prices as they come through market mechanisms. It has the advantage of a predetermined maximum emission level, if administered properly and if politically feasible if prices explode. It will include a national administration directly linked to national proceeds, to create the incentives for proper public administrative implementation, and from there the privately adequate administration. It has the disadvantage of unknown long term price

\footnotetext{
${ }^{11}$ McDermott's “Managed Carbon Price Act' introduced in the US House of Representatives in 2014, starts at $\$ 12.50$ per metric ton of $\mathrm{CO}_{2}$, increasing yearly with that same amount. In 35 years' time this amounts comes close to $450 \$ /$ tonne.
} 
levels. From a long term perspective, the predictability of the price level is an important issue for long term investment decisions, and for helping to direct research and R\&D in climate relevant directions. Heat pumps with seasonal storage require high capital investments, returned only if there is an operating cost differential with low-capital natural gas based heating systems. The emission price is one key factor then, of course operant only if that price signal is translated into decentral market prices. Also for medium term investments emission pricing may be decisive, see the car example based on current technologies, in BOX 4. Such cost considerations are due in any investment decision. The long term trajectory of pure cap based permit prices may be estimated based on past prices and trends therein. These shorter term trends are made less clear because of price volatility, see the survey paper by (Dinan and Stocking 2012) and the assessment by (Schmalensee and Stavins 2013) on the US experience with carbon trading for SOx. With future emission prices uncertain, decisions cannot be based on reasonably expected future prices. There is some certainty however, as long as it is not other instruments taking over from the cap-andtrade system: permit prices will rise substantially. Their overall expected level will be higher than the level deemed relevant for the carbon tax, due to inherent price uncertainty. The expected long term price also carries a subjective uncertainty as there is no carbon tax price given as a reference. Investors will therefor reckon with a lower price than actually would evolve with perfect foresight. This underinvestment in emission reducing measures bites back: it also raises the long term permit prices as will actually evolve.

There are several options to deviate from the fixed volume pure cap system, moving permit prices to an aspired higher level, or lower level as well. Adapting the volume of permits brought on the market is the main option, involving other instruments in the same domain the other. Currently there is an agreement to take non-used permits temporary but substantially out of the market, in the Market Stability Reserve, to be introduced by 2019. Such a fix on-the-go measure may be a perfect solution in the current situation, but is belongs to satisficing, not optimizing and is certainly not part of strategic planning. If too low prices are a problem in not guiding long term private R\&D and Investment, the strategic solution is to stabilize the price at relevant levels, rising similar to the emission tax case to avoid unnecessary costs. Two cap options will thus be taken into account in the bottom up instrumentation development for the four sectors, in Chapter 5 : the Pure Cap-and-Trade option and the price stabilized cap version, as Hybrid Cap-and-Trade. (The term is coined after (Goulder and Schein 2013) ${ }^{12}$ ). The pros and cons of these cap options will be analyzed in turn.

\section{BOX 2 Rising emission prices in time? Theoretical positions}

There are different positions on the most relevant dynamics of emission pricing. A strict economic-Pigovian type of reasoning is that the damage cost of emissions at time $\boldsymbol{t}$ should be reflected in the price level, as is advocated for example by (Tol 2008) who is a strong believer in a single and precise outcome of emission damage specification. With emissions going down to the optimum level, and adaptive measures being implemented, damages go down and the Pigovian tax is to be going down. The price starts high, directly, and then goes down as also advocated by Tol. This is the most clear and simple economic optimality reasoning, assuming markets to function and technologies to be there, the better ones replacing the

\footnotetext{
12 They mention as an advantage of price stabilization a reduction in the rent income of oil producing countries, a subject left out of discussion here.
} 
existing ones. Start now at the relevant highest pricing level and things will only become easier, as marginal damages will go down. The implementation would be direct in the carbon tax and in the tradable cap system could be realized by moving from a fixed yearly reduction rate to a variable one inducing the required decreasing prices with volumes long term fixed in the Pure Cap system or more regular in the Hybrid Cap system. Politically this seems hardly feasible, certainly not if the EU would take a lead in policy. The second position in reasoning is close but makes technology variable in time. Several low carbon technologies to be introduced are still to be developed. As the EU Commission states: 'The effort would become greater over time as a wider set of cost-effective technologies becomes available." (COM 2011). The emission price should be high enough by the time these cost-effective technologies have become available for investment. A first step in reasoning is to see which emission price level would make a renewable competitive, assuming all costs for all technologies as constant. See (IEA 2015) on the diversity of cost concepts, with levelized cost of electricity (LCOE) then including the cost of emission pricing. Also, a high speed of shifting to the new technologies implies a faster write off of existing capital. Furthermore, the speed of technology change is always restricted by many factors to be adapted, from adjoining technologies to norms and regulations, see (Kramer and Haigh 2009) with empirical data on energy and the more general ' 35 years' rule by (Hirooka 2006), stating that it takes 35 years for substantially new technologies to reach their maximum expansion rate, the fuller penetration rate following. Thirdly, with rising income, the value of damages will increase because of higher physical damage like by extreme weather events, with higher valuation. Finally, emissions are not falling for some time to come, but rising, with damages increasing, also due to delay effects. This is a similar type of optimality reasoning as in position number one, but with more factors made variable and hence more apt for longer term optimization. This version of optimality reasoning leads to a slowly rising emission price to start with, like rising to relevant levels in the next two decades, and later possibly leveling off and decreasing, if policies are successful. Implementation in the Hybrid Cap system and in the Emission tax seems possible.

The third type of reasoning is of the backcasting type, the Baumol type of reasoning. Targets are set, with the required prices to get there following. The target is not a specific path but the time integrated volume of emissions, like here the ' 1 teratonne $\mathrm{CO}_{2}$ ' for the aspired level of 2-degrees climate stabilization. Within that target, the timing is somewhat open again, linking reasoning towards the second position. The abstract version of optimality, not technically specified, is guiding the path. One factor is added here: the last $10 \%$ of emission reductions may well be more difficult to realize than then first $90 \%$, as low hanging fruits will have been picked in 25 years' time. This would lead to a steadier rise in emission prices. The option of slowing down the rise in emission price can maybe be evaluated based on performance in 2040, mirrored by the requirement of raising the price faster. The (UNFCCC-Experts 2015) meeting in Bonn advocates fast reductions, for climate risks reasons, as later negative emissions are uncertain in their feasibility.

A fourth type of reasoning leaves the realm of integrated optimality reasoning. Targets are set, as in the Commission Roadmap, and the emission price is following, whatever that price may be. This position is linked to the pure and strict version of tradable emission permits, with a yearly specified immutable cap. That pure position has been left somewhat by the Commission, reducing permit volumes in the market somewhat to raise their price. This then links to the third type of reasoning. It has been the position in the UNFCCC, with substantial literature on how to set the targets per year to remain within the climate budget, following RCP2.6 modelling. Later emission reductions require larger negative emissions later this century. Finally, a fully different type of reasoning of a much more tax-practical type may be applied: what would be the proceeds of emission pricing, see Table 5, to help development of a green the tax system? From a tax office point of view, stable proceeds then are to be preferred. Ideally, then the price of emissions would be inversely proportional to the volume of emissions. This again links to a rising emission price, extreme in the end, with steadily decreasing emissions. 
For all carbon pricing a consideration of primary producers is to reduce the risk of future very low product prices, bringing their resources on the market at higher volumes, and hence - collectively - lower prices now, see (Sinn 2012) for the reasoning involved in this paradox. (Edenhofer and Kalkuhl 2011) expand outcomes of the paradox to more precise assumptions and (Michaelowa 2012) gives a critical review indicating that the base assumption of equal cost for all production is highly unrealistic. Investment in most expensive new production capacity will be reduced by emission pricing, reducing the incentive to increase production now. (Harstad 2012) sees this leakage as undermining climate coalition efforts and proposes that the coalition buys all fossil resources to keep them in the ground, globally. This seems fully impossible, given the undefined nature of what constitutes resources and the extreme prices and related transfer payments that would be involved. More realistic leakage modelling methods have been developed by (Hoel 2011a, Hoel 2012) with more diverse outcomes. In their review on the subject (Fischer and Salant 2013) conclude that the paradox effect will be limited, if present at all. Other mechanisms induced by lower prices also due to climate policy may play a role however. The OPEC (Saudi) reaction to low oil prices, hardly induced by effective climate policy, has been to increase production to press US fracking production out of the market, accepting even lower prices. Such imperfect market mechanisms will remain.

Overall conclusion is that slowly but predictably rising prices reduce the cost of emission reduction, with a revision of the level after maybe two decades, to avoid underperformance or too substantial overperformance. Starting low and rising predictably has proven politically feasible in the UK price floor tax on $\mathrm{CO}_{2}$ emissions linked to ETS and the Canadian emission tax in British Columbia.

Table 5 Proceeds of emission pricing: emission price starting at $100 € /$ ton in 2020 rising by $10 €$ per year

\begin{tabular}{|c|c|c|c|c|c|c|}
\hline & $\begin{array}{c}\text { Emissions } \\
\text { Mton } \\
\text { CO2* }\end{array}$ & $\begin{array}{c}\text { EU GDP } \\
+1.5 \% \text { pa } \\
\text { B€ } * *\end{array}$ & $\begin{array}{l}\text { Emissions } \\
\% \text { relative } \\
\text { to } 1990^{* * *}\end{array}$ & $\begin{array}{c}\text { Emission } \\
\text { price } \\
€ / \text { ton }\end{array}$ & $\begin{array}{c}\text { Pricing } \\
\text { proceeds } \\
\text { B€ }\end{array}$ & $\begin{array}{c}\text { Proceeds } \\
\text { as } \% \text { of } \\
\text { GDP }\end{array}$ \\
\hline 2010 & 3771 & 11964 & 85 & 10 & 38 & $0.32 \%$ \\
\hline 2020 & 3106 & 13897 & 70 & 100 & 311 & $2.23 \%$ \\
\hline 2030 & 2662 & 16128 & 60 & 200 & 532 & $3.30 \%$ \\
\hline 2035 & 2219 & 17375 & 50 & 250 & 555 & $3.19 \%$ \\
\hline 2040 & 1775 & 18718 & 40 & 300 & 532 & $2.84 \%$ \\
\hline 2050 & 887 & 21723 & 20 & 400 & 355 & $1.63 \%$ \\
\hline 2060 & 444 & 25210 & 10 & 500 & 222 & $0.88 \%$ \\
\hline \multicolumn{2}{|c|}{ *EEA 2014} & \multicolumn{2}{|l|}{ **IMF 2014} & \multicolumn{2}{|c|}{ ***Roadmap 2011} & \\
\hline
\end{tabular}

\subsubsection{Pure Cap-and-Trade}

How to allocate caps to countries in time has been a core discussion, reasoning backward from a given carbon budget. Most detailed proposals specify emission caps per country per year for the next decades, as by (Frankel 2008), also as Chapter 2 in (Aldy and Stavins 2009) and similar in (Bosetti and Frankel 2009). For EU climate policy a global specification per country is not required however. Without global agreement, a front runner climate coalition, like EU and China, could start with mutually agreed voluntary caps, with others coming in later, at then higher costs, see (Kriegler, Riahi et al. 2014) on such dynamics. Costs for the EU are comparatively low, due to limited amount of fossil resources and an already well developed infrastructure. The EU cap in 
the pure-cap carbon pricing option is reduced by a fixed amount per year, legally established and binding for the total of the member states.

In the ETS (intended) pure cap-and-trade system the cap is fixed, with a fixed yearly percent point reduction relative to the base year 1990 . It is now set at $1.74 \%$ per year and intends to rise to $2.2 \%$ per year in 2021 . The long term reduction rate of $2.2 \%$ implies a rising reduction rate on a per annum percentage basis, extremely high towards 2050 , rising to well over $10 \%$ reduction per year on a compound rate basis. As some emission domains are difficult to reduce very substantially, like iron and steel and aviation, most other activities would have to reduce even faster. A more modest reduction rate when the goal is near might be a better option. The current compound reduction rate of around $1.5 \%$ per year would have to rise to roughly $5 \%$ within the next decade to arrive the same 2050 target $^{13}$. A reduction rate of $5 \%$ at a growth rate of $1.5 \%$ would imply a reduced emission intensity of $6.5 \%$ per year or, formulated as the inverse, an ecoefficiency improvement by $6.5 \%$.

For guiding long term decisions on decarbonization, the core question to answer is what the permit price will be in the near and far future, that is what price development might reasonably be expected. Answering that question must be based on estimating the factors determining demand for permits, as the supply is purely inelastic. The main factors determining demand are economic growth; the price development of fossil energy sources; cost development for low carbon production technologies; the system costs induced, substantially depending on market structure and the cost and market development in other sectors; the role demand spreading can take in the internet of things; the costs to be induced for decarbonizing the energy use chain and its speed of implementation; and the cost for energy storage systems, both for electricity and heat and other options; the volumes of iron and steel use and of aviation, and a few more. Most of these factors are highly uncertain, and can be brought under policy control to a very limited extent only, with the exception of the development of electricity markets. When explaining the price drop in the EU ETS, is a bit of everything (Feng, Zou et al. 2011) (Koch, Fuss et al. 2014), a difficult to disentangle mix of low economic growth; shift of material production to Asia, especially China; substantial $C D M$, the upcoming of national climate policies like widely used feed-in tariffs; and technology development also induced by Chinese and US renewables policies. Overall however, permit demand development is highly unpredictable. One thing is for sure: not only is supply fully inelastic in a pure cap system, also demand is highly inelastic in nature. On short and medium notice technologies are mostly given, so only market volumes can adapt to price changes of emission permits, with highly uncertain developments. This implies that also price development is highly unpredictable, not the one on short notice due to trading effects, but the longer one, over years and decades However, short term price fluctuations will also blur the long term picture somewhat, increasing at least subjective uncertainty.

Empirical analysis is available on substantial also longer term price volatility of the US SOx, and later also NOx cap on utilities, the major example for the EU ETS. There is some analysis on factors behind EU ETS price volatility, but hardly linked to time frames, see (Meng 2013) for the analysis of some factors, and on broader references. For energy, the long term elasticity of demand has been in the order of minus one, see (Lowe 2003), who analyses also long term expected

\footnotetext{
${ }^{13}$ The cap reduction rate set by the Commission is now at $1.74 \%$ (of 2005 emissions), rising to $2.2 \%$ (of 2005 emissions) in 2020. This implies a rising compound emission reduction rate.
} 
development of price elasticity of energy demand under effective climate policy. The emission permit price elasticity is different from energy price elasticity, more elastic long term as then shifts in technology use can be realized. Long term predictions of price elasticity of permit demand seem quite difficult however, and no predictions seem available. The more inelastic range (long term) might go to minus 0.2 , let us assume as an option. This is not a prediction but an option a pure cap system would have to reckon with. Combining fully inelastic supply with this range in elasticities of demand indicates what the price effect of a disturbance could be. With a $10 \%$ increase in demand, the unitary elasticity we mostly are used to in other domains would lead to a $10 \%$ increase in price. The same demand increase with a price elasticity of -0.2 would lead to a $50 \%$ price increase, see Figure 2 . The figure conveys the mechanism but cannot be based on empirical data for the basic reasons mentioned. The converse would be true for a demand decrease by $10 \%$ leading to price decrease by $50 \%$. Of course elasticities are not known or even fixed, depending on the time horizon and certainly are curves, not straight lines. But the message is clear, non-predictable factors can lead to very substantial price changes over a period of years. Figure 2. Demand and supply for emission permits under pure cap-and-trade: graphical analysis.

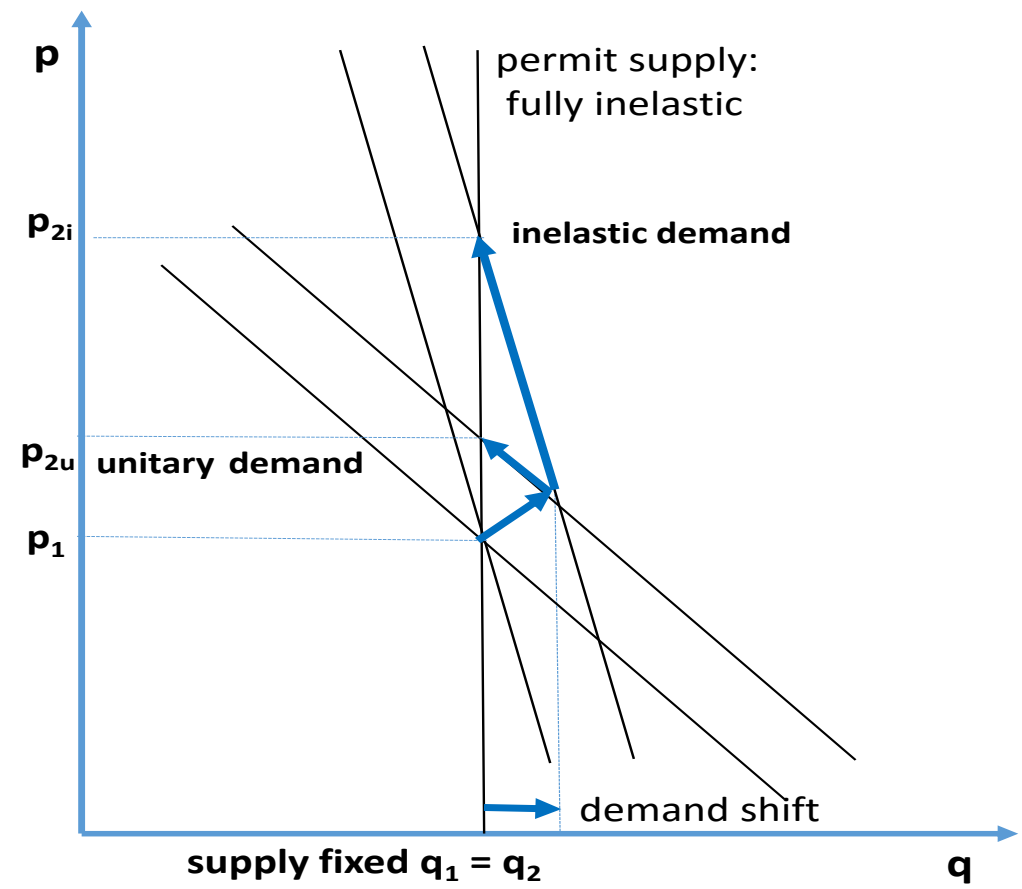

The elasticities not only are hardly known, they will not be stable.

Substitution as a major factor depends strongly on the time horizon. Shifts of demand to other technologies and sectors are easier in the long term, as when investing in heat pump based heating systems to better use intermittent renewables. Such mechanisms in turn are also highly dependent on the future market structure in the electricity domain. In the long term elasticity then will be higher than on the short term. However, other mechanisms work towards reduced elasticity in the longer term. Picking low hanging fruit can only be done once; options for changing technologies tend towards increasing costs; and shifts in demand are limited as by given infrastructure and given tastes. The net effect on long term price elasticity of demand may therefore be in a broad range, with expected volatility in a broad range as well. 
This is the main long term weakness of the pure cap-and-trade system: there is no good basis to predict the long term price development of permits. This implies that there is no good price expectation possible for guiding public and private R\&D and neither for long term investments towards a low emission society. 'The permit price has collapsed before, so be careful.'

Substitution effects depend strongly on the time horizon. Shifts of demand to other technologies and sectors are easier in the long term, as when investing in heat pump based heating systems to better use intermittent renewables. Such mechanisms are also highly dependent on the future market structure in the electricity domain, see Section 4.4. In the long term elasticity then will be higher than on the short term. However, other mechanisms work towards reduced elasticity in the longer term. Picking low hanging fruit can only be done once; options for changing technologies tend towards increasing costs; and shifts in demand are limited as by given infrastructure and given tastes. The net effect on long term price elasticity of demand for emission permits may therefore be in a broad range, with expected volatility in a broad range as well. Price predictions can only be highly uncertain.

The pure cap-and-trade system is to be a major instrument in an instrument mix. Other instruments in the same domain, like national policies, local initiatives, and private contributions and innovations may seem interesting from their micro levels but don't contribute to emission reductions, see (Sorrell and Sijm 2003, Sijm 2005) for an early convincing analysis of this relation with other instruments, and (Agnolucci and Drummond 2014) Chapter 5 for a recent literature survey with the same conclusions. The demand for permits is reduced, the demand curve shifting down along the vertical permit supply curve, see Figure 2 . The lower price of permits just makes it cheaper for others to emit, these then emitting more. The relation also holds with other EU instrumentation. If a well-functioning electricity market is introduced to allow for easier introduction of renewables, that effect may occur, but the emission reduction not. Lower emission prices will make fossils so much more attractive that the cap is filled. This is an unavoidable characteristic of the cap-and-trade system being pure, and is not based on any empirical analysis or experience. This makes ingenuity and creativity in emission reduction superfluous from an emission reduction point of view. If, for climate reasons, you introduce an automat to lower your thermostat already before leaving your house, you just are silly. This demotivating characteristic is a main obstacle for the long term functioning of a pure cap-andtrade system. If all other instruments together are effective enough for to create the emission reduction of the cap, the permit price will collapse, making the pure cap scheme superfluous.

\subsubsection{Price stabilized cap-and-trade}

The first step towards price stabilization as taken in the ETS is a shift in volume of permits brought on the market, without an explicit price reference, in discussions indicated as a more relevant price level. See for the importance to have a specified permit price (Goulder and Schein 2013), who name that cap variant "hybrid". Long term instrument development would make this hybrid cap option explicit in the intended price level, specifying explicitly what is relevant. There is national legislation in the UK indicating what is relevant, in the price floor tax. That tax is complementary to the EU ETS. Its level is the difference between the actual price level in the ETS and the price deemed relevant, see (Revenue\&Customs 2012 (2010)). At its introduction, the price path was specified at 16 per tonne of $\mathrm{CO}_{2}$ in 2012 and follow a linear path to maximum $f 30$ 
per tonne in 2020, rising to $f 70$ in $2030^{14}$. By 2050 this price rise would lead to an emission price in the order of $200 €$ per tonne $\mathrm{CO}_{2}$, see similarly Table 5 . The UK price floor is a tax. Setting a price floor for the EU ETS would not be a tax, but a volume adjustment. At auctioning, no more permits would be auctioned if the price would fall under a certain level; if no one bids at that price, the auction is cancelled. That pricing element would override the indicated cap volume. In current circumstances this would mean that the auctioned part of the cap would be restricted, not the emission permits distributed for free, see (Burtraw, Löfgren et al. 2013) for detailed proposals and literature not focused at the long term. For the long term the price floor would be specified along a time path towards 2050. Discussions now focus on the price floor as the price of now in the order of $€ 5$ per tonne is too low to have any impact on economic decision making. The price of $1000 \mathrm{~km}$ air travel is raised by at most $€ 0.50$. During periods of high economic growth and stagnating innovation and cost reductions, the price may explode however, bankrupting sensitive industries, with undesirable capital losses resulting, and unavoidable political reactions. The mirror then is the price ceiling to avoid such effects, together forming a price band or collar, see proposals as by (Edenhofer 2014). There is substantial support for such an adaptation in the grey literature, see for example (Borenstein 2013) and (Fell, Burtraw et al. 2011), but without specifics on the time path of floor and ceiling and without reasoning towards the width of the band. These considerations are essential for a long term view on the hybrid cap instrument. A study by the US Congressional Budget Office (Dinan and Stocking 2012) warns that for hybrid cap systems clear and detailed choices are required with relevant market controls established to avoid market manipulation.

The larger the bandwidth is, the more market price variation there might be. If there is however public-administrative discretion to steer the price into the upper, middle or lower level of the band, a more stable price path would result. If there is a volume basis as a reference, like cumulative exceedance or underperformance relative to the formally established cap volumes, the price would also stabilize, at least for periods, but then either at the floor level with overperformance and at the ceiling level with underperformance. The reasoning for having the bandwidth remains open however. In the high price and low price version of the stabilized price path trading would become superfluous. Only during the shift between floor and ceiling, trading would play a role. Reducing the band to near zero would make all trading superfluous, then reducing control requirements on undue trade manipulation as well. The cap system then would come close to the emission tax in pricing though not yet in its administrative set-up. The full step towards the administratively simplified emission tax would reduce transaction costs also privately, see (Coria and Jaraitè 2015).

The four options for emission pricing, No Pricing; Pure Cap; Hybrid Cap; and Emission Tax, are starting point for the bottom up development of instrument mixes per sector in the next Chapter.

\section{Product prices and emission prices}

When starting at that endeavor, it is good to have some idea on product price effects of different levels of emission price, be it formed by either cap system or the emission tax. The price effect here is purely the direct effect, without market mechanisms which certainly will result.

\footnotetext{
${ }^{14}$ Due to international competitiveness, the UK going it alone, and to reduce energy cost the price floor has been frozen at $£ 18$ per tonne, see http://researchbriefings.parliament.uk/ResearchBriefing/Summary/SN05927.
} 
Substantially reduced demand for fossils will certainly depress their market prices substantially, see (Meyer, Meyer et al. 2014). A price of for example 20 Euro per barrel of oil equivalent is feasible with reduced fossil use and will be a lure for getting it into the market, directly or indirectly. However, an all fossils covering carbon price of $300 € /$ tonne of $\mathrm{CO}_{2}$ in 2050 , by cap or tax, would add $135 €$ to the barrel of oil price, bringing it up to that price even at near zero production prices. By then, emission free alternatives would be competing out oil and gas at such emission prices, even if having been brought into the market by standards and regulations. And if not, the emission price could be raised, to avoid a fall back to fossils. Assume an emission price of $300 €$, not as a choice but as a long term benchmark, roughly in line with the intended rising UK price floor tax and the rising British Columbia emission tax. The price of a barrel of crude oil would initially increase with $134 €$. This would certainly reduce demand even on the short term. Natural gas would outcompete coal in electricity production, having around half the carbon content per unit of energy. A one thousand kilometer airline city trip (return) in Europe would become around $64 €$ more expensive, before taxes. The substitution to near zero emission technologies would be more attractive with higher emission prices. But substitution of course depends also on the costs of the alternative and on more complex mechanisms. But certainly, renewable electricity would become much more competitive. Of course the advantage increases with the emission price.

Table 6 Effects of emission pricing on exemplary product prices

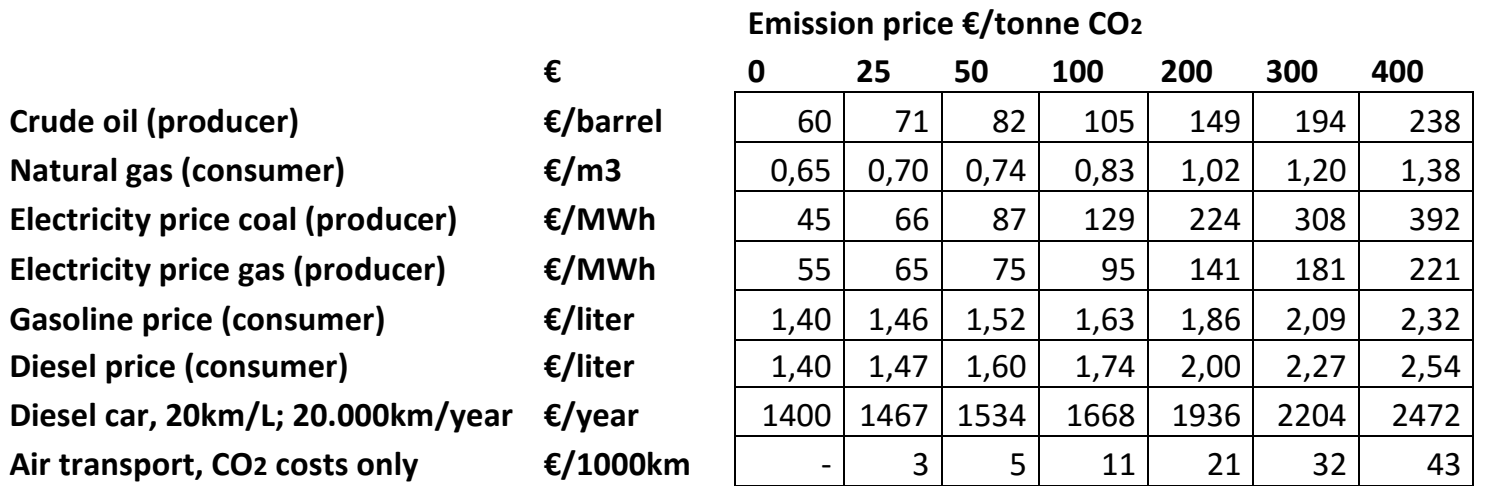

\subsection{Institutions: Electricity market designs}

\subsubsection{Extreme numbers coming up in production and consumption markets}

There are many options to create electricity markets, highly relevant for climate policy. Each has different infrastructure requirements, both public and private, and each has different shares of more public and more private infrastructure elements. There is a direct relation with other climate policy instrumentation, with some instruments fragmenting markets and well-functioning markets supporting other climate policy instruments.

Long term developments will lead to substantial shifts in terms of actors linked to the grid, both for climate reasons, supply security reasons and energy efficiency reasons, with climate reasons focused on here. The number of primary producers may well increase from a few hundred not so long ago to several tens of millions in the next decades. The number of storage facilities will grow from a few hundred to several tens of millions. Transformation technologies with storage, 
as to heat and hydrogen, will increase from a few hundred to maybe up to tens of millions. Final users will become active market participants as in smart grids and the internet of things in the hundreds of millions. See Figure 3 for the actors involved and their potential numbers. Key characteristic of the transition is an extreme shift towards decentralization, and mostly a shift towards dispatchable technologies with fast reaction time options, and also in the use phase extremely short reactions time. This structural change in number and type of actors will require development of new electricity markets, and related energy markets, and new infrastructure for transmission and storage. The EU market will also be connected to other electricity markets, certainly including Norway and Switzerland but with high potential also for Iceland and possibly Eastern Europe, non-EU Balkan countries and North African countries.

Currently, the European grid consists of a set of mainly national transmission grids, with substantial differences between them, and with limited connections, and a high number of distribution grids, with various ownership. Most countries have unbundled substantially following the Unbundling Directive, with operation of grids by mostly public Transmission System Operators (TSOs), and details as on their independence further worked out, see (EC 2013). Pricing systems differ between all of them. Swing producers (larger producers who adapt the volume of production for load balancing) and grid operators work closely together at wholesale markets to maintain grid balance and stability, also at international markets for swing producers. Sometimes these actors are fully independent, sometimes they are closely connected and sometimes they are combined in one organization, as a quasi-public near monopolist. There are some high tension international connections, both AC and DC, based on mainly bilateral agreements. Some grid operators have gone international as traders, and some operate in more than one country. Differentiated prices for producers and for users are common, different between different countries, as based on feed-in tariffs and similar with cost distributed uneven over different users, and also by differentiated tax regimes. The Commission is pressing for wider international trade options, requiring national public interventions to be better mutually aligned (COM 2013) and setting quantitative targets (COM 2015), and adjoining rules how international trade is to be organized, as in relation to load balancing (COM 2015b). At a technical level the alignment has been evolving in cooperation with ENTSO-E (European Network of Transmission System Operators - Electricity), who also are involved in development of EU market rules ("network codes"). Though clearly opening up to European market development, no clear pan-European market design is yet involved.

What could be long term development options, reckoning with the challenge of the coming power system without fuel (Taylor and Dhople 2015). Intermittent, non-dispatchable, decentralized primary production becomes dominant, with much primary production having close to zero short term marginal costs. Secondary production and active demand reaction will play a key role in market stabilization, under adequate market design. North-south and East West linkages can also flatten out production and consumption somewhat. One line jumps out now: With high voltage direct current (HVDC) transmission becoming the long distance mode of transport, national and subnational grids can be adequately linked with high efficiency. They also can function more independently, without rising faults levels due to intermittency and related fast shifts in flows.

For the 2-degrees climate stabilization target $\mathrm{CO}_{2}$ emissions in electricity production are to be reduced by over $95 \%$ by 2050 , see section 3.4 . CCS may become up to $80 \%$ effective only, see (IEA 2015), where applicable. It may only play a supporting role therefor regarding fossils. The 
conclusion is that future energy supply systems, long term, will have to be dominated by nonfossil production, that is renewables and nuclear. The expansion of renewables in the next half century will probably be based on wind and solar electricity, both with high intermittency, limited predictability and non-dispatchability. One fine Christmas day the wind has not blown for days over a week and snow had covered all solar panels. Most emission free is not or only limited dispatchable in relation to demand.

- Wind/wave

- Solar

- Concentrated solar

- Tidal

- Nuclear

- Geothermal

- Biomass with CCS
Intermittent and non-dispatchable Intermittent and non-dispatchable Intermittent with some heat storage dispatchable Intermittent and non-dispatchable Stable and only slightly dispatchable Stable and somewhat dispatchable Substantially variable and dispatchable

Figure 3. Actors potentially involved in market clearing in the long term electricity market

Market clearance at time $i$ :

$P p_{i}+P s_{i}+P o_{i}=D_{i}+S t_{i}+S d_{i}+T_{i}+L_{i}$

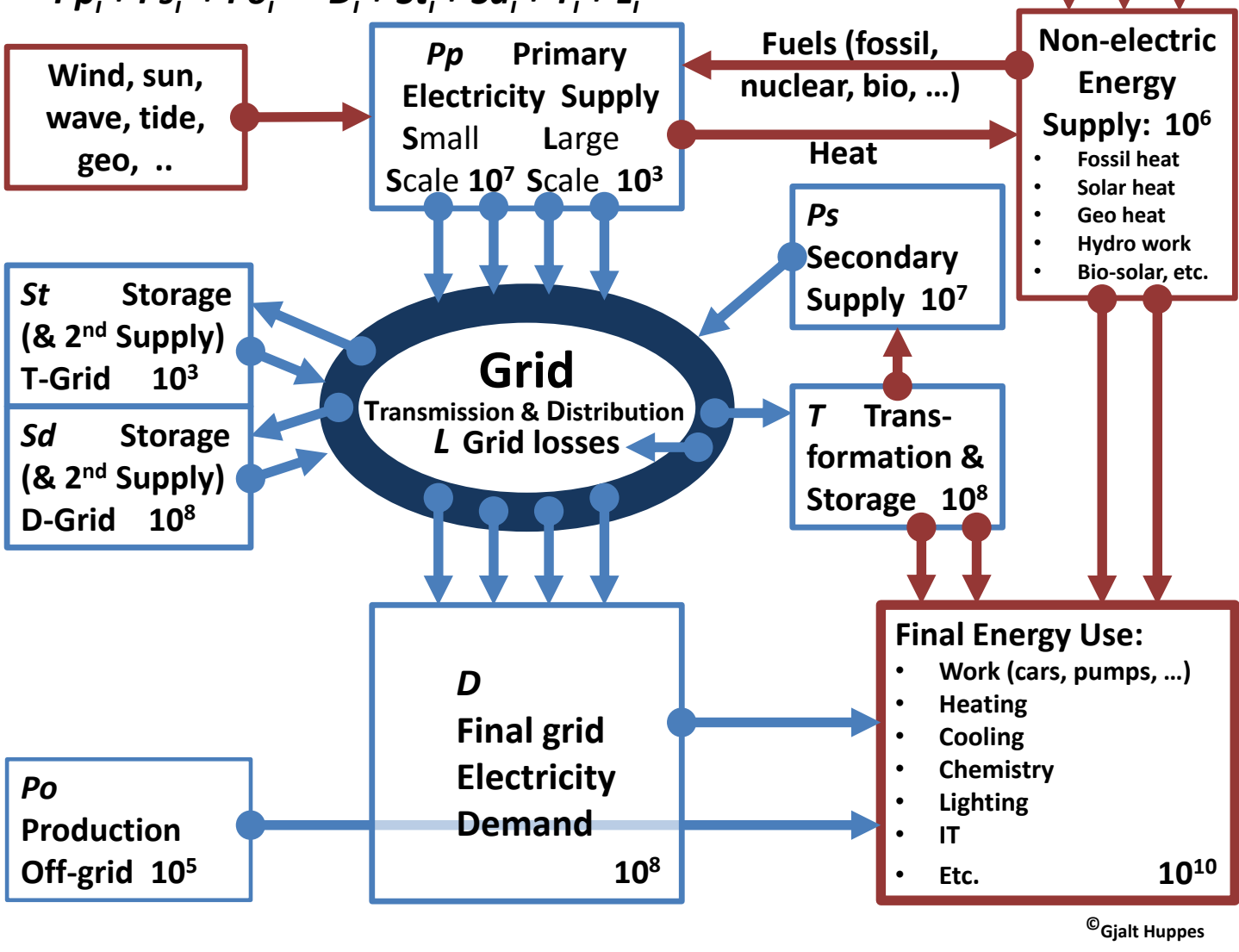

Matching final demand with varying primary supply just is not possible most of the time. Final demand can be spread out in time and can be timed in relation to supply to some extent only. Larger grids can even out demand, like over East-West time zones and can link hotspots in supply 
(like Scottish wind) to areas of demand. Flexible supply options like with cheap natural gas installations with CCS, expensive due to their very small load factor, may be incorporated to help cover low renewables supply periods and also for some special peak demand. But primary supply will have to be stored substantially as well for secondary supply. Technical options are there. But how can the vast number of primary and secondary producers be linked to the vast number of to be variable energy users, and all their internet-linked apparatus? The number of primary and secondary grid producers in Europe will rise from a few hundred at the turn of the century to tens of millions in the next decades, see Figure 1.

Coordination is a most demanding issue for electricity, as supply and demand are to match real time, always. Heat, chemical energy like hydrogen, and power as in pumped hydro can be stored more easily, over days and sometimes even seasons and years. Electricity can be stored in battery systems for more frequent use and hence shorter periods. Many options are there in a technical sense now already and can certainly be improved in the course of time. But what will develop in a technical sense, and what will be implemented in practice cannot easily be predicted. It very much depends on incentives created, by climate policies and other policies, but also on the serendipity of invention and innovation. It is for example not possible now to predict the long term role of hydrogen fuel cells in transport and next in grid stabilization. The design of electricity markets will play a key role in the transformation towards a near zero emission electricity system. There are different views on how this market could be designed, leading to different options.

\subsubsection{Design requirements}

For the large numbers of actors involved the set-up of energy markets, in particular electricity markets plays a key role. Their long term design and their short and medium term development, are always in relation to adjoining policies. The low carbon future is to be bright. The path to that future must be well lighted as well. There are two main requirements to be met also in renewables dominated electricity markets, and linked to other energy markets.

1. Short-term supply adequacy, matching primary and secondary supply and demand real time, as supply and demand must match real time in electricity markets.

2. Long-term supply adequacy, based on investment in primary production, including flexible production; in storage and secondary production ${ }^{15}$; and in spreading out of demand to higher production periods.

Supply adequacy is closely related to supply security, including the prevention of brown-outs. The traditional role of large fossil suppliers in load balancing in wholesale markets will vanish with vanishing fossil shares in production. With the large numbers of small scale primary and secondary producers involved also the concept of wholesale markets becomes obsolete. New market designs are required, quite unavoidably.

Short-term markets set prices. In energy only markets, see (Hogan 2005), these market prices have to cover the average cost of production for all primary producers in order to finance their long-term investments in capacity, then involves scarcity rents Otherwise additional payment is required like capacity payment. In the energy-only market the scarcity rent prices have to be

\footnotetext{
${ }^{15}$ Secondary production is electricity production from stored energy derived from primary electricity production, as with stationary batteries, mobile batteries, pumped hydro, fuel cells using electricity based hydrogen, flywheels, compressed gases, etc.
} 
predictably enough to create the necessary expectations for inducing market based investment, overcoming unavoidable uncertainty as well. The prices have also to be variable enough to finance secondary production and to cover the cost of shifting demand away from peaks towards high supply periods. These two requirements are the overarching ones, for any governance direction. Any design has to fulfill these requirements, with funding based on markets only or also on other payment like capacity payment.

More detailed requirements follow depending somewhat on 'circumstances'. Technologies determine the adequacy of markets. Without short-term flexible decentral secondary production, central facilities will have to be developed, with different market requirements, especially different roles for system operators in matching supply and demand So how markets will function in a technical sense cannot be predicted. Their design is to allow for a broad range of possible technology combinations. If hydrogen fuel cell drives would dominate in transport, their flexible supply of electricity to the grid may solve all intermittency problems in primary electricity production, see BOX 1 . Their low efficiency, if remaining so, then would require markets with high enough price fluctuations to pay for their higher cost, in a market development mode. In a planning mode, a different type of market would be designed and developed, as for example involving capacity payment to assure the availability of enough hydrogen fuel cells. Of course, the hydrogen fuel cell would be acquired primarily for car driving reasons: electricity grid stabilization is a co-product ${ }^{16}$.

The issue of capacity and flexibility has been investigated by (Baron 2015) as chapter 7 in (OECD/IEA/NEA/ITF 2015). There it is assumed that adequate low carbon supply cannot be solely organised on the basis of variable-cost pricing combined with carbon pricing. One solution coming up then is based on some form of capacity payment, as a capital subsidy for being available, replacing production subsidies like feed-in tariffs. Tendering procedures based on average prices then may be required, leading to a market design based on feed-in premiums or Contract-forDifference arrangements. Such subsidies are to be funded by surcharges or more general taxes. However, when going in the direction of capacity payment, the market based option effectively is closed off as the price variability is reduced and average price levels are depressed. But is it indeed impossible to have markets cleared and funded based on usual market mechanisms? There is not much research on this subject, but see for some key aspects (Taylor, Mathieu et al. 2015), who however start from current US circumstances; (Koliou, Eid et al. 2014) who analyze current restrictions on effective trading; (Verzijlbergh, De Vries et al. 2014), who analyze the need for grid congestion pricing; (Verzijlbergh, Grond et al. 2012) analyze the importance of linking electrical vehicles to the grid; and (Brancucci Martinez-Anido, De Vries et al. 2012), who analyze the importance of enlarging EU internal international markets with increasing renewables penetration.

Lifting the assumption that electricity only markets cannot function adequately then requires a view how well-functioning markets might be developed, without the brown-outs and unacceptably extreme market prices as envisaged by (Baron 2015). One most extreme situation to imagine is that there is only intermittent non-dispatchable primary production, disregarding

\footnotetext{
${ }^{16}$ Toyota delivers a separately sold AC power supply unit to its Mirai hydrogen fuel cell car. The drive battery is short term dispatchable and may then cover also short term extreme demand peaks. It cannot yet be connected to the grid directly, as Tesla can.
} 
hydropower and options for other low carbon production like based on nuclear power and fossils with CCS. In this hypothetical extreme, there will be peak final demand with hardly any primary production for several hours during some days, and with production well below daily demand for several days: the White Christmas example. The requirement then is that after flattening out demand, short term demand peaks must be covered by flexible secondary supply with stored electricity and other stored energy like pumped hydro and hydrogen fed fuel cells electricity. In a technical sense this is perfectly possible with current technologies, see BOX 1. Of course there is wide variety of technical options for timely dispatched secondary production. Predicting which ones will emerge is not possible, not just for technical-economic reasons. The design itself of electricity markets will also determine which secondary supply options may come up, and which not. In a feed-in tariffs dominated market heat pumps based heat storage will hardly develop, see BOX 3. With such technical options available, markets may be designed to make use of these options, inducing their technical development, including techniques for real time price reactions. Such long term market development would have prices fluctuating enough to activate the secondary production technologies. At peak production time with low demand all storage and transformation options would be used, and at peak demand with low supply the price would peak and they would deliver. Waiting too long for the really high price would mean running the risk of earning nothing in trade.

\subsubsection{Four main electricity market designs}

With the implementation of the unbundling directive (EC 2013) a clear difference between production, transmission and distribution has evolved and is evolving still. Additional policies are developed as regarding ownership of the transmission grids (EC 2013)and international trade (COM 2015). Although the direction envisaged is clear, there is a wide variety of options to fill in market functioning, regarding the legal set-up of market coordination; the ownership of production and storage facilities; the ownership of the grid; the clearance responsibility (load balancing); and the spatial scale level of transmission grid and also distribution grid. All these dimensions can be filled in in different ways, with three main options specified for each of them, see Table 7. For each of them there is a line from roughly current centralized electricity markets, based on a limited number of main producers for only slightly linked mainly national markets; to a pan-European fully integrated public central market structure with decentral private production and storage and market participation by users; and with some in between options. Real time clearing markets have developed in currency markets, metals and resource markets, some financial markets. They use IT systems for fast decision making, while maintaining a (near) single price for all parties involved. Futures markets might evolve in the case of electricity, to transfer the risk of price fluctuations to risk taking parties. As this opens the route to price manipulation maybe, this is an issue to investigate. If futures trading would be part of the market as created, then also there the question is how to regulate that part of the market to avoid fraudulent manipulation, see (Taylor, Mathieu et al. 2015).

The issue of capacity payment or market based investment funding is left open here. The requirement of capacity payment depends very much on the market design and, not independently, on the development of technologies and their costs. With cheap pan-European long distance high tension DC transport lines; low cost batteries like stored fluid; shared cost batteries as in homes and cars; some additional pumped hydro; more flexible nuclear; and a 
substantial amount of hydrogen fuel cell cars with hydrogen storage; and with flexible use systems as with heat-pump-heat-storage systems, there will hardly be a need for capacity payment. The market incentives as required don't link to one market design specifically by necessity. Without real time equal pricing for all it seems difficult to have such broad development incentivized however, then requiring additional policy instrumentation maybe, like subsidizing heat storage systems. Without substantial variable pricing it seems near impossible to create relevant incentives for primary supply flexibility, secondary supply, and demand variation. The relation of capacity payment to the two governance strategies might seem obvious at first sight. The institutionalist mode goes for electricity only market and the planning and control mode for capacity payment. That is not the case however. There is no strategic reason to go for capacity payment, only a practical-tactical one. Both modes go for the electricity only option, as the most basic and simple solution, in line with other product markets. However, in the Planning \& Control mode the incentives are weaker and then the shift to capacity payment may be more probable than in the Institutionalist mode. The possible short term role of capacity payment is left out of discussion here.

Table 7 Design variables for electricity markets

\section{A. OWNERSHIP OF GRIDS}

\begin{tabular}{|c|l|}
\hline 1. & $\begin{array}{l}\text { Main producers (co- } \\
\text { lown distribution } \\
\text { grid; Others own } \\
\text { transmission grid, } \\
\text { public or private }\end{array}$ \\
\hline 2. & $\begin{array}{l}\text { Transmission grid } \\
\text { as public utility; } \\
\text { distribution grids } \\
\text { public utility, mixed } \\
\text { ownership }\end{array}$ \\
\hline 3. & $\begin{array}{l}\text { Transmission grids } \\
\text { publicly owned; } \\
\text { distribution grids } \\
\text { publicly owned. } \\
\text { Double unbundling }\end{array}$ \\
\hline 4. & $\begin{array}{l}\text { Transmission grids } \\
\text { publicly owned; } \\
\text { distribution grids } \\
\text { publicly owned. } \\
\text { Double unbundling }\end{array}$ \\
\hline
\end{tabular}

B. OWNERSHIP OF PRODUCTION \& STORAGE

Few main producers own all large scale installations Grid owners own large scale storage, possibly also private producers

Fully decentral private ownership of primary and secondary production Fully decentral private ownership of primary and secondary production
C. MARKET COORDINATION \& CAPACITY

\section{Contractual with} central suppliers market; also distribution grid funded Mixed contractual, and short term open markets; also distribution grid funded

Mixed contractual, and short term open markets

Pure real time market; as public good exceptional swing capacity
D. Clearance RESPONSIBILITY

E. SPATIAL SCALE LEVEL

\begin{tabular}{|l|l|}
$\begin{array}{l}\text { Main swing } \\
\text { producer(s), } \\
\text { with } \\
\text { transmission } \\
\text { grid owners }\end{array}$ & $\begin{array}{l}\text { Regional } \\
\text { transmission and } \\
\text { distribution; } \\
\text { bilateral } \\
\text { international trade }\end{array}$ \\
\hline $\begin{array}{l}\text { TSOs, } \\
\text { coordinating } \\
\text { main producers }\end{array}$ & $\begin{array}{l}\text { Some } \\
\text { international } \\
\text { transmission; } \\
\text { national/ regional } \\
\text { distribution }\end{array}$ \\
\hline $\begin{array}{l}\text { TSOs, } \\
\text { coordinating } \\
\text { main producers }\end{array}$ & $\begin{array}{l}\text { Supranational } \\
\text { main transmission; } \\
\text { national/regional } \\
\text { transmission and } \\
\text { distribution }\end{array}$ \\
\hline $\begin{array}{l}\text { TSO(s), through } \\
\text { market } \\
\text { mechanism }\end{array}$ & $\begin{array}{l}\text { Supranational } \\
\text { main transmission; } \\
\text { national/regional } \\
\text { transmission and } \\
\text { distribution }\end{array}$ \\
\hline
\end{tabular}

The market coordination can be mainly contractual, between main producers, but contracts may also leave some room for short term market mechanisms, and contracts may be fully abandoned, the relation between supply and demand being a matter of market mechanism only, as in many spot markets now. The market structure in production and storage may be privately oligopolistic, with a few main producers; may involve grid owners for large scale storage; or all ownership in primary and secondary production may be purely private. Similar structures pertain to the 
transmission and distribution grids, ranging from private ownership of the distribution grid and, separated, the transmission grid; to operating these grids privately as public utilities; to publicly owned transmissions and distribution grids. The way grid use is priced will differ fundamentally between these options, ranging from profit and funding to congestion pricing. The special characteristic of the electricity market is real time clearance at any moment in time, to be somehow organized. Main swing producers can have that responsibility, coordinated by the transmission system operator (TSO); or the responsibility is fully with the TSO per region, actively trading in capacity; or the TSO is a market follower, facilitating the working of the market only. Finally, the market evolving may be national with international bilateral linkages; may be organized internationally between regional TSOs; or it may be a fully international market, based on the public international transmission infrastructure.

Spatial scale level and uniformity are main dimensions for designing electricity markets, closely related. Without uniformity higher spatial scale levels are difficult to effectuate. And with uniformity there are still additional requirements for establishing EU level markets. The extremes are low spatial scale level and differentiated markets and high spatial scale level with uniform markets. Similarly, a substantial role for large swing producers seems difficult to reconcile with a pan-European electricity market. So permutations along the dimensions don't deliver feasible options; a typology of roughly matching combinations is most useful, spanning the space from current national/regional fragmented markets to a real time integrated European market. Four market types may cover this field: wholesale markets dominated by swing producers; fully unbundled national markets with bilateral international relations; full unbundling with a public EU international transmission grid; to a single priced European electricity market, with real time equal prices for all primary and secondary producers and for all users on the same conditions.

From a climate perspective, main differences relate to how decentralized renewables production; centralized and decentralized storage; and final use load shaving can be incorporated; and to how long distance grid balancing can be incorporated in the future mostly fossil free electricity system. The four market designs may also be seen as consecutive steps towards the Single European Electricity Market. The publicly also EU owned international grid, number 4, allows for an open to all real time single priced European electricity market, with congestion pricing of all grids.

General preparatory work for developing electricity markets in technical sense is well under way, especially by ENTSO-E and in a more political sense in the European Electricity Regulatory Forum, relevant for all four market designs.

Table 8 Four main types of electricity markets

1. Swing Producers Market, limited links bi-nationally

2. National Unbundled Markets, public Transmission grids, linked bi-nationally

3. Unbundled Markets with EU High Tension Grid, EU/multi-nationally owned

4. Single Priced European Electricity Market, real time, market balanced

The market designs are linked to the long term. However, with the limited amount of renewables currently on the European market, there already are periods in regional markets where producer prices are near zero, making the operation of gas and coal fired power stations less attractive and reducing investment in capacity. Emission pricing, high enough and long term predictable, would create an incentive for investment in renewables. These renewables have periods of limited 
capacity however, somehow to be supplanted then with other production sources, primary or secondary, for balancing market real time. The different market designs may deal differently with this basic problem for the long term. The low marginal cost issue will be discussed in a separately, in section 4.4.4.

\section{Swing Producers Market}

This is roughly the situation the EU is currently in, after implementation of the Unbundling Directive. This market design may be adequate in a planning and control mode of climate policy.

\section{1.a Ownership of grids}

The national distribution grids are owned and operated in close cooperation between major swing producers and the national grid operators, with room for traders and local authorities.

The national transmission grids are publicly operated by transmission system operators. They may be fully or partly publicly owned.

The international transmission grids may have substantial mixed ownership by transmission system operators (TSOs), main producers and main storage providers, and may include partners like capital providers and public bodies.

Physical grid capacity at all three spatial levels is based on cost minimization within regulatory boundaries as also regarding security of electricity supply. Grid pricing is based on cost recovery, and preferably more than that.

\section{1.b Ownership of production and storage}

Primary and secondary electricity production is mostly private, but not necessarily so, as with (partial) public ownership of producers as by communities. Large scale storage capacity is partly with main producers and partly with transmission system operators, and with combinations also involving other parties.

\section{1.c Market coordination and capacity}

\section{Trading rules}

Pricing is controlled by grid operators based on public rules and public contracts, as on feed-in tariffs and premiums and payment of surcharges differentiated as to users. There is substantial market price differentiation between sellers, as with supported renewables and secondary delivery to the grid, and between buyers, with some firms paying lower prices, as being exempted from surcharges. As such systems differ between member states international trade is restricted, with hence limited trade between member states.

With price signals not equal for all producers and end users, several market mechanisms function to a limited extent only, as with heat pumps for heat production and storage, see BOX 3 .

International trade is between large producers, swing producers and balancing service providers, and national grid operators, linked internationally in mostly binational European transmission markets.

Electricity transport pricing

Pricing of national electricity transport infrastructure is implicit in the wholesale and retail price received by main producers involved in distribution networks. All producers are connected to the grid at the site of production. For international transport it depends on the contract form, with pricing invisible for actively trading international grid operators and implicit in prices with time specific capacity sold in such capacity use prices.

The electricity transport price is part of the buyers' price, implicit or not. 


\section{Capacity availability}

Owning distribution grids, with some control on prices, provides some of the funding for the capacity requirements. However, direct capacity payment will also be required for maintaining long term total capacity and balancing capacity.

Capacity availability depends on investments, these in turn depending on the average price a producer may expect to receive. There are permanent subsidies for all technologies, as capacity payment or other investment or production subsidy. Additionally, there are temporary subsidies for creating new technologies' learning curves. These subsidies to be unified as much as possible. Also, they are to shift away from on-market-price support as much as possible; and are less to be funded by surcharges differentiated between user types for markets to become more integrated. This requires some EU level regulation.

\section{1.d Clearance responsibility}

Grid balancing is the combined responsibility of the grid operators and the central swing producers. Swing producers accommodate to market demand real time, with wholesale markets organized by grid operators. Based on response time, markets with different time horizons are organized. Swing production is mainly by natural gas fired power stations, and shifting to large scale storage like hydro, and to a limited extent to other production like solar heat electricity and (made more flexible) nuclear.

There are open contractual relations with larger users for demand peak shaving. Demand peak shaving with smaller end users is based on standard contractual relations, with price differentiation based on day time and season, and obligatory smart meters as required for this purpose. Decentral production, as for example with fuel cell electricity from cars, cannot be combined with return delivery to the grid at fixed/standard consumer prices, and certainly not with feed-in tariffs. Aggregation of users, like fleet owners of electric vehicles, may lead to contractual price differentiation to support market clearing. With such instruments in place grid delivery based on decentral production is to be specifically regulated and measured, or capped, or forbidden, depending on circumstances.

\section{1.e Spatial scale level}

Distribution grids are regional, nearly fully dependent on regional/national transmission grids. International transmission grids are operated mostly bilaterally between two transmission system operators and their partners. The operators earn on market equilibration either by trading directly or by selling peak capacity on the transmission lines.

\section{1.f Emission pricing}

EU emission pricing - if present - reaches main fossil producers in a clear form, as in the current ETS. Contractual electricity prices for users don't differentiate between higher and lower emission production sources and so reduce the emission price signal for down-stream actors, even if the cost of emission pricing are passed on in the aggregate.

\section{National Unbundled Markets, public TSO, linked internationally}

This may roughly be the situation the EU is in after implementing the ideas of the Energy Union.

\section{2.a Ownership of grids}

Distribution grids are regulated as a public utility, with substantial but not exclusive public ownership by lower level governmental organizations. 
National/regional transmission grids are operated as public utilities, mostly publicly owned and not involving producers, also not indirectly.

International transmission grids are publicly owned by one or more transmission system operators, excluding co-ownership of producers of private parties but possibly involving other public organizations.

\section{2.b Ownership of production and storage}

Primary production is fully private. Secondary production is private mostly, large scale facilities also owned by larger primary producers. Exceptions relate to grid balancing activities of TSOs in an international context. Public bodies may be involved in production and storage, then acting similar to private producers.

\section{2.c Market coordination and capacity availability}

Trading rules

Pricing systems depend on regulations substantially, with wholesale markets playing a key role not so much in price setting for users but for load balancing. Main producers and organizations of smaller producers operate on markets with different time horizons to allow for volume planning, guided by the TSO operant in the region.

Pricing is market based within substantial constraints of public regulations, as on feed-in tariffs and premiums and payment of surcharges differentiated as to users. There is substantial market price differentiation between sellers, as with supported renewables and rules for secondary delivery to the grid, and between buyers, with sensitive firms paying lower prices, as being exempted from surcharges. As such systems differ between member states international trade is restricted. With price signals not equal for all producers and end users, several market mechanisms function to a limited extent only, as with heat pumps for heat production and storage, see BOX 3.

Electricity transport pricing

Pricing of transport is diverse, as capacity pricing and other pricing are not integrated. Capacity availability

Capacity payment is required to keep enough capacity available in periods of low renewables production. Renewables also receive subsidies. But due to their low marginal cost they will produce whenever they are allowed to and cannot function as back-up.

\section{2.d Clearance responsibility}

Grid balancing is organized by transmission system operators in wholesale producer markets and by direct regulation in renewables markets to prevent overloading of the grid. Clearance involves international trade, partly controlled directly by TSOs, and partly in the bidding procedures similar to the national clearance procedures.

There are open contractual relations with larger users for demand peak shaving. Demand peak shaving with smaller end users is based on standard contractual relations, with price differentiation based on day time and season, and obligatory smart meters as required for this purpose. Decentral production, as for example with fuel cells from cars, cannot be combined with return delivery to the grid at fixed/standard consumer prices, and certainly not with even higher feed-in tariffs on renewables. With such instruments as part of the market, grid delivery based on decentral secondary production is to be specifically regulated and measured. At times decentral production will be capped or forbidden.

\section{2.e Spatial scale level}


International grids are mostly operated bilateral, except possibly for some long term base load contracts. Multinational market clearance is not possible in this market set-up.

\section{2.f Emission pricing}

EU emission pricing - if present - reaches all fossil producers in a clear form. Contractual and regulated prices diminish the working of the price signal to users as very low renewables prices and very high fossil prices as also due to emission pricing are not or not fully conveyed to them.

\section{Unbundled Markets with EU High Tension Grid}

This may be the situation required for effectively implementing the ideas of the Energy Union.

\section{3.a Ownership of grids}

The ownership of grids is fully public. Lower levels of government own the distribution grid in their area. Transmission grids are mostly nationally owned, with possibly regional splits within countries and co-owned bi-national transmission grids. The multi-lateral international grid is publicly owned by EU and possibly co-owned by a consortium of national public bodies, like TSOs 3.b Ownership of production and storage

Primary production is fully private, with no market power for large primary and secondary producers in the regionally enlarged market.

\section{3.c Market coordination and capacity availability}

\section{Trading rules}

Pricing is based on uniform codes to allow for similar market conditions concerning all TSOs and all bidding procedures. The market size is substantially expanded in a multi-country (or better multi-TSO) trading context. The responsibility for grid balancing remains with single TSOs, who use the same techniques as in option 2 National Unbundled Markets. However, the broader trading options bring in more parties and the link between larger producers and distribution ownership is severed. This makes producers more equal in the supply market, including smaller ones.

\section{Electricity transport pricing}

Pricing of the EU wide HT grid (mostly DC) is based on congestion avoidance, to avoid the perverse incentive of creating congestion to raise revenue. High priced grid nodes are the ones where investment is due. High tension grids administered by single TSOs, mostly concerning one country, are based on congestion pricing or similar. Whatever the national choice is, it should be implemented real time.

For the distribution grids under the national high tension grid(s) similar congestion pricing is involved, not just for downloading but also for uploading. Transport pricing is explicit, as opposed to pricing in type 1 and 2.

Details of this real time congestion pricing arrangement are to be developed.

Capacity availability

Capacity payment may start substantial but is phased out long term. When private fossil producers have mostly left the market (with full CCS for the remainder), market clearance may become a serious problem in periods of very low renewables production, as with the Long White Christmas. Secondary production capacity then is required at a very substantial scale. This might develop privately, as for example with hydrogen fuel cell cars, but then not for electricity market reasons but for car driving reasons. Getting enough reserve capacity on line for such exceptional situations then remains as a public task, like having enough near mothballed gas fired power 
stations available. The distribution of mainly mothballed capacity over countries, and linked to that the funding of such infrastructure, is to be resolved at EU level.

\section{3.d Clearance responsibility}

Grid balancing remains the task of individual TSOs, through dealing contractually with many producers and users, with short term markets becoming more dominant and some direct price volume mechanisms being implemented with specific users and groups of users. Deployment of the public backstop capacity is the responsibility of each TSO.

\section{3.e Spatial scale level}

International grids link all TSOs. Long distance DC transport allows for also economically relevant long distance transport volumes, between different time zones east - west and climate zones mainly north - south, and both focused at major use centers. The international grid is operated collectively by a body formed of TSOs and EU public organizations.

The national grids are operated by public TSOs and the distribution grids by local public bodies or also by the TSO.

\section{3.f Emission pricing}

EU emission pricing would reach all fossil producers in a clear form. Contractual and regulated prices, though limited in importance, diminish the working of the price signal to users as very low renewables prices and very high fossil prices as also due to emission pricing are not or not fully conveyed to them. At periods of close to zero market prices, the emission price could lead to a negative proceed for fossil producers, who then may decide not to produce.

\section{Single Price European Electricity Market, open, real time}

This pan-European market creates equal access to all primary and secondary producers and to all intermediate and final users, and plays a key role in the functioning of other energy markets, see Figure 3.

\section{4.a Ownership of grids}

As in market version 3, the grids are fully publicly owned. The international EU grid is owned by a consortium of primarily EU and all participating national TSOs. The (mostly) national HT grids are publicly owned and operated by TSOs as public bodies. The distribution grids may be owned by more local governments but may be made part of the national grid system, under the national TSO (or TSOs).

\section{4.b Ownership of production and storage}

Primary and secondary production are fully private, apart from public reserve capacity for calamity type of exceptional situations, like the Long White Christmas.

\section{4.c Market coordination and capacity availability}

\section{Trading rules}

Pricing is fundamentally different from the three other market types, being fully based on real time open market pricing. There is no difference in pricing and access between small and large producers, nor between primary and secondary producers, and neither between national and foreign (EU) producers. In terms of climate policy there is no price support for specific producers or production technologies, and only incidental short term investment subsidies for novel technologies to create learning curves. There is no price differentiation between different user 
groups, be they firms of private consumers. At a certain very high price point public backstop capacity is brought in, leveling off the price peak.

Electricity transport pricing

Transport pricing is congestion based. Investment in transport capacity is in the highest priced nodes, as public infrastructure investment. Details of pricing methods are to be developed. This is similar to congestion pricing in road transport. Transport pricing is explicit, as opposed to pricing in type 1 and 2.

Capacity availability

Capacity payment would bring down prices so much that capacity payment is required as a permanent subsidy. This is to be avoided fully in this self-financing market version; capacity payment is to be reduced to zero on short to medium term notice, to allow for the build-up of the long term open market.

\section{4.d Clearance responsibility}

Grid balancing is purely market based, except for the calamity type of backstop capacity brought in every few years or so. Market stabilization under exceptional circumstances can be considered a public good, see (Finon and Pignon 2008), with provision of that capacity as a public infrastructure investment. Clearance responsibility is basically in terms of orderly market provision however, including checks on fraudulent market participation. The clearance responsibility is in terms of the single price at the international grid and at the national grids. Clearance may be uniform for the whole EU. Detailed market design is required.

\section{4.e Spatial scale level}

The international transmission grid, with adequate capacity, allows for a single European market at uniform conditions. Combined with market rules this is a centerpiece for European climate policy in the Institutionalist Strategy for climate policy instrumentation.

\section{4.f Emission pricing}

EU emission pricing, here certainly present, is fully incorporated in all pricing, as far as open markets may go. At very low price periods fossil producers may have negative proceeds and may then decide not to produce.

These four designs for the electricity market may first be seen as independent from climate policy instrumentation, for example as part of European market unification. There are a few strong linkages with instrumentation however. Technology specific instrumentation with instruments like feed-in tariffs for renewables, and other subsidies like production premiums and capital subsidies lead to further capacity payments and make market functioning as in type 4 Single Price European Electricity Market impossible. As most of such subsidy schemes are national, they increase international transport complexities. The link of the Planning and Control strategy is therefore is with type 1 Swing Producers Market, with the option to move to type 2, and maybe to type 3 if there is pressure from other domains, but never to type 4 . Conversely, in the Institutionalist strategy, the logic is to link to Type 4, which stimulates all options for technology development with national and lower government levels, with firms and broader with civil society. Type 3, Unbundled Markets with EU High Tension Grid, might also be somewhat adequate but second choice. Type 1 and type 2 would substantially prevent broad emission reducing incentives in downstream activities, requiring additional technology specific measures, then moving from the Institutionalist to the Planning \& Control mode of governance. 
Smart meters would function very differently in the different market set-ups. In type 1 and 2, and maybe also type 3, they may be introduced obligatory, to force some flexibility into the market. Functioning would be based on contractual price differentiation over fixed periods of the day and with maybe some further differentiation over seasons and holidays. Contractual relations with large users would allow for a differentiated reaction related to actual supply - demand mismatches. In a single variable price for all market design, type 4, users and producers want to know the actual price, to avoid use at peak prices and increase production at peak price times. They will go for the best smart meters, best linked to their wishes in the internet of things, and with a specific form of smart grid resulting.

\subsubsection{Zero marginal cost considerations}

With a high share of renewables zero short term marginal cost, in any of the market types distinguished the producer price may fall to close to zero. With price support for small scale secondary production the primary producers will be driven out of the market. If this occurs regularly, some form of payment will have to compensate for the subsidized secondary production and the more so if part of primary production is subsidizes as well. Such detailed market correction, probably involving capacity payment, may be the consequence of choosing for market type 1 or 2 . The question here is how a well-designed pan European market, type 4, can deal with the characteristics of relevant renewables, solar, wind, tidal and wave. In that market form there is no difference between wholesale and small scale markets: there is only one market. The problematic characteristic of these renewables is that they have near zero short term marginal costs, and also are non-dispatchable; and are unpredictably intermittent on different time scales. Substantial secondary production may be required for balancing the grid, next to flexible primary production and demand reaction to prices.

The overall market price cannot lead to zero cost market prices however, as these market prices involve transport costs and scarcity rents due capacity restrictions while secondary production will also be above zero short term marginal cost as first primary production is to be acquired. Long term marginal costs involve the capital outlays involved and cannot be negative. The assumption by (Rifkin 2014) that zero marginal costs will lead to zero prices, heralding the end of capitalism, seems exaggerated at least. The experience with near zero marginal cost systems is substantial. Hotels, airplanes, oil and gas production, etc. all have near zero short term marginal costs. Similar holds for secondary production. Battery charging and de-charging and pumped hydro have near zero short term marginal costs but substantial opportunity costs: you can discharge only once and then have to charge again, at expected market price. They also have substantial capital costs, to be repaid from the difference in charging and discharging prices. Decisions on entering markets and investment decisions for existing firms are not based on short term marginal costs but on long term marginal costs, which include the costs of capital and its maintenance, and on long term expected proceeds. For the producers involved there is market supply matched with market demand, with expected price profiles coming out. If these expected prices do not cover expected long term marginal costs, investments will not take place. The capacity will not rise or go down and the price will go up. There are of course other considerations determining investments, but 
going for a loss is certainly quite seldom for private firms. Levelized cost are not relevant in this context, see (IEA/OECD 2015) ${ }^{17}$.

The price structure is to be high enough on average for justifying investment. This requirement holds for any producer in the market, from nuclear to wind. In dark times with no wind electricity prices will jump, with other primary but also all secondary coming in. Though secondary production as from batteries has zero short term marginal costs, battery owners will not dispatch if they expect prices to rise further; there are opportunity costs involved. The scarcity price may substantially be above the short term marginal cost price of the marginal producers.

There is not limit on the volumes of electricity involved, no limits to the share of renewables and there are hence no boundaries on emission reduction as related to short term zero cost nature of most renewables. The issue is to be resolved through capacity payment leading to some sort of production planning or through market mechanisms leading to a scarcity rent also for marginal producers. The speed of emission reduction will of course depend very much on the effective emission price as may be realistically expected.

\subsubsection{Energy storage and market stabilization: the heat pump example}

The low to zero marginal cost systems in primary production do not react to price shifts, unless the price becomes near zero. With shut-down and start-up costs, producers may even produce for negative prices. In a more developed situation, however, spread-out use, storage and secondary supply will stabilize prices. If at peak production and low demand the price becomes very low, heat pumps will start up to store heat, transformation processes as to hydrogen will speed up, all battery systems will start loading and delayed machines will start again like washing machines and dryers. This will happen well before the price is zero and hence the price will not drop to zero. Of course overinvestment with overcapacity will have a downward pressure on prices with low marginal cost systems. This has structurally been the case in aviation where governments tend to pay for losses of their flagship airlines.

\section{Heat pumps based heat storage systems}

Heat pumps with seasonal heat and cold storage are one option to decarbonize heating and cooling of buildings, if based on emission free electricity. Heat pump heat storage systems can help stabilize the grid over periods ranging from hours and days to seasons. It does not matter when exactly they are fed. They avoid the efficiency loss of electricity storage systems like battery and pumped hydro, which are in the order of 15 to $30 \%$.

In the Swing Producers Market, with solar PV electricity delivered to the grid at feed-in tariff prices or only tax and surcharges raised end-user prices, heat pumps face that price competition. As long as natural gas and also oil and butane/propane are available for heating of buildings, these fossils also compete with heat pumps, the more so the lower taxes and emission pricing are. Nonpredictable emission pricing makes investment in heat pump systems less attractive.

Heat pump based heating and cooling systems can come substantially into the market by technology specific policy instrumentation. Options are to subsidize them or to force them into

\footnotetext{
${ }^{17}$ See their statement in Chapter 2: “... LCOE is closer to the real cost of investment in electricity production in regulated monopoly electricity markets with regulated prices rather than to the real costs of generators in competitive markets with variable prices." This situation does not exist anymore, also not in the US where this method of pricing was near universal.
} 
the market. This then can be measures like forbidding natural gas and other fossils based heating, (as has been done in Denmark for countryside gas use), or more stringently, by prescribing heat pumps, for new buildings, for renovated buildings, or also when renovating the heating system. The situation is still similar in the National Unbundled Market, with contractually differentiated user prices combined with user-price based prices for delivery to the grid.

BOX 3 Heat pump investment under different electricity market regimes and $\mathrm{CO}_{2}$ emission prices Beware: This is not a prediction but an investigation of one corner of feasible technologies relevant for climate policy instrumentation.

An investment decision on heating and cooling systems for apartments is between heat pumps and underground storage and gas heating plus optional air conditioning. The heat pump would be driven by solar PV electricity. What will a wise investor do? That depends on the electricity market and on emission pricing, given the technologies as are available. (Roughly current situation in the Netherlands.) Market situation one is a fixed price for delivery back to the grid of $€ 0.25$. With a feed-in tariff the delivery back price would be higher. The second market situation is when producers of electricity receive producer prices, real time market based. That price will vary substantially but will be low for a substantial share of PV production, then used for driving the heat pump. The low electricity price is not influenced by emission pricing; the highest price levels might be. For the natural gas based system the price per cube is influenced substantially by the high emission price of $€ 300$ per tonne $\mathrm{CO}_{2}$, creating a price rise from $€ 0.60$ to $€ 1.15$ per $\mathrm{kWh}$. Induced market mechanisms would reduce that price somewhat.

The investor would compare the costs and proceeds, as in Table 9. The outcome is that with the high delivery back price the investor will always choose for gas heating, even with the high emission price of 300 Euro per tonne $\mathrm{CO}_{2}$. Yearly cost are $€ 1580$ for the gas system against $€ 1755$ for the heat pump system. With the low price for delivery to the grid (and similar for a low variable price from the grid) the choice is clearly for the heat-pump with heat and cold storage, even without any emission pricing. It would be €831 for heat pump system against €920 for the gas system without emission pricing, and $€ 1580$ with the high emission pricing.

The reasoning is based on decentral solar PV, funded by a partially high grid price, see the table. Grid connected renewables systems would favor heat pumps in the same way, with renewables based electricity production possibly at lower real costs than on apartment blocks. This holds however only under adequate market arrangements: real time variable market prices, equal for all.

Current electricity market arrangements as with net metering and more severe with feed-in tariffs, intended to incentivize solar PV, imply that building heating gets stuck to fossils for decades to come. Additionally some air conditioning can be expected for cooling, which is covered in the heat and cold storage system already. A variable market price equal for all producers and users would not only fund the solar PV installation but also the zero emission heat pump with heat and cold storage system. Of course a carbon tax would make that option even more attractive. Having the zero emission heat pump system under currently usual electricity market arrangements could be induced by very extreme emission pricing, well over 300 Euro, required on short notice. A second option is to subsidize not only the solar PV but also the heat pump with storage system. A third option is to regulate heating systems, as advocated by the (IEA 2015) in its analysis of energy using and producing products. This IEA approach would fit in an extreme technology specific governance mode. 
Table 9 Heat pump with heat storage under different electricity market designs and emission prices

\begin{tabular}{|c|c|c|c|c|c|c|c|c|}
\hline \multirow[b]{2}{*}{ Per year: } & \multirow[b]{2}{*}{$\begin{array}{l}\text { Capital } \\
\& \\
\text { mainte- } \\
\text { nance }\end{array}$} & \multirow[b]{2}{*}{$\begin{array}{l}\text { Electricity } \\
\text { kWh } \\
\text { (efficien- } \\
\text { cy 300\%) }\end{array}$} & \multicolumn{3}{|c|}{ Electricity costs per kWh: } & \multirow[b]{2}{*}{$\begin{array}{l}\text { Gas m3 } \\
\text { (efficien- } \\
\text { cy } 105 \% \text { ) }\end{array}$} & \multicolumn{2}{|c|}{ Gas costs per m3: } \\
\hline & & & $\begin{array}{l}\text { Deliver- } \\
\text { back } \\
\text { price }\end{array}$ & $\begin{array}{l}\text { Variable } \\
\text { market } \\
\text { price (also } \\
\text { if } \mathrm{CO} 2 \\
300 € / \mathrm{t})\end{array}$ & & & $\begin{array}{l}\text { Current } \\
\text { price; no } \\
\text { - emision } \\
\text { pricing }\end{array}$ & $\begin{array}{l}€ 300 / \\
\text { tonne } \\
\mathrm{CO}_{2}\end{array}$ \\
\hline Energy prices & & & 0.25 & 0.05 & & & 0.60 & 1.15 \\
\hline Natural gas heating & 200 & & & & & 1200 & 720 & 1380 \\
\hline Fixed cost delivery & & & & & & & 50 & 50 \\
\hline \multirow[t]{2}{*}{ Total yearly cost $(€)$} & & & & & & & 920 & 1580 \\
\hline & $\mathrm{kWh} / \mathrm{m3}$ : & 11 & & & & & & \\
\hline Heat pump \& storage & 600 & 4620 & 1155 & 231 & & & & \\
\hline Total yearly cost $(€)$ & & & 1755 & 831 & & & & \\
\hline Solar Panels & kW: & & & & $€:$ & \multicolumn{2}{|c|}{ kWh per year/Wpeak } & 900 \\
\hline 40 panels of $250 W_{\text {peak }}$ & 10 & & kWh: & Costs pa: & 1100 & \multicolumn{2}{|c|}{ Installing 40 panels } & $16000 €$ \\
\hline \multirow[t]{2}{*}{ kWh per year total } & 9000 & To grid: & 4380 & 0.25 & 1095 & \multicolumn{2}{|c|}{ Converter replace } & $2000 €$ \\
\hline & & Own use: & 4620 & 0.00 & 0 & \multicolumn{2}{|c|}{ Maintenance / year } & $380 €$ \\
\hline
\end{tabular}

Moving to the Single European Electricity Market, or the Unbundled Market with EU DCHV Grid, will change the situation substantially in favor of heat pumps. Producer prices, both primary and secondary, are becoming equal for all producers, net of transport cost and taxes and (expiring) feed-in-tariffs and their surcharges. Heat pumps operate when prices are low, not just because of own solar production but because of all peak production at low demand times. Heat pump use receives competition from all other storage systems, be they own storage of own production, other decentralized storage or central storage. Together they reduce price volatility and reduce very low price periods, linked through the energy markets as created.

\subsection{EU instruments, EU induced instruments and Member State instruments}

The focus here is on EU climate policy. The total of instruments covers EU level of instrumentation and Member State level instrumentation, the national level induced by EU requirements and also based on national and subnational initiatives without direct EU influence. Indirectly, the EU also has an influence through the setting of national targets. The most visible and substantial movement towards emission reduction have been implemented by independent nationally developed instruments. Feed-in tariffs have been developed in Germany, with a leading role by Scheer, and are applied widely in the EU, and beyond. Investment in wind power is based on national subsidies, including feed-in tariffs, feed in premiums and similar, and investment subsidies. Tax advantages and other subsidies for electric and hybrid electric cars at national level have played a major role in their introduction, with EU Fleet Standards becoming effective only 
recently, with improvements in performance measurement upcoming ${ }^{18}$. The EU instrument flag ship, the ETS, has been hampered by an ineffectively low price, partly due to the successful national programs in renewable energy.

Current instruments and their interrelations have been investigated for the EU in (Drummond 2013), with country level studies adjoining in separate studies. That analysis shows in detail how instruments interrelate but at a more detailed level than is applicable for the grand design in instrumentation developed here. Specifically, the interaction of the Renewable Energy Directive (RED) and the EU ETS are cost-inefficient regarding centralized electricity production as emission permits can shift to other member states and other sectors (Drummond 2013), p91. However, the redesign of emission pricing towards price stabilization would reduce the opposition, as in the market Stability Reserve where the amount of permits is reduced if there are too many in the market. The line of development towards price stabilization is followed here. Also, EU climate policy has mainly left the multiple target set-up with separate renewable energy targets (COM 2015), as it does not matter so much how emissions are reduced; GHG emission reduction is the overall goal. Long term instrumentation strategies should reckon with interrelations and avoid counteracting and cost increasing instrumentation in the design stage as much as possible. Stabilized emission pricing and avoiding all emission pricing are basic strategic solutions to incompatibility, with both options having been developed here in some detail in Section 4.3.

The four main approaches to emission pricing as distinguished differ in how the EU and national levels interact. Without emission pricing, most instruments will function nationally, partly induced by EU policy frameworks. All emission pricing schemes are encompassing over all fossil $\mathrm{CO}_{2}$ emissions, and possibly also covering some non- $\mathrm{CO}_{2}$ emissions. Emission trading systems have as a consequence that national targets become somewhat unspecified. Countries, that is the owners of the permits in a country, may sell emission permits to other legal entities in other countries for permitting installations there, shifting emissions to these other countries. Administratively these shifts may be noted but long term policies will not reckon with such past shifts, making national targets at least less easy to determine with simple criteria. With increased international trade in electricity and base industrial products shifts in hidden flows may also become substantial. These transboundary shifts mean that governments effectively lose control over what were "their" domestic emissions. Of course their national climate policy instruments apply to their remaining national emissions only.

The pure cap-and-trade system, encompassing all $\mathrm{CO}_{2}$ emissions long term and being the effective instrument, makes national policies and other decentral actions quite irrelevant. They cannot influence emissions at EU level, as these are determined by the fixed cap. If the cap is adapted if prices are deemed too low or too high, the pure cap system becomes a hybrid cap. The hybrid cap system and the emission tax have a converse effect; they stimulate national actions, by making them economically more attractive. These differences are so substantial that they are laid down in some detail in the sector specification of policy mixes, starting from these pricing options. In specifying EU instrumentation it is not possible to go into detail of what national policies might be, different between countries. The specifications of instrument mixes are made based on

\footnotetext{
${ }^{18}$ The NEDC (New European Driving Cycle) has a rising difference between norm measurement and actual emissions and may be replaced by WLTP (Worldwide harmonized Light vehicles Test Procedures), initiated by the EU in UN context. Optimizing for test results would then start anew. Real life measurement comes up in discussions now as an alternative.
} 
covering most emission sources, with some instruments clearly operant at EU level, and others in a general sense assumed operant at member state level. Adjoining instruments may be set up at EU level, may be induced from an EU level, or may be thought of as bottom-up developments. Such option on centralization and decentralization are analyzed in a parallel project report, D6.3 (Markandya, Rey et al. 2015).

\section{Instrument mixes for four emission pricing options and four main sectors}

The four broad sectors distinguished cover the total of fossil based $\mathrm{CO}_{2}$ emissions, very similar to the four main sectors distinguished in (IPCC-AR5-WGIII 2014). There is current climate policy instrumentation in these four main sectoral domains, which is to be adapted and expanded for the future deep emission reduction task. Options for instrumentation development include a mix of the main instrument types.

- Institutional framework as the fabric of society, including internalization of external effects, like in emission pricing with cap or tax systems, and organization of markets like for electricity and more generally for energy.

- Public and public-private infrastructure, ranging from transport infrastructure and energy infrastructure to city infrastructure, covering also spatial planning and implementation.

- Options creation as through research, R\&D and demonstration projects.

- Instruments regarding private parties include information instruments to clarify markets; financial incentives including specific subsidies and taxes and surcharges of all forms to incentivize specific technologies and behavior; and regulations, like standards involving prescriptions and prohibitions.

Design of future instrument mixes may be approached as a permutation exercise, adding all mutually exclusive variants per instrument type to one starting instrument, and then choose the best based on an evaluation procedure. There are for example many options for emission pricing (at least 20 in Table 4); many options for technology support, difficult to count even; many options for introducing specific technologies; and many options for market development as for electricity markets. Hundreds and more of possible mixes would emerge. A more reasoned and focused design approach is due, connecting instruments which in some sense belong together, like emission pricing options with some electricity market development options. Instrumentation may be more focused at specific technologies, as with feed-in subsidies per renewable technology, fleet standards per car vehicle category; and insulation standards for small and large houses and offices. Or they may be less planning oriented and more incentive oriented, using generic emission pricing systems and market development.

The overlap in domain of application with superfluous or counteracting instruments is relatively clear when relating to two instruments. In a broader mix the linkages and the analysis become more complex, see (Simões, Huppes et al. 2015), with difficult to disentangle webs of instruments having been formed. It then becomes very difficult to even assess consistency, especially in a dynamic context. 
The consistency criterion cannot be applied strictly as other considerations may play a role. Feedin tariffs have opened up new markets. Even if not being effective for emission reduction under a strict cap, they may dynamically be the reason to leave the pure cap and adapt the volumes under the cap based on price considerations. Also in instrumentation such evolutionary mechanisms may play a role and such mechanisms may be actively introduced. Again, that reasoning then should be explicit and clear. The intellectual challenge is to realize simplicity and encompassingness while avoiding overlap, powerful design principles to be fitted in any instrumentation strategy. They are not to be absolutized: instrument design is an art involving many considerations, at many levels. It is not a mechanical process. More practical issues will always play a role, always assuming effective climate policy instrumentation overall.

There will always be technological and economic uncertainty, preferably avoiding picking winners. For some instruments, like informational ones, norms and values play a key role, $b$ bur while certainly not being constant in time. There will be imperfect implementation, of any instrument, but with more robust and more vulnerable instruments and instrument mixes. Different instruments and mixes will function differently within administrative and legal constraints, these in turn becoming more flexible in the long run.

For all mixes a first requirement is internal consistency, closely related to avoiding overlap while being encompassing. In a mix involving a pure cap-and-trade system, for example, it does not seem logical to add substantial feed-in tariffs and emission standards in the same domain, though it is possible in an administrative-technical sense. In a price stabilized (not pure) cap-and-trade system or emission tax system these technology oriented instruments would work in addition. Such general criteria for combining some instruments and not others are fluid; they are not hard and dichotomous. A few hard oppositions exist however, where instruments just cannot be combined. Price subsidies for delivering to the grid, user differentiated surcharges, and main producers made responsible for market clearing make the functioning of a uniformly priced, real time Single European Electricity Market quite impossible. However, there are also many in between electricity markets options where instrument combinations may be seen as somewhat less 'logical' but not impossible.

In developing mixes preliminary choices will be made based on generic before detailed ones to avoid administrative and political overload, and based on first going for what fits well together and adding only where some conflict may be expected if otherwise coverage would be lacking. Ultimate evaluation criteria are also to be kept in mind. Lower administrative capacity and lower public and private cost of regulation are preferred, guiding choices towards simple instruments with broad innovative incentives. The prohibition of natural gas heating in new housing is an example of a simple technology specific instrument in the Standards domain; the uniform upstream emission tax an example of an also simple encompassing instrument from the Institutional framework domain.

The four main sectors will roughly be typified as to current instrumentation, next with new instruments added so as to enable the deep emission reductions required. Between sectors there are diverging options for instrumentation, leading to typical alternatives. The number of instrument sets per sector is limited to four, following the four main options for emission pricing. With the pure cap-and-trade system, the electricity sector is certainly covered, the other sectors in principle as well, but possibly with exceptions which then lead to measures to avoid as shift of fossils use to these sectors. Exceptions may be in transport and buildings. Similar holds for the 
price stabilized cap system: in principle all covering but not a full necessity, with transport maybe an exception. The emission tax is always encompassing, being applied fully upstream on all inflows of fossils. In their first description, regarding the electricity sector, some general aspects of these three versions of emission pricing come up.

When linking the sectoral approaches into overall instrument mixes for climate policy, these alternatives are grouped and adapted, again in a most consistent way, creating full sets of instruments, in Chapter 6 and 7. These mixes are reasoned top down, from the two basic governance strategies, Planning \& Control and Interventionist. Such governance considerations play a limited role only in the sectoral instrumentation development here.

Issues like legality under Lisbon treaty constraints, political vulnerability, leakage problem, and administrative implementation are not treated here for the four bottom up instrumentation designs for four sectors, avoiding substantial repetition. They have partly been treated Chapter 1 and in other chapters for example for the emission tax in Section 4.3.2, and for leakage in BOX 2. They will be revisited in the assessment of the two strategic instrument mixes, in Chapter 7. Also issues like induced energy efficiency increases due to emission pricing are left out of the discussion here. They will play a contributing role in emission reduction, in all four sectors, diminishing in time when fossils are substantially reduced to near zero. The core question here is how instrumentation may develop.

\subsection{Climate Policy Instruments in the Electricity Production Sector}

Currently, the main EU instrument is the ETS cap-and-trade system, with a fixed supply of permits. It operates at EU level fully covering electricity sector emissions (with regional exceptions), and a main part of industrial emissions, currently together around $45 \%$ of greenhouse gas emissions. It has not yet been investigated how strict the enforcement of the ETS is with its implementation at the firm and installation level in different countries. Technology-specific instruments are mainly implemented at the member state level. The main instrument there is feed-in tariffs, with feedin premiums coming up. These feed-in tariffs differ substantially between technologies and also between EU countries. Second instrument is investment subsidies as for wind parks, in many forms. Feed-in tariffs and most other subsidies on renewables are mostly funded by a surcharge on the electricity price, differentiated per user group. In some countries there also are emission standards limiting emissions per kWh. CCS has not been applied.

The tasks from now are substantial. The EC (2015) Energy Union Package states: “..... to meet the increased ambition decided in the 2030 framework, the EU Emissions Trading System will deliver a meaningful price on carbon emissions and stimulate cost-efficient greenhouse gas emission reductions." (p14). The overall EU emission reduction goal is given; at least minus $80 \%$. For 2050, the EU emission reduction target for the electricity domain is assumed here to be a $95 \%$ relative to $1990,25 \%$ of which is assumed to be realized by 2020 . From 2020 onwards this corresponds to an average emission reduction rate in the electricity sector of $8.5 \%$ per year ${ }^{19}$.

\footnotetext{
${ }^{19}$ Beginning value at 75 percent point, end value at 5 percent point, and 30 periods of 1 year implies a compound emission reduction rate of $8.5 \%$ per year. Reducing not by $95 \%$ but by $90 \%$ (relative to 1990 ) corresponds to minus $6.5 \%$ per year. The yearly reduction rate of $\mathrm{CO}_{2}$ from 1990 to 2012 has been $0.65 \%$ UNFCCC (2014). National greenhouse gas inventory data for the period 1990-2012. FCCC. Lima, FCCC/SBI/2014/20. .
} 
In the electricity sector, fossil production installations tend to last technically for several decades, typically to half a century, while economic life time will become much shorter, also due to lower average proceeds with rising shares of renewables. A substantial part of currently installed fossil power plants will have to be closed down before the end of the economic life time as it was envisaged when they were built, for some occurring now already ${ }^{20}$. Current instruments for renewables expansion are mainly at member state level and are substantially based on subsidies. Wind and solar have a share in primary renewables energy production now of around $15 \%^{21}$, while renewables have a share in total energy input of around 12\% (Eurostat 2015). The share of wind and solar in total energy input hence was around $1.5 \%$ in 2013 . To produce the volume for total energy use in $\mathbf{2 0 5 0}$ it is mainly wind and solar which have the capacity to expand in principle, while other sources may be included, like geothermal, wave etc, with however a less clear scaling up potential. Such renewables production would have to expand by 2050 to around $90 \%$ of a substantially growing overall energy use, by at least a factor of two (Brauner, D'Haeseleer et al. 2013). Their estimate includes a substantial rise in energy efficiency use, see for details also the CECILAI2050 reports by (Koning, Huppes et al. 2014, Meyer, Meyer et al. 2014) and externally (De Koning, Huppes et al. 2015). Energy use will be dominated by electricity, so this is the order of magnitude to be reckoned with. This implies a growth rate of new renewables as from 2020 to 2050 of $18 \%$ per year, rising from the current around $10 \%$ per year since 2000 , also depending on an uncertain level of nuclear and probably a limited role for CCS. At the same time the intermittency issue of wind and solar has to be resolved, partly by energy market reform, an instrument entailing hardly any costs itself, and partly by storage technologies, requiring very substantial amounts of investments. In a technical sense the task is clear: renewables are to be built and fossils based installations closed.

There are four main instrumentation options for the task of reducing emissions towards 2050 by $8.5 \%$ per year. For each sector they have emission pricing as a starting point: None; Pure Cap-andTrade; Hybrid Cap-and-Trade; and Emission Tax, with adjoining instruments added. These instrument mixes include how electricity markets may be developed, see the four main options distinguished in Section 4.4.

\subsubsection{Technology Stimulation and Forcing in private markets}

Increased technology subsidies, both for creating more learning curves and as renewables capacity payment, are first instrument. The role of EU is to stimulate such subsidy schemes and to harmonize them in order to reduce barriers to international trade in electricity. There is a shift from feed-in tariffs to feed-in premiums to allow for more integrated national markets. The subsidy schemes are set in a way to have emission reduction targets in electricity production met, combined with restrictive instruments. Next to these carrots there are the sticks: surcharges on electricity to fund subsidies, increasingly stringent $\mathrm{CO}_{2}$ emission standards on fossil electricity production, and special taxes on installations to be closed down before their expected economic end of life at time of investment. Such instrumentation is part of current policy instrumentation in the UK and the US, and similar in Germany. The emission standards are first only coordinated

\footnotetext{
${ }^{20}$ The price ratio coal/gas determines which will be closed down first, with cheap coal now leading to the closing down of even newly built natural gas fired power stations. This ratio is hard to predict long term.

${ }^{21}$ http://ec.europa.eu/eurostat/statistics-explained/index.php/Renewable_energy statistics, accessed 26 July 2015
} 
by the EU. Towards 2030 they are made obligatory at the EU level to avoid misinvestment in fossil production which would make it impossible to reach the climate target. Existing fossil electricity production facilities are forced out of the market. First this is done by setting emission taxes on the worst performing installations. Later, the strict standards as for new installations, going to zero in 2050, are also applied to existing electricity production, reducing their emission to near zero, with few exceptions.

As other instruments effectively take over, the EU ETS price remains low and irrelevant for long term decisions. Proceeds will also be negligible. The EU ETS will therefore be phased out.

The intermittency in production of the new renewables is resolved by creating enough reserve capacity, medium term in mainly natural gas based installations and pumped hydro. Later, gas is phased out with intermittency resolved with large scale in batteries, more pumped hydro, and later in hydrogen storage for fuel cells and in decentralized multifunctional battery systems and fuel cells in households and cars. The introduction and the use of these technologies are subsidized, as standards and prescriptions mostly are not possible. Subsidies are in diverse forms, like demonstration subsidies, learning curve creation and investment subsidies to create the capacity for balancing the renewables dominated grid. Hydrogen for fuel cells is to be produced fossils free, using strict emission standards.

The high tension grid infrastructure is mainly nationally developed and owned, with unbundling leading to private ownership of the distribution grid with substantial public regulation or publicprivate partnerships, see the Swing Producer Market described in Section 4.4.

Electricity markets remain substantially national, with bilateral international trade between major producers and system operators, using international high tension grids as made obligatory by the EU. Decentral producers, with mostly low marginal costs, are allowed to deliver to the grid at contractual prices, with limited variability, not real time. The international connections are constructed and owned bilaterally by the national grid operators, major producers and investors. They also control transnational transport, setting the conditions for this transport based on their commercial interests.

\section{Summary (1): Technology Stimulation and Forcing Instruments in Electricity Production}

- Renewables are brought in with subsidies, especially feed-in premiums and capacity payment

- Large scale storage capacity is brought in purely commercially and partly with subsidies,

- Small scale storage is brought in with subsidies

- Coal and later gas are phased out with emission standards

- ETS is phased out

- Electricity markets are Swing Producers Market, type 1, or with stricter unbundling, type 2

\subsubsection{ETS pure-cap with renewables subsidies}

The ETS pure cap is domain expanded in principle and then does not just cover the electricity domain but also the other three sectors. We here take the general emission reduction path to hold for the electricity domain specifically as well. If not applied in the other sectors, additional measures are required to avoid a shift of fossils use to these other sectors, see the treatment below of these other sectors. The permit lake problem is assumed to have been resolved, avoiding short 
term discussions on repair mechanisms here. The ETS emission cap for the electricity domain thus is set at a fixed reduction path of minus $8.5 \%$ per year ${ }^{22}$, with permit prices following. The substantial increase in yearly emission reduction, rising from less than $1 \%$ per year the last 30 years to a cap reduction of $8.5 \%$ as from 2030 , leads to very substantial price rises, with substantial price variation over the years based on more structural fluctuations in demand. Proceeds, fully national according to cap volume, are fluctuating similarly. Extreme permit prices will lead to undesirable short term economic consequences, to be politically contained somehow. If not, as by introducing a ceiling, the pure cap-and-trade system will be transformed into a price stabilized one, the next option. The expected (not set) path of price development in time can hardly be predicted, as predicting economic growth and economic cycles is notoriously difficult and breakthroughs in technologies and their implementation are even more unpredictable. Compared to the rising emission tax, for example rising linearly to 300 Euro per tonne in 2050, the average price level will have to be somewhat higher to achieve the same emission reduction. This is because limited price predictability makes long term decision making less focused on emission reduction. Econometric modelling (see report D3.2) may indicate how high the price will be or must be, replacing uncertainty with assumptions. Such models may tend to overestimate effectiveness of instrument implementation and underestimate the effects of innovation with related substitutions and broader market shifts.

The limited price predictability increases uncertainty on investment paths for the mainly intermittent renewables and for investment in grid stabilizing options in storage, transformation and spread of peak in final use. This uncertainty can be counteracted by planning of technology deployment for stabilizing the electricity market, as in subsidizing stabilization technologies. However, developing an open electricity market partly is an alternative to subsidies. Specific ways of technology support in this instrumentation alternative could make setting up of open real time electricity market cumbersome, like price guarantees for secondary delivery to the grid during peak hours. However, with an open electricity market in mind, technology support may shift to using instruments like investment subsidies, leaving at least short term electricity markets unaffected. In this variant generic investment subsidies (as opposed to technology specific) are used for all market equilibration installations, including for example fuel cells and heat pumps. The basis for subsidizing is the contribution these technologies can make to real time market equilibrium. If they actually will do so then next depends on how exactly the electricity market will be organized. The problem of very low short term marginal costs, see Section 4.4.4, can be resolved in two directions: capacity payment or scarcity rent payment. In a technical sense the intermittency of renewables can be solved, quite independent from exact volumes of electricity production, with the possible exception of the long White Christmas situation.

How electricity markets and infrastructure will develop is quite open in this fixed-cap option. There is some logic in this control oriented pure cap system to see capacity payment coming up, requiring long term subsidies in main parts of the primary and secondary electricity production system. However, the generic nature of the cap-and-trade system points to a market orientation. With the choice in technology support made to allow for open market functioning, the real time

\footnotetext{
${ }^{22}$ These percentages are the compound percentages as usual in (de)growth quantifications. They are not to be confused with the percent points relative to a base year (1990, or 2005) as are used in the EU climate domain. We stick to the usual growth rate convention. This makes relating to economic growth possible for example.
} 
open market is the connected choice, see for a more extensive description in Section 4.4. Core in its design is one real time price for all producers, including all decentralized primary and secondary producers, and one singe price for all users, reckoning with transmission and distribution costs. The internet of things as an active ingredient for market equilibration will develop autonomously within this market structure, but might also be planned.

If the pure emission cap system has a leading role, that is if its permit price is consistently high, the adjoining national policies, like emission standards and technology subsidies, lose their meaning. They would create national costs without overall emission reduction ${ }^{23}$. However, if the national policies are more successful, as has been the case in the last decade, the cap price will become so low as to become irrelevant, as now is the case. If emission reduction slows down, zero emission technologies for primary and secondary production might then be forced into the market, and the $\mathrm{CO}_{2}$ emitting ones pushed out. This then would further erode the role of the pure cap system, shifting this variant in the direction of alternative 1, Technology Stimulation and Forcing, but with a different electricity market. Another option might be to raise the price to a relevant level by reducing the cap volume. That would lead to alternative 3 with a price stabilized cap, the Hybrid Cap-and-Trade system.

\section{Summary (2): Pure Cap-and-Trade Instruments in Electricity Production}

- ETS transformed into strict cap (no MSR), implementation with electricity producers

- $R \& D$ funding for electricity storage systems, including transformation heat/chemical

- Electricity markets, preferably Single EU, possibly Unbundled EU grid (types 4 and 3)

- Learning curves subsidies for some new renewables (possibly)

- National technology subsidies for resolving intermittency, especially for electricity storage, both large scale and small scale

\subsubsection{Price Stabilized Cap-and-Trade with national technology support}

The current price support actions in the Market Stability Reserve are replaced by active market operation, keeping permit prices between a floor and a ceiling, both rising along an explicitly indicated price path. This is a shift from a volume based cap system to a price based cap system. All floor and ceiling and collar systems in the literature have this price orientation, with volumes following. The price stabilization is realized by the EU purchasing permits when the price gets close to the floor and selling permits when the price is close to the upper limit. There is one single EU permit market on which the EU operates. Net proceeds from auctioning are distributed to the member states first according to their stated share in the total EU cap. The cap volume has become somewhat variable here, with stated shares in the cap later being established as based on a criterion like share in EU GDP.

The wedge between floor and ceiling may accommodate shorter term fluctuations in demand for emission permits within the specified emission reduction pathway. The floor and ceiling operations would use the same mechanism, quantity adaptation through sale and purchase of permits by government. A wedge in the order of $10 \%$ would accommodate changes within a one to a few years period.

\footnotetext{
${ }^{23}$ National subsidies and other regulations based on prime mover motives remain relevant for such non-climate reasons, but then only for some countries, for some technologies. Being prime is a positional good.
} 
The price path set for the price stabilized cap system is slightly lower than the pure-cap price would be because of higher long term predictability by fixing the floor and ceiling path. The price would be somewhat higher than the emission tax price, to compensate for the slightly lower long term predictability.

With the price stabilized cap system functioning, the emission price signal is to be effectively delivered to all actors in the electricity market. The logic in this pricing system is for open electricity market design, possibly with Unbundling plus EU transmission grid market version (market type 3), but most effectively with the Single EU Electricity Market, Type 4. The logic also is to avoid subsidizing renewables and have investments based on scarcity rents.

A main difference with the pure cap system related to further instrumentation is that with permit prices flexible, decentralized actions in the cap domain make sense, both public and private actions, contrary to the pure cap system. Successful decentral action will reduce the cap volume, automatically, as soon as the price floor is reached. More subtle arrangements are possible, like establishing a guiding middle price, correcting for short term deviations towards floor or ceiling. With lower permit prices the volume of permits brought on the market then is reduced, and emissions are going down faster. These further actions may overlap with those considered in alternative 1 and 2, with instruments inducing renewables and storage and diminishing fossils. With more emphasis on technology specific instruments, reduction is faster, but more expensive.

\section{Summary (3): Price Stabilized Cap-and-Trade with national technology instruments in Electricity Production}

- ETS transformed into variable cap with a rising price floor and ceiling, implementation with major fossil electricity producers

- Electricity markets, preferably Single EU, possibly Unbundled EU grid (types 4 and 3)

- Limited investment support for renewables and secondary production

- $\quad R \& D$ funding for electricity storage systems, including transformation heat/chemical

- Learning curves subsidies for some new renewables

- National technology subsidies for resolving regional and national intermittency

\subsubsection{Emission Tax with Single EU Electricity Market}

The ETS covers the electricity system nearly fully already, with only small scale producers left out. It is stepwise transformed into an emission tax, by first bringing the permit price to a relevant level, with floor and ceiling, and then fixing the price level, rising for all consecutive years towards 2050. The administrative implementation is first with electricity producers, but then moves to fossil fuel producers and importers, in relation with application in other sectors, then also covering all small scale electricity producers. The price level is based on econometric modelling. The price is equal for all emissions, with focus here on the electricity domain. See the discussion with references on maybe or probably required emission price levels in Section 4.3.2. Simple backof the-envelope arithmetic indicates that an emission price of $400 €$ per tonne increases cost price of coal fired electricity by 35 cents per kWh and of gas by 17 cents per kWh, shifting primary production from coal, to gas, to renewables. With some optimism on the speed of technology development a lower price of around $€ 300$ would be relevant. With such prices certainly efficiency increases in production would be induced, but also downstream in all use stages. 
However, ultimately it is the shift away from fossils, use with a slight role maybe for CCS, which is required for $95 \%$ emission reduction.

The Emission Tax is set at a linearly rising rate, coming to its ceiling in 2050. The price ceiling may be earlier if emissions are reduced faster than necessary for the reduction target, while the rate may be increased and the ceiling set later if emission reductions are not high enough, with a revision for example in 2035.

The emission tax is functioning most effectively in the electricity domain if combined with a Single European Electricity Market, see Section 4.4, market type 4. With less effectively functioning international markets, as in type 2 and 3, the cost of near zero emission electricity will be higher due to system costs related to secondary production and back-up capacity, both not induced, and the more limited amount of demand flexibility in relation to price changes. The tax would then have to be higher in order to press out the same amount of fossil emissions. It seems probable that in a context where the EU establishes an emission tax, the EU will also set up an EU high tension grid with relevant open trading. Less developed markets like market type 1 and 2 are therefore not considered here.

Infrastructure is a public EU planning and implementation task for the transnational grid, due to its natural monopoly nature, in market type 4, and, second choice, in close combination with public national transmission grid owners, in market type 3. National transmission grids and distribution grids are not regulated at EU level, apart from the full unbundling requirement.

Standardization plays a limited role as new HVDC lines already are introduced and make grids more independent. Some standardization of the transformation technologies is useful but may come from industrial partners. In terms of $R, R \& D$ and $D$, the focus is on Research and R\&D regarding energy storage.

Information is mostly transmitted through the price system, with private support in decentralized markets.

\section{Summary (4): Emission Tax with Single EU Electricity Market in Electricity Production}

- ETS transformed into fully fixed emission pricing, as an emission tax.

- Electricity market international transmission grid publicly owned involving EU

- Electricity national grids and distribution grids publicly owned nationally.

- Electricity balancing by market forces, real time

- Guiding private standardization for internet of things

- Funding of $R$ an $R \& D$, not much of Demonstration

\subsection{Climate policy instruments in the Industry Sector}

Currently, the main instrument is the ETS cap-and-trade system, with a fixed supply of permits, operating at EU level. It covers $\mathrm{CO}_{2}$ emissions from larger energy using industrial firms and installations, with free permits for many installations. With cap systems, full auctioning is assumed in the medium and long term. The ETS has a low price now as the supply is larger than demand, for various reasons. For 2050, the EU emission reduction target for the industry domain is assumed as an $80 \%$ reduction relative to $1990,25 \%$ of which is assumed to have been realized by 2020. From 2020 onwards this corresponds to an average emission reduction of $4.5 \%$ per 
year ${ }^{24}$. With substantially lower reductions in iron and steel, cement and a few more, the remaining firms are to reduce emissions with a much higher percentage, in the order of $6-8 \%$, also depending on the overall instrument mix over all sectors. Modeling with some specifics on instrumentation indicates that this task is a hard one, see the modelling in the CECILIA2050 project by (Meyer, Meyer et al. 2014) and the bottom up modelling by (Deetman, Hof et al. 2014). More abstract ideal market optimization models seem to reach the high emission reduction targets more easily, see for example (Solano and Drummond 2014).

There are four main instrumentation options, one with a focus on emission standards and no ETS; one based on an encompassing pure cap-and-trade system for all industry, possibly with subsidies and prescriptions for emission reduction; next a price stabilized cap-and-trade system covering all industry; and an emission tax covering all industry, all with different adjoining instruments.

\subsubsection{Technology Stimulation and Forcing in the Industry Sector}

For all major emitting industries low carbon technology paths are specified, using long term dynamic BAT specifications developed in substantially public funded R\&D and Demonstration projects, also reckoning with structural developments in the economy. Some crowding out is unavoidable, see section 4.2.3, also on directions for reducing this. Technically, a major shift will have to come long term from fossils based heating to electricity based heating, also for higher temperature applications, like now already in electro-steel furnaces. Gas and oil based power generation in industry will have to be replaced mainly by electric power and by hydrogen fuel cells also delivering some heat. Building heating is treated as a different sector, see there, of course technically with substantial overlaps. As generic price incentives are limited, regulating private actors (instrument type 4) will play a central role, with financial instruments (type 4.2) and with standards and regulations (type 4.3).

Current ETS based emission pricing on industries is not implemented any more in industries sensitive for international leakage and with few options for emission reduction, like iron and steel, several other metals, and chemicals. Implementation at smaller energy users is administratively for them too complex. Upstream administration is difficult due to overlap then with fossil flows to larger energy users. With dynamic BATs being developed and implemented by subsidies and taxes and standards and regulations, the already only partially applied ETS is phased out in industry. Emission pricing may remain operational indirectly, as when electricity would still be covered by emission pricing, cap or tax. Electricity then will have a price disadvantage relative to natural gas use in industry. This price disadvantage exists more forcefully for smaller firms that are to pay the surcharges on electricity for funding the subsidies in electricity production. An industrial tax on natural gas might then be an option to avoid a move from electricity to natural gas, as an industry-specific carbon tax on most but not all technologies. Partial application of emission pricing, cap or tax, may not be part of a strategic approach; it is current reality. Efficiency improvements as in cascaded heat use, combined transport, etc, have always been possible, and may still be stimulated. Publicly arranged heat transport systems in industrial areas may be one

\footnotetext{
${ }^{24}$ Beginning value at 75 percent point relative to 1990, end value at 20 percent point, and 30 periods of 1 year implies a compound emission reduction percentage of $4.5 \%$ per year. With industrial growth at $1.5 \%$ an ecoefficiency / climate intensity improvement of $6 \%$ per year is required.
} 
instrument, not specific for the Technology Stimulation and Forcing approach in industry however.

The uptake of renewable energy in industry is more effective and efficient with a well-developed EU electricity markets, type 3 at least but preferably type 4, the single European electricity market. However, direct control in industry links to also direct control in electricity production, then dominated by swing producers, market type 1 or maybe 2. A clear choice for open markets restricts some subsidy schemes in industrial electricity and heat production.

In terms of infrastructure, the diversity of the industries involved reduces options for generic instruments. One option might be the set-up of a hydrogen distribution grid. A main but very partial grid has developed mostly privately, especially linking refineries and nitrogen fertilizer production. This grid could be expanded in public-private partnerships, partially also using the now existing but then phased out natural gas grid. There then would be a forced move-over to hydrogen, with the option of adding decentralized fuel cells for combined heat and power production. The domain of attractive heat pump applications with heat storage would be enlarged, also for heating of industrial buildings. However, there then are strict regulations required on emission free hydrogen production. There are now a few underground hydrogen storage facilities in the world, one in the UK. They would have to be expanded, also replacing natural gas storage for hydrogen storage, see the results of the HyUnder project ${ }^{25}$, with a case (exemplary) on Spain (Simon, Ferriz et al. 2015). This infrastructure option may not only be relevant for industrial heating and building heating but also for the development of the infrastructure for loading hydrogen for fuel cells in transport. Fuel cells then also might play a role in stabilizing electricity markets, delivering electricity to the grid during peak demand. Such mechanisms function only if real time markets would be developed, which is not in the line of reasoning which leads to leaving emission pricing out in industry.

In a very broad domain of change, RD\&D is required, with a focus on Demonstration for dynamic BAT specification. Supporting the change to low emission requires innovation and investment, means supporting at least the climate financing for low emission technologies in smaller firms, in many regions. New standardization of low carbon technologies is required for pushing the right technologies into the market, based on dynamic BAT specifications, and adapted regularly.

Driving the change in energy use towards low emission is increasingly stringent emission standards in many industries, supported with subsidies for the investments required in integrated low emission systems. The effective prohibition of coal and oil use in most industries can be realized well before 2050, say 2030, as will be the case with oil somewhat later. Ultimately, by 2050, the industrial application of natural gas is to be effectively prohibited in most industries, also as by upholding its supply and prescribing to shift the use of the pipes to hydrogen transport. A shift to synthesis gas and propane and butane is prohibited; these are phased out earlier already, together with oil and most other refinery fuels.

\section{Summary (5): Technology Stimulation and Forcing for emission reduction in Industrial Production}

- No generic emission pricing in industry

- Choice of electricity market open, for cost reasons open market but then restrictions on technology specific instrumentation

\footnotetext{
${ }^{25}$ www.hyunder.eu, an FP7 project surveying storage options in several EU countries.
} 
- Electricity prices raised by electricity policies relative to coal, oil and gas

- Coal, oil and gas to industry phased out with standards

- Hydrogen infrastructure forced in, with subsidies and prescriptions and prohibitions

- National emission standards, based on dynamic BAT specification

\subsubsection{Pure cap-and-trade with BATs implemented in permits and with subsidies/taxes}

The pure cap combined with specific industrial climate policy is in between option 1 and option 3 , industrial policy in the context of a price stabilized ETS. It is an ambivalent option, as effective technology specific policy instrumentation would tend to make the cap superfluous, while a high cap price would make most technology specific measures redundant. It is not sure if in-between shades of gray can be realized, requiring a complicated dynamic balancing act. The pure cap would be set so as to reach the climate target regardless of general economic development, and irrespective of breakthroughs in new technology applications, or the lack of them. This means that a very broad range of permit prices is to be reckoned with, from as low as in current ETS to maybe a short term multiple of the price level as specified in the Price Stabilized Cap-and-Trade and the Emission Tax. With an extreme price explosion, then adapting the volume of the cap would transform it into a price stabilized version of emission pricing. The first only reactive nature would lead to a broad and unspecified wedge between floor and ceiling, till the changeover to an explicit better ordered price system is made.

Of course the broader embedding makes a difference for what industry-specific instruments can do. It seems quite impossible to have substantial change in industry without also having a substantial pricing system in electricity production, with transport playing a more modest role.

Technology specific instrumentation can be set up in the same way as in variant 1, Stimulation and Forcing, but then more modestly, with a focus on BAT with permits and subsidies on emission reducing investments. The subsidies and maybe standards used would not lead to reduced emissions as these are defined by the cap. They lower the price of emission permits. The goal then is cost reduction, with a focus on long term issues where markets react slowly. Stabilizing the price might be done very indirectly by administering technology-specific emission reductions not full speed, as in variant 1, enforced gradually so as to keep the price within reasonable limits. Such price planning seems beyond what governments in market economies may be capable of however, and certainly goes against the spirit of a pure cap system.

Remaining on an economically and politically not too erratic price path therefore seems difficult to realize. This pure-cap emission pricing based alternative for instrumentation may therefore easily move in due time to either the technology specific policy instrumentation as in variant number 1 or to the price stabilized variant with adjoining instruments, as in instrumentation alternative 3.

\section{Summary (6): ETS pure cap with BATs and subsidies in Industrial Production}

- Cap on all industrial emissions

- EU electricity grid, at least EU grid.

- Hydrogen infrastructure forced in, public-private

- Substantial industrial climate policies with BATs and subsidies

- Tension between main instruments: Possible shift towards either option 1 or option 3? 


\subsubsection{Price stabilized cap-and-trade, with specific industrial policy}

The cap is set reckoning with required overall industrial emission reductions indicatively set at 4.5\% per year, with those in the non-iron and steel industry in the order of minus $7 \%$ per year, and in industries like iron and steel and other metals much less, as technical options are limited and CCS is not well applicable in most if not all industrial installations ${ }^{26}$. The price floor and ceiling are set to be on the required reduction path, based on middle of the road expectations regarding economic and technology development, the same expectations as determining the emission tax. The system comprises electricity production quite unavoidably as well, and may also cover buildings and transport. If prices are consistently too low or too high, the cap volume is adapted automatically, for all in the system. With prices reaching the ceiling too often this may lead to long term under-accomplishment. The window on pricing then may be adapted, by raising the price ceiling, and vice versa for too low prices combined with over-accomplishment. This last option is possible with highly effective technology-specific instrument application for example, as might be induced by dynamic BAT development and implementation.

For the emission price signal to reach all parties the electricity market is key, reaching all market parties. The single European electricity market then is required, also implying a trans-European high tension grid. In current market designs, type1, and also type 2, emission pricing may reach the electricity producer but is only partly translated into differentiated prices for the user as prices are substantially fixed contractually. A single European hydrogen infrastructure and market would be required for fast hydrogen based technology development, as when hydrogen fuel cell technology would replace fossil power and heating. The hydrogen transmission grid linked to large scale storage might be an interesting option for low cost industrial emission reduction, to be further investigated and then implemented with substantial public involvement in planning and funding of infrastructure. Combining heat and power production in larger fuel cells is one industrial option which then might develop commercially. As with cars, such systems may help stabilize the grid as well, producing for others when electricity prices are high, then requiring a real time electricity market open to all producers.

Several industrial installations with high emissions have sunk costs so they can operate below average costs. To get them to disinvestment the carrot and the stick may be used in addition to the price stabilized permit incentive, to speed up emission reduction and next raise the floor price to prevent others from taking over these reduced emissions. The carrot can be in the form of subsidies for early replacement of high emission installations by near zero emission ones. The stick is operating permits with increasing stringency, requiring new investments. Such measures are to be focused at industries with high emissions and good improvement options. This has been the situation in the US electricity and high energy using industry under the SOx tradable emission permit systems in the 1990s, with individual permits taking over again at very low emission levels when the cap was discontinued. Planning such additional measures may allow for setting a somewhat lower emission ceiling price.

For most industries, the strong price signal allows for a shift in energy use towards near zero emission electricity or to hydrogen (non-fossil) fuel cell based heat and power, in house or by specialized firms.

\footnotetext{
${ }^{26}$ The cost of CCS in steel and cement production are much higher than in installations with large chimneys.
} 


\section{Summary (7): ETS price-stabilized with adjoining instruments for emission reduction in Industrial Production}

- Cap on all industrial emissions, with pre-indicated rising price levels

- Single EU electricity market, type 4, or 3

- Hydrogen infrastructure coming in, public or public-private

- Substantial subsidies for industrial restructuring

- Some increasingly stringent emission standards forcing disinvestment

- With highly effective other instruments, the floor and ceiling can be raised, reaching emission targets faster

\subsubsection{Emission Tax with Single EU Electricity Market: Industry}

Currently part of industry is covered by the EU-ETS. This coverage is broadened to cover all emissions and the price is fixed at a predetermined rising level. There is upstream administration so as to also cover smaller firms, possible because all other sectors move to full coverage and upstream application as well. This effectively establishes an encompassing Emission Tax. The price signal is as indicated in the legislation guiding longer term technology development and investments. At any moment in time the emission price information is given, in terms of market prices. This allows also for short term optimization, which however is secondary to the long term transformation towards zero emission technologies. A clear market signal requires open electricity markets, also internationally, market type 4 and at least type 3 as more extensively described in Section 4.4. Similar as with the Price Stabilized Cap-and-Trade the hydrogen option may require long distance transmission and storage infrastructure, to be publicly provided (possibly with regulated private implementation). With a clear also long term price signal, disinvestment may occur more market based, with low emissions competitors taking over markets and creating new alternative markets. An example of a technology substitution mechanism is the production of nitrogen fertilizer, now contributing to over $1 \%$ of $\mathrm{CO}_{2}$ emissions. One option for emission reduction is not using methane (or coal, etc.) as the hydrogen source; or replacing current processes by electrolytic processes; or making all these technologies redundant by having the nitrogen fixing capacity developed for major crops. Such options can hardly be specified and forced. In principle there is no technology specific policy involved in this variant: hydrogen infrastructure, electricity markets and emission pricing act as generic instruments in this variant. Public support may play a role, but in any of these technology directions. But substantial private $R \& D$ is there already, easily leading to crowding out.

Public research and R\&D might involve an extremely broad range of zero emission technologies as may be developed. As most R\&D will have to take place in the private domain, public spending focuses on more basic research. In most industrial markets also demonstration can develop privately. In exceptional cases where market development is too risky and long term, subsidies may be used to start the market innovation process. Technology forcing as by emission standards and technology standards is to be avoided as causing unnecessary costs. 


\section{Summary (8): Emission Tax with Single EU Electricity Market for emission reduction in Industrial Production}

- Tax on all industrial emissions, rising according to set levels

- Single EU electricity market, type 4

- Public provision of hydrogen main transport and storage

- Public Research and R\&D focused on basic research

- Few subsidies for high-risk high-potential technologies

\subsection{Climate policy instruments in the Building \& Consumption Sector}

Current instrumentation and instrument options in the building sector have been surveyed by (Nauleau, Branger et al. 2014) indicating the difficulties in upgrading the existing building stock to reduce energy use, with a preference of obligatory retrofitting over financial incentives. For the short and medium term, energy reduction also in existing buildings may be a most important issue, to be resolved with a full set of instruments for retrofitting, stimulating and forcing, as (Nauleau, Branger et al. 2014). However, in the long term considered here emissions are to be reduced much beyond what can be reached with energy efficiency improvement. The use of coal, gas and oil will have to be reduced to near zero, also in existing buildings. This holds for new buildings a fortiori. The long term therefore is to focus on emission free energy use in buildings with energy use reduction possibly relevant in the medium term.

Heating, cooling, cooking and warm tap water households and tertiary sector are a major emission source, with around two third of total energy consumption in buildings. Indirect emissions due to electricity use have a smaller share in energy emissions in buildings now. With upstream decarbonization of electricity production having been realized mainly by 2050, direct fossil energy use in buildings is the key issue to deal with. In city regions natural gas is the main source, with butane/propane and heating oil dominant where there is no natural gas. Micro-CHP based on natural gas is relevant in the short to medium term but cannot deliver the over $90 \%$ reduction required in the housing sector by 2050 and may create a costly lock-in due its life time. The now feasible non-fossil options for energy delivery to households are electricity, including decentral solar PV; hydrogen, from low carbon upstream sources; and heat, as more local solar heat, geothermal heat, and distributed heat as from nuclear power stations. Distributed heat from fossil power stations which will have been phased out mainly by then. More exotic options exist like local biosolar fuel, microwave irradiation and certainly more to possibly come.

\subsubsection{Stimulation and Forcing low Emission Buildings}

The strategies for decarbonizing buildings may follow two routes. One is the full electrification, with heat pumps for efficient heating for all new and refurbished buildings, and certainly also other technologies, while phasing out natural gas. Systems for energy storage are to be developed, especially for fitting into refurbished buildings. The core instrument is the phasing out of natural gas in new buildings based on zoning regulations and in refurbished buildings as a condition for subsidizing. Subsidies on heat pumps and heat storage systems complete the instrumentation for this group of buildings, if owners choose so. Roof top solar cells may be part of the system but are not a condition for its low carbon functioning. Locally produced hydrogen may be an (expensive) option to avoid electric cooking. 
The other route is hydrogen delivery replacing natural gas in distribution systems. Current high temperature low efficiency heating systems with natural gas will need limited adaptation for the change-over to hydrogen. They tend to be replaced every 10 to 20 years so the stock by 2050 is nearly fully renewed. This may be a fall back option, requiring a hydrogen distribution grid. With hydrogen available locally, a changeover to hydrogen fuel cells is also possible, providing both heat and electricity, probably less expensive. The hydrogen may also feed fuel cars fueling stations and the fuel cell electricity may also directly feed electric cars. The main instrument is relatively simple: the forced changeover from natural gas to zero emission hydrogen in basically the same distribution system, as also took place in the changeover from town gas to natural gas half a century ago. Additionally, subsidies for fuel cells can make for a faster change to the inherently less expensive fuel cell systems. This would imply a very substantial increase in hydrogen production, then fossil free.

The two routes to decarbonization seem mutually incompatible but may be implemented in the same region, starting with replacing natural gas with hydrogen. During changeover hydrogen may be subsidized first to avoid price differences with the still natural gas using neighbors, these subsidies being reduced in a decade or so. Cost developments may then determine the choices between the two main routes. The local costs depend substantially on how electricity markets are set up. Heat pumps with storage are now economically attractive already as compared to gas based heating, but only so if the electricity price is variable, feeding the heat storage cheaply at times of low demand and high supply, and natural gas is not too cheap. The easily variable demand for electricity then can also help keep down the cost of the zero emission electricity systems.

The implementation of instruments is nearly fully at a national level. The required legislation may be guided by EU Directives. The international hydrogen infrastructure cannot be developed by changeover from natural gas to hydrogen as regionally there will be a long changeover period with both gases being distributed. The parallel international hydrogen grid would require the active support by the European Commission in planning and subsidizing but not with EU ownership; public-private partnerships would be an option.

\section{Summary (9): Stimulation and Forcing for emission reduction in Buildings}

- Main international hydrogen grid with large scale hydrogen storage

- Public-private national hydrogen infrastructure replacing natural gas infrastructure

- Phasing out of all fossils for heating, with few exceptions

- Demonstration projects on new heat-pump \& heat-storage systems

- Demonstration projects on new multifunctional fuel cell systems

- Subsidies on insulation refurbishing and zero emission heating, cooling \& cooking systems

- Strict insulation standards for new and for subsidized refurbishing

- Prohibition of natural gas for heating right now (Denmark)? Not applicable in most countries

\subsubsection{Pure Cap-and-Trade on all Buildings Energy}

The pure cap system on electricity is expanded so as to cover all hydrogen production and all fossils use in buildings. The administration is not possible with actual emitters in buildings, moving 
the administrative level upstream, at least to their energy suppliers. For natural gas this is the grid owners and traders. For heating oil and butane/propane the level is with oil companies and wholesale traders, if transport is left out of this pure cap system. With transport part of it, the administrative level can be more upstream at refineries or even more upstream to primary producers of gas and oil and importers. The price level depends on economic growth and technology development. The cap volume can be set at the start assuming well specified adjoining emission reducing policy instruments like used in variant 1 of instrumentation. The speed of introduction of such adjoining policies then determines price levels more than the cap itself, successful introduction reducing cap prices. Costs and hence speed of introduction and hence price levels depend substantially on the set-up of the electricity market. With well-functioning internationally linked markets these cost can be lower, with variable pricing allowing for relatively cheap heating-with-storage options. Assumed here is electricity markets of type 2 or 3 . With active building specific policies being successful, the pure cap system may be confronted with a long price lull, as happened with the ETS. The long term price signal then is absent, as is the short term one. Investments then will not tend to zero emission technologies, and development of such technologies will halt, making the 2050 target for buildings impossible to reach without extremely costly final spurts. Additional measures, to be sure of results, may then be implemented, especially at the national level. The more such measures are successful the more the price of permits in the pure-cap system will drop. This instability mechanism may again lead to the cap system either becoming superfluous and being phased out, moving to alternative 1 , or to actively adjusting the cap volume to maintain relevant price levels, moving to instrumentation alternative 3. To avoid such developments, there should be no competing instruments in the pure cap domain, which however may well go against national considerations, like with the feed-in tariffs first set up in Germany.

\section{Summary (10): ETS pure-cap for emission reduction in Buildings}

- Ambivalence of pricing with technology regulation: no adjoining instruments

- Fixed cap on all direct emissions from buildings, as part of overall pure-cap

- International hydrogen pipe lines set-up by EU in parallel to natural gas piping

- Hydrogen distribution grid substantially replaces natural gas

- Price level electricity and hydrogen depending on open market structure, type 4, s or 3

\subsubsection{Hybrid Cap-and-Trade (price stabilized) on all Building Energy}

The EU Hybrid Cap-and-Trade system covers all building energy and the full electricity and hydrogen production system. Also at EU level there is the EU electricity grid and the open electricity market, type 4 or possibly type 2 . There also is an international hydrogen transport system, publicly planned and operated as utility or in public private partnership. The rising floor and ceiling are specified in advance. The predictably rising price of emission permits covers all building energy, both direct emissions and indirectly for emissions from distributed electricity, hydrogen and heat. The administrative level is upstream at least to decentral energy providers but more upstream if the sectors Transport and Industry apply the same system. The electricity market is of type 3 or 4 , 
Infrastructure supply covers electricity supply and possibly hydrogen supply, with also an EU transmission grid and storage systems. With hydrogen from electricity and adequate storage the electricity market can be substantially stabilized through demand variation.

The supply of natural gas remains an option of choice, albeit at rising costs due to emission pricing, and being long term phased out for economic reasons. Infrastructure development for the supply of hydrogen instead of gas is a local decision based on local economic considerations. It is to be planned well in advance to avoid misinvestment in heating systems, especially as other systems may have closed off the potentially interesting hydrogen fuel cell option. Several hydrogen based options may be interesting additionally, like using car based fuel cells for electric heat pumps with heat storage, and connecting the fuel cell heat to homes as well. When buildings don't have a hydrogen connection such car based options might be induced, assuming supply of hydrogen for transport. Insulation policy plays an intermediate role in the short and medium term, with standards for new building protecting especially rental homes from underinvestment.

Research and R\&D are prime, less so Demonstration. It is focused at low emission building technologies where private research will not play a substantial role. Especially seasonal energy storage, including heat and cold, still is a bottleneck for low emission systems.

The support for private technologies is mainly limited to creating some learning curves and overcoming lock-ins. However, national and subnational initiatives are supported by the stabilized but still varying permit price level. The price level of permits determines all long term choices on investments in energy systems, aided by information to support market functioning. Fluctuating prices reduce the predictability of return on investment. Conversely, the other instruments operant, especially at the national, and local level co-determine the permit price, as do purely private initiatives. All additional instruments like stimulating and forcing emission reductions of private parties will lower the permit price. Successful additional instrumentation, potentially the same as used in alternative 1 , will ultimately depress the permit price to the floor price level. The bandwidth then does not play a role as government buys emission permits to maintain the minimum price, but not at a higher price. If additional instruments are not so effective, the price will rise to the ceiling, with permits brought on the market to avoid the price to rise further. The middle area, shifting between floor and ceiling, will be the exception in the cap functioning, as possibly when economic growth picks up or slows down. The bandwidth does not seem to have a function in determining behavior, including investment behavior; it either is not present, or it is a temporary noise factor. If the price is consistently at the floor, the ceiling can be lowered, if at the ceiling, the floor can be raised, reducing the bandwidth to zero. The complexity of having a trading system then superfluous.

Summary (11): ETS Price stabilized with low emission heating for emission reduction in Buildings

- ETS price level predictably rising

- ETS covering natural gas, butane/propane oil and coal use in buildings, as part of broader cap

- Single EU electricity market, or close (type 4/3)

- Substantial RD\&D on integrating seasonal energy storage for buildings

- Financing insulation medium term

- Insulation standards long term replaced by standardized information 


\subsubsection{Emission Tax on all Building Energy}

The emission tax functions fully similar to the Price Stabilized Cap-and-Trade, but links to a slightly more incentive oriented approach to emission reduction in buildings. The fuller price predictability allows for a slightly lower price path. In the logic behind the choice for this option, also the Single EU Electricity Market is established, type 4. Where long term markets don't function, as might be the case in long term development of energy storage systems, public Research and R\&D is to supply such innovation, but only very exceptionally brought to the Demonstration level. This seems hardly relevant for zero emission housing towards 2050 however, as implementation may well take decades or more. Institutional aspects of such systems may have to be developed however, like who may own and use underground energy storage systems, and under what conditions they may be used.

Infrastructure for delivering hydrogen is publicly provided, leaving use options to private parties. Phasing out natural gas is a public task, with hydrogen taking over according to decisions and arrangement not made by the EU but at member state level or well below that. With a hydrogen grid available, interesting options like linking to hydrogen fuel cell cars are fully left to market development and more broadly to civil society and lower level administrations.

Information to improve market functioning is limited and left to private parties, based on some standardization as for measuring building energy requirements. Information like in BAT specification or the Eco-design Directive are not used beyond providing information and are not applied in standards and regulations, with exceptions where markets are nearly fully absent. There are no technology specific subsidies and taxes and no emission standards or technology standards for climate reasons, with few exceptions to overcome very serious lock-ins. Refurbishing of existing buildings is left to private parties. Public financing of them might be an option where small scale capital markets don't function and cannot be developed. Such public funding may well prevent such markets to develop however.

\section{Summary (12): Emission Tax on all direct and indirect emissions in Buildings \\ - Emission tax predictably rising \\ - Emission tax also covering all fossil energy in buildings, and all indirectly \\ - Single EU electricity market (type 4) \\ - Substantial RD\&D on integrating energy storage in buildings \\ - No specific subsidies and taxes for implementing technologies. \\ - Insulation standards replaced by standardized information}

\subsection{Climate policy instruments in the Transport Sector}

Current instrumentation in the transport sector has been analyzed in (Máca, Eberle et al. 2013), also indicating several options for improvement. Pricing instruments are quantified as most efficient, linking to mostly existing technologies. Light road transport $\mathrm{CO}_{2}$ emissions from fossils have a share of around $20 \%$ in total EU emissions while total transport emissions contribute around a third. Options to reduce emissions differ strongly between transport modes. Person cars can become electric or hydrogen based, with other options on the horizon maybe, like compressed nitrogen. Similar holds for buses and trucks and for water transport, each with maybe 
additional options. This technology development is global, with Japan betting on onboard hydrogen storage and the US on electricity storage. Rail transport is mainly electrified already, with still some Diesel and Diesel-electric. Aviation has hardly options for zero emission flight on the horizon now. Efficiency improvements are possible, but not as fast as volume growth. Technology development is costly and global, while planes remain in service for about half a century. Projections by the UN show an absolute rise in emissions by around a factor 4 , which will be somewhat lower in the EU but not much lower for EU international transport. The share of aviation in total $\mathrm{EU} \mathrm{CO}_{2}$ emissions will therefore rise substantially under successful climate policy, with other modes of transport to be reduced more strictly than the overall over $80 \%$ EU reduction. With developments like self-driving cars and peer to peer systems, the distinction between public and private modes of transport may become soft.

Modal shifts will in the 2050 future mostly have a limited impact on emissions as all drives are mainly zero emission by then, including upstream for electricity and hydrogen. There is one major exception, if decarbonizing aviation indeed proves elusive: a shift from air transport to ground transport and water transport, countering the rising trend in aviation also in rich countries (Goodwin 2012). Even if high speed systems like maglev trains and tunnel systems would use similar amounts of energy, electric, they would emit a mere fraction only of still mostly fossil aviation emissions. There is a clear positive relation between transport speed and average daily transport distance. Other modal shifts to reduce traffic volume therefor are to move away from high speed to lower speed modes, that is from high speed trains to low speed (except for outcompeting aviation); from highway car driving to local car driving and from trains to metro and bus systems. Modal shifts towards cycling and walking constitute the ultimate reduction in energy use for transport. Such shifts play a limited role in emission reduction with all transport modes, except aviation.

Core policy tasks therefor relate to:

- Decarbonizing all land and water transport

- Creating a modal shift from air transport to land transport.

In transport there is a stocks aspect, requiring new investments and sales to be near zero emission well before 2050, as the older part of the stock will still be emitting. Ships and trucks last for decades while passenger cars have an expected life time of around 12.5 years (Nemry, Leduc et al. 2008). This means that combustion engine passenger cars should not be sold any more by 2040, and that new trucks, buses and ships should be emission free substantially earlier already. Instrument development starts from now, see the substantial analysis in (Máca, Eberle et al. 2013). Overall their analysis shows mostly additive relations in using price incentives (fuel pricing; car pricing; road pricing) and some perverse elements in the set-up of the EU Fleet Standards like due to different standards for overlapping partial fleets and a mass correction in the standards. Current policy instruments for road transport have as their core these fleet standards for person cars and vans. The interaction with other mostly national instruments is complex. If remaining long term, the fleet standards have to be adapted, removing some of the limitations. They then are to be purely $\mathrm{CO}_{2}$ emission based, removing premiums for low and zero emission cars and removing the current mass correction which allow heavier cars to emit more. They should be all encompassing, covering (almost) all road transport. The reduction rate (apart from aviation) between 2020 and 2040 is to be around 14\% per year in order to reduce the fleet standard emissions by $95 \%$, halving every 5 years. As fleet standard reductions overestimate actual 
emission reduction, this is a low estimate. Data from (Mock, Tietge et al. 2014) show that between 2011 and 2013, the difference between fleet standard use and actual use has risen with $7 \%$. When coming closer to zero, this difference loses relevance however. Currently, EU fleet standards apply to passenger cars and vans (up to $2510 \mathrm{~kg}$ empty mass). Firstly, moving from passenger cars to vans should lose its current attractiveness. Currently in the US the most sold car type is the pickup truck, some weighing already more than the EU maximum mass regulating vans ${ }^{27}$. Effectively this is the passenger car, with some additional functionality, developed because consumers are willing to pay more to get out of the constraints of the fleet standards regulated fleet even if lowly priced. Next, also all heavier transport will have to be covered. Additionally there now are national programs to favor lower emission cars, including hybrids and zero emission cars, electric cars and some fuel cell cars. With purified fleet standards such subsidy schemes on technologies would become ineffective, resulting in transfer payments to car producers. An exception might be the creation of learning curves for not yet widely marketed technologies, like hydrogen fuel cell cars. Road pricing and fuel pricing would have their influence on behavior not covered by the fleet standards. Their future role depends on the EU level instrumentation chosen, as there may be overlap with emission pricing. Modal split policies must primarily focus on fast train systems replacing some aviation, but also attracting longer distance driving replacing cars. In the medium term slower city transport systems may support volume reductions, both fleet volume and driving volume.

The four variants for instrumentation are presented in turn, starting from carbon pricing options.

\subsubsection{Stimulation and Forcing Low Emission Transport}

Fleet standards are expanded so as to cover all major transport categories. The set-up of fleet standards is reduced to emissions only, taking out special premiums for very small, hybrid and full electric cars. Such premiums become irrelevant and even counterproductive long term when the fleet involves a majority of non-fossil drive vehicles. Also subsidies for low/zero emission vehicle may be useful on short and medium term but lose their relevance long term: there is no good reason to subsidize nearly all cars. To arrive at near zero emissions for land transport, all fleets together are decarbonized, for example on a path from current emission levels to a near zero emissions fleet sold in 2040, latest. The last combustion cars sold by then will still be on the road by 2050 , as will be part of those sold several years before. The fleet standard reduction path may be linear, with equal percent points as from 2020, with 5 percent points down per year. A corresponding compound reduction rate would then rise from $5 \%$ in the first year to $24 \%, 33 \%$, $50 \%$ and $100 \%$ in the last four years. A yearly compound reduction rate going down to $95 \%$ in 2040 from now would be $14 \%$ per year, with the last reduction by closing down the few remaining combustion vehicle factories in 2040. The compound rate specification seems most useful, allowing for comparisons with other domains and with economic growth rates. Special vehicles like possibly cranes and ultra-heavy trucks and some tractors may be exempted.

The fleet standards are to better link to actual emissions than currently is the case now NEDC (New European Driving Cycle) tests, and from 2021 possibly the improved WLTP (Worldwide

\footnotetext{
27 The 2015 Chevy Silverado 3500, functioning mainly as a passenger car similar to SUVs, has a mass now of $2702 \mathrm{~kg}$, with EU vans regulated till $2510 \mathrm{~kg}$.
} 
harmonized Light vehicles Test Procedures) being set up in the UN framework ${ }^{28}$, especially by the EU, Japan and India. Ultimately it is real driving emissions however which should feed the standards, as vehicle designs and procedures will be directed so as to better score at tests: what you measure is what you get. This may hold in perverse ways as when vehicles have different engine calibrations for real driving and test driving. The recent issues regarding Volkswagen Diesel emissions of NOx have been brought up in the US, indicating factors of difference between test drive emissions and actual emissions. These differences had been noted by the European Commission but accepted for economic expediency reasons, see the survey of facts in (Brunsden and Oliver 2015) $)^{29}$. Even if such issues could be resolved for $\mathrm{CO}_{2}$ emissions, fleet standards cover drive technology but they do not cover fleet volume sold, driving distance and driving style of person cars, vans and other more heavy vehicles. Indirectly their influence on spatial planning and consumption style development therefore is more limited than with pricing instruments.

In terms of institutional framework, there is no EU emission pricing in transport. There may be emission pricing in electricity production however, as a pure cap, stabilized cap or emission tax, see below.

The market option developing linked to fleet standards is that of the Swing Producers or National Unbundling. They lead to relatively high electricity prices, different between countries. Therefore electricity will become more expensive, making the change to electric drives more costly, also because national fuel excises will rise modestly at best. This will give a premium on the price of combustion cars as long as they are on the market, unless offset for example by high subsidies on electric cars and car drive electricity and car drive hydrogen, and by special taxes on combustion cars. Such overlaps may be avoided if the fleet standards are strict enough.

The infrastructure for the supply of emission free hydrogen is stimulated by public bodies but not publicly owned. Distribution is supplied privately and the main grid and central hydrogen storage supplied in public-private partnerships and when functioning privately.

In the medium term there is substantial investment in high speed railway infrastructure and efficiency improvement in road transport. Apart from reducing aviation volumes there is no climate advantage involved due to induced increases in traffic volumes by faster drive systems. This therefore does not constitute a long term climate policy option, but of course may be useful for several other reasons. Similarly, a shift to cycling and walking in cities is attractive for many reasons but has medium term climate relevance; less long so term relevance.

Stimulating zero emission transport requires relevant refueling infrastructure, forced by national governments and indirectly by EU Directives.

\section{Summary (13): Emission Standards \& Non-fossil drive subsidies for reducing emissions in Transport}

- Fleet standards for all vehicle categories, pure emission, towards zero 2040

- Public-private partnership in hydrogen transmission + distribution grid

- Also for industry and households)

\footnotetext{
${ }^{28}$ The final UN text is at: chrome-extension://gbkeegbaiigmenfmjfclcdgdpimamgkj/views/app.html

${ }^{29}$ Environment Commissioner Mr Potocnik raised concerns about carmakers misleading testers as early as May 2011, when he warned in a speech that some cars may be 'tweaked' to fulfil the required test cycle. The issue was brought up forcefully by the Danish Environment Minister Ida Auken but economic considerations led to postponement of action, the US EPA now overtaking and forcing the Commission to act.
} 
- Air and probably sea transport mostly left out of climate policy (but taxed normally)

- Refueling electric and hydrogen network obligatory for member states

- Subsidies on transport electricity and hydrogen, reduced to zero long term

- Fuel taxes rising only modestly (otherwise better more general emission tax)

- Subsidies on electric and H2 fuel cell drives, reduced to zero long term

- Taxes on combustion motor vehicles, to prevent relapse to fossil

\subsubsection{ETS pure-cap on Transport Fuels + National Subsidies}

The pure-cap type ETS+ on transport fuels is always combined with a pure-cap on electricity production. Its market orientation links to well-developed electricity markets, with a fully developed EU transmission grid or most effectively the Single EU Electricity Market. As the market price of the pure cap system alone can hardly be predicted it gives little guidance on long term dynamics in technology development and dynamics. In addition therefor more specific policies are added, almost all of the ones as specified instrumentation variant 1 for transport. There is one major difference. Emission pricing, not on fuels but on oil, gas and coal works only indirectly on fuel prices, with administrative implementation behind the (often coal heated) refineries, at imports and primary production. These market type prices are additional to current fuel excises. The introduction emission pricing by the cap works out very similar to oil price fluctuations which mostly have no consequences for the level of fuel excises. Such excises have mostly been already implemented before climate policy came and hence are without clear link to it. Subsidies to make non-combustion drive more attractive can therefore be lower than in instrumentation variant 1. Heavily subsidizing non-fossil drives would undermine the price level of the pure cap, possibly leading to its phase out, especially if such technology specific measures would be implemented in electricity production, industry and buildings as well.

\section{Summary (14): ETS pure-cap on Transport Fuels + National Subsidies for reducing emissions in Transport}

- Domain expanded to all transport: land, water and air

- ETS pure-cap price levels fluctuating and hardly predictably

- Very low permit price if technology specific instruments dominant, see ETS experience

- Very high permit price with cap dominant, possibly substantially higher than emission tax

- Open real time electricity grid preferably (type 4, or else type 3)

- EU transmission grid for electricity and hydrogen

- Recharging and refueling electric and hydrogen network obligatory for member states

- Temporary subsidies on electric and H2 fuel cell drives

- Increased taxes on combustion motors for faster phase out?

\subsubsection{ETS Price Stabilized on all Transport Energy}

The Price Stabilized Cap-and-Trade on all transport fossils would cover all oil products; natural gas and natural gas liquids, and coal derived fluids and synthesis gas. Together with the coverage of emissions in electricity production, industry and buildings all fossil inflows in society then are 
covered. This allows for the simplification by fully upstream administrative implementation, at primary production and imports of all fossil energy products. All fossil energy products then have coverage for their emission at incineration or other oxidation. Upon export of a fossil energy product, an amount of permits corresponding to its carbon/ $\mathrm{CO}_{2}$ content can be sold on the $\mathrm{EU}$ permit market. When the price is under the price floor, permits can be sold back to the government at the floor price. If it is rising high permits can be purchased from government at the ceiling price. The price of the stabilized permit market is specified in advance to guide long term technology development and investment. The market signal has some spread, so is not as clear as with the fully fixed emission tax. This requires a slightly higher price level on average as compared to the rising tax. The wedge between price floor and price ceiling may be in the order of $10 \%$, not just for transport but for all fossil emissions, though there is no clear reasoning for choosing a wedge or collar.

The Single EU Electricity Market is a logical complement to this method of emission pricing, or at least having an EU wide transmission grid.

Public infrastructure is in addition as for electricity also for hydrogen, the international transmission grid publicly owned by EU and member state organizations.

Standardization is limited, if no clear market agreement is reached for refueling systems for batteries and hydrogen. The EU coordinates standardization, preferably at a global level.

There may be limited subsidies for market creation of novel technologies, and limited taxes for moving specific emitters faster out of the market. The market correction to have in mind by 2050 is in the order of [400] $€$ per tonne of $\mathrm{CO}_{2}$, which translates into a price increase of $1.15 €$ per liter of Diesel and 0.92 cents per liter of gasoline.

\section{Summary (15): ETS Price stabilized for reducing all energy related emissions in Transport}

- ETS price rising predictably

- Domain expanded to also aviation and shipping

- Single EU Electricity Market (type 3 or 4)

- Public transmission grid electricity and hydrogen

- Some spatial planning as for modal shifts

- Limited standardization as for energy loading

\subsubsection{Emission Tax on all Transport Energy}

The emission tax covering all transport is part of the encompassing emission tax on all fossils. It is levied fully upstream at primary production of fossils in the EU and upon import of all fossil energy and energy products, as a product excise, and returned upon export of energy products and upon adequate CCS. CCS is not relevant in the transport domain directly due to the diffuse and mobile emissions, but is relevant indirectly, possibly playing a role in electricity and hydrogen production. All fossil emissions are covered this way, indirectly. Not returning the carbon makes you lose the deposit paid, creating an emission tax. This is the simplest form of administration for emission pricing, easily expanded to other countries. Proceeds of the emission tax system are distributed to member states according to their actual share in emissions. In the build-up stage of the emission tax to substantial levels the EU Fleet Standards may remain, in a revised version: purely 
based on $\mathrm{CO}_{2}$ emissions; encompassing, at least covering person cars, vans and small trucks together; and linked to real fuel use.

Infrastructure with monopolistic tendencies is public responsibility. Electricity infrastructure and markets have been set up for policy in the electricity domain already and deliver for transport (and building and industry) as well. For hydrogen, similarly, the infrastructure and markets are to be set up as well. This is to be done not just for making zero emission drives in transport possible but for reducing emissions cheaper and faster in other sectors as well. Simple options like connecting motor vehicle batteries to the grid for stabilization start to be implemented (recently in the Netherlands). For fuel cells linking their production potential to the grid would allow for substantial grid stabilization also for longer periods of time. Emission tax plus a single EU electricity market would drive this development, further based on private actions. There should be hardly any publicly funded RD\&D in the transport domain in the long term nor technologyspecific subsidies and taxes or emission and technology standards.

\section{Summary (16): Emission Tax for reducing all energy related emissions in Transport}

- Emission tax rising predictably, same for all sectors

- Domain expanded to also aviation and shipping

- Single EU Electricity Market (type 4)

- Public transmission grid electricity and hydrogen

- Limited standardization only, as for loading

BOX 4 Emission pricing and real time electricity markets for electric drives with grid stabilization Beware: This is not a prediction but an investigation of one corner of feasible technologies relevant for climate policy instrumentation.

Some examples may give an idea of the primary price effect induced by emission pricing, by the tax or by the tradable cap system, see Table 6 . At 300 Euro per tonne $\mathrm{CO}_{2}$, the price of Diesel would rise with 90 cents to in the order of 2.30 Euro per liter, disregarding here their market price reducing effect. This effect is roughly the same as for a price rise of oil with $135 €$ per barrel. With electricity for recharging at $0.25 €$ per kWh, electric trip costs, already lower at current prices, would become even lower comparatively. It then is the high purchase price of electric cars determining outcomes in terms of total costs. A Swiss study on currently available cars (see http://www.e-mobile.ch/index.php?pid=de,2,138) shows roughly similar overall costs for comparable car types now on the market, with advantages for electric drives if the car drives more kilometers, as with taxies and shared cars.

With the price of fuel raised by the emission tax there would be a clear advantage for electric drives, more so with further improved technologies. Using variable electricity prices would further increase the advantages of electric drives, using the low prices for loading and the high prices also for delivering to the grid, making money as secondary producer. So the attractiveness of electric cars may increase substantially if there is an open to all real time electricity market, helping stabilize the electricity market in the process. The example in Table 10 shows how a price difference between peak price and lowest price of 20 cents might work out on overall costs, assuming modest technological advances. Electricity market operations would earn the car owner around $45000 €$ over the life time of the car. Depending on the number of 
charging cycles a future battery can manage, a highly uncertain and even ill-defined number, some of the proceeds would have to pay part of an additional battery. If really so attractive, the price differential of 20 cents then would be reduced by this market force alone. The example is not a prediction but is to show the importance of real time electricity markets in intermittent renewables dominated electricity production.

Of course a choice for electric drive is not just cost based. Quality aspects, like driving range, speed of recharging, and availability of recharging stations are also main determinants, improving fast in the last decade. Public supply and public support for charging stations has already been effective in several cities and countries, especially Norway, see:

http://info.nobil.no/images/downloads/nobilbrosiyre.pdf. In combination with subsidies for electric cars the share of hybrid and full electric cars there has risen to $2 \%$ now, and is rising very fast, with a share in new registrations of $33 \%$ with the Netherlands following at $5.7 \%$ and the UK $1.2 \%$. Other countries are well below 1\%. (Source: http://www.forbes.com/sites/niallmccarthy/2015/07/23/norway-leads-theworlds-market-for-electric-vehicles-infographic/ )

Similar reasoning may be set up for hydrogen fuel cell cars, with slightly different characteristics for their grid connection: they can only upload their locally produced electricity, but they can supply flexibly over longer periods using stored hydrogen. Currently hydrogen charging stations are rolled out in Europe, starting large scale in Germany, and Japan.

Table 10 Electricity market operations with car battery (1 car, 10 years)

\begin{tabular}{|l|r|l|}
\hline Battery capacity in kWh & 100 & $\mathrm{kWh}$ \\
\hline De-charge at peak price hours, twice daily: & 50 & $\mathrm{kWh}$ \\
\hline & 25 & $\mathrm{kWh}$ \\
\hline Market activity nr of days per year & 300 & \\
\hline Difference peak price - low price & 0.20 & $€$ \\
\hline Proceed market operations & 4500 & $€ /$ year \\
\hline Proceeds of 10 year operation & 45000 & $€$ \\
\hline Additional battery cycles per year & 100 & \\
\hline Battery cycles per battery life time & 1000 & $*$ \\
\hline Additional battery replacement & $? ?$ & \\
\hline New cycle after 10 years, in new car & PM & \\
\hline *Tesla model S (2013-14) has capacity loss now 5\% per 50 000km \\
\hline
\end{tabular}




\section{Towards full sets of instruments for long term climate policy 6.1.From satisficing and optimizing to deep transitions and transformations: timing}

The deep transformations required for deep emission reductions by 2050 first require political determination. That determination is presumed here in principle, and then the question is: how? There must be a practical choice now, as a choice for coherent instrumentation specified towards that accepted goal. Day-to-day improvements in instrumentation and optimization of instrumentation are important but lack the overall zeal required for deep transitions. The choice on basic directions for instrumentation may be postponed, but then essential instrumentation will not be specified now. Effectively, this would mean that the instrument pathway for deep reductions is not specified now. This seems a most realistic assumption, sadly, that the 2-degrees instrumentation pathway from now will be decided on later. This implies that current too slow pace of emission reductions will continue, with faster reductions to be implemented later. Continuing the current rate of $\mathrm{CO}_{2}$ emission reduction of around $1.5 \%$ till 2020 will require emission reductions from 2020 by $-4.5 \%$, to get at the $80 \%$ reduction by 2050 , and substantially higher to get to $90 \%$ or $95 \%$ reduction, by $-7.5 \%$ or $-9.5 \%$ per year as is required in several domains. A most realistic route politically seems to have the transformative instrumentation decided by 2020 , leaving 30 years for the deep emission reductions, stressing the Hirooka 35 years rule $^{30}$ already (Hirooka 2006). A substantial part of the economic transformations has to have taken place well before 2050, due to stock mechanisms. For person cars stock replacement is substantial in a decade, requiring a fully zero emission fleet sold by 2040 latest, but for trucks and buses earlier. For fixed installations the life time may be much longer so to avoid misinvestment and guide the right investment, policy instrumentation has to be in place much earlier. Some intermediate technologies like gas fired power stations, may reach their end-of The long term horizon towards 2050 therefore requires basic instrumentation choices as soon as possible, in a full policy preparation sense by 2020 . Fixed infrastructure has the longest life time, requiring infrastructure choices now already to be made with a near zero emission future in mind. Satisficing and optimizing towards 2020 is not compatible with the 2-degrees goal.

\subsection{Main entries to instrumentation, over all sectors}

The methodology for strategic instrumentation design first starts from now, and looks into developments required. That step has been gone through in the previous chapter 5 , for the four main sectors distinguished there. The second line of reasoning is instrument-technical and based on more abstract reasoning. Instruments can be ordered as to generality of application and with more technology specific instruments as to their bindingness, see type 1 to type 4c in Table 3 . Instrumentation design then is to refer to Sparseness, Completeness and Non-Overlap, see Chapter 4 and specifically Section 4.2.5. Consider the most generic options first and then add towards full coverage while avoiding overlap. The third entry to design relates to desired modes

\footnotetext{
${ }^{30} \mathrm{His}$ analysis shows that deep innovations, if successful, get to their fullest speed of market development typically after 35 years, slowing down to full saturation thereafter.
} 
of governance, in general, and specifically for climate policy instrumentation. Two main strategic governance directions are distinguished, a Planning \& Control Strategy and an Intuitionalist Strategy, see Section 3.3. Planning \& Control links to a direct public task in technology and market development, with substantial use of technology specific instrumentation, but still: as sparse as possible. There is a close public-private relation for fast and controlled development, also of infrastructure. The Institutionalist mode links to the institutional framework primarily, creating long term incentives, and leaving more concrete developments mostly to lower administrative levels, private parties and civil society in general. There is a sharper delineation between public and private responsibilities. Strategic design is not about details of instruments and their implementation but about the main structure and set-up. Is emission pricing uniform over all sectors? And if not why not, as economic and administrative advantages are clear? Such strategic choices precede the detailing of instrumentation, which will always be substantially on-the-go. The why question is basic. Why go for the price stabilized cap-and-trade, as compared to the pure cap and the pure emission tax? In the final design strategy governance takes a prime role, reckoning with bottom up developments and with the logic and tactics of developing instruments and instrument mixes.

The bottom up line of reasoning builds on the four instrument mixes per sector of the previous chapter. Starting at the four basic options of emission pricing, four instrument mixes resulted per sector based on the prime choice on carbon pricing: No emission pricing; pure cap-and-trade; price stabilized cap-and-trade; and pure emission tax. In principle the four instrument mixes linked to each pricing system can be added over all sectors, with not well fitting overlaps resolved. For example, the four sector sets with emission tax can be added. This results in: one uniform and upstream administered emission tax; a single real priced EU electricity market; public infrastructure for long distance transport of electricity and hydrogen; RD\&D focused at research; and some more technology specific additions for speeding up transformations. This is a bottomup and instrument-technical approach to instrumentation, with only a sniff of governance in it. The open real price electricity market fits to the emission tax in a governance sense, but was also argued on pure efficiency considerations, as for reducing the costs in industry in reducing emissions.

In the development per sector the abstract design principles were followed, starting generically in the institutions domain. However, the bottom-up approach with instrumentation theory then also included: no carbon pricing, for governance reasons. A strong focus on Planning \& Control requires technology specific instrumentation, making the pure cap-and-trade system which was starting point superfluous. The instrument mixes as developed for the four main sectors are here combined into full sets of climate policy instruments. As there are four variants per sector sixteen combinations could result. This would assume independence of all elements, like having four different options for emission pricing in the four different sectors. However this seems to lack governance logic and is cumbersome administratively. It would imply to treat emission from natural gas, from coal, and from oil and oil products differently according to their sector of use, like natural gas for industrial furnaces treated differently from gas used in electricity production, for room heating, and for transport. So the four different options for emission pricing (no pricing; pure cap; price stabilized cap; emission tax) first link to four overall sets of climate policy instruments. Upstream applied emission pricing covering all emissions avoids boundary complexity and reduces administrative requirements substantially as compared to within-system 
application. So, to start with, in any strategy there is only one type of emission pricing, cap or tax, equal in all sectors, or there is none.

In the second step of the design methodology the instrument typology next main instruments have to match consistently. In a pure cap-and-trade system restrictive standards for coal fired power stations and subsidized renewables violate the sparseness and non-overlap criteria. They just don't make long term sense: they are wasted policy effort and wasted public money. Coal will lose out anyway and renewables receive an indirect subsidy by having their competitors' emissions priced. From some strategy point of view one might choose for the standards and subsidies instruments; but then the cap system would be superfluous. Similarly, having electricity markets dominated by swing producers with contractual relations with energy users does not fit well with an emission tax, as the price signal of the tax is not translated into the market price at times when fossils still are the marginal producers. A relation with governance strategies certainly exists but the reasoning here is purely instrument-theoretical as yet. A final issue in instrumenttechnical reasoning goes against sparseness in instrumentation: Add instruments to be sure that the climate target is reached even if they overlap. This is different from reasoning out of encompassingness, which may also lead to some overlap. The example is again technologyspecific instruments as for bringing renewables and secondary electricity production in the market, and many more, in parallel to a pure cap-and-trade system. Would it be feasible to have two fully overlapping sets of instruments available, each capable of reaching the climate targets in its domain effectively in principle? The consequences for further instrumentation are mind boggling. What is the public role in developing infrastructure; which type of electricity market is to be developed; how to deal with public-private partnerships and with technology demonstration? This to-be-sure argument also is a dangerous one however as chances are that neither instrument set is effectively developed as the other one can take over. Would it be feasible to have and keep the highly complex cap system operational and updated if the technology specific instruments effectively do the job? And conversely; with cap high priced and causing hardship, as it should in reducing emissions, would additional technology-specific hardship be accepted? With neither system being really operational there is the danger of instrumentation collapse. More specific reasoning for choosing instruments into an instrument mix seems required, avoiding overlap as much as possible.

The third element in the design methodology refers to governance strategies. It may technically be possible to have technology specific instrumentation matched with an open real time electricity market. But why choose this combination? The reasoning involved would have to link to some idea on governance, as the technical logic would link technology specific instrumentation to technology specific support on renewables and secondary electricity production, making open markets difficult if not impossible. This combination would however not fit in either of the governance strategies distinguished here. The Planning \& Control strategy would not put main effort in building up an open real time electricity market, which would reduce instrument options for technology specific policy. The Institutionalist strategy would put emphasis on electricity markets and other institutions so as to have a most generic incentive effect, avoiding technology specific instrumentation as much as possible. Mixing just cannot lead to clear instrument development.

In the next chapter the governance oriented approach is developed, screening from the sector mixes what is technically possible, from the perspectives of the two governance directions. This 
screening process results in only two sets of instruments in the long term: a Planning \& Control Mix and Institutionalist Mix.

\subsection{Reduced emission pricing options in long term strategies}

The instrument-technical reason to have emission pricing is to guide private actions towards emission reduction. In long term reasoning, pricing is to guide public and private behavioral choices towards the desired low emission future, regarding infrastructure development; research; research \& development; and ultimately private investment. It is not current emission prices which are relevant but long term expected prices. The two main pure pricing options, cap and tax, differ in that the pure cap prices are uncertain long term and the pure tax is fixed long term. However, there are uncertainties related to political vulnerability which reduce the difference, as the freezing in the rise of the UK Floor price tax has shown. These political vulnerabilities extend to the pure cap as well: at irrelevant low prices the volume is reduced, as currently with the Market Stability Reserve in the ETS, and at exploding prices, the volume will be increased, to reduce prices and avoid short term damages to national industry. In this respect the difference between cap and tax is not so absolute: the Pure Cap will evolve into a Hybrid Cap, with an implicit price path.

There then is a next line of more formal reasoning. Shifting from an implicit to an explicit price path gives more guidance for long term emission reducing behavioral choices. The next question then is: why have a price collar? The price variability plays a key role in the pure cap system; to distribute the given amount of permits over all emitters in a short term optimal way. But with volume adaptation the floor and ceiling of the collar clear the market by volume adjustment. The collar has no climate policy function, and worse, the collar obscures the long term price by allowing price fluctuations. Stating the mid value explicitly and reducing the price variation are clear improvements, ultimately leading to a fixed price system. The upstream administration, covering all fossil emissions was assumed already, so the fixed permit price transforms the cap system into a tax-like system, with conceptually and operationally simpler set up of an excise. This is instrument-technical reasoning. How would the reasoning from the two other entries to strategic design look like, the strategic governance views and how to develop from now?

The Institutionalist Strategy directly links to the emission tax. The Planning \& Control Strategy has a less clear link however. On the one hand, a fixed emission path, following yearly emission reductions, is attractive. That does not seem feasible however due to interference with other more concrete instruments, like feed-in tariffs, leading to low prices and, without them, steep price hikes being near unavoidable. Development into a price based system is covered in the institutionalist approach already. So the strategic logic in Planning \& Control is to go for control one step deeper, at the level of technology specific instrumentation, leaving the emission pricing domain.

How could these two strategic options materialize, starting from now? Currently, the ETS has a long term (and short term) irrelevant price level, with emission reductions effectively being realized by bringing renewables into the market with subsidies and by emission standards in electricity production and transport. The two directions for development seem both feasible in an instrument sense. The current ETS can be domain expanded, with administrative implementation moving upstream. It can be stepwise price stabilized, on a rising price path, reducing price variability to zero, and finally administratively be simplified into an emission tax. 
The other line of development is to bring more coherence in the EU coordination of technology specific instrumentation. Renewables and secondary electricity production can be subsidized in different ways and at different levels, also covering decentral production as in private households. Bringing unity in set-up and some unity in levels - similar to current treatment of national fuel excises - would create more options for national development. Standards have been harmonized at EU level for road transport in Fleet Standards and for many products in efficiency standards. They can be expanded. Currently emission standards in industry mostly lack climate emission standards. These may be introduced more actively in the BAT regulations of the Seville process, implemented nationally. Emission standards in electricity production are nationally diverse or lacking, and could benefit from unification, creating an equal playing field across Europe. Emissions from buildings currently are mostly regulated from an energy perspective, as in obligations for energy efficiency specification and more detailed national requirements. EU rule making could indicate more direct climate relevant requirements, as on heating and cooling technologies, ultimately regulating out direct fossils use, or requiring member states to do so.

The conclusion on emission pricing development here is that current instrumentation may develop in the two directions coming out of instrument-technical considerations and strategic governance considerations. They are active EU and guided member states instrumentation in a technology specific direction, and an EU level specified emission tax implemented at the national level, with technology specific developments and instrumentation left to member states, firms and civil society. The four options for emission pricing investigated in the sector analysis in Chapter 5 are reduced to two: no generic emission pricing and the encompassing emission tax.

\subsection{Developing Planning \& Control and Institutionalist Instrument Mixes \\ 6.4.1. Strategic choices on emission pricing: not pure cap-and-trade}

The pathway for the two strategies will have to start at the mixed system we are currently in. First we have an ETS of a near pure cap type; with a limited domain of application; applied to direct emitters; with a permit focused administrative implementation; and with now a too low price to guide long term actions. Second, it is combined with technology-specific instruments mainly at the member state level, currently the most successful instruments. If remaining the most effective instruments, the ETS would be insignificant. If the ETS would take over, decentral measures would be insignificant. For neither strategy this contradictory approach is an acceptable state of affairs, and certainly is not the basis for long term strategic instrumentation. The pure cap-and-trade system has two basic flaws, to be resolved.

A first requirement relates to emission pricing. Clear explicit long term emission price guidance is one main option, as with the emission tax. The other is price based technology guidance to be realized for the long term, with indirect price considerations guiding the choices on technology stimulation and prescription. Secondly, the pure cap-and-trade system now makes local initiatives and creativity useless for emission reduction, as only making emissions for others cheaper. Only short term economic considerations would be relevant for emission reductions, messaging a poor view on a responsible society. A city creating a low emission transport system just reduces emission prices so others can emit more cheaply. A strategy based on this instrument would falter due to collapsing legitimacy. 
Could these deficiencies be mended, keeping ETS as a pure cap-and-trade pricing system? The price instability seems difficult to mend, as unpredictable market forces determine price developments. Aligning other instruments to keep the permit price in a certain domain is technically possible but lacks justification. If such other instruments are so effectively available, why also have a complex tradable cap system? And if the price signal is to be clear, price stabilization seems a most direct option available in a political sense now already, as the support in the EU Parliament for the Market Stability Reserve shows. But then the ETS leaves the realm of a pure cap-and-trade system. Also on the short term already the emission price is to be brought to a relevant level, see (Drummond 2015) Section 3.1, leaving the realm of pure cap-and-trade. The second deficiency seems more basic. In a liberal society local government bodies and civil society play a key role in policy development and implementation. Restricting decentral actions to short term market mechanisms seems a sure road to high costs of climate action as potentially interesting initiatives are made ineffective. Private responsible behavior, like lowering the thermostat in office and at home and cycling instead of car driving cannot reduce emissions under a well-functioning pure cap-and-trade system. Low emission cities may reduce emissions locally but don't reduce emissions overall. The message that this is the case may take some time to arrive, but the message is there in public publications now already. Legitimacy of such climate policy will dwindle, killing effective climate policy in the process as long as a pure cap-and-trade instrument remains core.

So though being the actual starting point in time for any strategy, the current pure-cap ETS cannot be the core in a long term instrumentation strategy.

\subsubsection{Strategic choices on emission pricing: two pathways and directions}

Governance strategies indicate desired directions and function as a filter for development of instrumentation. Does a development fit? In the Planning \& Control line, there is no objection to have a pure cap system in the background as a remnant of the old; in a certain way it links to the planning mode, but at an institutional level only. But it is not core of that technology specific strategy and there is no drive to its improvement: technology specific actions are required long term and with quite some urgency now already. Expanding the domain of application of ETS has no priority. Without active maintenance of an administratively complex instrument it will succumb on the first hurdle or it will just fade away as when firms don't really comply with their substantial administrative tasks. From an institutionalist point of view, the disadvantage of a wellfunctioning pure cap system is that it reduces low emission development into a purely market economic process, detrimental to all bottom-up initiatives, public or private. The lack of long term price guidance creates unnecessary costs and bottlenecks. These disadvantages increase with the all-sectors application as will be developed in the emission pricing system, covering all fossils, and more. A first step therefor is to make the permit price stable and predictable, by setting a floor and ceiling price. That is a move from a Pure Cap system to Hybrid Cap system. But why have a difference between floor and ceiling? Price fluctuations have no function. If prices go up and down between floor and ceiling, the price signal is weakened without good grounds. The logic therefor is next to reduce that difference to zero. The permit price then is fixed, on a rising path. But is still is permits, with substantial administrative complexity, as in matching permits with carbon flows on a yearly basis for all firms involved administratively. Replacing the yearly administration per firm with a transaction administration as also used for value added tax is a substantial 
simplification, bringing emission pricing in the well-developed domain of taxes and excises. The system then has been transformed into an emission tax.

The choice for either governance direction in climate policy instrumentation is not one made yesor-no at a certain date. It is the considerations involved which may lead into the one or the other direction. Also, some shifts in instrumentation may be possible in special circumstances only, as when political blockages are alleviated following extreme climate events. Such soft considerations may be valid. Here a choice is assumed to be made effectively by 2020 , from then going in the one or the other direction.

The conclusion in this governance strategy analysis is that two clear instrument pathways evolve. In the Planning \& Control Strategy technology specific instruments are broadened and strengthened, with the ETS-type pure cap system going into oblivion. In an institutionalist strategy the ETS-type emission pricing is actively developed towards price stabilization, ultimately into an emission tax with adjoining instruments. These two pathways will be detailed in Chapter 7.

\section{Pathways towards Planning \& Control and Institutionalist Instrumentation}

The pathways towards covering instrument mixes require different organization for the two governance strategies. The bottom up analysis starting at sectors may be linked quite directly to the planning \& control strategy for instrument development, with some general considerations for choices. In the institutionalist strategy this sector and technology entry is to be avoided: it starts it with generic instruments with only some gaps filled in with technology specific additions. In the planning \& control mode, the active role of governments is instrumental towards private parties primarily, with public tasks added for effectiveness and efficiency, and often using publicprivate partnerships. In the instrumentalist mode there are well-defined reasons for incentive creation and for purely public provisions, as with monopolistic infrastructure. It leaves the private domain more independent within the confines of strong institutional incentives. The instrument mixes for the two strategies are developed in turn.

\subsection{Long term Instrumentation in the Planning \& Control Strategy \\ 7.1.1. Instruments development strategy}

The thrust of instrumentation is directed at private technologies and the corresponding behavior, at Level 4, with direct public tasks following, at Level 2 and 3. The most successful schemes can be strengthened and can be expanded so as to cover a full low-carbon electricity system using standards and subsidies; a nearly full low carbon transport system mainly by using standards; major improvements in industry by dynamic BAT based standards and transition subsidies; substantially reduced emissions from building, using zero emission standards for new buildings and subsidy and standardization programs for refurbishing of existing buildings, including subsidies for heat pumps and heat storage. 
The instrumentation strategy first follows the order of generality of the instrument typology, see Table 3.

Level 1 instruments first involve emission pricing. The ETS is first left in place, with limited domain expansion and very incidental cap adjustment. Active and effective technology specific instruments will further undermine its role for a substantial time to come, with very low price levels not relevant for long term decision making. If so, the demise may come of this administrative complex instrument. Maintaining a complex instrument that does not have a function seems highly improbable and certainly is not part of a long term strategy. The ETS either fade slowly or stop by an explicit decision to halt its functioning at a certain date, not going for a next trading period. Conversely, not with low but with exploding prices, as with limited effectiveness of technology specific actions and high economic growth, the logical step is to increase permit volumes. That would change the pure cap system into a price-based cap system, as a hybrid cap, preferred by (Goulder and Schein 2013). It then would shifts to ultimately developing into a carbon tax, key instrument in the institutionalist strategy. So in Planning \& Control the ETS remains with a limited role or vanishes, its function taken over by more technology specific instruments at level 4.

The ETS domain now involves electricity production and emissions in larger industries, with however technology-specific subsidies and user-specific taxes as dominant instruments in the electricity domain. Electricity market institutions therefore now are substantially national and fragmented, even if not based on feed-in tariffs but feed-in premiums and capital subsidies. Market functioning is limited, also requiring capacity payment to avoid breakdowns of the mainly national grids. Bringing all production and grids under national control is nearly unavoidable, according to (Finon 2013). More modestly, (Díaz-González, Hau et al. 2014) indicate detailed requirements on country Grid Codes to accommodate intermittent renewables.

Instruments at Level 2 and 3 have substantial overlap and subtle differences between the strategies, developed together below, in Section 7.3. As instrumentation substantially involves national instrumentation, the EU distributes EU emission targets to the member states.

The technical descriptions given in Chapter 5 give the starting points per sector for technology specific instrumentation. Standards play a core role in all four main sectors, their stringency based on leveling burdens between sectors, also using the subsidy instrument.

\subsubsection{Instrumentation in the electricity sector and large industries}

In the electricity sector emission standards for all fossil using electricity and for fossil heat production are set up for new installations, on short notice. They specify the allowable $\mathrm{CO}_{2}$ emissions per kWh and megajoule of heat, going to zero on short notice, with few exceptions like for back-up power, remote islands and some industry integrated electricity production. With a time delay these standards are applied gradually to all existing installations as well, pressing out fossils in a clear time path. At the same time, the renewables revolution is forced in, mostly by subsidies on renewables, subsidies on public-private grid expansion, and subsidies on storage systems, both at micro level and at larger scales. To keep electricity production and demand balanced, capacity payment is introduced on a large scale, especially for variable fossil production with natural gas. Phasing out fossil capacity payment is delayed till there is enough build-up of other capacity, including variable secondary capacity for load balancing. Then variable fossil production can be closed down, with compensation payment. 
The possible role of CCS is incorporated in the emission standards, allowing for the CCS storage to be deducted from actual emissions. The CCS storage is to be incorporated net of emissions required for that CCS, reckoning with upstream emissions as for the additional energy and the materials required. Similar rules apply for other large scale stationary emissions, as in iron \& steel and cement production and refineries. For large scale centralized CCS, like in the Norwegian Sleipner field or depleted gas fields, a transport infrastructure would have to be developed, in public-private partnership with fossil electricity producers and site owners, and possibly involving coal and natural gas producers.

\subsubsection{Instrumentation in the industry sector}

More specific instruments will take over from the ETS, contributing to its demise. Fossil heating is are phased out similar to the phase out in buildings. Fossil power might be brought under a regime similar to road transport, if not integrated in industrial processes. In all more complex cases generic prohibitions and prescriptions for phasing out fossils are difficult to apply. Then detailed more technology specific prescriptions are used, based on dynamic BAT (Best Available Technology) specification, combined with subsidies to ease the change-over. These standards apply to new installations, and with a time delay are applied to existing installations. Dynamics are created by moving the Best Available Practice into a low emission direction, through joint public-private development of technologies, cooperating with advanced companies. Noncompliance with the new standards does not lead to closing of the industry but to a rising fine related to the estimated volume of over-emission, similar to the fine in current ETS and Fleet Standards. The rising fines structure is set up so that by 2030 most firms adhere to the general BAT based standards, following the BAT specifications as have effectively been developed by then, and continuing that BAT development. In industries where application of these instruments would lead to their bankruptcy, temporary support mechanisms are set up, including subsidies and access to low rates capital markets for either transition or their managed close down.

This standards based approach is not always possible however, as for large emitters in iron and steel production; clinker production for cement; refineries; and chemical industry. For iron and steel some efficiency improvement is possible using cokes based production. Public R\&D on noncokes based production might maybe have long-term success. Clinker production will increase, with coal based clinker substantially decreasing. Reducing cement use can reduce clinker emissions, as involving green concrete options. Refineries will process a fraction of current oil volumes by 2050, with traffic decarbonized. They remain producing for the chemicals industry, including coating and plastics. For all these industries, emissions can be measured quite well. A rising share of subsidized CCS is prescribed for such firms with fossils derived emissions, with credits tradable between them.

\subsubsection{Instrumentation in the transport sector}

In the transport sector, there is differentiated policies regarding different transport modes. Road transport, including non-person transport, is most homogeneous and can be covered by relatively generic instrumentation, expanding on current Fleet Standards. Transport $\mathrm{CO}_{2}$ emissions come from oil, with as yet very small amounts of other fossils-based fuels and natural gas. Fleet 
standards are transformed to reduce total transport emissions predictably by the total fleet sold, not just the average emissions per car as currently is the case. Compensation and certainly premiums for weight and share of non-fossil drive systems in the fleet are removed, transforming it to a pure emission standards system. Also, the distinctions between person cars and vans is removed, which is a difficult boundary in practice now. Next the instrument domain is expanded so as to also cover heavier transport, made possible by a further adaptation, referring to total expected emissions of the fleet. The expected life time emissions per vehicle type constitute a first element, based on expected life time in kilometers per type, times emissions per kilometer. Type-specific emissions are measured realistically, as by a representative set of on-road vehicles in the EU. These simplifications allow for full coverage of all road vehicles, then also trucks. The number of vehicles sold is the third element, not present in current Fleet Standards. Life time driving distance $x$ average emission $x$ number of cars sold constitutes the emission volume specified in the Fleet Standards, one unit per credit. As also in US CAFE standards, see (ICCT 2014), credits may be traded. With the expected emission volume of the fleet sold not reducing enough, the producer has to obtain additional credits from other producers. A fine for non-compliance may create some short-term flexibility, functioning as a price ceiling similar to the current fine in the ETS. The fine is long term rising. Fleet standard lead to delayed emission reduction in the allages full transport fleet, related to vehicle life time, in years. Standards for the new fleet sold are therefore advanced on the emission target for the full fleet. For near zero emissions by 2050, the fleet standards should be zero-emission ultimately by 2040 . This implies a reduction rate of life time emissions in the fleet sold in a year to over $10 \%$ per year, if starting now ${ }^{31}$.

To reduce the substantial stock delay effects, there are subsidies for scrapping older fossil combustion vehicles, starting roughly mid Thirties. To ease the process of decarbonization, there also are subsidies for new types of zero emission vehicles when they start to come on the market, to create learning curves and overcome lock-ins. This process has been gone through for electric cars by 2020 and then applies to heavier vehicles only, roughly above 3.5 tonne of mass, and may include hydrogen driven cars, including fuel cell drives. The hydrogen supply for fuel cell drives in transport is regulated to be emission free, not using the production facilities based on natural gas as now exist for industrial use. LPG can be phased out directly now already, being a most expensive way of driving, in real terms, with a transition period of maybe a decade. This is not a serious problem for users as they can easily switch back to gasoline. The share of Diesel may depend on air quality issues, but both gasoline and Diesel will be on a strong downward curve. If air quality issues remain, the earlier phase out of Diesel drives might simplify the transition to non-fossil drives. The US non-Diesel fleet may be taken as an example; there is no basic problem in doing so. Differences between countries in their tax and subsidy schemes are evened out somewhat, in the process reducing their variety, now including vehicle purchase taxes and exemptions; VAT differentiations vehicles; annual registration taxes and exemptions; scrappage taxes and subsidies; fuel duties and excises with differentiations; VAT differentiations on fuels; road use charges on different bases; and public parking price differentiations, all with further subdifferentiations as to domain of use. The reasons for differentiation between countries differ but certainly include tax competition reasons (see (Máca, Eberle et al. 2013) p71) and creating advantages for own sectors relative to similar sectors in other EU countries. There may be a role

\footnotetext{
${ }^{31}$ Reduction by $95 \%$ over 25 years implies compound reduction rate of $11.3 \%$ per year; over 20 years $14 \%$.
} 
for the Commission to end tax competition and industrial competition through national fuel tax and other transport policies. However, from a climate point of view, simplified fleet standards take over. Other measures may also have positive outcomes on reducing emissions but are not part of EU climate policy. Adaptation to non-fossil drives and using their incentives for the changeover is well possible, especially if the national tax competition is ended. For all these major transport instruments, more smaller scale instruments may be added, like preferential car parking for electric cars; bus lanes open to electric cars; freedom from road pricing, etc., but this is not part of EU policy or policy guidance, and seems useful temporary only, before non-fossil drives become dominant.

Infrastructure development for modal shifts focuses on high-speed rail (and similar) transport to reduce aviation volume. Standards will not be able to substantially reduce emissions in aviation, so curbing the still rising travel volumes seems the only option. Bringing aviation in the normal tax domain is a priority now, including fuel taxes similar to Diesel taxes, where the Commission has set EU wide minimum levels already for road transport. A softer task is in reducing traffic in cities, by making them more amenable for slow traffic: walking and cycling. There are highly successful examples in Europe already, where broader adoption would reduce road traffic also in the longer run with reduced private car ownership and increased use of car sharing systems. Such developments may be attractive medium term and for other reasons but have limited long term impacts, when all road transport has mainly been decarbonized, like rail transport already is.

\subsubsection{Instrumentation in the buildings and appliances sector}

Electric appliances are difficult to cover with generic standards, but will use near-zero emission electricity by 2050. Appliances based on natural gas and coal, like terrace heating and some stoves, will be phased out, possibly replaced by electric ones. For heating in buildings, natural gas is dominant now. Reducing emissions on the short and medium term for existing stock can be through better insulation and heat recovering ventilation, reducing gas use in heating. In the long term strategy however, heating and cooling must be (nearly fully) electricity or clean hydrogen based, as is substantially the case now already in Japan. All fossil heating is phased out, including mixed heating with renewables. No coal is allowed in wood pallet ovens. The phasing out of natural gas heating is in stages. For new buildings it is very fast. Fossils-free heating and cooling standards are introduced as soon as possible. It is easy to implement and avoids costly refurbishing later. In the first years after 2020 new buildings cannot use gas heating anymore and have to be highly insulated including obligatory heat exchangers on ventilation. For existing buildings natural gas is phased out in two different ways. First there is a subsidy program connected to the refurbishing of existing houses, which does not allow for natural gas (or butane, propane, etc.) heating anymore. Secondly, city districts are systematically disconnected from the natural gas grid, in a planned operation, latest with the oldest housing areas, and starting with areas where major maintenance is due, with buildings around 30 years of age. Subsidies for all fossil based systems are halted directly, including micro combined heat and power (micro-CHP) and similar district systems at block and district level. Options for district heating with renewables are investigated, feeding current district heating transport systems, first as demonstration projects, with larger scale introduction based on the economics of these projects. Options for replacing natural gas distribution with clean hydrogen distribution are investigated. They allow for a smoother changeover to low emission heating, with electricity jointly produced when 
advanced technologies are introduced in a building. A larger scale shift from natural gas to hydrogen distribution is decided on when cost considerations can be better filled in. It might be interesting to combine hydrogen distribution with loading of hydrogen based fuel cell cars, these possibly delivering electricity to the grid at peak demand, as could battery electric cars do. Larger hydrogen fuel cells in buildings might also play a role in electric grid equilibration, especially if direct solar hydrogen could outcompete non-fossil electricity based hydrogen.

To all major instruments, smaller scale instruments may be added like minimum efficiency standards for specific electric apparatus; quality standards for LED lighting; non-LED lightbulbs phased out; smart windows installation subsidies; and hundreds more. Instruments to create learning curves, at Level 3, focus on promising advanced systems, like combinations of heat pumps; heat/cold storage; solar; geothermal heat; and more.

\subsubsection{Generic instrumentation}

Public financing mechanisms are set up to help transfer to the often capital intensive transitions to low carbon systems. The power asymmetry in landlord-tenants relations and the limited time horizon of tenants and households leads to underinvestment in energy efficiency and emission reduction. Some institutional corrections might be relevant in some countries, like that emission reducing investments in buildings by tenants are not a reason for raising their rent. Conversely, tenants should cooperate with owners who want to improve their property. The tensions resulting seem unavoidable. The EU can supply countries with draft legislation for this complex issue.

Direct public tasks further relate to the organization of the electricity market. With many subsidy schemes in place, market differentiation both for producers and users will be unavoidable, also limiting international trade in electricity. This is especially the case for nationally implemented schemes, where subsidies will not be paid abroad and surcharges not paid on exports, which then easily become export subsidies. The task of the Commission is to create some base rules for national subsidy schemes and their corresponding funding mechanisms. This directly links to keeping intact as much parts as possible of the Single European Electricity market. Unbundling and forcing in the physical infrastructure for international DC high tension transport are minimum requirements, allowing for at least reasonable bilateral trade. Where more than two countries border, regional organization may emerge, especially where cables may be laid easily as now developing in the North Sea and the Baltic. However, markets remain national substantially. Adequate capacity is based on capacity payment on primary production and on subsidies for secondary production, with in exceptional cases standards, as on making some back-up capacity obligatory in firms and households, similar to obligatory back-up capacity in hospitals. The electricity market is of type 1 or shifting to type 2.

In the infrastructure domain there is a further task in standardizing loading and charging stations, also fast ones, and in safeguarding their broad availability. After substantial shifts to electric drives this can further be left to the market.

There is a major research efforts for all four main sectors, with priority for industry to actively develop 'new-BATs'. Developing decarbonized technologies in industry has the highest priority for process integrated energy use, where decarbonization requires smaller or larger redesign, and then also substantial investments. For all industries dynamic BAT specifications are to be made as a basis for standard setting, to be based on newly developed technologies with active public 
support at EU level. This will require substantial funding of R\&D and Demonstration projects, in a broad industrial domain. The share of basic research will therefore be smaller.

\subsubsection{International aspects under Planning \& Control Instrumentation}

The international agreement under planning and control specifies a binding emission cap per year, reducing long term by over $80 \%$, for the EU and most countries, see (Hare, Stockwell et al. 2010). Agreement partners must verify their emissions administratively, requiring national emission planning and control. The international climate agreement is not linked specifically to this Planning \& Control instrument mix, only to its results. In the planning mode of thinking however, emission reductions would be specified in some detail, in line with current negotiations on caps per country per year. The international cap discussion now is closely linked to tradable caps, as tradable emission permits within and between countries, see the discussion by (AlexeevaTalebi, Löschel et al. 2009). Tradable emission permits are however not part of this instrument mix, so internationally tradable permits cannot play a role. See for example (Raupach, Davis et al. 2014) for possible distributions of the global emission budgets in time. The volume of the national caps as internationally agreed may be linked to heterogeneous national approaches and circumstances, see (Hoel 2011) and (González-Eguino, Iñigo et al. 2015), ultimately requiring negative emissions, like based on CCS of biomass energy, see (Fuss, Canadell et al. 2014). The nature of the international agreement on caps may differ, especially in bindingness and encompassingness, see the scenarios as distinguished in the CECILIA2050 report by (Zelljadt 2014), which however are all based on national cap-and-trade systems, not linked to agreement versions like in (Mackay, Cramton et al. 2015).

The border adjustments considered may refer to two very different types of cost differences, created by transfer payments to government as by emission pricing, or created by the real cost of emission reductions induced by any type of instrument. The transfer costs are easier to establish as proceeds are at least know in total. In this Planning \& Control strategy they hardly play a role however, transfer payments being dominated by subsidies. The real cost differences remain. Whatever the nature of national policies, there will be competition effects vis-à-vis countries with limited or with no climate policy in place, or other policies, like taxes versus subsidies versus standards. Specifying such cost differences is cumbersome however, being part of total relative cost differences which form the basis of mutually advantageous trade. Long-term BTA prices cannot be specified at all, but are low according to models indicating low real costs of climate policy. The level of border tax adjustment (BTA, also as BCA, Border Carbon Adjustment) when going into real costs differences due to climate policy is based on a counterfactual: what would the cost have been in the two countries with, or without the cost inducing climate policy, but then also including the cost reducing effects of climate policy as with development of open electricity markets and capacity payment for electricity production technologies. That route may easily lead to trade conflicts, as the border tax adjustment will be disputable, see (Holmes, Reilly et al. 2011), and given political processes often rightfully so. That discussion has started already, with the EU being seen as inconsistent in its climate related actions towards China, see (Voituriez and Wang 2011), not as a final answer but to show the complexity of this discussion.

There is reasoning towards the use of proceeds from border tax adjustments for funding of measures in poorer countries, see (Grubb 2011). This option does not pertain to proceeds from international trade in permits, where payments are to the owners of permits in the other country. 
Such a supranational use of national border taxes, which would hardly come about even in the EU, would create a further incentive for the export tax in non-climate policy countries, to avoid proceeds going from national discretion to a global goal.

The most encompassing international competition issue in the EU is at country level, see (Kuik, Branger et al. 2013). For the EU long term effects will be difficult to discern, as factors determining relative attractiveness of national goods and products are manifold. There is no accepted theory on the backgrounds of international specialization. Also the absolute levels of costs are not the most relevant issue but relative costs, linked internationally through long term adjusting exchange rates. There hence is not much reason to incorporate international trade aspects in climate policy instrumentation based on real cost differences. The capacity to grow, level three in the OECD framework of competitiveness analysis, see (Kuik, Branger et al. 2013) Section 3.2, seems most affected by the induced national costs of climate policy. For the given climate goal, cheaper is better. Of course with more similar climate policies beyond the EU, especially with major trade partners, the importance of border tax adjustment is reduced.

\subsection{Long term Instrumentation in the Institutionalist Strategy \\ 7.2.1. Instruments development strategy}

The thrust in instrumentation is directed at institutional reform, at Level 1, with substantial public infrastructure, Level 2, and basic research, Level 3. This generic EU wide instrumentation leaves further policies and actions to member states, incentivized and enabled, see (Rayner 2010) on bottom-up action and more general (Ostrom 2010). There is no reason to specify emission volumes per year per member state. Doing so would require a planning and control type of instrumentation at the national level. Instruments at level 2 and 3 are discussed for the two strategies together. Prime institution is the internalization of climate effects through adapted emission pricing. The ETS is actively transformed into an all emissions covering and administratively much simplified emission tax, section 7.2.2. Second, the internal energy market is substantially revised, especially the electricity market, section 7.2.3, with next a few adjoining institutional developments, section 7.2.4. Public infrastructure, Level 2, next plays a central role, as in the transmission and distribution grid and broader in the energy and transport domain where monopolistic tendencies are dominant, see section 7.2.5. Research, R\&D and Development, Level 3, are focused at basic research for energy conversion and storage systems, see section 7.2.6. With these generic conditions installed there is limited involvement in the private sector, where boundary conditions and incentives create the framework for broad and diffuse emission reducing development, mainly by directing innovation and inducing and enabling substitution mechanisms. Public action in the private domain is mainly limited to short term market introduction of some new technologies to create learning curves. With learning curves established, public funding is reduced and stops, as then uncertainty for private parties has substantially been reduced and lock-ins overcome. Technology specific instruments regarding private actors are only applied where important markets are fully deficient and cannot be repaired. Examples would have to come up empirically. Very incidentally public provision may be for very high risk with very high positive climate impact projects, where private development and investment cannot be expected. Non-climate examples have been the development of nuclear power, most public health in most countries, much of IT, and fully internet and GPS. In the climate 
domain there here are no suggestions yet, beyond infrastructure and research subjects. Binding $\mathrm{CO}_{2}$ from the air might become an option.

\subsubsection{Generic emission pricing}

Emission pricing starts at the current ETS, and develops emission pricing along the three dimensions as specified in Table 4: domain expansion; level of administrative implementation moving upstream; and variability reduced leading to predictability rising emission price levels. The first step is to transform the Market Stability Reserve into an explicit price floor system, with the price floor rising in time. As long as there is a surplus in the market the price ceiling is not relevant. The ceiling can however be set now already as a safeguard against a later price explosion. This operation is combined with a domain expansion, first covering all coal and gas and, more complicated, all non-transport oil and oil products use. For effective and simple implementation, a shift from the administration of actual emitters to their upstream primary suppliers is required. This can be done in one move, towards EU natural gas production and imports and coal production and imports. The number of regulatees then is very small as compared to the number of emitters: a few thousand against in the order of a hundred million, now including all small emitters. The rising price floor is not yet a tax, like the rising UK Price Floor Tax is, but a quantity measure leading to a predetermined price level. The difference in functioning is small however. The bandwidth between price floor and ceiling is set at zero; there is no good reason to have a bandwidth in a price based system: the single price indicates the scarcity of available emission space in society best. Price variation diffuses the price signal and increases public and private implementation costs. Trading systems are expensive short term already as compared with taxlike single price systems, and the reduced long term investment guidance by price volatility increases real costs of emission reduction dynamically. The experience built up allows next for a swift expansion in the transport domain, planned in advance but maybe implemented a few years later, then covering all fossil resources upstream only. With fully upstream application the permit character remains a hindrance to administrative efficiency. Yearly sales then are to be matched after closing the year administratively with the required amount of permits, with the firms involved in primary production and with (certified) importers. The administrative implementation can better shift from a firm oriented yearly implementation to a direct transaction oriented implementation, similar to how VAT and excises on products like alcoholic beverages are administered. This fits into taxing experience which goes back for centuries in all countries in Europe and in most countries of the world. The permit system is transformed into a tax system in this last administrative step. Any firm importing coal, gas or oil products has to pay the emission tax, for each transaction, linked to the VAT-administration. As with all other taxes the administrative implementation is at member state level, and proceeds are distributed over member states according to their shares in $\mathrm{EU} \mathrm{CO}_{2}$ emissions.

The emission tax is implemented upstream at primary production and import of fossils and derived fossil energy products (as also proposed for example by (Metcalf 2008) for the US), and refunded upon export of such products and upon approved CCS, paid from tax proceeds. All fossil $\mathrm{CO}_{2}$ emissions are taxed this way. Less clear system definitions were discussed in (Victor 1992). The tax and refund at external borders are not border tax adjustments but administrative elements of the EU emission tax (confusingly named Border Carbon Adjustments by (Droege 2011)). The administrative implementation is at member state level. The tax is not Pigovian, 
equating it with marginal damages, but follows (Baumol 1972), set at a level to reach the climate goal. The tax may best be linearly rising, like the British Columbia Emission Tax (Min-Fin-BC 2014) and UK Price Floor Tax (Revenue\&Customs 2012 (2010)), to an amount of in the order of $€ 350$ in 2050 , but see different reasoning in BOX 2. As total proceeds are distributed over member states according to their share in total EU emissions, there is a national incentive not to 'forget' emissions as that would mean forgoing income.

There might be a different route from pure cap to an emission tax, by first expanding the UK Price Floor Tax to more countries, as a coalition of the willing. With the principle broadly implemented, the EU could employ a similar dynamic approach could be to have the UK Price Floor Tax model expanded to all other countries, avoiding the tension of specific competitive disadvantages between the UK and other willing countries. The volume based cap system then would evolve into a fully price based system, as the fixed (lowering) volume of the cap would have become irrelevant for the price, as long as there is oversupply. The high enough price of the price floor tax would make sure that the cap remains irrelevant for a long time to come. This double system could easily be simplified into a uniform encompassing emission tax. In developing a strategy this line would not come up. Introducing the emission tax in this indirect way involves the development of a double instrument system with substantial complexity, as the UK price floor tax has shown, easily leading to unexpected obstacles on this path.

The permit proceeds transformed into tax proceeds, one way or another, are distributed between the member states (and countries joining in the EU system) based on their share in actual total EU emissions. The lower a country's emissions are, the lower is its share. With the rising price set at the level required for deep reductions, the total tax proceeds will first rise, towards the mid Thirties roughly, and will then decrease. How these tax proceeds work out on overall economic activity depends mainly on how they are used, especially in terms of reducing other taxes, see (Meyer and Meyer 2013).

The emission tax level is based on intended emission reductions. The empirical relation between rising tax level and emission reduction is soft, being conditional on electricity market institutions, on climate technology development and on all more general developments in society, including economic growth. Predictions are not well possible but some conditional cornerstones can be established, like a tax level where natural gas will outcompete coal in electricity production, where heat pumps with seasonal storage can outcompete gas heating, and where electric cars become competitive with combustion cars. To take the coal and gas example, assume zero (!) real cost for coal based electricity, and assume a carbon tax of $€ 400$. The real cost of natural gas based electricity production then would have to rise from current $€ 55$ per MWh to above $€ 181$ to keep some coal based electricity in the market, see for numbers Table 6. Such back-of-the envelope computations are more enlightening than modelling exercises for long term reasoning, as price predictions are not well possible. Coal would be out of the electricity market long before that $€ 400$ tax level, and natural gas probably as well, as renewable systems become more attractive in static considerations and more attractive to invest in longer term. Of course the outcomes will substantially depend on electricity market design as well, see below. There is no clear single tax level connected but a level rising long term to in the order of $300 €$ per tonne of $\mathrm{CO}_{2}$ in 2050 seems a reasonable middle of the road estimate, with $400 €$ as a high estimate on the required level. Setting the emission price at $50 €$ in 2020 , rising by $5 €$ per year would lead to the $200 €$ price level 
by 2050 . Going for more safe would be a price rise by $10 €$ per year, leading to a price of $350 €$ per tonne by 2050.

These emission prices may seem substantial but getting emission reductions with other means in principle leads to substantially higher real costs, estimated with different modelling types at a factor two in the transport domain (see (Anderson, Parry et al. 2011) and more generally (Parry, Evans et al. 2014)) and similar doubling of costs with economic modelling using technology specific instrumentation (Deetman, Hof et al. 2014). The tax proceeds are used for tax reductions, greening the tax system, see (Andersen and Ekins 2009). Preferably the most economically disturbing taxes are the reduced, and reductions may be used for some redistribution, to compensate for undesirable income effects. A review of actual emissions development towards 2035 is built into the emission pricing regulations. If by then emissions have not been reduced enough, an increase in emission prices is due, and vice versa. Because of reduced volumes by then this emission tax is a less heavy burden on society. The place of CCS in the emission pricing system is similar to exports. Wherever authorized CCS takes place, the refund is paid, from the EU level of total emission tax proceeds, before distribution to the country level. The authorization may involve CCS outside EU boundaries, as in Norway in the Sleipner field. That is currently the only large scale CCS option in Europe with a somewhat proven safety record, with 20 years of controlled experience funded substantially by the Norwegian emission tax. It would require an extensive $\mathrm{CO}_{2}$ transport system with a monopolistic character. The base structure would therefore be set up through public provision, if overall cost estimates for CCS would indicate this route to emission reduction. (Mikunda, Kober et al. 2014) see this option as essential for long term climate policy, with action required now to make this option feasible, see (Scott, Gilfillan et al. 2013).

A further adjoining pricing instrument might relate to the road transport sector, the national fuel taxes. Such taxes existed already before the climate problem was perceived. EU coordination of national fuel taxes is not an instrument of climate policy, as it now is seen as being the case a bit ('20\%'), assumption based only. That element is out with EU, reducing EU level policy to just a single-market operation, to reduce tax competition. This of course helps structurally to enable countries to raise fuel taxes somewhat in a less mutually adverse manner, like many other policies may also be relevant for emissions. In the long term effective climate policy will reduce fuel excises to near zero, solving this tax competition issue fully.

There are many more climate emission relevant policies, rules and regulations, ranging from tax rules on company person-car use to insulation rules for buildings. These just are not part of climate policy in this Institutionalist Instrument Strategy. Neither are personal tastes in consumption and life time working hours the subject of climate policy instrumentation, though together constituting a most decisive single determinant of long term climate emissions. Using $1 \%$ of productivity rise not for growth but for leisure would reduce emissions roughly by $50 \%$ in the next 70 years, with given technologies. However, with technologies changed by climate policy instruments towards near zero emission, that $50 \%$ reduction would dwarf to near zero. Reducing working hours therefor is not subject of long term climate policy instrumentation, how useful it might be if climate policy is not successful. Through similar reasoning, with different outcome, the redesign of electricity markets is a key instrument in the Institutionalist strategy: without it key emission saving technologies will not emerge. Of course, climate considerations may play their role in more complex considerations involved in broader developments. Using Life Cycle Analysis of products in decisions on consumption and consumption style may make well make 
sense. Calling LCA a climate policy instrument seems one step too far, certainly too far for long term climate policy instrumentation. Making the social security system, the pension systems, tax systems, health care, child care, holiday regulations, etc. all part of climate policy instrumentation seems the end of climate policy, however well intended the broadening might be. Long term instrumentation has emission reduction as its focus. The combination of emission tax and corresponding electricity market may have indirect effects already relevant medium term, like shifting consumption culture away from high emission products and services.

The internalization of climate emission in prices is the main dynamic influence on long term technology development and market development. It also works in the public level as for moving spatial planning and research planning in a more climate relevant direction. The influencing role of climate policy is there but in a limited way, being next to energy considerations, amenity considerations, general international competitiveness considerations, etc.

\subsubsection{Electricity markets}

For climate incentives to become operational the electricity market has to transmit the price signals adequately. Fragmented, primary national, oligopolistic markets create limits on what carbon pricing can do. The electricity market is to accommodate the tens of millions primary and secondary producers, with the price for all producers and users real time variable to spread out peaks and troughs in supply and demand, see (Palensky and Kupzog 2013, Yigit, Gungor et al. 2014, Baron 2015) on requirements and options. Smart grids, smart meters and internet of things are purely private, avoiding privacy problems in the publicly regulated version where household data are gathered by energy supply firms. The real time priced open electricity market at EU level is set up based on an EU wide grid with an EU level super-transmission grid operator (TSO), linked to all regional/national publicly owned and operated TSOs. All producers receive the same market price at each moment, and all users pay the same price, for them including transmission costs based on real time congestion pricing, see (Verzijlbergh, De Vries et al. 2014) for requirements and NordPoolSpot.com for developments in this direction. Net-metering becomes impossible. Heat pumps and heat storage would outcompete natural gas without emission pricing in many circumstances now already. Battery electric and fuel cell cars are central in grid stabilization, see (Palensky and Kupzog 2013, Huppes, Huele et al. 2015), covering their cost partly by market operations. This design for a single EU electricity market goes well beyond the European Target Model for electricity market integration, see (ENTSOE 2014).

The market has to deal with substantial intermittency in supply of major share renewables, with market clearance by flexible low efficiency gas fired power stations a very low frequent exception. With this limited role for fossils this is only possible by increasing the role of hydro power, electricity storage, electricity transformation (heat, chemical) with secondary production and shifting final use to off peak demand. Market clearance involves information related to the actions of sharply increased numbers of producers, hundreds of millions of primary and secondary producers, joined by hundred millions of users, with billions of smart apparatus, see Figure 3. This is hardly possible in a planning or contractual manner. The market to be created is a real time open market, with continuous price adaptation resulting in market clearance. Establishing the open EU wide electricity market is done stepwise, including both market rules and infrastructure development. In terms of market structure, the unbundling is to expand public ownership of 
transmission grids and distribution grids. Congestion pricing, not proceeds, is the prime pricing mechanism, using the experience of for example road congestion pricing.

A key issue the establishment of the trans-European high tension DC grid, connecting the mainly national high tension AC grids flexibly. Such power lines have been built bi-nationally between Germany and Sweden and the Netherlands and Norway, with the UK coming in with connections to Norway and Sweden, and later Belgium and Iceland. The current profit oriented exploitation is replaced by open access use, comparable to the internet, based on public ownership. All producers and users can use the DC grid, first connecting contract partners internationally. But when the infrastructure has been developed adequately, in about 15 years, real time market relations replace contractual relations. The rules required for open electricity trading at the European grid need development, avoiding the coordinating role by a limited number of large producers or net operators. The EU grid rules need to be the same or at least fully compatible with rules for national public transmission grids and distribution grids. With the extremely large numbers of decentral producers to also connect to the market, the difference between transmission and distribution fades; the same rules must apply for all producers and for all users. The technical implementation of high, medium and low tension grids and their connections is to done by the public operators of this essentially monopolistic infrastructure.

In order to move towards the open European markets, current impediments are removed. Feedin tariffs, most damaging to open market functioning, are transformed into feed-in premiums and these are phased out, as also most investment subsidies. Surcharges for funding of renewables are replaced by tax funding, as is the case with most other subsidies. Capacity payment is not introduced. Current regulations on smart metering, like 'at least variable per hour', or a quarter of an hour, are abolished; smart meter regulations are halted and reversed. Smart meter introduction is not based on public regulations but on market mechanisms, by any party willing and able to do so, ranging from Google and a-likes to fossil energy companies looking for new business. The smartest meters save most money, and also contribute most to market stabilization. Delivery to the grid is not at prices including taxes and surcharges any more but at producer prices, equal for all producers and real time variable. Long term contracts between large producers and consumers are transformed by public regulation as present in many countries already, so users can shift to real time markets when they please, that is when they are ready for that. The core is to have the private behavioral rules in place for all one's electricity using and primary or secondary electricity producing apparatus on how they react to the then variable price signal. The swing producer market as currently operating nationally and internationally may continue but will lose its role in load clearance and will then be discontinued.

The full set of changes requires new EU policy development and quite complex national regulatory and ownership transformations. The build-up of the EU high voltage DC (HVDC) grid also takes time, involving national planning procedures. Current HVDC lines have been laid at sea floors to avoid planning delays. The availability of this grid, Supergrid called by some, will create an incentive for member states to adapt to the rules for using this EU grid to their advantage, as by linking to cheapest renewables and shaving peaks on East-West connections.

\subsubsection{Other institutional framework conditions}

Climate policy itself may be a source of deficiencies, as by breaking up markets that otherwise might function. Both instrumentation strategies try to avoid creating such deficiencies, with 
substantial differences between them. Technology specific instruments, with capacity payments, will tend to reduce the effectiveness of electricity markets, and reduce the emission pricing signal. They are part of the strategic choice for planning and control.

There are also market deficiencies broader in society which might be remedied for climate reasons. They may relate to the limited time horizon and limited access to borrowing of small firms and private households; to the asymmetry in some contractual relations like landlord-tenant relations; and broader to monopolistic and oligopolistic market structures reducing innovation. These are relevant for example for reducing energy use in buildings and shifting to low emission energy systems. The solutions relate to long term institutional development and to a few specifics in the legal structure. Credit for small scale investment is a broader issue in society, with extreme overpricing in many situations due to market power asymmetry. Rules for costs to be borne by borrowers and on the allowable level of interest rates exist but erode easily. The uncertainty for the lender on repayment cannot be resolved, accept by public guarantee, which however moves the responsibility for knowing the borrower to governments who are not good at that (vide the subprime mortgages in US). In some countries such small scale lending is well developed and in others not. The reasons for such differences are to be studied, preparatory to possible institutional rearrangements for general, not climate specific reasons. The landlord-tenant issues also differ between countries. Similarly, competition law and antitrust regulations may be useful for efficiency and trade reasons but may become part of climate policy instrumentation only when primarily and directly relevant for emission reduction. For the design of electricity markets that clearly is the case. Other clear cases are lacking. Especially for financing green investments special lending organizations are proposed, with lower interest rates, essentially subsidies. Well working financing markets are part of the broader institutionalist approach but not part of climate policy strategies, and certainly not fragmented financial markets. Though relevant for emission reduction, mending of such market deficiencies is part of the overall fabric of society.

Of course the reasons for resolving such deficiencies may also include climate considerations. One subject coming close to climate relevance is innovation, linked partly to funding. Limited access to funding for small and medium sized enterprises may impede innovation, but as part of broader factors determining success or lack of it in innovation, see (Mazzanti, Antonioli et al. 2014). There is however only a limited empirical relation between the volume of R\&D and emission reducing development, see for example (Marin and Mazzanti 2010). Moving innovation in an emission reducing direction already is a main part of instrumentation here: the emission tax. Though innovation is of broad importance, the subject seems to be too broad to indicate development of specific instrumentation as part of climate policy.

There are a few further climate technology specific institutional deficiencies which could be mended based on climate emission considerations directly. Geothermal heat and especially heat pump based subsoil energy storage may play a key long term role in the low emission energy system for heating and cooling. However, they now have a diffuse ownership structure, technically not fixed to the above-soil land-ownership. This somewhat collective good nature (no clear excludability and limited rivalness) constrains their development. Contractual solutions, as with EU developed standard contracts, are one option. This solution will be cumbersome when larger numbers of actors are involved, as is the case with heat and cold storage under private housing. Then standard contracts (as opposed to grab-as-you-can, as often the case with water now) may well delay development. The other option is to treat this resource as a public good, 
with rules for access, including permits and pricing. The option for use then is to be publicly supplied. This seems a most feasible option, very comparable to rules on groundwater use and oil and gas exploitation in many EU countries (very different from the US). The role of the EU is to create the general legal framework, with differentiated implementation in the legal structure of the member states, and possibly even the sub-member state government level, see (Mehling, Bausch et al. 2013). Though certainly requiring substantial attention, there are no concrete long term impediments for such legal-administrative adaptations.

Novel technology developments with long term implications relate for example to the internet of things and to decentralization tendencies in a globally integrated world (e.g. through 3D printing facilities); and novel automated transport systems. Such systems require some standardization to become effective, made or coordinated by the EU, and through the EU also at a global scale. Competing standardization developments, as now initiated from the US and from the EU for the communication standards in the internet of things should be avoided. In this respect there is a clear standardization role for EU guided organizations like CENELEC (European Committee for Electrotechnical Standardization) and ETSI (European Telecommunications Standards Institute), opening up the route towards private development of smart grids and internet of things. As longer term developments tend to be uncertain, wrong choices may easily be made, as with obligatory smart meters not being able to integrate users in variable priced electricity markets; such public prescriptions are not part of this strategy.

Generally, core tasks in these domains are to initiate processes with a long term view in mind. This then has the role more of opening options than making choices for specific technologies and products, even for promising technologies, when also other interesting options may be coming up. Postponement of choices may be a preferred option. Even if losing out on short term developments this may be wise, to avoid initiating lock-ins, at high costs later. Forcing development of lower emission road transport now may be detrimental to long term zero emission transport developments.

\subsubsection{Infrastructure and spatial planning}

EU infrastructure for climate policy reasons first concerns the build-up of the high tension DC grid. Transport systems are mostly public provision, like roads, railroads, harbors, airports, and sewer systems. Their operation may be privatized but then under public utility type market regulations. Mostly this is a national affair, without a clear role for the EU, except at the general institutional level and for transnational transport infrastructure. There is limited reasons to incorporate such elements in this version of climate policy instrumentation.

The new vehicle drive modes - certainly battery electric drive and nearly certain hydrogen fuel cell based electric drives, and possibly more - require a recharging and refilling infrastructure. With current negligible market shares in most countries, the commercial development will not take place. Fast battery loading stations and hydrogen refilling stations are expensive and must be used extensively to become commercially attractive. Also there are learning curves to be created. The instrument to use therefore is a bit open: public supply or subsidized introduction, both paths followed in Norway, where the infrastructure for electric vehicles is now in place already ${ }^{32}$. Slow charging stations have been introduced widely in many cities privately with public

${ }^{32}$ See: http://info.nobil.no/images/downloads/nobilbrosjyre.pdf 
support in funding and location development. They can be placed in public parking spaces, as the infrastructure costs are low and loading and parking can be combined. In several larger cities such slow charging stations have been introduced based on a cooperation between cities, electricity companies and the charging supply firms. Public supply of fast charging stations, one option, can be set for example as a task for the publicly owned distribution grids. These would not cover the highway system so easily. With subsidized private introduction of fast recharging stations, the current network of fuel stations could be at least partly expanded with fast charging connections. Later, the subsidy scheme could be abandoned, with the requirement to include fast charging stations in any new permitting of gasoline stations to also cover less densely serviced areas. Private hydrogen distribution can be combined with the phase out of LPG, replacing the LPG refilling connection with a hydrogen connection. This would however delay the introduction of fuel cell cars substantially. The combined option is to start public supply of hydrogen, first expanding the filling stations as have been created in many cities for public buses; subsidizing the set-up of hydrogen refilling at key gasoline stations, and later subsidize the transformation of LPG filling stations into hydrogen filling points.

Summarizing:

-Slow charging stations are set up at city level with limited subsidies, as currently already taking place in many cities, first Oslo and then many more like Paris and Amsterdam.

-Fast charging stations are set up exemplary in cities as by electricity distribution companies, combined with subsidized introduction at private gasoline stations on highways.

Spatial planning at EU level is focused at transboundary transport infrastructure mainly, with a view on interesting long term options to be facilitated and not restricted, as for very high speed public transport to reduce air traffic. Guidance for the national level is informational only, as with attractive scenario sketches for low-energy city development. There are no subsidies to guide national planning and related actions.

From a climate point of view, long term spatial planning plays a role at the purely national level, guided by overall market structure and by a direct interest in belonging to the low-carbon future. Issues at national and local level relate to integrating renewables production and the restructuring of cities for low speed mobility, underground transport and decentralized clean production, for a combination of reasons at that applied level.

\subsubsection{Research, R\&D and Demonstration}

Research, R\&D, and Demonstration (the last two often combined into RD\&D) with a long time horizon is first focused on the basic science for energy transforming systems, ranging from basic physics and nano and materials science, to biobased energy systems like algae and artificial trees, and to large scale applications, like may be still DC-AC transformation systems and energy beaming systems for energy transport. The focus is primary and secondary energy production. Apart from lucky hits this research has long term relevance.

The second domain may be closer to private markets technologies, but where markets cannot operate due to high uncertainty and long duration towards return on investment, if successful. There then are CARPs, Climate Advanced Research Projects. The internet example indicates how first public research has set up the technology, with public investments making it operational, and only then private development following. There are no clear candidates for substantial funding, so some experimental open invitational research funding might be useful, similar to ARPA-E 
projects in the US. For important technical issues beyond the grasp of specific market partners design contests may be attractive, to pre-develop the architecture of complex technologies. Contests might functioning similar to CARPs. Such non-predefined elements could be entered in DG-Research projects, as part of Open Projects in H2020. Prime relevance is to have some research on how to assess if novel technologies, assuming their successful development, are fit for the long term near-zero emission society. Pre-evaluation methods for such research project selection are mainly lacking $n$ ow. The DARPA and ARPA-E experiences in the US may constitute valuable empirical material.

The important public role as indicated here substantially overlaps with ideas of (Mazzucato 2011, Mazzucato 2013), who shows that almost all major technological revolutions of the last half century, with the internet as a main example, have evolved from public initiatives, starting with direct public funding. The 'Mazzucato line' could be set up very similar in the Planning \& Control mode, but there more focused at public-private partnerships and more clear market relevance directly, while in the Institutionalist mode the public infrastructure element would have more emphasis, not requiring private partners at the start but opening up options.

\subsubsection{Regulating private actors}

In the transformation phase towards the open electricity market and relatedly the build-up of variable capacities some investment subsidies may play a role as financial instruments, as for example to create learning curves in the novel domains of storage and variable use, but then limited to really new options and temporary only. This is part of R\&D and Demonstration instruments already. One might think of another reason: to speed up the reduction of the share of fossils. However, the more appropriate method then would be to have a faster rising generic emission tax at the institutional framework level, not public support of specific technologies or specific taxes on their competitors. Public funding of relevant infrastructure development may open up options for specific private developments, like the set-up of hydrogen distribution infrastructure for fuel cell applications. Such infrastructure activities also are not part of regulating private parties but are to create options for private partners.

The result of these restrictive views is that there is a limited amount of regulations regarding private actors in specific technology domains. Creating dynamics and normal functioning are integrated mostly at the public level: institutions, infrastructure and RR\&D\&D. Also informational instruments are not set up in a technology specific way. The three types of instruments, Type 4.1, 4.2 and 4.3, Information, Financial and Standards, will be checked in turn on their possible role.

\section{Information instruments}

Information instruments, to stimulate and clarify markets, are limited to supporting standardization of information systems as through CEN and ISO. In the electricity and information domain there may be a role for CENELEC (European Committee for Electrotechnical Standardization) and ETSI (European Telecommunications Standards Institute), relevant for standardization which opens the route towards private development of smart grids and internet of things. Though primary having a standardization role, there also is a communication role broader in industry, involving public support.

Standards may include the way information on climate effects of products are specified, as in using life cycle based information. There currently are no relevant operational methods for long term life cycle analysis, as requiring novel methods and scenarios on future technologies replacing 
databases on past processes currently used in LCA. First steps are there, based on usual public academic funding, see (Hertwich, Gibon et al. 2015) on renewable energy technologies and more at a systems level (De Koning, Huppes et al. 2015), based substantially on EU DG Research funding. Basic issues in methods and operationalization are difficult to resolve however, like allocation problems when processes have multiple functions and the fundamental uncertainty on future surrounding processes.

Leaving the climate discussion in content to civil society seems the wise approach from an institutionalist point of view, as the nature of long term analysis will remain open, by necessity. The short term may be approached differently.

\section{Financial instruments,}

Financial instruments, of any legal status, may be used to induce specific low carbon technologies. However, these would fully overlap with domain expanded emission pricing. For stronger incentives a higher emission price is the solution, not adding more instruments based on short term reasoning. This also holds for low and zero emission road transport drives.

Heating and cooling as main final energy use category, are fully covered by the emission tax. Some really new technologies might deserve public support to create learning curves, in the RD\&D domain.

For transport, the diverse taxes and subsidies as have historically developed mostly have only limited background in climate policy, with some partial exceptions like for fuel excises first in the UK and then Germany in the Nineties and start of the last decade. However, differences between countries seem hardly to relate to such public considerations, which therefor seem verbal only. International alignment for solving border problems and tax competition, not just for fuel taxes, is very useful but hardly part of climate policy. Of course generic emission taxes do also have an effect on fuel prices. In the transition to zero emission cars the competitive advantage of noncombustion cars will also depend on broader socio-technical developments, like self-driving cars, probably used very differently from current private cars. Abstaining from the support of specific drive systems seems wise. However, if by 2035 combustion cars would still have a substantial market share, taxing schemes for combustion cars, or similarly lower taxes for zero emission vehicles, may be used for a smooth phasing out of combustion cars, announced well in advance. Supporting specific groups, as subsidizing lower income groups in zero emission heating of dwellings and buying zero emission cars might be a direct way to overcome income limitations. The generic line however is to have relevant income distributions measures, long term not just taxes and minimum income rules but also schooling and broader education. Such issues are highly important but cannot be part of climate policy and certainly not part of an institutionalist strategy.

\section{Standard and Regulations}

Standards and Regulations, involving prescriptions or prohibitions, play a limited role, as they tend to favor specific existing technologies at the cost of future ones, hence possibly creating lock-ins. So there is not prescriptions on smart meters, no EU building standards, no heating and cooling systems prescribed and no transport drives made obligatory or forbidden. Of course facilitating measures in terms of institutions and infrastructure are in place to allow for a broad range of technologies to enter the market, and press others out of the market. A major one now is the recharging and refilling infrastructure for electric vehicles and hydrogen fuel cell drives, having and being developed in some countries and regions as yet. 


\subsubsection{International aspects under Institutionalist Instrumentation}

Under the institutionalist instruments strategy for climate policy international agreements are set up substantially different from current emphasis in negotiations on caps. The prime international agreement in the institutionalist strategy is on a roughly equal set-up and level of emission tax, agreed in a core group, see (Brenton 2013, Falkner 2015, Falkner 2015a). For (MacKay, Cramton et al. 2015) the reason to prefer this type of agreement is because of its greater political feasibility as compared to binding caps. Agreements here focus on equal emission pricing between the countries joining this Climate Club $^{33}$ (Nordhaus 2015, Falkner 2015a). With (MacKay, Cramton et al. 2015) the main reason for shifting the international agreement to equal emission prices is political feasibility, avoiding the difficulties as have been encountered in Kyoto-Copenhagen and still present in the set-up of the goals of COP21 in Paris, as focused at binding cap agreements. There are no caps involved in the pricing agreement. Border tax adjustments are based only on the tax element, not on the real costs of emission reduction. This relatively simple reasoning for border tax adjustments allows for a fast and simple sanction mechanism against free riders in this institutionalist mode, while giving a direct incentive to also join the climate club. The exporting country confronted with the import levy on its products can prevent that loss by taxing the same amount upon export. Then the option to tax under the WTO rules vanishes, see (Dong, Ishikawa et al. 2015). This emissions based export tax can be the start of an emission tax, first covering exports only, but with quite some logic to also cover inland production and consumption. The position taken by (Droege 2011) that BTAs could endanger international climate negotiations relates to Kyoto-type of cap agreements, not to international emission tax agreements. The emission distribution between taxing countries resulting would be similar to the imaginary results of an international emission trading scheme linked to national trading schemes, with countries with less costly emission reduction options reducing more, other countries paying them, and vice versa. The political and administrative feasibility of such an extensive international agreement may be doubted. The assumption here is that at least some partial international agreement is reached on equal set-up and level of an upstream emission tax, easier for the small group starting Climate Club than for the globally binding caps agreement.

The emission tax levied upstream on imports of coal, oil and gas and derived energy products is not a border tax but an upstream inland emission price, equal for national and foreign producers. However, for emission intensive products a Border Tax Adjustment (BTA) is part of instrumentation, not covering induced cost of production due to climate policy, as in the planning \& control case, but only the transfer costs of the emission tax. For the disadvantaged exporter, a most simple and economically equivalent measure is an export subsidy based on generic pricing rules, like an exemption from emission pricing, as now used in the EU ETS, or more precisely through a repayment of implicitly paid emission tax, based on specified emissions related to the export product. Enacting taxes upon import would be the mirror, to also create an even playing field within the climate policy country. These import levies need also to fit within the constraints set by the WTO, see (Green 2005) and more positive (Tamiotti 2011) for considerations. Effectively this would create a partially applied emission tax abroad, but received by the importing

\footnotetext{
${ }^{33}$ The term originates from public goods domain. Collective goods have Non-Rivalness and Non-Excludability. Club goods exhibit substantial Non-Rivalness and Excludability. Goods fit for Rivalness and Excludability. By creating a Club, non-participating countries pay a price for not having climate policy.
} 
country, see (Gros and Egenhofer 2011). The exporting country confronted with the import levy on its products can prevent that proceeds loss by taxing the same amount upon export, using the same method of quantification. Then the option to tax under the WTO rules vanishes for the importing country, see (Dong, Ishikawa et al. 2015). The application is limited to cases where the cost of transfer payment under the emission tax are substantial, above at least a few percent of total cost of production. Such cases will be rare now already and dwindle under decarbonization of the production sector, with few exceptions

Leaving out induced price effects of the emission tax in BTA solves otherwise hard to quantify issues. The border tax is set equal to the emission price in the EU and is imputed on estimated emission levels abroad, disregarding real cost of emission reduction and also disregarding other mechanisms induced by emission pricing, like lower prices of fossils. If a dispute arises, better data on foreign emissions may be supplied by the complaining country. At export of energy intensive products to non-climate policy countries, the refund is given based on actual emissions. Steel is one clear example where such import and export corrections are due.

The Adjustments here don't reckon with induced price and technology changes, like lower energy oil and gas prices due to the reduced use because of the emission tax, and reduced costs due to technology adaptation. Including such effects would lead to lower BTAs. Nor do they cover the induced cost of avoiding the emission tax to some extent by emission reducing measures, which would increase BTAs. See (Böhringer and Rutherford 2002) for decomposition of effects and (Böhringer, Balistreri et al. 2012, Böhringer, Rutherford et al. 2012) for an extensive survey. Induced effects on costs and prices are empirically inherently soft, because based on historical developments amidst many other factors, as difficult to establish counterfactuals. These constitute the basis for BTAs in the Planning \& Control strategy, as there is no carbon pricing there. Such complex reasoning might well lead to a substantial amount of uncertainty and hence to manipulation and then conflicts in WTO, see (Holmes, Reilly et al. 2011). It is not sure to what extent such considerations are allowable yet under current WTO rules. The BTA for correcting only the direct effect of the emission tax is acceptable now already.

The global welfare effect lost long term by not reckoning with induced cost effects seems small however, see the extensive study by (Böhringer, Balistreri et al. 2012) and the modelling study by (Meyer and Meyer 2013) and in a similar vein (Kuik, Branger et al. 2013). Without having BTA on the emission tax element, the effect would be more substantial, but very much depending on how other suboptimal taxes are reduced based on emission tax proceeds. Such general considerations are highly relevant with a very limited role for climate policy instruments however. Overall tax structure, labor market design and education will be main determinants of long term competitiveness, measured at OECD level 3, see (Kuik, Branger et al. 2013) Section 3.2.

Summarizing, the institutionalist approach differs from the current mainly planning \& control approach in three main respects.

- There are no national emission targets per year, only a long term global reference emission volume used for setting the emission price path.

- The agreement is not universal but between core starting countries, open for others to join the Climate Club ((Nordhaus 2015) and similar (Brenton 2013)), for all joining on the same conditions. 
- Border Tax Adjustments cover only the transfer payment of the emission tax and create a sanction on not joining. They can conform to BTA rules (Tamiotti 2011) and can be avoided by the exporting country by levying the same tax on its exports itself (Dong, Ishikawa et al. 2015).

\subsection{Instruments common between strategies}

The instrumentation in the two strategies has been exposed with emphasis on differences. At different places however also similar elements have come up, both substantial and smaller issues. The common elements in both strategies are mostly tainted by their different philosophies however, see the following examples, following the order of instrument levels from general to specific and binding as in Table 3.

- Ownership and use rules on geothermal energy \& underground heat storage capacity (level 1) The focus with Planning \& Control is on use rules, with Institutionalists on ownership rules.

- Infrastructure planning for trans-European DC High Tension transmission grid (level 2)

The capacity requirements with Planning \& Control will be more limited as compared to the more extensive Institutionalist requirements in a fully open single EU electricity market.

- Infrastructure planning for fast charging electric cars and refilling of hydrogen fuel cell cars (level 2)

With Planning \& Control the planning and implementation are directly linked, in public-private partnerships; with the Institutionalist strategy, the main monopolistic infrastructure is planned and implemented publicly, with further implementation left to private parties.

- Infrastructure planning for low speed transport in cities (level 2)

These might fully overlap between the two modes.

- Pre-competitive $R \& D$ on promising technologies and competitive Demonstration projects (level 3)

In the Planning \& Control mode these would be combined, never in the Institutionalist mode. There also are equal mechanism induced between the two instrumentation strategies, in an economic-technical sense. Under effective climate policy fossil resources now on the balance sheets of fossils producing firms will lose their value, ultimately to near zero, unless CCS takes off substantially after efficiency increases in emission reduction. In planning \& control this would require political strength also in periods of budget squeeze and upcoming competing issues for funding. Similarly, investments made in many products and installations will not be recovered, ranging from mining apparatus and road infrastructure to harbors and bulk carriers, and the industries behind that. Such structural changes in the economy are usual and of course cause hardship. But they belong to normal economic life, even on shorter notice. The shale gas revolution in the US has reduced the value of coal mines by $90 \%$, on relatively short notice. The low coal price in the US has reduced coal prices in Europe, leading to the closing of newly built gas fired power stations, as in the Netherlands. Political pressures to compensate such unpleasant developments for those concerned will of course come up. Halting the subsidies on renewables may then be more directly in view than not raising the price of the emission tax. Of course the emission tax will reduce the attractiveness of coal fired power stations, and natural gas fired power stations as well. With periods of very low (but not zero) market prices every day, the profitability of fossil electricity production will be reduced, as is the intention of the emission tax. 
Having emission standards and renewables subsidies will squeeze fossils out of the market as well. A further indirect effect, the tax effect will be different as well. The emission tax lowers other taxes in the Institutionalist approach, while with Planning \& Control the subsidies for renewables and other primary and secondary production capacity require funding, through increased taxes, in the broadest sense, including surcharges.

\subsection{Divergent pathways managed in the short, medium and long term}

The end results in terms of instrumentation are substantially different for the two strategies. The starting points are equal, with their long term divergence leading to somewhat different pathways following short term already and, more so, medium term. How long might the options for either strategy direction in instrumentation be kept open? This may not only depend on the requirements for each strategy but also on an active choice to keep options open as long as possible. Instruments may be adapted so as to fit in both strategies. Temporary subsidies on renewables may shift from feed-in tariffs (FiTs), not compatible with open real time markets; to feed-in premiums (FiPs) or Contracts for Difference (CFDs), more compatible; to investment subsidies (with conditions) which are nearly fully compatible with open markets in the Institutionalist Strategy, but are also compatible with a Planning \& Control Strategy. This may allow to postpone basic strategy choices somewhat. Similarly, development of a pan-European transmission grid does not yet determine the type of electricity market it is to function in. The more limited electricity transport volume required in the Planning \& Control mode may well be set up so as to allow for the later expansion for the Institutionalist mode. Conversely, specific choices now may reduce options for either strategy later. Most clearly this is the case in a binding international agreement on yearly reduced caps per country, as being incompatible with an international agreement on a common yearly rising level emission tax, possibly as a Carbon Club ${ }^{34}$, starting with limited membership. The current UNFCCC process now considers the cap option only, but discussions on the tax approach have opened with influential supporters, see recently in Nature (MacKay, Cramton et al. 2015).

The long term unavoidably comes after the short and medium term however. Would there be obstacles for developing either of the strategies in due time, or for both of them?

A few obstacles can be imagined but are mostly easy to avoid.

- The option of a Carbon Trading Authority is not to be realized as it would create an obstacle to developing a simplified price stabilized emission pricing system in the institutionalist mode, and is not required for the planning \& control mode. This obstacle can easily be avoided by not having this Authority.

- For learning curves creation, hybrid electric drive cars are not any more incentivized as by subsidies and Fleet Standard premiums, in neither strategy. There are millions of hybrid cars now sold per year already (market share Japan: 30\%). There also is a substantial underestimation of their actual fuel use due to the non-realistic measurement standards used. In such circumstances hybrid drive vehicles may even help create a lock-in at high powered gasoline using heavy weight cars. Hybrid SUVs are expanding fastest in this market now. The lock in results from such drives being very actively promoted by current climate

\footnotetext{
${ }^{34}$ Carbon Club is a less military term than coalition of the willing, or more neutral: climate coalition or more dynamic: front runner coalition.
} 
policies. This obstacle can easily be avoided by removing the subsidy and replacing the NEDC (New European Driving Cycle) measurement standards by real performance measurement ${ }^{35}$. In the Intuitionalist strategy Fleet Standards and their adjoining measurement rules (NEDC and coming WLTP) are abolished fully, moving the measurement issue to the private domain.

- Subsidies for creating learning curves in electric cars also seem a waste of money, given that several main producers are marketing them now already, globally. This obstacle can easily be avoided, by pure real life fleet standards in the Planning \& Control strategy and by rising emission taxes in the Institutionalist strategy.

- For the Institutionalist strategy the strict implementation of a strengthened Unbundling Directive is essential, probably not at variance with the Planning \& Control Strategy. However, with Planning \& Control the fruits of a better functioning electricity market cannot be fully realized due to technology specific intervention in the electricity market. This obstacle cannot easily be avoided.

- Changes in the ETS cannot avoid a choice for either of the governance strategies. In the Institutionalist Strategy the ETS domain is expanded so as to cover all fossil emissions, also the transport sector, making Fleet Standards, also improved ones, superfluous in due time. In the Planning \& Control strategy, the ETS first remains as is and becomes superseded by other instruments.

- For the option of pure and strict cap-and-trade, not part of any governance strategy here, additional measures would be due: phase out all subsidies on technologies under the cap as these don't lower the fixed cap and constitute complex transfer payments to producers and users only.

- The difference between the two strategies regarding road transport are fundamental. Planning \& Control uses fleet standards and electric vehicle subsidies, in a high priced electricity market, in current prices in the order of $€ 0.25$ cents per $\mathrm{kWh}$. In the Institutionalist mode, the emission tax raises gasoline and Diesel prices substantially, see Table 6 , while loading at very low electricity prices, in the order of $€ 0.05$, see BOX 1 . Additional attractiveness comes from the option to use the battery advantageously in the open real time electricity market.

Table 11 Instrument Mixes in Planning \& Control and Institutionalist Governance

\begin{tabular}{l} 
PLANNING \& CONTROL STRATEGY \\
\hline 1. Institutional Framework Conditions \\
\hline ETS not expanded and maintained, overtaken by technology \\
specific instruments; no relevant generic emission pricing \\
Electricity markets somewhat fragmented, with some \\
vertical integration of production \& distribution; load \\
clearance by large producers \& operators; bilateral \\
international trade \\
Access rules for use for underground energy storage and \\
geothermal resources
\end{tabular}

INSTITUTIONALIST STRATEGY

\section{Institutional Framework Conditions}

Generic emission tax, fully upstream, rising levels specified

Electricity market, single price, equal for all, also internationally; phase out of FiTs and similar

Small lender markets rules as for low emission housing Minor revision of landlord-tenant relations.

Ownership rules for underground energy storage and geothermal resources

\footnotetext{
${ }^{35}$ Also WLTP (Worldwide harmonized Light vehicles Test Procedures) as agreed in UN context will be prone to "optimization" by car producers, as any other lab standard. A-select real drive performance measurement does not have this optimization option.
} 
EU Directives on Spatial Planning for low energy cities and transport infrastructure

Standardization at EU level, if possible global: as for communication in internet of things, for plugs etc.

Smart grid regulation

\section{Public Infrastructure}

EU subsidies for implementation of low energy building and transport infrastructure by member states; public-private partnerships as negotiated for management of main infrastructure.

Pricing of infrastructure use based on funding, including profits.

\section{Publicly funded Research, R\&D and Demonstration}

Less basic research, more RD\&D

Design contests

More close to application R\&D and many learning curve cases

\section{Regulating Private Actors}

\subsection{Informational instruments}

Public information systems: methods and data, tending to short/medium term, e.g. current energy performance based: mandatory energy performance labelling (MEPL)

\subsection{Financial Instruments}

Electricity: production subsidies, feed-in premiums and investment subsidies; nuclear premiums and inv. subsidies; fossil capital subsidies (as capacity payment); electricity storage subsidies; electricity to flex heat subsidies; ....

Heating: Non-fossil heating tech subsidies; insulation subsidies stock; ....

Transport, additional to low-price ETS: EU guidance on differentiated subsidies on cars (purchase, registration, road use, parking, etc.; rising additional carbon based fuel taxes, also LPG (and similar household butane/propane and heating oil), rising with reference 'relevant' price level.

Subsidies on all non-combustion drive vehicles

\subsection{Standards \& Regulations}

Detailed and changing smart grid metering prescriptions

Energy in building: insulation standards; technology standards heating/cooling and cooking; etc.

Expanding the Energy Using Product Directive, using CE labelling to enforce

Transport: Fleet standards reformed to pure climate, covering all, vanishing differentiation between categories; increasing stringency to zero
No Directives on national spatial planning

Standardization at EU level, if possible global, as for communication in internet of things, for plugs etc. No smart grid regulation

\section{Public Infrastructure}

No energy efficiency policy for climate reasons

Long distance EU High tension DC grid;

Public ownership for inherently monopolistic intercountry energy transport

Pricing of infrastructure use substantially based on capacity pricing.

\section{Publicly funded Research, R\&D and Demonstration}

More basic research and CARPA projects

Design contests

Less close to application R\&D and few learning curve cases

\section{Regulating Private Actors}

4.1 Informational instruments

Standards for technology comparison, linked to long term low emission scenarios (to be developed)

\subsection{Financial Instruments}

Electricity: None by EU, open to member states iff in line with open EU-wide electricity market

Heating: None by EU

Transport): None for climate reasons, apart from EU emission taxes

\subsection{Standards \& Regulations}

No smart grid metering prescriptions Building standards: None by EU?

Heating/cooling: None by EU?

Reducing use of Energy Using Product Directive: (very useful but not for LT climate reasons)

Transport: Fleet standards first reformed to pure climate covering all, fading medium term 


\section{Comparing strategic Instrument mixes}

\subsection{Effectiveness, Cost-effectiveness, Feasibility and Optimality}

Customary evaluation criteria for instrument mixes include effectiveness, efficiency as costeffectiveness, and feasibility aspects, see [(Görlach 2013)]. They are difficult to specify for long term transformations however, and certainly not fit for quantified overall weighted optimality analysis. Strategic governance considerations are prime background for judgment on long term instrument strategies. Fitting with views on broader governance, societal and socio-economic developments is overarching on the more technical-economic criteria related to optimality. Quantified optimality criteria may apply in more short-to-medium term analysis. For the long term, all such considerations can be applied only softly and qualitatively.

Optimality criteria to assess instrument mixes relate to effectiveness; cost-effectiveness or efficiency; different feasibility aspects; and some overarching integrative concept of optimality, see the CECILIA2050 report (Görlach 2013). These concepts are modulated by the time frames distinguished here following (Grubb, Hourcade et al. 2014), leading to different frames of analysis: satisficing in the short term, optimizing in the medium term and transformation in the long term. The long term frame of analysis is prime here, as the two strategies are both long term strategies. What is added here is the requirement that these strategies must be able to be effective in reducing EU emissions. That effectiveness requirement shifts all other criteria to a specific corner. Cost-effectiveness is reduced to costs but not bounded by any specific level: at takes what it takes to arrive at the 2-degrees goal. Also feasibility shifts. An emission tax going up to $€ 400$ per tonne $\mathrm{CO}_{2}$ and an emission standard on electricity production and vehicle use going mostly to zero may seem unacceptable and hence not feasible politically. But then the question is how other equally effective instrument sets might be designed with higher long term political feasibility. Increasing cost of policy certainly does not contribute to political feasibility. Also legal and administrative feasibility change nature with a moving time horizon. What does not fit into current regulations is to be amended. What does not fit into the EU government procedures might be a reason to adapt them, like the rules in the Lisbon Treaty. This seems not to be required in either of the two strategies however. The optimality issue remains very open, apart from the assumption that effective climate policy is required for optimality. As there are substantial differences between optimality concepts some discussion on how the strategies stand there is due.

\subsection{Long term effectiveness and cost effectiveness}

EU effectiveness in a climate sense is prime of course in EU climate policy instrumentation. Effectiveness seems possible in both strategies, assuming political willingness and adequate operational implementation. Technologies for a near-zero $\mathrm{CO}_{2}$ emission society are mostly there already, though innovation will certainly create different ones, also conditional on instrumentation choices.

Global climate effectiveness of policies cannot be realized by the EU alone. In a non-cooperative global context, when the EU would be going it alone, effective EU level climate policy would reduce global temperature rise by $0.1^{\circ} \mathrm{C}$ according to (González-Eguino, Iñigo et al. 2015) to $3.7^{\circ} \mathrm{C}$ above preindustrial levels in 2100 , instead of $3.8^{\circ} \mathrm{C}$. In these circumstances it seems quite 
impossible to keep EU policy on the $90 \%$ reduction path for $\mathrm{CO}_{2}$. Two less extreme scenarios are investigated by (González-Eguino, Iñigo et al. 2015), the Non-global-deal scenario and the Middleof-the-road scenario assuming climate policy abroad, but less strict than the more optimistic assumption on climate policy in here in this report. Their conclusion in Section 3.2 of their CECILIA2050 report is that the global effects of EU climate policy would still be limited. Also more stringent border tax adjustment are to be installed to reduce long term carbon leakage. In this report effectiveness relates to EU effectiveness, with also different global governance scenarios per strategy, but both assuming enough international cooperation to keep EU policy on track, and both assuming border tax adjustments, though on a different basis.

EU-effectiveness between the EU climate policy strategies depends on the stringency with which they are implemented: the emission standard reduction for electricity and vehicle emissions, and further instruments, need harsh quantification and the unpleasant price path for $\mathrm{CO}_{2}$ emissions is to be determined, with time lines also for the introduction of other instruments, like the real time open electricity market. There seems to be a difference between the effectiveness of the strategies in terms of time lines of emission reduction involved. In both, resistance to change as described by (Geels 2014) may be highly relevant but is assumed to have effectively been overcome.

Technology specific actions can work fast, locally. But their later expansion may be limited with rising burdens of taxes for funding subsidies, including surcharges on electricity, and as creating long term dynamics is difficult with future technology options not yet present. The rising emission tax level works more long term, leaving more current technologies in place till substitution processes and transformative processes start to dominate. Overall both instrument strategies may however be effective.

The speed of emission reduction may differ between strategies, with concrete, now available, options being implemented short and medium term in the planning \& control strategy, especially when involving reduction of energy use. However, technology-specific measures with primary positive effects may have overall limited and sometimes even negative effects through rebound mechanisms, see (Font Vivanco and van der Voet 2014a, Font Vivanco, Kemp et al. 2015), which then are to be controlled. The institutionalist strategy might start slower but may lead to deeper technology and behavior changes towards zero emissions, also by reducing rebound mechanisms. The idea that planning \& control will deliver more "sure" results seems not justified, vide Dieselgate and the soft handling of the issue in the $\mathrm{EU}$ and the recent $17 \%$ Chinese data revision on coal use, which might allow for on-paper reductions later.

Long term cost-effectiveness cannot be established in an operational sense, as as yet unknown innovations and unknown market mechanisms will determine what comes up. For the long term, the technologies and their cost structure are very open. Cost-effectiveness then can be established at best in a semi-quantitative way, on an indirect primarily qualitative basis. Qualitative reasoning might involve reasoning that a stable price signal based on long term expectations of emission price development is conducive to cost-effective long term technology development. However, such an analysis has no absolute meaning. But alternative instrument mixes may be compared in a reasoned way. Also quantitative modelling may give some general indication as to cost of emission reduction. Based on several types of modelling (Anderson, Parry et al. 2011) conclude that reducing emissions with pricing instruments can be at roughly half the cost as reducing the same amount by technology specific standards and regulations. However, 
the instrument scenario they have in mind differs from the instruments mixes developed here and all assessment of future technologies by necessity are more open than they assume. So there may be reasons to associate cost-effectiveness with design of open markets, reasoning towards semi-quantitative differences would remain speculative. Overall, there are qualitative reasons only to expect a higher cost-effectiveness for the Institutionalist strategy, unquantified and unquantifiable.

\subsection{Long term feasibility aspects}

Feasibility is an evaluative concept, indicating how difficult or probable it is that an instrument strategy will come about and will have the desired effectiveness. Effectiveness is a starting assumption here, with both sets of instrumentation in principle being able to get to the 2050 emission target. Feasibility may relate to simple preferences individuals may have, like preferring subsidies over taxes. Though a political reality, such simple-minded preferences over individual instruments are blocking long term effectiveness of relevant instrument mixes. One may reason on the relative feasibility of individual instruments but it is the feasibility of the effective mixes which is to be compared. Long term effectiveness is prime, even if this will mean going against preferences on specific instruments people have now, see for an analysis regarding a general public (Zvěřinová, Ščasný et al. 2013) and for public policy officials (Munaretto and Walz 2015). Any effective instrument mix of course should avoid contradictions where possible. In real life political development, additional issues like co-benefits and compensating measures in other policy domains will be part of the deal, but not part of the strategy.

Feasibility, as a multifaceted concept, may involve legal feasibility, economic feasibility, administrative feasibility, and social and political feasibility. An encompassing feasibility aspect is the overall legitimacy of climate policy, as part of total policy. Again, these aspects all have to be assessed in the realm of successful climate policy, and only in a comparative way, stating relative feasibility of overall instrument mixes.

\subsubsection{Legal feasibility}

Legal feasibility relates to how far the EU legal system would have to be adapted to have either of the two instrument mixes fully implemented. This would be repeated for the national level instruments, relative to national legal frameworks and relative to EU regulations, our of scope here. More detailed analysis of EU and national legal frameworks is in (Mehling, Bausch et al. 2013). In their general analysis no long term impediments come up, neither at the EU or at the member state level, though details are important. Such details are beyond the current project. Legal feasibility regards two main aspects: do the climate policy instrument mixes fit the Lisbon Treaty and are possible national level instruments in line with EU regulations, especially those related to state support and free trade of products and services in the EU. It seems that with proper attention both instrument mixes can comply with these requirements.

\subsubsection{Economic feasibility}

Economic feasibility relates to the required speed of transformation; introducing new technologies takes time and new technology systems take substantial time. In the energy domain novel technologies tend to lose momentum as soon as they approach relevant volumes (Kramer and Haigh 2009) while basically new technology systems need around 35 years to reach their highest speed of penetration, the Hirooka Rule (Hirooka 2006). The speed is however 
substantially dependent on the strength of the incentive, where planning and control may start fastest and the institutionalist approach may have the best long-term cards.

Contrary to most economic reasoning, cost-effectiveness (or efficiency) is not a prime evaluative criterion when assessing long term climate policy instrumentation, as specification of technologies, including their future relative costs is neigh impossible. It may play a role in a different, indirect, sense: would the instrumentation allow for cost-effective choices 'by then', say 25 and 35 years from now? Also in this limited sense the criterion is quite secondary however. Structural change is a key feature of dynamic economies. The prime issue seems how large the risk on substantial losses is, particularly losses in specific sectors and regions. Again it is not the losses due to the success of climate policy. Coal fired power stations will have a difficult time, and lose out, quite unavoidably, and gas fired power stations later as well. Such closures are unavoidable in successful climate policy and hence must be feasible. Predictability and adaptability of the conversion path to a low emission economy seems a main factor for avoiding substantial losses, by not investing in the wrong directions any more.

Conversely, the economic feasibility refers to the possibility to build-up a mainly renewables based energy production and use chain by 2050: are there unsurmountable economic bottlenecks? Do they differ between governance strategies? There seem to be no hard obstacles, also not in a resource sense (Koning, Kleijn et al. 2015). But there will be differences between the instrument strategies, as the institutionalist strategy is more flexible, and gives more long term economic guidance.

\subsubsection{Administrative feasibility}

Administrative feasibility refers to size and complexity of the administrative tasks involved in effective implementation, with options for fraud and improper use of the instruments to be mainly resolved. It is a more general evaluative aspect of administration. However, if the capacity is required for effective implementation it is to be delivered. In a comparative sense, the volume and complexity of the administrative tasks may be evaluated. The Institutionalist mix requires substantially less administrative input as there is not much detail in regulation for effective emission taxing and the electricity market is a privately going concern after having set up the rules and the infrastructure. At the member state level there are no specific problem to be expected in an administrative sense, not more than in other domains. Excises as the mode of emission tax administration are a most broadly applied instrument already in all EU countries. The more detailed instrumentation in the planning \& control mode uses familiar instruments as well, ranging from subsidies and taxes in all legal forms to standards and regulations. More specifically, the administrative aspects of renewables subsidies and fleet standards seem surveyable, as are emission standards in electricity production. Current issues as in Dieselgate may substantially be avoided by setting up controls closer to reality. Implementing technology-specific regulations in industry will require the most extensive apparatus and sensitive tactics for advancing more stringent technologies, but in a well-established tradition present in most countries. Though related to a more substantive tasks, there are no fundamental administrative novelties with problems to be expected, beyond what is usual in other domains. The national administering of the upstream implemented emission tax is also established routine, fully comparable to centuries old excises as on alcohol, and even simpler than that.

Overall, there are no basic administrative problems in either strategy but there is a substantially higher density of regulation in the planning and control mode. 


\subsubsection{Social and political feasibility}

Social feasibility refers to how acceptable or unacceptable climate policy instruments, and their induced technology and market changes, are to persons and organizations. Again, the assumed effectiveness of climate policy means that much will have to be accepted overall.

Political feasibility has a willingness and a capacity element. Willingness is assumed here for effective climate policy. The capacity element is more diverse. More specific regulations tend to have more specific opponents, and a larger number of policy decisions is required, competing with other also non-climate issues. The Diesel fraud, detected by the Commission in 2013, was put on hold as economic recovery had priority (Brunsden and Oliver 2015), action forced only by the US EPA. Such mechanisms are part of regime resistance, see (Geels 2014). Fleet standards in an easy range may create limited opposition, and even support for other reasons, like creating barriers for new entrants to the EU car market. However, when car factories start to be closed the opinion on fleet standards may change abruptly. Greening the tax structure (Andersen and Ekins 2009) as by introducing the generic high rising emission tax, with compensating national reductions of other taxes, will have broader but diffuser opposition. The high $\mathrm{CO}_{2}$ emission tax in Norway and Sweden, and the yearly rising emission tax in British Columbia and similar Price Floor Tax in the UK did not meet with strong opposition. Overall, single large decisions like the introduction of the institutionalist high emission tax or planning \& control strong fleet standards will need the momentum of the right moment, readily prepared, with strategy-dependent justifications.

In the design of instrumentation the most conflicting options have already been avoided. Forced movement for home insulation and forbidding touristic long distance flight might be useful measures but not socially feasible. The design process has dealt with such socially infeasible extravagancies, in both instrumentation strategies. The related political feasibility again must be approached from the long term effectiveness perspective. It certainly will not be a walk-over to present emission standards in major domains of energy, buildings and transport to go down to near zero in surveyable time period of 25 years from now or starting in 2020 . Neither will it be easy to introduce an emission tax rising to $€ 300$ or 400 a year in 2050 , even though accompanied by compensating tax reductions. The public actions involved in the mixes, from electricity market design to spatial planning and infrastructure seem of lesser importance in terms of political feasibility, vide the ease with which a fundamental change like the unbundling of electricity production has effectively been introduced.

Again, though specific instruments may slightly differ, there don't seem to be deep differences in social and political feasibility between the two instrumentation strategies.

\subsubsection{Legitimacy}

Legitimacy of climate policy as part of the legitimacy of the political system is a final feasibility aspect. Planning and control may generate short term enthusiasm with climate environmentalists and beneficiaries of subsidies. Individuals prefer subsidies over taxes (Brannlund and Persson 2012). The subsidy given requires raising the same amount of tax however. Long term planning \& control policy will have to deal with lack of support for continuously constraining specific instruments, with unavoidable implementation scandals, and with additional taxes (in the 
broadest sense) to fund substantial subsidies. Emission taxes with their diffuse 'normal' market mechanisms may create less of a legitimacy issue, being part of continuous economic transitions due to many factors. They also allow for more decentral participatory processes, assumed to contribute to legitimacy, see (Borrás and Ejrnæs 2011).

There are some deeper legitimacy aspects. Responsibility for climate results is a main governance and legitimacy issue, different between the strategies. In the planning \& control direction the full responsibility is with the central government level in the EU, implementing what is required for the quantified emission reduction target. A centralizing tendency then is nearly unavoidable, preferably backed up ultimately with a legally binding international agreement on national caps. Such EU policy may act directly, as with fleet standards, or indirectly with decentralized tasks. If countries then don't play their part in emission reduction, central EU level government must step $\mathrm{in}^{36}$. In the Institutionalist direction there are no binding targets for the EU nor for member states. There is only one EU level implemented incentive for emission reduction, the uniform emission tax, and one key enabling element in institutions and infrastructure: EU-wide infrastructure and open markets for electricity and hydrogen. How emission reductions will emerge is up to member states, to regions, cities, and communities, and broader to civil society and firms, in an also international context. If over decades emissions remain too high for a relevant reduction level, the Baumol tax must be raised, pressing decentral responsible action further.

Overall, there seems to be a legitimacy advantage for the institutionalist mode.

\subsection{Long term optimality aspects: risks, costs and welfare}

Optimality, viewed differently in the theoretical domain, is focused here at the combination of climate effectiveness, cost-effectiveness and different feasibility aspects as surveyed in the preceding sections. For the long term it is a qualitative aspect only. The analysis given indicates slight differences in terms of long term efficiency and similarly only few differences in the feasibility aspects distinguished.

Some remarks of caution are due in this discourse. There is a tendency to equate markets with optimality. Whatever the exact relation may be, here markets are first seen as a major mechanism for resource allocation, with details in market design relevant for specifics in resource allocation. Though direct public determination of resource use is possible, the public span of control is limited. Market failures may be specified, and possibly remedied, like undue market power of monopolist and cooperating oligopolists. There will always be deviations from the optimal in a very basic sense however, as Nobel prize winners (Akerlof and Shiller 2015) have eloquently described; there are no independent utility functions in their perspective, and consistency is economic choices is substantially lacking, see also (Thaler 2015). So optimality of markets is a basically fluid concept. Efficiency can then be a partial concept only, with costs not related to an overall welfare concept related to optimality. Markets create resource allocation but not necessarily in the ideal welfare optimal way, with a few clear sub-optimalities possibly resolved for climate reasons.

The most basic issue in optimality here is the climate issue itself. It tends to be specified in terms of the damages caused by emissions on the welfare of current and future populations, expressed

\footnotetext{
${ }^{36}$ EU Parliament acclaimed a procedural resolution on 27 Oct 2015 to centralize surveillance to an EU authority to oversee car-emission tests, intending to prevent further fraud, cheating and similar.
} 
in market terms and in broader terms like disability adjusted life years lost, and using discounting procedures in order to express future effects in current terms. However, such measures are first extremely difficult to predict in any quantified sense, being highly uncertain and contingent, as on adaptation measures, and depending on deeply contested discounting procedures. The most basic issue however is that deep risks go beyond what can be economically measured: the possible breakdown of society. In modest economic terms called that falls under fat tail effects (Weitzman 2009, Weitzman 2011), and named more alarmingly Weitzman's Dismal Theorem.

In a market type of reasoning, the institutionalist approach of emission pricing and overall electricity market design may have a cost advantage over technology specific instrumentation with standards and subsidies, dominant in the command and control approach. Well-designed technology specific instrumentation may however have a faster start, as feed-in tariffs have shown. For overall (soft) welfare development it seems that other considerations will be more relevant, linked deeply to the strategy choices also made for climate policy: how will our society be actively developed in the next half century?

\subsection{Long term strategic governance choices}

The considerations leading to the two instrument strategies developed here are basic in societal development, not in a directly political sense but in an ideological guidance sense for all governance development, not just in the EU but nearly globally. Climate policy instrumentation is not independent from these more general considerations and can be framed in them, as has been done. So ultimately it is not optimality considerations guiding choices, even if one could come up with an overall preference. It is much softer and deeper considerations related to the role of civil society; independence from government interference; certainty on climate outcomes; views on possible global governance and more such basic views which determine preferences over the two strategic directions for climate policy instrumentation developed here.

So it is basic ideological governance aspects which constitute the core difference between the two strategies. The Planning \& Control Strategy of course adheres to planning and control. The community sense of all together doing what is collectively deemed best is part of its ideological attractiveness. The Institutionalist Strategy has its focus on decentral independence and the role of civil society in guiding cultural and socio-economic development. Also in climate policy instrumentation a choice is unavoidable. 


\section{Key outcomes and general recommendations}

\subsection{On governance}

1. There are two mutually incompatible approaches to governance, a more technology specific Planning \& Control Strategy and more incentives oriented Institutionalist Strategy.

2. Instrument mixes go in either direction: One cannot have feed-in-tariffs or premiums; BATbased industrial standards; obligatory housing insulation and Fleet standards, and at the same time have an open real time electricity market.

3. Technology specific instrumentation may be combined administrative-technically with price based emission pricing but not with strict volume based emission pricing, as in pure cap-andtrade systems and pure fleet standards.

4. The Planning \& Control governance strategy uses technology-specific instrumentation, including technology specific financial incentives, making a rational set-up of generic emission pricing difficult.

5. The incentivizing Institutionalist governance strategy tries to avoid technology-specific instrumentation as much as possible, using more abstract incentives.

6. With an EU level Institutionalist instrumentation in a few domains only, encompassing carbon pricing and a an open real time EU electricity market, more technology specific instruments can be left to the domain of Member States and private actors, with their complex motives, like being prime mover, clean city, clear firm or clean person, etc.

7. In the Planning \& Control development the role of EU instrumentation is more encompassing and is substantially intermingled with national level instrumentation, easily leading to lobbying activities and legitimacy issues at member states level.

\subsection{On combined energy and climate policy instrumentation}

1. The single most effective and most low-cost measure is at the level of institutional framework conditions: to set up an open to all real time EU electricity market, increasing efficiency and translating emission price incentives to all market parties. This is a side effect of this climate policy instrument.

2. Effective climate policy based on replacement of fossils by renewables (and possibly nuclear) will also increase supply security, weaning the EU from fossils with their uncertainties. This is a co-benefit in this respect.

3. Reduced energy use belongs to the most expensive instruments for long term climate policy when deep reductions are to be realized; societies cannot function well with a constrained energy supply.

4. In a nearly fully decarbonized energy systems, long term, energy reduction does not lead to emission reduction. 


\subsection{On emission pricing}

1. ETS as a pure cap-and-trade system is instable: it will go to oblivion if taken over effectively by technology-specific instruments or will be price stabilized to avoid irrelevantly low prices or unacceptably high prices. Instable systems will not function long term.

2. The lack of long term predictable emission prices is resolved by explicit price stabilization helping guide both research, $R \& D$, and investment planning.

3. Upstream application of the emission pricing system allows for including smaller energy users, also private users, increasing the domain of application from current $45 \%$ to near to $100 \%$.

4. Upstream application reduces also administrative complexity and cost, as by reducing the number of regulatees very substantially.

5. The advantage of a predictable price level, as with the UK Price Floor Tax, is strongest with a long term fully fixed price path.

6. With full coverage of all fossil emissions and a fixed single price path, transforming the cap permit system into the domain duties, taxes and excises allows for substantial administrative simplification, shifting from a permit system to a transaction system.

7. All emission pricing systems can be made compatible with the Lisbon Treaty, with administrative implantation at member state level and (nearly all) proceeds going to Member States, different from current ETS.

8. Explicit and stable emission pricing systems allow for an easier introduction of Border Tax Adjustments.

9. Emission pricing systems require a well-functioning electricity market and related energy markets for the price incentive to reach all relevant decision makers; that is all government bodies, firms and persons in the EU.

10. Emission reduction may be earlier and faster in the Planning \& Control Strategy, but slow down later due to more limited innovation incentives, with the Institutionalist Strategy catching up later with deeper innovations and transformations.

\subsection{On electricity markets}

1. In the Planning \& Control Strategy specific adaptations in the electricity market are introduced so as to allow controlled input of renewables as through public-private partnerships; the funding of renewables by subsidies like Feed-in tariffs, and funding of subsidies by surtaxes differentiated as to user groups. This precludes the emergence of an open real time electricity market and requires bodies with the responsibility and authority for market clearance. EU level trade will be limited and mostly restricted to bilateral trade.

2. In the Institutionalist Strategy an open real time market - with equal prices for all delivering and equal prices for all using electricity - translates emission prices to all producers and users of electricity, and related markets. This precludes the use of different electricity prices for technology specific purposes.

3. In the Planning \& Control Strategy the transmission grid may be owned publicly or publicprivately, but with pricing cost and profits based, also if operated by public bodies. Grid investment planning is based on expected needs and proceeds. 
4. In the Institutionalist Strategy the transmission grid is owned and operated publicly, with congestion based pricing. Grid investment planning is based on where congestion prices are high, indicating that capacity should be expanded in these parts of the grid.

\subsection{On research, research and development, and demonstration}

1. In the Planning \& Control Strategy funding is focused at R\&D and Demonstration projects and on public-private market development.

2. In the Institutionalist Strategy funding is focused at Research and R\&D, with public development exceptionally where risks are too high for private development, as happened in the IT domain with the roll-out of internet infrastructure. There are no candidates yet.

\subsection{On instruments regarding specific technologies, markets and behaviors}

1. In the Planning \& Control Strategy, electricity production can be transformed roughly with current instrument means, then substantially expanded and stricter applied. Similar holds for buildings and households, where electrification can be stimulated and forced. The political challenge in transport is to expand fleet standards to all transport and use really high reduction percentages per year ( $14 \%)$ to press fossil drives out of the market. Subsidizing non-fossil drives can ease the process in the medium term, but is not feasible in the long term. There is a great challenge in industry. Standards are differentiated as to production domains, based on BATs. Current BATs do not induce dynamics very much, mainly pressing out laggards. The climate BATs are to be dynamically developed and next diffused into industry, with carrots (subsidies) and sticks (standards).

2. In the Institutionalist Strategy, there is limited interference in market processes, with two main exceptions. Near monopolistic sectors like electricity transmission and hydrogen transport are public, taking them out of private market functioning. The introduction of charging stations for electric vehicles and refueling stations for hydrogen are brought into the market with mixed means. A few large very-high-risk, long-term, very-high-impact projects may be implemented publicly.

\subsection{General recommendations}

1. Roadmaps for long term instrumentation strategies are to be developed, not one but several most relevant ones. This avoids incremental development without the transformative power required for a low carbon society, and makes the political process more transparent.

2. These Roadmaps are at least to include a Planning \& Control Strategy, focused on tangible results, primarily using technology specific instruments, especially caps, standards and subsidies, and an Institutionalist Strategy focused on incentives and avoids technology specific instrumentation.

3. Strategic choices are to be made in climate policy: a Planning \& Control and an Institutionalist Strategies of governance lead to substantially differing instrumentation of climate policy, regarding: internalization of external effects in prices; electricity market structure; physical infrastructure; innovation policies; and volume and nature of technology regulation in the private sector. The strategies are mutually exclusive. A strategic choice on instrumentation is to be made in the next half decade. 
4. Subsidies and premiums for creating learning curves in hybrid and plug-in hybrid vehicles are to stop as they have been mass produced already. Battery electric cars are near that point as well, while fuel cell cars may need substantial learning curves still, with subsidies.

5. Emission reduction percentages are better to be specified relative to the previous year, similar to economic growth rates, efficiency improvements, and emission intensity improvements in the economy, as compound yearly rates. This better supports long term perspective on performance development through better comparability.

6. Pure volume systems in instrumentation, like the EU ETS and the EU Fleets Standards, are at variance with other instruments applied now in the same domains. These other instruments don't much change the cap and standard as set in these instruments. Not just ETS, also Fleet Standards make bottom-up actions mostly irrelevant, if not worse through the in-built premiums: more electric cars allows for higher overall $\mathrm{CO}_{2}$ emissions on the medium term. This is a socially and politically undesirable consequence of volume systems, to be repaired as soon as possible.

7. A pure cap-and-trade system, without price stabilization, as the ETS intended to be before the Market Stability Reserve (MSR), is instable economically and politically. Either effective technology specific instruments lower its price, the lower price making it less relevant, with the importance of technology specific instruments then further increasing. Or the pure cap system is dominant, accepting very low prices as now and extreme price rises as may come up, especially in periods of high economic growth, and not introducing technology specific instruments effectively. If these consequences are not accepted and permit volumes are adapted, the pure cap domain is left. A choice for either leaving the cap pricing system or making it price dependent is due on short notice; the MSR is only an intermediate step.

8. The introduction of a price element in the cap system, adapting volume to an intended price, resolves the incompatibility with decentral instruments and initiatives, first possibly by creating a price floor and a price cap, with a bandwidth. The bandwidth has no economic or environmental meaning however and should converge to zero, making costly trading (with tax evasion and fraud) superfluous. In a further step, the administrative set-up can be much simplified by moving from a permit to an excise system. The ETS cap than is transformed into an encompassing generic emission tax. This transformed ETS is to be the core instrument in the Institutionalist Strategy for long term climate policy instrumentation.

9. The electricity market plays a key role in linking low emission energy technologies, as most renewables produce electricity, and electricity will play a main role in energy use. The number of primary and secondary producers may well rise to in the order of 100 million. For linking such numbers and for translating emission prices into market prices, a substantially changed European electricity market is to be developed, well beyond the targets of the Unbundling Directive and the European Energy Union. Core target is a real time variable priced market system, with equal prices for all producers and all users, and load clearance by market forces, not central operators. EU infrastructure as a pan-European DC High Tension grid linking national transmission grids is to constitute the physical basis.

10. Having fleet standards determining car technology regarding emissions at the EU level makes subsidy schemes for low emission cars as now common at the national level mostly irrelevant. These then use substantial amounts of public money going to the car industry, without 
reducing overall emissions and without creating innovation incentives or learning curves. This state of affairs is to be effectively communicated to member states.

11. In the Planning \& Control strategy, Fleet Standards are to be substantially adapted to make them pure emission reducing instruments: no mass correction; no low emission vehicle premiums; no differentiation between person cars and vans; and realistic emission measurement to replace NEDC measurement standards, and fleet volumes sold being part of the system, with trade in expected emission volumes made possible. In the Institutionalist strategy such adapted standards may play a role in the short to medium term till emission tax has risen enough, as the period towards all cars being zero emission is very short, to be $100 \%$ zero by 2040 latest.

12. Proceeds from the emission tax will first be rising roughly towards the mid-Thirties and decreasing thereafter. There is no reason in the Institutionalist strategy to link proceeds to specific outlays. Proceeds are due to member states, to their discretion, for greening the tax system, to reduce budget imbalances or for specific outlays. 


\section{References}

Acemoglu, D., S. Johnson and J. A. Robinson (2005). Institutions as a Fundamental Cause of Long-Run Growth. Handbook of Economic Growth. P. Aghion and S. M. Durlauf Amsterdam, North Holland.

Agnolucci, P. and P. Drummond (2014). The Effect of Key EU Climate Policies on the EU Power Sector. An Analysis of the EU ETS, Renewable Electricity and Renewable Energy Directives. Choosing Efficient Combinations of Policy Instruments for Low-carbon development and Innovation to Achieve Europe's 2050 climate targets. CECILIA2050. London, UCL.

Akerlof, G. A. and R. J. Shiller (2015). Phishing for Phools: The Economics of Manipulation and Deception, Princeton University Press.

Aldy, J. E. and R. N. Stavins (2009). Post-Kyoto international climate policy: implementing architectures for agreement, Cambridge University Press.

Alexeeva-Talebi, V., A. Löschel and T. Mennel (2009). "Climate policy and the problem of competitiveness: Border tax adjustments or integrated emission trading?" IOP Conference Series: Earth and Environmental Science 6(10): 102012.

Ambec, S., M. A. Cohen, S. Elgie and P. Lanoie (2013). "The Porter Hypothesis at 20: Can Environmental Regulation Enhance Innovation and Competitiveness?" Review of Environmental Economics and Policy.

Andersen, M. S. and P. Ekins (2009). Carbon-energy taxation: lessons from Europe, Oxford University Press.

Anderson, S. T., I. W. Parry, J. M. Sallee and C. Fischer (2011). "Automobile Fuel Economy Standards: Impacts, Efficiency, and Alternatives." Review of Environmental Economics and Policy 5(1): 89108.

Baron, R. (2015). Reframing investment signals and incentives in electricity. Chapter 7. Aligning Policies for Low-carbon Economy. OECD/IEA/NEA/ITF. Paris, OECD/IEA/NEA/ITF.

Baumol, W. J. (1972). "On taxation and control of externalities." American Economic Review 62(3): 15.

Baumol, W. J. and W. E. Oates (1971). "The Use of Standards and Prices for Protection of the Environment." Swedish Journal of Economics, 73(1): 12.

Bausch, C., E. Roberts, L. Donat and C. Lucha (2014). European governance and the low-carbon pathway: Analysis of challenges and opportunities arising from overlaps between climate and energy policy as well as from centralisation of climate policies. Choosing Efficient Combinations of Policy Instruments for Low-carbon development and Innovation to Achieve Europe's 2050 climate targets. CECILIA2050. Berlin, Ecologic Institute.

BC, M. F. (2014). Carbon Tax. Overview of the revenue-neutral carbon tax. Vancouver, Ministry of Finance, British Columbia http://www.fin.gov.bc.ca/tbs/tp/climate/carbon tax.htm.

Bentham, J. (1776). A Fragment on Government: Being an Examination of what is Delivered, on the Subject of Government in General, . London, Payne, Elmsly and Brooke.

Böhringer, C., E. J. Balistreri and T. F. Rutherford (2012). "The role of border carbon adjustment in unilateral climate policy: Overview of an Energy Modeling Forum study (EMF 29)." Energy Economics 34: S97-S110.

Böhringer, C. and T. F. Rutherford (2002). "Carbon abatement and international spillovers." Environmental and Resource Economics 22(3): 391-417.

Böhringer, C., T. F. Rutherford, E. J. Balistreri and J. Weyant (2012). "Introduction to the EMF 29 special issue on the role of border carbon adjustment in unilateral climate policy." Energy Economics 34 S95-S96. 
Boldrin, M. and D. K. Levine (2008). Against intellectual monopoly, Cambridge University Press Cambridge.

Borenstein, S. (2013). "Putting a Collar on Carbon Prices." https://energyathaas.wordpress.com/2013/05/28/putting-a-collar-on-carbon-prices/ 2015.

Borrás, S. and A. Ejrnæs (2011). "The legitimacy of new modes of governance in the EU: Studying national stakeholders' support." European Union Politics 12(1): 107-126.

Bosetti, V. and J. Frankel (2009). Global Climate Policy Architecture and Political Feasibility: Specific Formulas and EmissionTargets to Attain 460 ppm CO2 Concentrations, Fondazione Eni Enrico Mattei.

Brancucci Martinez-Anido, C., L. De Vries and G. Fulli (2012). Impact of variable renewable energy on European cross-border electricity transmission. CESUN 2012: 3rd International Engineering Systems Symposium, Delft University of Technology, The Netherlands, 18-20 June 2012.

Branger, F. and P. Quirion (2013). Understanding the impacts and limitations of the current instrument mix in detail: industrial sector. Choosing Efficient Combinations of Policy Instruments for Lowcarbon development and Innovation to Achieve Europe's 2050 climate targets. CECILIA2050. Paris, SMASH-CIRED.

Brannlund, R. and L. Persson (2012). "To tax, or not to tax: preferences for climate policy attributes." Climate Policy 12(6): 704-721.

Brauner, G., W. D'Haeseleer, W. Gehrer, Glaunsinger Wolfgang, H. Kaul, M. Kleimaier, W. L. Kling, H. Michael, W. Schröppel and W. Skomudek (2013). Electrical Power Vision 2040 for Europe. Brussels, Eurel.

Brenton, A. (2013). "'Great Powers' in climate politics." Climate Policy 13(5): 541-546.

Brunsden, J. and C. Oliver (2015). "EU failed to heed emissions warnings in 2013." Financial Times.

Buchanan, R. (1992). "Wicked problems in design thinking." Design issues: 5-21.

Burtraw, D., A. Löfgren and L. Zetterberg (2013). A Price Floor Solution to the Allowance Surplus in the EU ETS. Gothenburg, Mistra Indigo.

Carrigan, C. and C. Coglianese (2011). "The Politics of Regulation: From New Institutionalism to New Governance." Annual Review of Political Science 14(1): 107-129.

Chang, H. J. (2002). "Breaking the mould: an institutionalist political economy alternative to the neoliberal theory of the market and the state." Cambridge Journal of Economics 26(5): 539-559.

Coase, R. (1999). "The task of the society Opening Address to the Annual Conference, September 17, 1999 of the International Society for New Institutional Economics." ISNIE Newsletter 2(2): 7.

Collini, S. (2012). What are universities for?, Penguin UK.

COM (1991). A Community Strategy to limit Carbon Dioxide emissions and to improve energy efficiency Communication from the Commission to the Council. Brussels, European Commission.

COM (2011). A Roadmap for moving to a competitive low carbon economy in 2050. Brussels, European Commission. $\operatorname{COM(2011)} 112$ final.

COM (2013). Delivering the internal electricity market and making the most of public intervention. $\mathrm{E}$. Commission. Brussels, European Commission. COM(2013) 7243 final.

COM (2015). ENERGY UNION PACKAGE Achieving the 10\% electricity interconnection target. Making Europe's electricity grid fit for 2020. Brussels, European Commission. COM(2015) 82 final.

COM (2015b). Establishing a guideline on capacity allocation and congestion management. Commission Regulation (EU) 2015/12222. Official Journal of the European Union. E. Commission.

Coria, J. and J. Jaraite (2015). Carbon Pricing: Transaction Costs of Emissions Trading vs. Carbon Taxes. CERE. Umeå, Sweden, CERE, Department of Economics, Umeå University.

Cyert, R. M. and J. G. March (1963). A behavioral theory of the firm. Englewood Cliffs, NJ.

Dahl, R. A. (1982). Dilemmas of pluralist democracy: Autonomy vs. control, Yale University Press. 
Dahl, R. A. and C. E. Lindblom (1953). Politics, economics and welfare: planning and politico-economic systems, resolved into basic processes, Harper \& Brothers.

Dasgupta, P. and E. Maskin (2005). "Uncertainty and Hyperbolic Discounting." American Economic Review 95(4): 1290-1299.

De Koning, A., G. Huppes, S. Deetman and A. Tukker (2015). "Scenarios for a $2{ }^{\circ} \mathrm{C}$ world: a trade-linked input-output model with high sector detail." Climate Policy: 1-17.

Deetman, S., A. F. Hof and D. P. Van Vuuren (2014). "Deep CO2 emission reductions in a global bottomup model approach." Climate Policy: 1-19.

Díaz-González, F., M. Hau, A. Sumper and O. Gomis-Bellmunt (2014). "Participation of wind power plants in system frequency control: Review of grid code requirements and control methods."

Renewable and Sustainable Energy Reviews 34: 551-564.

Dinan, T. and A. Stocking (2012). "U.S. Cap-and-Trade Markets: Constraining Participants, Transactions, and Prices." Review of Environmental Economics and Policy 6(2): 169-189.

Dong, Y., M. Ishikawa and T. Hagiwara (2015). "Economic and environmental impact analysis of carbon tariffs on Chinese exports." Energy Economics 50: 80-95.

Droege, S. (2011). "Do border measures have a role in climate policy?" Climate Policy 11(5): 1185-1190.

Drummond, P. (2013). Country report: The European Union, part of Review of the existing instrument mix at EU level and in selected Member States. Choosing Efficient Combinations of Policy Instruments for Low-carbon development and Innovation to Achieve Europe's 2050 climate targets. CECILIA2050. Berlin, Ecologic Institute.

Drummond, P. (2014). Scenarios for a Low-Carbon Europe for 2050: Discussion of Results from the ETM-UCL Model, EXIOBASE Input--Output Model and the GINFORS Model. Choosing Efficient Combinations of Policy Instruments for Low-carbon development and Innovation to Achieve Europe's 2050 climate targets. CECILIA2050. London, University College London (UCL).

Drummond, P. (2014). Understanding the Impacts \& Limitations of the Current

EU Climate Policy instrument Mix. Choosing Efficient Combinations of Policy Instruments for Low-carbon development and Innovation to Achieve Europe's 2050 climate targets. CECILIA2050 WP2 Deliverable 2.10. CECILIA2050. London, University College London.

Drummond, P. (2015). Short-Term Development Options for the EU Climate Policy Mix: Short-Term Improvements for an Effective, Cost-Efficient and Feasible Policy Mix. CECILIIA2050. CECILIA2050. London, Universtity College London (UCL).

EC (2013). Ownership unbundling. The Commission's practice in assessing the presence of a conflict of interest including in case of financial investors. E. Commission. Brussels, European Commission. Commission Staff Working Document (2013) 177 final.

Edenhofer, O. (2014). "Climate policy: Reforming emissions trading." Nature Clim. Change 4(8): 663-664.

Edenhofer, O. and M. Kalkuhl (2011). "When do increasing carbon taxes accelerate global warming? A note on the green paradox." Energy Policy 39(4): 2208-2212.

EEA. (2015). "Overview of the European energy system (ENER 036) Assessment Version September 2015." Retrieved 07Sep15, 2015, from http://www.eea.europa.eu/data-andmaps/figures/summaries-the-overall-picture-of- 2 .

EGTEI (2005). Car Coating: Synopsis sheet, CITEPA (Interprofessional Technical Centre for Studies on Air Pollution ); EGTEI (Expert Group on Techno-Economic Issues).

ENTSOE (2014). ENTSO-E overview of Internal Electricity Market-related project work. Brussels, ENTSOE. EP-PressOffice (2015). ETS market stability reserve: MEPs strike deal with Council [06-05-2015 - 12:11]. Brussels, European Parliament.

Eurostat (2015). Energy balance sheets 2013 data. Luxembourg, Eurostat, Publications Office of the European Union. 
Falkner, R. (2015). "International negotiations: Towards minilateralism." Nature Climate Change 5(9): 805-806.

Falkner, R. (2015a). A minilateral solution for global climate change? On bargaining efficiency, club benefits and international legitimacy'. London, Grantham Research Institute on Climate Change and the Environment. Working Paper No. 197.

Faure, M. and M. Peeters (2011). Climate change liability, Edward Elgar Publishing.

Fell, H., D. Burtraw, R. Morgenstern, K. Palmer and L. Preonas (2011). Soft and Hard Price Collars in a Cap-and-Trade System: A Comparative Analysis. Washinton, Resources for the Future. RFF DP 1027-REV.

Feng, Z.-H., L.-L. Zou and Y.-M. Wei (2011). "Carbon price volatility: Evidence from EU ETS." Applied Energy 88(3): 590-598.

Finon, D. (2013). "The transition of the electricity system towards decarbonization: the need for change in the market regime." Climate Policy 13(sup01): 130-145.

Finon, D. and V. Pignon (2008). "Electricity and long-term capacity adequacy: The quest for regulatory mechanism compatible with electricity market." Utilities Policy 16(3): 143-158.

Fischer, C. and S. W. Salant (2013). "Limits to limiting greenhouse gases: Intertemporal leakage, spatial leakage, and negative leakage." Work.

Font Vivanco, D., J. Freire-González, R. Kemp and E. Van Der Voet (2014b). "The remarkable environmental rebound effect of electric cars: a microeconomic approach." Environmental science \& technology 48(20): 12063-12072.

Font Vivanco, D., R. Kemp and E. van der Voet (2015). "The relativity of eco-innovation: environmental rebound effects from past transport innovations in Europe." Journal of Cleaner Production(0).

Font Vivanco, D. and E. van der Voet (2014a). "The rebound effect through industrial ecology's eyes: a review of LCA-based studies." The International Journal of Life Cycle Assessment 19(12): 19331947.

Frankel, J. (2008). "An elaborated proposal for global climate policy architecture: specific formulas and emission targets for all countries in all decades." Harvard Project on International Climate Agreements. Working paper, October 20.

Fuss, S., J. G. Canadell, G. P. Peters, M. Tavoni, R. M. Andrew, P. Ciais, R. B. Jackson, C. D. Jones, F. Kraxner, N. Nakicenovic, C. Le Quere, M. R. Raupach, A. Sharifi, P. Smith and Y. Yamagata (2014). "Betting on negative emissions." Nature Clim. Change 4(10): 850-853.

Geels, F. W. (2014). "Regime Resistance against Low-Carbon Transitions: Introducing Politics and Power into the Multi-Level Perspective." Theory, Culture \& Society 31(5): 21-40.

González-Eguino, M., C.-P. Iñigo, I. Arto, A. Ansuategi and A. Markandya (2015). Global effects of EU climate policy under fragmentation,. Choosing Efficient Combinations of Policy Instruments for Low-carbon development and Innovation to Achieve Europe's 2050 climate targets. CECILIA2050. Bilbao, Basque Centre for Climate Change (BC3), Leioa: University of the Basque Country.

Goodwin, P. (2012). Peak Travel, Peak Car and the Future of Mobility. Evidence, Unresolved Issues, Policy Implications, and a Research Agenda. Roundtable on Long-Run Trends in Travel Demand, 29-30 November 2012, OECD/ITF Discussion Paper 2012-13.

Görlach, B. (2013). What constitutes an optimal climate policy mix? Defining the concept of optimality, including political and legal framework conditions. Choosing Efficient Combinations of Policy Instruments for Low-carbon Development and Innovation to Achieve Europe's 2050 climate targets. CECILIA2050. Berlin, Ecologic Institute.

Goulder, L. H. and A. Schein (2013). Carbon taxes vs cap and trade: a critical review. NBER. Cambridge MA, National Bureau of Economic Research. NBR Working Paper Series Nr 19338.

Green, A. J. (2005). "Climate change, regulatory policy and the WTO: How constraining are trade rules?" Journal of International Economic Law 8(1). 
Gros, D. and C. Egenhofer (2011). "The case for taxing carbon at the border." Climate Policy 11(5): 12621268.

Grubb, M. (2011). "International climate finance from border carbon cost levelling." Climate Policy 11(3): 1050-1057.

Grubb, M., J. C. Hourcade and K. Neuhoff (2014). Planetary economics : energy, climate change and the three domains of sustainable development, Taylor and Francis.

Guinée, J. B., (Ed.) (2002). Handbook on Life Cycle Assessment. Operational Guide to the ISO Standards. Dordrecht, Springer.

Guinee, J. B., R. Heijungs and G. Huppes (2004). "Economic allocation: Examples and derived decision tree." International Journal of Life Cycle Assessment 9(1): 23-33.

Hamamoto, M. (2011). "Energy Efficiency Regulation and R\&D Activity: A Study of the Top Runner Program in Japan." Low Carbon Economy 2(02): 91.

Hare, W., C. Stockwell, C. Flachsland and S. Oberthür (2010). "The architecture of the global climate regime: a top-down perspective." Climate Policy 10(6): 600-614.

Harstad, B. (2012). "Buy coal! A case for supply-side environmental policy." Journal of Political Economy 120(1): 77-115.

Heal, G. and A. Millner (2014). "Reflections: Uncertainty and Decision Making in Climate Change Economics." Review of Environmental Economics and Policy 8(1): 120-137.

Heinen, S., D. Elzinga, S.-K. Kim and Y. Ikeda (2011). "Impact of smart grid technologies on peak load to 2050."

Hertwich, E. G., T. Gibon, E. A. Bouman, A. Arvesen, S. Suh, G. A. Heath, J. D. Bergesen, A. Ramirez, M. I. Vega and L. Shi (2015). "Integrated life-cycle assessment of electricity-supply scenarios confirms global environmental benefit of low-carbon technologies." Proceedings of the National Academy of Sciences 112(20): 6277-6282.

Hirooka, M. (2006). Innovation dynamism and economic growth: a nonlinear perspective, Edward Elgar Publishing.

Hoel, M. (2011). "The supply side of CO2 with country heterogeneity." The Scandinavian Journal of Economics 113(4): 846-865.

Hoel, M. (2011a). "The green paradox and greenhouse gas reducing investments." International Review of Environmental and Resource Economics 5(4): 353-379.

Hoel, M. (2012). Carbon taxes and the green paradox, Oxford University Press,(ISBN: 9780199692873).

Hof, A. F., D. P. van Vuuren and M. G. J. den Elzen (2010). "A quantitative minimax regret approach to climate change: Does discounting still matter?" Ecological Economics 70(1): 43-51.

Hogan, W. W. (2005). ON AN “ENERGY ONLY” ELECTRICITY MARKET DESIGN FOR RESOURCE ADEQUACY Cambridge, Massachusetts 02138

September 23, 2005. Cambridge, Center for Business and Government, John F. Kennedy School of Government, Harvard University.

Holmes, P., T. O. M. Reilly and J. I. M. Rollo (2011). "Border carbon adjustments and the potential for protectionism." Climate Policy 11(2): 883-900.

Hood, C. (2011). Summing up the Parts. Combining Policy Instruments for Least-Cost Climate Mitigation Strategies. Paris, International Energy Agency, IEA Climate Change Unit.

Hupkes, G. (1982 (1977)). "The law of constant travel time and trip-rates." Futures 14(1): 38-46.

Huppes, G. (1993). Macro-Environmental Policy: Principles and Design. Amsterdam, Elsevier.

Huppes, G. (2011). Instruments for Effective Global Climate Policy: the Carbon Deposit system. Leiden: $\mathrm{CML}$, Leiden University. Downloadable at:

http://cml.leiden.edu/research/industrialecology/research/publications-ie.html. Leiden, CML, Leiden University http://cml.leiden.edu/research/industrialecology/research/publicationsie.html. 
Huppes, G., M. Davidson, J. Kuyper, L. Van Oers, H. Udo de Haes and G. Warringa (2007). "Eco-efficient environmental policy in oil and gas production in the Netherlands." Ecological Economics 61(1): 43-51.

Huppes, G., R. Huele, R. Kleijn and A. d. Koning (2015). Instrumentation Strategies and Instrument Mixes for Long Term Climate Policy. Choosing Efficient Combinations of Policy Instruments for Lowcarbon Development and Innovation to Achieve Europe's 2050 climate targets. CECILIA2050. Leiden, CML, Leiden University.

Huppes, G. and R. A. Kagan (1989). "Market-Oriented Regulation of Environmental Problems in the Netherlands." Law \& Policy 11(2): 215-239.

ICCT (2014). Credit Trading in the US Corporate Average Fuel Economy (CAFE) Standard. Hui-He. Beijing, etc., ICCT International Council on Clean Transportation.

IEA-OECD (2015). Energy and Climate Change. World Energy Outlook Special Report. Paris.

IEA (2014). Technology Roadmap Solar Photovoltaic Energy. Paris, International Energy Agency.

IEA (2015). Energy Technology Perspectives 2015. Mobilising Innovation to Accelerate Climate Action.

Paris, International Energy Agency.

IEA/OECD (2015). Projected Costs of Generating Electricity. 2015 Edition. Projected Costs of Generating Electricity. C. wachtwoord. Paris, IEA/OECD/NEA.

Immergut, E. M. and K. M. Anderson (2008). "Historical institutionalism and west European politics." West European Politics 31(1-2): 345-369.

Interpol (2013). Guide to Carbon Trading Crime. E. C. Programme, International Criminal Police Organisation (Interpol).

IPCC-AR5-WGIII (2014). Mitigation of Climate Change. Contribution of Working Group III to the Fifth Assessment Report of the Intergovernmental Panel on Climate Change. O. Edenhofer, R. PichsMadruga, Y. Sokona et al. Cambridge, IPCC.

IPCC-WG3 (2014). Working Group III - Mitigation of Climate Change, Annex III: Technology-specific cost and performance parameters.

Jackson, T. (2011). Prosperity without growth: Economics for a finite planet, Routledge.

Kettner, C., A. Köppl, S. Schleicher and C. Strategies (2012). Carbon authority as price stabilising institution in the EU ETS, WIFO, Österr. Inst. für Wirtschaftsforschung.

Koch, N., S. Fuss, G. Grosjean and O. Edenhofer (2014). "Causes of the EU ETS price drop: Recession, CDM, renewable policies or a bit of everything? -New evidence." Energy Policy 73: 676-685.

Kokoni, S. and J. Skea (2014). "Input-output and life-cycle emissions accounting: applications in the real world." Climate Policy 14(3): 372-396.

Koliou, E., C. Eid, J. P. Chaves-Ávila and R. A. Hakvoort (2014). "Demand response in liberalized electricity markets: Analysis of aggregated load participation in the German balancing mechanism." Energy 71: 245-254.

Koning, A. d., G. Huppes and S. Deetman (2014). Scenarios for 2050 for a 2-degrees world: Using a four regions trade linked IO-model with high sector detail. Choosing Efficient Combinations of Policy Instruments for Low-carbon development and Innovation to Achieve Europe's 2050 climate targets. CECILIA2050. Leiden, Institute of Environmental Sciences CML, Leiden University.

Koning, A. d., R. Kleijn, G. v. Engelen and G. Huppes (2015). Resource constraints in successful climate policy: Key constraints and bottlenecks, and some solutions. Choosing Efficient Combinations of Policy Instruments for Low-carbon development and Innovation to Achieve Europe's 2050 climate targets. CECILIA2050. Leiden, Institute of Environmental Sciences CML, Leiden University. Kramer, G. J. and M. Haigh (2009). "No quick switch to low-carbon energy." Nature 462(7273): 568-569. Kriegler, E., K. Riahi, N. Bauer, V. J. Schwanitz, N. Petermann, V. Bosetti, A. Marcucci, S. Otto, L. Paroussos, S. Rao, T. Arroyo Currás, S. Ashina, J. Bollen, J. Eom, M. Hamdi-Cherif, T. Longden, A. Kitous, A. Méjean, F. Sano, M. Schaeffer, K. Wada, P. Capros, D. P. van Vuuren and O. Edenhofer 
(2014). "Making or breaking climate targets: The AMPERE study on staged accession scenarios for climate policy." Technological Forecasting and Social Change(0).

Kruger, J. and C. Egenhofer (2005). "Confidence through compliance in emissions trading markets." Sustainable Dev. L. \& Pol'y 6: 2.

Kuik, O., F. Branger and P. Quirion (2013). International competitiveness and markets. The current policy mix. Choosing Efficient Combinations of Policy Instruments for Low-carbon development and Innovation to Achieve Europe's 2050 climate targets. CECILIA2050. Amsterdam, Institute for Environmental Studies.

Kuik, O. and A. Kalfagianni (2013). Food and Agriculture: The Current Policy Mix. Choosing Efficient Combinations of Policy Instruments for Low-carbon development and Innovation to Achieve Europe's 2050 climate targets. CECILIA2050. Amsterdam, Institute for Environmental Studies. Künze, S. (2012). Compliance with the EU ETS, Grin Publishers.

L'Orange Seigo, S., S. Dohle and M. Siegrist (2014). "Public perception of carbon capture and storage (CCS): A review." Renewable and Sustainable Energy Reviews 38: 848-863.

Lévêque, F. (2014). The Economics and Uncertainties of Nuclear Power, Cambridge University Press. Lindblom, C. E. (1959). "The Science of "Muddling Through"." Public Administration Review 19(2): 79.

Lowe, R. (2003). "A theoretical analysis of price elasticity of energy demand in multi-stage energy conversion systems." Energy Policy 31(15): 1699-1704.

Máca, V., A. Eberle, A. Pearson, M. Ridgway, M. Braun Kohlová, B. Görlach, J. Novák and M. Ščasný (2013). Climate Policies and the Transport Sector. Analysis of Policy Instruments, their Interactions, Barriers and Constraints, and resulting Effects on Consumer Behaviour. Choosing Efficient Combinations of Policy Instruments for Low-carbon development and Innovation to Achieve Europe's 2050 climate targets. CECILIA2050. Berlin, Ecologic Institute.

Mackay, D. J. C., P. Cramton, A. Ockenfels and S. Stoft (2015). "Price carbon - I will if you will." Nature 526(7573): 315-316.

Marin, G. and M. Mazzanti (2010). "The evolution of environmental and labor productivity dynamics." Journal of Evolutionary Economics 23(2): 357-399.

Markandya, A., L. Rey and M. Gonzáles-Egiuno (2015). Assessment of EU Instrument Options under Different Supranational Governance Scenarios. CECILIA2050. Bilbao, Basque Centre for Climate Change (BC3).

Mazzanti, M. and D. Antonioli (2013). Inducing Greenhouse Gases Abatement through Policy Packages. Ex Post Assessments from EU Sectors. Choosing Efficient Combinations of Policy Instruments for Low-carbon development and Innovation to Achieve Europe's 2050 climate targets. CECILIA2050. Ferrara, University of Ferrara.

Mazzanti, M., D. Antonioli, S. Mancinelli and C. Ghisetti (2014). The availability of finance for the low carbon economy. Evidence on Eco innovation diffusion from sector analyses. Choosing Efficient Combinations of Policy Instruments for Low-carbon development and Innovation to Achieve Europe's 2050 climate targets. CECILIA2050. Ferrara, University of Ferrara.

Mazzucato, M. (2011). The entrepreneurial state. London, Demos.

Mazzucato, M. (2013). "Why innovation needs the help of an active state." Financial Times.

Meadows, D. H., D. L. Meadows, J. Randers and W. W. Behrens (1972). "The limits to growth." New York 102.

Mehling, M., C. Bausch, L. Donat and E. Zelljadt (2013). The Role of Law and Institutions in Shaping European Climate Policy: Institutional and legal implications of the current climate policy instrument mix. Choosing Efficient Combinations of Policy Instruments for Low-carbon development and Innovation to Achieve Europe's 2050 climate targets. CECILIA2050. Berlin, Ecologic Institute.

Meidinger, E. (1987). "Regulatory Culture: A Theoretical Outline*." Law \& Policy 9(4): 355-386. 
Meng, K. C. (2013). Essays in the economics and political economy of climate change, Columbia University.

Metcalf, G. E. (2008). "Designing a Carbon Tax to Reduce U.S. Greenhouse Gas Emissions." Review of Environmental Economics and Policy 3(1): 63-83.

Metz, D. (2010). "Saturation of Demand for Daily Travel." Transport Reviews 30(5): 659-674.

Meyer, B., M. Meyer and M. Distelkamp (2014). Macroeconomic routes to 2050. Choosing Efficient Combinations of Policy Instruments for Low-carbon development and Innovation to Achieve Europe's 2050 climate targets. CECILIA2050. Osnabrück, Gesellschaft für Wirtschaftliche Strukturforschung (GWS.

Meyer, M. and B. Meyer (2013). Impact of the current economic instruments on economic activity. Choosing Efficient Combinations of Policy Instruments for Low-carbon development and Innovation to Achieve Europe's 2050 climate targets. CECILIA2050. Osnabrück, GWS.

Michaelowa, A. (2012). "Is all demand-side mitigation policy doomed to fail?" Climate Policy 12(6): 784786.

Mignone, B. K. (2010). "A 'safety deposit' mechanism for US climate policy." Climate Policy 10(2): 232238.

Mikunda, T., T. Kober, H. de Coninck, M. Bazilian, H. Rösler and B. van der Zwaan (2014). "Designing policy for deployment of CCS in industry." Climate Policy: 1-12.

Min-Fin-BC (2014). Carbon Tax. Overview of the revenue-neutral carbon tax. Vancouver, Ministry of Finance, British Columbia http://www.fin.gov.bc.ca/tbs/tp/climate/carbon tax.htm.

Mintzberg, H. (1994). The rise and fall of strategic planning. New York, Prentice Hall.

Mintzberg, H. (1994b). "The fall and rise of strategic planning." Harvard business review 72(1): 107-114.

Mock, P., U. Tietge, V. Franco, J. German, A. Bandivadekar, N. Ligterink, U. Lambrecht, J. Kühlwein and I. Riemersma (2014). From Laboratory tot Road. A 2014 Update of Official and "real World) Fuel Consumptions and $\mathrm{CO} 2$ values for Passenger Cars in Europe. Berlin, International Council on Clean Transportation Europe.

Mokyr, J. (2004). The Gifts of Athena: Historical Origins of the Knowledge Economy. Princeton, Princeton University Press.

Munaretto, S. and H. Walz (2015). Political feasibility of climate policy instruments in the EU, Deliverable 4.9. CECILIA2050. Amsterdam, Institutute for Environmental Studies, Free University.

Munck af Rosenschöld, J., J. G. Rozema and L. A. Frye-Levine (2014). "Institutional inertia and climate change: a review of the new institutionalist literature." Wiley Interdisciplinary Reviews: Climate Change 5(5): 639-648.

Nakicenovic, N., R. J. Lempert and A. C. Janetos (2014). "A Framework for the Development of New Socio-economic Scenarios for Climate Change Research: Introductory Essay." Climatic Change 122(3): 351-361.

Nakicenovic, N. and R. Swart (2000). Emissions scenarios. Cambridge, Cambridge University Press / IPCC.

Nauleau, M.-L., F. Branger and P. Quirion (2014). Abating CO2 emissions in the building sector: the role of carbon pricing and regulations. Choosing Efficient Combinations of Policy Instruments for Lowcarbon development and Innovation to Achieve Europe's 2050 climate targets. CECILIA2050. Paris, Centre International de Recherche sur l'Environnement et le Développement (Cired).

Nemry, F., G. Leduc, I. Mongelli and A. Uihlein (2008). Environmental Improvement of Passenger Cars (IMPRO-car). IPTS. Luxembourg, European Commiossion JRC.

Nishitani, K. and M. Itoh (2014). Product Innovation in Response to Environmental Standards and Competitive Advantage: A Hedonic Analysis of Refrigerators in the Japanese Retail Market.

Nordhaus, W. (2015). "Climate Clubs: Overcoming Free-Riding in International Climate Policy." American Economic Review 105(4): 1339-1370. 
North, D. C. (1990). Institutions, institutional change and economic performance. Cambridge, Cambridge University Press.

Nussbaum, M. and A. Sen (1993). The quality of life, Oxford University Press.

OECD (1972). Recommendation of the Council on Guiding Principles concerning International Economic Aspects of Environmental Policies. C(72)128, 26 May 1972. O. f. E. C. a. Development. Paris, OECD. C(72)128.

OECD (1992). Climate change : designing a practical tax system. Paris, Organisation of Economic Cooperation and Development.

OECD (2013). Effective Carbon Prices. Country Note on Germany: High Costs in Electricity Generation. Paris, OECD.

OECD/IEA/NEA/ITF (2015). Aligning Policies for a Low-carbon Economy. Paris, OECD Publishing.

Olivier, J. G. J., G. Janssens-Maenhout, M. Muntean and J. A. H. W. Peters (2014). Trends in global CO2 emissions: 2014 Report. EDGAR Database. The Hague, PBL \& JRC.

Ostrom, E. (2010). "Beyond Markets and States: Polycentric Governance of Complex Economic Systems." American Economic Review 100(3): 641-672.

Palensky, P. and F. Kupzog (2013). "Smart Grids." Annual Review of Environment and Resources 38(1): 201-226.

Parry, I. W. H., D. Evans and W. E. Oates (2014). "Are energy efficiency standards justified?" Journal of Environmental Economics and Management 67(2): 104-125.

Pearson, M. and S. Smith (1991). The European Carbon Tax: an assessment of the European Commission's proposals. London, Institute fro Fiscal Studies.

Pigou, A. C. (1932 (1920)). The Economics of Welfare. (downloadable at: http://www.econlib.org/library/NPDBooks/Pigou/pgEW.html ). Indianapolis, Library of Economics and Liberty.

Piketty, T. (2014). Capital in the twenty-first century. Cambridge Massachusetts, The Belknap Press of Harvard University Press.

Porter, M. E. and C. Van der Linde (1995). "Green and competitive: ending the stalemate." Harvard business review 73(5): 120-134.

Portney, P. R. and J. P. Weyant (1999). Discounting and intergenerational equity. Washington, Resources for the Future.

Raupach, M. R., S. J. Davis, G. P. Peters, R. M. Andrew, J. G. Canadell, P. Ciais, P. Friedlingstein, F. Jotzo, D. P. van Vuuren and C. Le Quere (2014). "Sharing a quota on cumulative carbon emissions." Nature Clim. Change 4(10): 873-879.

Rayner, S. (2010). "How to eat an elephant: a bottom-up approach to climate policy." Climate Policy 10(6): 615-621.

Revenue\&Customs, H. (2012 (2010)). Carbon price floor. U. Government. London, HMRC.

Rey, L., A. Markandya, M. Gonzáles-Egiuno and P. Drummond (2013). Assessing Interaction between instruments and the 'optimality' of the current instrument mix. Choosing Efficient Combinations of Policy Instruments for Low-carbon development and Innovation to Achieve Europe's 2050 climate targets. CECILIA2050. Bilbao/London, BC3/UCL.

Rifkin, J. (2014). The zero marginal cost society. The internet of things, the collaborative commons, and the eclipse of capitalism. New York, Palgrave Macmillan.

Riley, J. P. and M. Tongudai (1964). "The lithium content of sea water." Deep Sea Research and Oceanographic Abstracts 11(4): 563-568.

Rio, P. d. and M. Howlett (2013). "Beyond the "Tinbergen Rule" in Policy Design: Matching Tools and Goals in Policy Portfolios." Annual Review of Policy Design 1.

Samuelson, P. A. (1977). "Reaffirming the Existence of "Reasonable" Bergson-Samuelson Social Welfare Functions." Economica 44(173): 81-88. 
Schmalensee, R. and R. N. Stavins (2013). "The SO2 Allowance Trading System: The Ironic History of a Grand Policy Experiment." Journal of Economic Perspectives 27(1): 103-122.

Schumpeter, J. A. (1947 (1942)). Capitalism, Socialism, and Democracy. New York and London, Harper \& Brothers Publishers.

Scott, V., S. Gilfillan, N. Markusson, H. Chalmers and R. S. Haszeldine (2013). "Last chance for carbon capture and storage." Nature Climate Change 3(2): 105-111.

Sen, A. K. (1970). Collective choice and social welfare. San Francisco, Holden-Day.

Sijm, J. (2005). "The interaction between the EU emissions trading scheme and national energy policies." Climate Policy 5(1): 79-96.

Simões, S., G. Huppes and J. Seixas (2015). "A Tangled Web: Assessing overlaps between energy and environmental policy instruments along the electricity supply chain." Environmental Policy and Governance: n/a-n/a.

Simon, H. A. (1956). "Rational choice and the structure of the environment." Psychological review 63(2): 129.

Simon, J., A. M. Ferriz and L. C. Correas (2015). "HyUnder - Hydrogen Underground Storage at Large Scale: Case Study Spain." Energy Procedia 73: 136-144.

Sinn, H.-W. (2012). The green paradox: a supply-side approach to global warming, MIT Press.

Solano, B. and P. Drummond (2014). Techno-Economic Scenarios for Reaching Europe's Long-Term Climate Targets Using the European TIMES Model (ETM-UCL) to Model Energy System Development in the EU. Choosing Efficient Combinations of Policy Instruments for Low-carbon development and Innovation to Achieve Europe's 2050 climate targets. CECILIA2050. London, University College London (UCL).

Solano, B. and P. Drummond (2014). Techno-Economic Scenarios for Reaching Europe's Long-Term Climate Targets Using the European TIMES Model (ETM-UCL) to Model Energy System Development in the EU. Choosing Efficient Combinations of Policy Instruments for Low-carbon development and Innovation to Achieve Europe's 2050 climate targets. CECILIA2050. London, University College London (UCL).

Sorrell, S. and J. Sijm (2003). "Carbon Trading in the Policy Mix." Oxf Rev Econ Policy 19(3).

Stern, N. (2008). "The Economics of Climate Change." American Economic Review 98(2): 1-37.

Stiglitz, J. E., A. K. Sen and J.-P. Fitoussi (2009). "Report by the Commission on the Measurement of Economic Performance and Social Progress." www.stiglitz-sen-fitoussi.fr.

Stone, S. J. and D. Zaelke (2005). The essential role of compliance in emissions trading schemes. Proceedings of the Seventh International Conference on Environmental Compliance and Enforcement.

Sunstein, C. R. (2014). Simpler: The future of government, Simon and Schuster.

Tamiotti, L. (2011). "The legal interface between carbon border measures and trade rules." Climate Policy 11(5): 1202-1211.

Taylor, J. A., J. L. Mathieu, D. S. Callaway and K. Poolla (2015). "Price and capacity competition in balancing markets with energy storage." Submitted to Energy Economics arXiv:1503.06851 [cs.GT].

Thaler, R. H. (2015). Misbehaving: The Making of Behavioral Economics, WW Norton \& Company.

Tietenberg, T. (2009). "Reflections--Energy Efficiency Policy: Pipe Dream or Pipeline to the Future?" Review of Environmental Economics and Policy 3(2): 304-320.

Tinbergen, J. (1970). On the Theory of Economic Policy. Amsterdam, Elsevier Science \& Technology. Tol, R. S. (2008). "The social cost of carbon: trends, outliers and catastrophes." Economics: The OpenAccess, Open-Assessment E-Journal 2(2008-25): 1-22. 
UNFCCC-Experts (2015). Matters relating to science and review. The 2013-2015 review. Bonn, 1-11 June, UNFCCC Subsidiary Body for Scientific and Technological Advice \& Subsidiary Body for Implementation.

UNFCCC (2014). National greenhouse gas inventory data for the period 1990-2012. FCCC. Lima, $\mathrm{FCCC} / \mathrm{SBI} / 2014 / 20$.

Valinia, A., R. Moe, B. D. Seery and J. C. Mankins (2013). ISS-based Development of Elements and Operations for Robotic Assembly of A Space Solar Power Collector. Annual International Space Station Research and Development Conference; 2nd; 16-18 Jul. 2013. Denver, Colorado; United States, American Astronautical Society.

van den Bergh, J. C. J. M. (2011). "Environment versus growth - A criticism of "degrowth" and a plea for "a-growth"." Ecological Economics 70(5): 881-890.

van den Bergh, J. C. J. M. and W. J. W. Botzen (2014). "A lower bound to the social cost of CO2 emissions." Nature Clim. Change 4( 4): 6.

van der Voet, E., L. van Egmond, R. Kleijn and G. Huppes (1994). "Cadmium in the European Community A Policy-oriented Analysis." Waste Management \& Research 12(6): 507-526.

van Vuuren, D., E. Stehfest, M. J. den Elzen, T. Kram, J. van Vliet, S. Deetman, M. Isaac, K. Klein Goldewijk, A. Hof, A. Mendoza Beltran, R. Oostenrijk and B. van Ruijven (2011). "RCP2.6: exploring the possibility to keep global mean temperature increase below $2^{\circ} \mathrm{C}$." Climatic Change 109(1-2): 95116.

van Vuuren, D. P., K. Riahi, R. Moss, J. Edmonds, A. Thomson, N. Nakicenovic, T. Kram, F. Berkhout, R. Swart, A. Janetos, S. K. Rose and N. Arnell (2012). "A proposal for a new scenario framework to support research and assessment in different climate research communities." Global Environmental Change 22(1): 21-35.

Verzijlbergh, R., L. J. De Vries and Z. Lukszo (2014). "Renewable energy sources and responsive demand. Do we need congestion management in the distribution grid?" Power Systems, IEEE Transactions on 29(5): 2119-2128.

Verzijlbergh, R., M. O. Grond, Z. Lukszo, J. G. Slootweg and M. D. Ilic (2012). "Network impacts and cost savings of controlled EV charging." Smart Grid, IEEE Transactions on 3(3): 1203-1212.

Victor, D. G. (1992). Practical aspects fo implementing greenhouse taxes: Issues for OECD countries. Climate Change : Desigining a practical tax system. OECD. Paris, Organisation for Economic Cooperation and Development.

Vogel, D. (1986). National styles of regulation : environmental policy in Great Britain and the United States. Ithaca, Ny, Cornell University Press.

Voituriez, T. and X. Wang (2011). "Getting the carbon price right through climate border measures: a Chinese perspective." Climate Policy 11(5): 1257-1261.

Voss, J.-P. and B. Bornemann (2011). "The politics of reflexive governance: challenges for designing adaptive management and transition management." Ecology and Society 16(2).

Vuuren, D. P., E. Stehfest, M. G. J. Elzen, T. Kram, J. Vliet, S. Deetman, M. Isaac, K. Klein Goldewijk, A. Hof, A. Mendoza Beltran, R. Oostenrijk and B. Ruijven (2011). "RCP2.6: exploring the possibility to keep global mean temperature increase below $2^{\circ} \mathrm{C}$." Climatic Change 109(1-2): 95-116.

Weitzman, M. L. (2009). "On modeling and interpreting the economics of catastrophic climate change." Review of Economics and Statistics 91(1): 1-19.

Weitzman, M. L. (2011). "Fat-Tailed Uncertainty in the Economics of Catastrophic Climate Change." Review of Environmental Economics and Policy 5(2): 275-292.

Wiebe, K. S., M. Bruckner, S. Giljum, C. Lutz and C. Polzin (2012). "Carbon and Materials Embodied in the International Trade of Emerging Economies." Journal of Industrial Ecology 16(4): 636-646. 
Wiseman, J., T. Edwards and K. Luckins (2013). "Post carbon pathways: A meta-analysis of 18 large-scale post carbon economy transition strategies." Environmental Innovation and Societal Transitions 8(0): 76-93.

Yaksic, A. and J. E. Tilton (2009). "Using the cumulative availability curve to assess the threat of mineral depletion: The case of lithium." Resources Policy 34(4): 185-194.

Yigit, M., V. C. Gungor and S. Baktir (2014). "Cloud Computing for Smart Grid applications." Computer Networks 70(0): 312-329.

Zelljadt, E. (2014). Scenarios for international climate policy instruments. Choosing Efficient Combinations of Policy Instruments for Low-carbon development and Innovation to Achieve Europe's 2050 climate targets. CECILIA2050. Berlin, Ecologic Institute.

Zvěřinová, I., M. Ščasný and E. Kyselá (2013). What Influences Public Acceptance of the Current Policies to Reduce GHG Emissions? Choosing Efficient Combinations of Policy Instruments for Low-carbon development and Innovation to Achieve Europe's 2050 climate targets. CECILIA2050. Prague, Charles University Environment Center. 
Annex 1 List of Challenge Papers used as input in D6.1, D6.2 and D6.3

\section{Challenge 1}

Establish a Meaningful Carbon Price in the Short, Medium and Long Term

Gjalt Huppes \& Paul Drummond

\section{Challenge 2:}

Tackle the Energy Consumption and Climate Emissions of the Housing Stock

Philippe Quirion

\section{Challenge 3}

Non-CO2 Emissions, particularly from Agriculture

Onno Kuik \& Agni Kalfagianni

\section{Challenge 4}

Make Sound Infrastructure Choices despite Technological Uncertainty

Paul Drummond

\section{Challenge 5}

Electricity market reform and EU-wide integration of energy markets

Katharina Umpfenbach, with contribution Gjalt Huppes)

\section{Challenge 6}

Provide finance and mobilise the investments necessary for a low-carbon economy

Massimiliano Mazzanti

\section{Challenge 7}

Stimulate Innovation in Industry

Bernd Meyer, with contributions from Massimiliano Mazzanti and Philippe Quirion

\section{Challenge 8}

Transport and Mobility

Gjalt Huppes

\section{Challenge 9}

Low-Carbon Lifestyles

Gjalt Huppes, with contributions from Mikołaj Czajkowski and Paul Drummond 


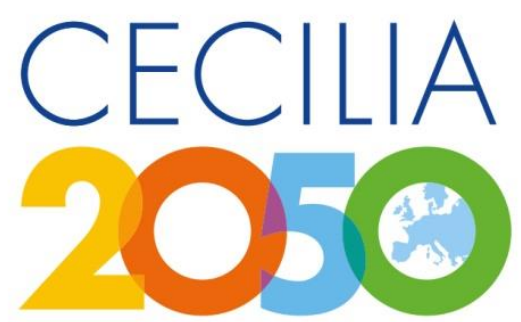

OPTIMAL EU CLIMATE POLICY

Choosing Efficient Combinations of Policy Instruments for Low-carbon development and Innovation to Achieve Europe's 2050 climate targets 